Designing A grometeorological Information Services in G hana by Combining Local and Scientific Forecasting Knowledge

Talardia G bangou

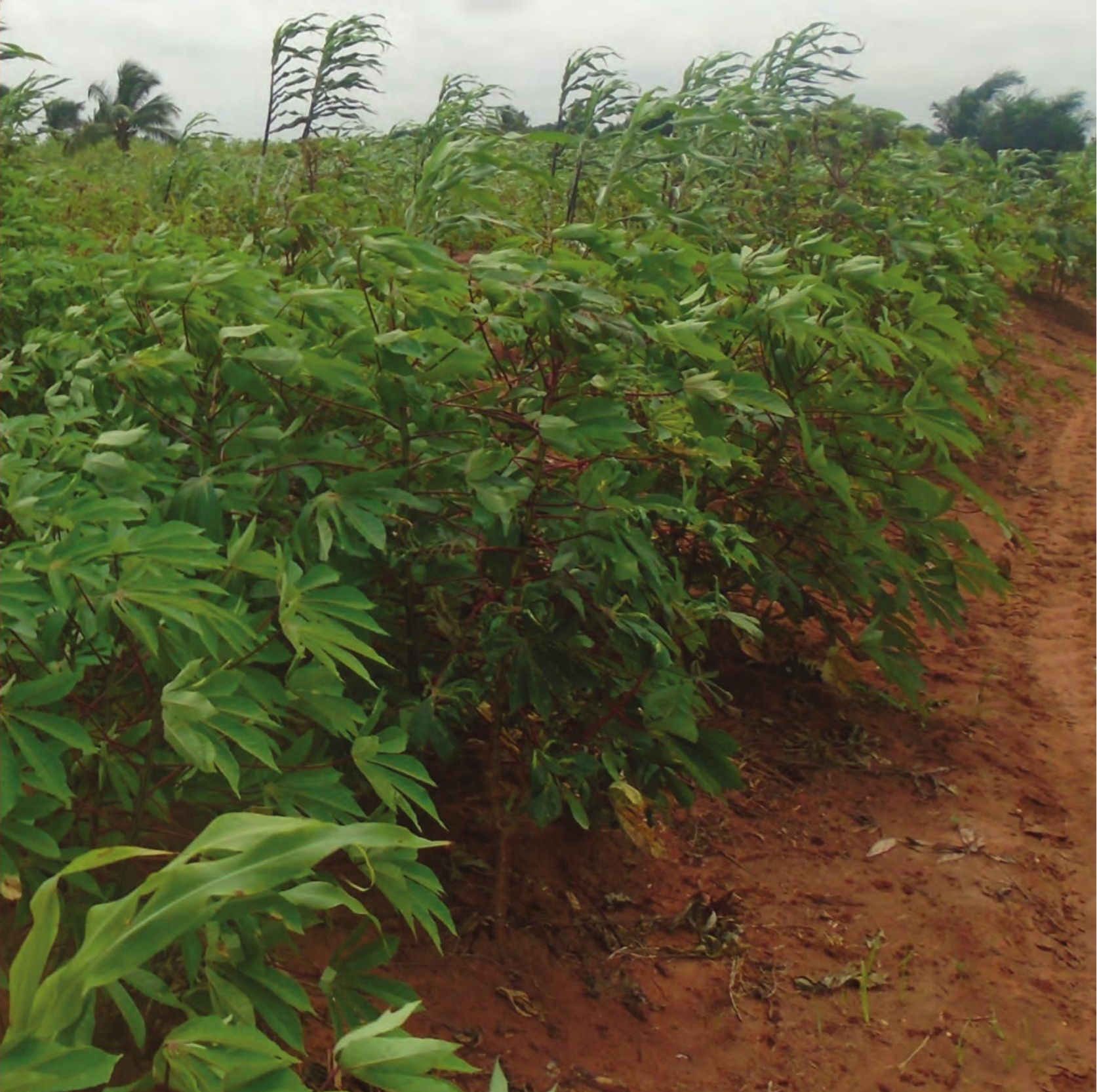




\section{Propositions}

1. There is no single approach to integrating local and scientific forecasting systems. (this thesis)

2. Understanding the full potential of local forecasting system requires an interdisciplinary approach.

(this thesis)

3. Observational data sets are more important for rejecting bad models than for improving good models.

4. Both climate and non-climate related actions are needed to address food insecurity.

5. Synchronizing science, society, and technology for climate change adaptation is like aligning the best strikers in a 'football game'.

6. The passion for solving environmental problems drives creativity.

Propositions belong to the thesis, entitled

Designing Agrometeorological Information Services in Ghana by Combining Local and Scientific Forecasting Knowledge

Talardia Gbangou

Wageningen, $18^{\text {th }}$ January 2021 
Designing Agrometeorological Information Services in Ghana by Combining Local and Scientific Forecasting Knowledge 


\section{Thesis committee}

\section{Promotor}

Prof. Dr F. Ludwig

Personal chair, Water Systems and Global Change Group

Wageningen University \& Research

\section{Co-promotors}

Dr E.J.J van Slobbe

Researcher and Teacher, Water Systems and Global Change Group

Wageningen University \& Research

Prof. Dr G. Kranjac-Berisavljevic

Director of Office for International Relationships and Advancement of the University for Development Studies (UDS-DIRA), Tamalé, Ghana

\section{Other members:}

Prof. Dr A.M.G. Klein Tank, Wageningen University \& Research

Dr R. Kasei, University for Development Studies, Tamalé, Ghana

Prof. Dr E.J. Moors, IHE Delft Institute for Water Education

Dr A.M.E. Groot, Wageningen University \& Research

This research was conducted under the auspices of the Graduate School for Socio Economic and Natural Sciences of the Environment (SENSE) 


\title{
Designing Agrometeorological Information Services in Ghana by Combining Local and Scientific Forecasting Knowledge
}

\author{
Talardia Gbangou
}

\section{Thesis}

Submitted in fulfilment of the requirements for the degree of doctor at

Wageningen University

by the authority of the Rector Magnificus

Prof. Dr A.P.J. Mol,

in the presence of the

Thesis Committee appointed by the Academic Board
to be defended in public
on Monday 18 January 2021
at 1:30 p.m. in the Aula. 


\section{Talardia Gbangou}

Designing Agrometeorological Information Services in Ghana by Combining Local and Scientific Forecasting Knowledge,

213 pages.

$\mathrm{PhD}$ thesis, Wageningen University, Wageningen, the Netherlands (2021)

With references, with summary in English

ISBN 978-94-6395-634-5

DOI https: //doi.org/10.18174/536154 
This book is dedicated to:

The loving memory of my late Father (Boari Gbangou) and Mother (Diakpampoa Naba). Rest on Dad and Mom, you are forever in my heart. 


\begin{abstract}
Agriculture is a key source of food and income security for farmers in Ghana. The farming sector, however, is severely affected by climate variability and change, with subsistence farmers impacted worst of all. Providing reliable, accessible and actionable agrometeorological forecast information can enable smallholder farmers to increase their adaptive capacity in the face of climate variability and change. This study investigated weather and climate information services for smallholder farmers, particularly, how the quality, accessibility and use of such services can be improved. Several methods and tools were developed drawing on and/or integrating scientific and local forecasting knowledge systems. The study first identified and investigated trends in the variability and predictability of key local agrometeorological indicators, namely wet season onset dates, dry spell occurrence and seasonal rainfall. Forecast performance was assessed using both dynamical (i.e., ECMWF System 4) and statistical (i.e., influence of sea surface temperatures) models, which were compared to weather station observations across Ghana. Results show high interannual variability of the agrometeorological indicators, especially across the coastal zone and in northern Ghana. Performance of the scientific, model-based seasonal forecasts in reproducing the observed interannual variability was a function of location, lead time, categories and the agrometeorological indicators considered. Categorical (probabilistic) seasonal predictions provided smallholder farmers valuable information for coping with climate variability. Forecast performance was greater for the coastal savanna than for the other agroecological zones.
\end{abstract}

Next, the potential for improving forecast accuracy by combining local and scientific, model-based forecasts was explored in the Ada East district case study location. There, I found that combining a specific set of local forecast indicators could improve local forecast performance. Particularly, one-day rainfall forecasts could be improved by use of local and scientific forecasts side-by-side, depending on the set of local forecast indicators observed by farmers. The range of identified local forecast indicators offers the potential for development of other approaches to integrate local and modern forecasting systems, to improve and enrich each.

I also analysed a citizen science coproduction experiment to produce and implement an ICT-based climate information service tailored for smallholder farmers in the Ada East district of Ghana. In this case, the co-design of user-friendly digital tools (smartphone apps) and coproduction of local and scientific forecast information with and for smallholder farmers facilitated access, understanding and the usefulness of the tools and information for decision-making. Implementing 
such a service requires intensive collaboration between researchers and a dedicated group of farmers and extension agents to build a basis for information production and dissemination in the area of interest. In this case, the collaboration included a capacity building component, as well as monitoring and technical assistance, especially in the development phase.

Overall, the current research indicates that access to and use of reliable, locally actionable agrometeorological forecast information is possible in Ghana and elsewhere. Three key findings of this research warrant particular mention: (i) scientific forecasts need to be tailored to smallholder farmers' needs; (ii) integration of local forecasting knowledge can add value to scientific, modelbased climate information services; and (iii) a tailor-made ICT-based weather and climate information platform can effectively deliver useful and actionable information to smallholder farmers while providing a vehicle for feedback. 


\section{Table of Contents}

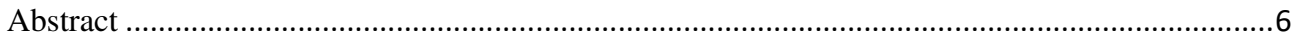

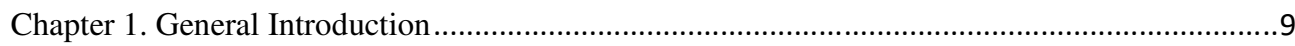

Chapter 2. Seasonal variability and predictability of agro-meteorological indices: Tailoring onset of rainy season estimation to meet farmers' needs in Ghana .........................................................22

Chapter3. Rainfall and dry spell occurrence in Ghana: trends and seasonal predictions with a

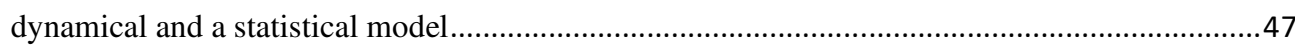

Chapter 4. Harnessing local forecasting knowledge on weather and climate in Ghana: documentation, skills and integration with scientific forecasting knowledge...............................74

Chapter 5. Coproducing Weather Forecast Information with and for Smallholder Farmers in

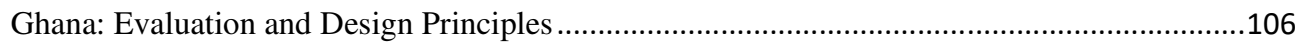

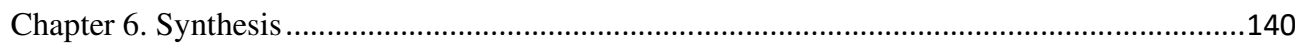

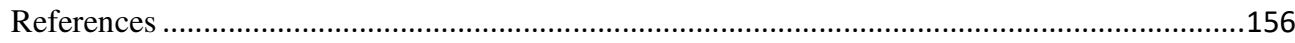

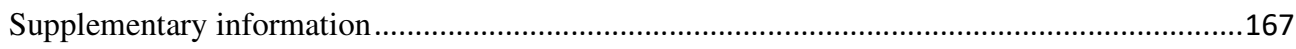

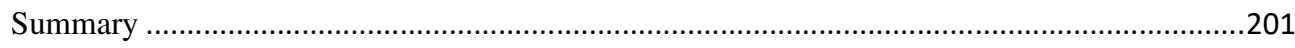

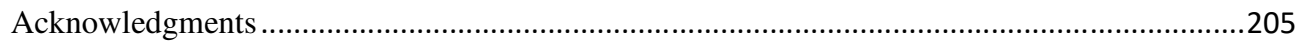

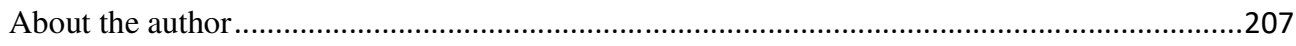

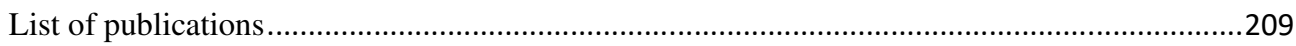

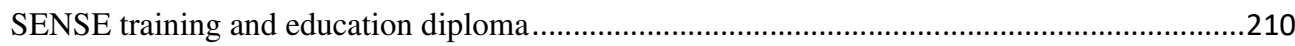

Chapters 2-5 have been published as peer reviewed scientific articles. The text, figures and tables of the published articles have been adjusted to the $\mathrm{PhD}$ thesis format. Editorial changes were made for reasons of uniformity of presentation in this thesis. References should be made to the original articles. 


\section{Chapter 1. General Introduction}

\subsection{Background}

Agriculture plays an important role in income and food security in sub-Saharan Africa, but the sector is highly impacted by climate variability and change (Collier and Dercon, 2014, Rockström and Falkenmark, 2015, Shimeles et al., 2018). With climate variability on the rise in Africa, as elsewhere, average crop yields are expected to diminish in the coming years (Sultan and Gaetani, 2016, Knox et al., 2012, Roudier et al., 2011). Even if global warming can be retained to within the limits set in the Paris Agreement, negative effects on agriculture are unavoidable (IPCC, 2018, 2019). People involved in agriculture will be affected differently by these impacts (Jalloh et al., 2013, Atta et al., 2015), with the strongest negative effects felt by the poorest and most vulnerable populations (Holt-Giménez et al., 2012, Stringer et al., 2020).

Throughout sub-Saharan Africa, farming shares common struggles related to weather and climate risks (Stringer et al., 2008, Dixon and Stringer, 2015). Most of the region's smallholders are involved predominantly in rainfed agriculture (Gbangou et al., 2018, Pirret et al., 2020). Moreover, they must manage their activities with very limited access to timely, location-specific and tailored weather and climate information (Vaughan et al., 2019). This renders smallholder crop production, which is the dominant mode of food production in the region, especially vulnerable to weather extremes - such as drought, heavy rains, heatwaves and frequent storms (Atta et al., 2015, Pirret et al., 2020). Due to climate variability and change such extremes are likely to occur much more often. Development and provision of adequate weather and climate information services (WCIS) can help farmers make better farming decisions, for example, in the face of uncertainty about water availability.

WCIS can also be a valuable instrument for climate change adaptation and mitigation. For instance, the information provided can signal progress towards the objectives of the Paris Agreement and Sustainable Development Goals (Jones et al., 2015). Recent improvements and increased availability of weather and climate model predictions have brought opportunities to support decision-making in farm and water management, even at the farm level (Vaughan and Dessai, 2014, Ingram et al., 2002). Already, many African countries are involved in development and provision of scientific, model-based seasonal forecasts, drought predictions, flood monitoring and 


\section{Chapter I}

agrometeorological bulletins (Kadi et al., 2011, Dube et al., 2016, Plotz et al., 2017). However, several barriers prevent appropriate interpretation and use of such forecast information by smallholder farmers. Among these barriers are the forecasts' unsuitable spatial and temporal scale, users' lack of understanding of scientific model output jargon, gaps in communication channels, lack of decision-relevant information and poor communication of model uncertainties (Ingram et al., 2002, Vaughan and Dessai, 2014, Sultan et al., 2020).

In Ghana, too, these obstacles affect smallholder farmers' access to, reliance on and use of WCIS in farm decision-making (Yaro, 2013, Codjoe et al., 2014, Nyadzi, 2020). Many Ghanaian farmers still rely mainly on local or traditional knowledge to make decisions on farm operations. Particularly in today's context of increasing weather and climate variability, farmers need improved knowledge to base their responses to uncertainties regarding the weather and climate (Codjoe et al., 2014, Nyadzi, 2020).

Within the scientific community, too, there is a growing appeal to combine data from large-scale models with local, traditional knowledge systems, to obtain a better representation of local environments and thereby improve information services (Berkes, 1999, Riedlinger and Berkes, 2001, Speranza et al., 2010, Balehegn et al., 2019, Gbangou et al., 2018). Information about users' specific needs and local data can be employed to adjust and tailor weather and climate model outputs to meet end-users' specific needs. Also, the many scholars who have compared modern and traditional knowledge on weather and climate have found positive connections between the two knowledge systems, and recommend creation of a new knowledge system that synergizes the two systems for greater accuracy (Speranza et al., 2010, Chisadza et al., 2015, Balehegn et al., 2019, Nyadzi, 2020). Nonetheless, current WCIS undertakings in Africa, including in Ghana, operate based only on modern forecasting knowledge, mostly using a one-directional approach, with little focus on understanding users' specific requirements and integrating local forecasting knowledge into modern, scientific systems (Hansen, 2002, Lourenço et al., 2016). This, possibly, limits the credibility, trust and acceptance of WCIS by local-level users such as smallholder farmers (Ingram et al., 2002, Kniveton et al., 2015, Nyadzi, 2020). The research presented in this dissertation explores the potential for improving the quality, accessibility and usefulness of weather and climate forecast information for smallholder farmers in Ghana. To achieve this objective, I investigated (i) the prediction performance of model-based forecasts tailored to smallholder 
farmers' needs, (ii) approaches to integrate local, traditional forecasting knowledge with scientific WCIS systems and the added value of such integration and (iii) design principles for an effective WCIS tailored for smallholder farmers.

Defined broadly, climate information services (or climate services) provide short- to medium-range predictions (one day to several months) and long-term climate projections (several years) (Tall et al., 2018, Vaughan et al., 2019). However, the current research considered only the first range of climate information services. Also, the term 'weather and climate information services' (WCIS) is used alternatively with 'climate information services'. The sections below introduce the research problem, knowledge gaps and approaches adopted in this research to fill these gaps. The chapter then introduces the research questions, which are answered in the subsequent chapters.

\subsubsection{Tailoring scientific, model-based forecast information for smallholder farmers}

Interest in agricultural WCIS is growing. Many scholars welcome climate information systems as an integral part of sustainable development strategies to meet food security goals in a climate uncertain future (Campbell et al., 2014, Chandra et al., 2017, Vaughan et al., 2019). In Ghana, national meteorological services and other organizations are actively involved in the production of weather and climate information to support decision-making in agriculture, and in other sectors (World Agrometeorological Information Service, 2020, Ghana Meteorological Agency, 2020). However, the information made available to smallholder farmers is often not at an appropriate scale or is too raw, without relevant agro/hydro-meteorological indices to meet farmers' needs (Codjoe et al., 2014, Matthews et al., 2013, Wetterhall et al., 2015, Gbangou et al., 2018). For instance, accurate prediction of the onset of the rainy season, dry spells and rainfall amounts at critical points in the growing season are of key interest to farmers to reduce the risk of crop failure (Owusu et al., 2017, Nicholson, 2017, Baidu et al., 2017, Atiah et al., 2019, Kumi et al., 2020). Up to now, however, most local farmers in Ghana receive only daily rainfall and temperature forecasts (and even then, only occasionally). They continue to lack access to long-term and seasonal forecasts (Jost et al., 2016, Limantol et al., 2016, Sarku et al., 2020). Understanding and improving forecasts of key agrometeorological indicators at the appropriate spatial and temporal scales can provide valuable support to smallholder farmers in Ghana.

\subsubsection{Integrating local and model-based forecasting knowledge}




\section{Chapter I}

Scholars increasingly recognize that integrating local and scientific forecasting knowledge can strengthen both knowledge systems, leading to better responses to climate variability (KalandaJoshua et al., 2011, Ingram et al., 2002, Lebel, 2013, Kniveton et al., 2015). This thesis defines local forecasting knowledge (LFK) as indigenous or traditional forecasts by smallholder farmers or pastoralists (non-scientists) based on experience in observing biophysical indicators (Radeny et al., 2019, Balehegn et al., 2019). Scientific forecasting knowledge (SFK) refers to forecasts derived from scientific weather and or climate models. LFK, by definition, encompasses knowledge and practices that are embedded in local institutions, values and beliefs. It is thus more likely to be accepted and influential in decision-making within local communities, compared to SFK (Kniveton et al., 2015). Some have suggested that combining SFK and LFK could increase not only local adoption of SFK, but also the quality of weather and climate information (Crane et al., 2010, Kniveton et al., 2015, Radeny et al., 2019). While LFK is built-in and established in many African communities, including in Ghana, there is a general lack of coordinated research on LFK, including its formal documentation, verification of its quality (e.g., its accuracy and reliability) and methods of integration with modern forecasting knowledge. Exploring integration possibilities between the two knowledge systems could improve the quality and use of weather and climate information by smallholder farmers in Ghana.

\subsubsection{Role of coproduction in facilitating knowledge integration}

The coproduction approach can be employed to integrate local and scientific knowledge. Coproduction, by definition, facilitates a joined-up development of new and combined knowledge to address societal problems of common interest or concern. In short, knowledge is gathered from different actors representing different sources, experiences and working practices (Audia, 2018). Smallholder farmers in developing countries like Ghana typically have low literacy levels (Barnett et al., 2017, Naab et al., 2019). Coproducing WCIS with and for these farmers can engender local interest and interaction and help farmers use and understand weather and climate forecast information provided (Ingram et al., 2002). Through the coproduction process, the complex scientific jargon used in scientific weather reports, seasonal forecasts and agrometeorological bulletins (including terminology for forecast uncertainty) can be translated with and for farmers (Kniveton et al., 2015). The result can be a better understanding among information users of the uncertainties inherent in forecasts. This can prevent misinterpretations and thereby maintain the 
credibility of information and its source, while building community resilience (Kniveton et al., 2015, Patt and Gwata, 2002). Moreover, farmers can contribute to co-generate weather and climate knowledge by collecting local forecast observations and data through the citizen science approach (Buytaert et al., 2014). Contributions of local knowledge and forecast information are important, as scientific models vary in their predictive performance across time and space, so they might not always be good enough to support local decision-making by smallholders (Audia, 2018). Despite recognition of the value of knowledge coproduction, there is as yet little evidence and few case studies on participatory approaches to WCIS coproduction combining scientific and local knowledge systems in developing countries like Ghana (Vaughan et al., 2019, Nyadzi et al., 2018).

\subsubsection{ICT and knowledge coproduction}

Information and communication technology (ICT) can be used to facilitate knowledge sharing and coproduction. In particular, the rapid rise of digital media has brought a wealth of opportunities for farmers to access and use modern information systems and tools (Vaughan and Dessai, 2014, Sultan et al., 2020, van der Burgt et al., 2018). Data management systems, the internet, smartphones and mobile-based applications can be used to facilitate data collection, dissemination and direct interaction with users. Indeed, no technology has spread around the world faster than the mobile telephone (Qiang, 2009, Khalil et al., 2009). George et al. (2011) found that mobile phone use had a significant positive impact on economic growth in developing countries. The devices are becoming more affordable, too, and can be increasingly linked to data management systems via the internet, with smartphone applications fostering interactive sharing of information. Nonetheless, in many developing countries, including Ghana, information on weather and seasonal forecasts still passes through several intermediaries before it reaches end-users (Tall et al., 2014b). Existing WCIS in Ghana primarily reach users via radio and television (Jost et al. (2016)), and provide little opportunity for farmers to provide feedback to improve the usefulness of the forecast information. Also, the ICT-based forecasting tools available are weak in data visualization, which makes probabilistic and ensemble-based forecast information difficult to grasp for low literate populations (Stephenson, 2000, Elkhatib et al., 2013). Use of an ICT-based knowledge-sharing platform in a coproduction process can help ensure access to WCIS by both smallholder farmers and intermediaries, like agricultural and meteorological extension agents.

\subsection{Knowledge gaps and research focus}




\section{Chapter I}

Despite progress in accelerating climate information service development in Ghana and other developing counties, questions remain regarding the provision of timely, location-specific, accessible, understandable and useful weather and climate information, especially for smallholder farmers. The type of weather and climate information systems available locally varies across West Africa (Vaughan et al., 2019). Information on the weather is generally more accessible than seasonal forecasts (Rasmussen et al., 2014, Zongo et al., 2016). Information formats differ as well, with some WCIS offering tailored agrometeorological information, while others are more general. Accuracy, or reliability, varies too, as does the influence of forecast information on decisionmaking by smallholder farmers (Coulibaly et al., 2015, Roudier et al., 2014, Hansen et al., 2009, Patt and Dessai, 2005). Previous studies found that West African farmers do use WCIS when it is accessible and considered reliable, understandable and relevant to their decision-making (Amegnaglo et al., 2017, Roncoli et al., 2009, Vaughan et al., 2019, Coulibaly et al., 2015). The need for information on agrometeorological indices such as onset and cessation dates of seasonal rains, dry spell occurrence and seasonal rainfall is acknowledged throughout West Africa, and in Ghana (Atiah et al., 2019, Gbangou et al., 2018, Fitzpatrick et al., 2015). Tailoring model-based seasonal forecasts to include these indicators is crucial to provide farmers the information they need for decision-making. Similarly, combining local forecast knowledge with model-based forecasts can increase forecast reliability and local acceptance (Ingram et al., 2002). Poor dissemination media can hamper access to and use of weather and climate information (Roudier et al., 2016, Coulibaly et al., 2015, Zongo et al., 2016). Other factors that can impact WCIS effectiveness are design, targeting and implementation (Vaughan et al., 2019). ICT tools can contribute to better design, while facilitating knowledge coproduction and sharing, which fosters WCIS that benefit vulnerable smallholders.

Against this backdrop, I identified three knowledge gaps in provision of credible weather and climate information for smallholder farmers in Ghana:

- Poor understanding of seasonal variability and of the performance of scientific, model-based forecasting systems regarding agrometeorological indicators tailored to smallholder farmers' needs 
- Lack of insight into the performance of local forecasting knowledge and the potential to integrate such knowledge with scientific, model-based forecasting systems for increased accuracy

- Inadequate understanding of the design requirements of ICT-based WCIS tailored for smallholder farmers and including both local and scientific forecasting knowledge

\subsection{Research objectives}

My objective in this $\mathrm{PhD}$ research was to analyse the quality of, access to and use of weather and climate forecast information to support decision-making by smallholder farmers in Ghana. To achieve this, I developed methods, ICT-based tools and processes using and/or integrating both scientific and local forecasting knowledge and data. I formulated four research questions to address the knowledge gaps identified above.

The first two research questions focus on the tailoring of scientific, model-based forecasts to meet local farmers' needs. The first question is how and with what results can a dynamical model be used to tailor and improve predictions of the onset of the rainy season (RQ1, Chapter 2)? In this part of the research, I sought to define and explore trends and variability in location-specific onset dates of the rainy season and to assess the predictions of this indicator to better serve farmers' information needs. Drawing on scientific, model-based seasonal forecasts, I developed two definitions of the local rainy season onset date and demonstrated the challenges involved in location-specific onset predictions. This serves to demonstrate the potential for improving such predictions.

The second research question is how and with what results can dynamical and statistical models be used to tailor and improve predictions of dry spell occurrence and seasonal rainfall (RQ2, Chapter 3)? This question explored trends, variability and predictability of rainfall amounts and dry spell occurrence at critical points in the growing season in the study area, based on forecasts from statistical and dynamical models. In this part of the research, I identified challenges in the use of agrometeorological indices to predict seasonal rainfall and dry spell occurrence. I also explored the potential of using dynamical and statistical forecasts to improve predictions of both indices. 


\section{Chapter I}

The third research question focused on the integration of local and scientific forecasting systems. Thus, our third research question asks what are local forecast indicators, their accuracy and integration opportunities between local and modern forecasting systems (RQ3, Chapter 4)? In this part of the research, I set out to document local forecasting knowledge (LFK), to assess LFK performance and to develop methods for integrating it with scientific forecasting knowledge in the study area. Insights were particularly sought on the diversity and accuracy of LFK, compared to scientific forecasts. Another aim was to identify integration opportunities between local and scientific forecasting systems to improve the accuracy of both systems, for better weather and climate information for local farmers.

The final research question focused on principles for designing ICT-based weather and climate services tailored for smallholder farmers: What are the benefits and design principles of ICT-based climate service coproduction with and for smallholder farmers (RQ4, Chapter 5)? In this part of the research I evaluated an ICT-based climate service coproduction process with and for smallholder farmers combining local and scientific forecasting knowledge. I thus provide case study evidence regarding a collaboration between farmers, extension agents and scientists in the design and production of tools, and the sharing and use of weather forecast information. Drawing on results from the case study, I derived design principles for an effective ICT-based climate information platform integrating local forecasting and scientific knowledge. The principles derived will help guide science and policy towards development of climate services that are more accessible and actionable by smallholder farmers.

\subsection{Research methodology and thesis outline}

\subsubsection{Study area}

The research was carried out in Ghana with a focus on the coastal savanna zone of the Volta Delta. Figure 1.1 shows the sites where scientific (model-based) forecasts were interpolated and evaluated, as well as the Ada East district, where the local forecasting knowledge system was explored and the coproduction experiment was carried out. Ada East district is peri-urban and located in the savanna zone. It is the pilot site of the Waterapps project (www.waterapps.net), which seeks to improve water information services for farmers in the urbanizing delta of Ghana. Four 
agroecological zones were identified in the study region, representing areas for which model-based climate forecasts were evaluated or verified.

Ghana is a tropical country characterized by two seasons (wet and dry) (Amekudzi et al., 2015). Rainfall patterns exhibit high spatio-temporal variability (Lacombe et al., 2012, Asante and Amuakwa-Mensah, 2015). Rainfall is also characterized by a unimodal and bimodal pattern, respectively, in the northern and southern halves, due to the meridional movement of the intertropical discontinuity (Sultan and Janicot, 2003). The lowest rainfall values are found in the northern and coastal savanna areas (Atiah et al., 2019) where Ada East district is located. This complex rainfall regime makes food production difficult, as farmers are heavily reliant on rainfed agriculture (Antwi-Agyei et al., 2012, Kanu et al., 2014).

Agricultural production in Ghana is dominated by traditional smallholder, rainfed farming (MoFA, 2011, OECD/FAO, 2016, Angelucci et al., 2019). This mode of cultivation is characterized by significant weather and climate-related risks and low productivity (Sonwa et al., 2017, Vaughan et al., 2019). Particularly, rainfall fluctuations induce variability in soil moisture which can limit plant growth and yield. Yet, food production demand in Ghana is on the rise (Angelucci et al., 2019) and is projected to increase further under the influence of climate change and economic growth. The country's farmers, nonetheless, have limited access to climate information to help them navigate the burgeoning weather and climate risks (Jost et al., 2016, Naab et al., 2019). Improved weather and climate information could aid them in facing the challenges of an increasingly variable climate, leading to reduced poverty in Ghana as a whole (Naab et al., 2019).

Fishing and farming are the main sources of livelihood in the Ada East district. The most economically important crops here are cassava, pepper, rice, maize and tomato (Amisigo et al., 2015). According to Ghana Statistical Service (2014), engagement of young adults in crop farming has given a major boost to the economy of the district and Ghana as a whole. Improving peri-urban agriculture could increase farmers' yields and incomes. Also, there seems to be substantial potential for adoption of digital technologies in this region, due to its proximity to several urban areas. 


\section{Chapter I}

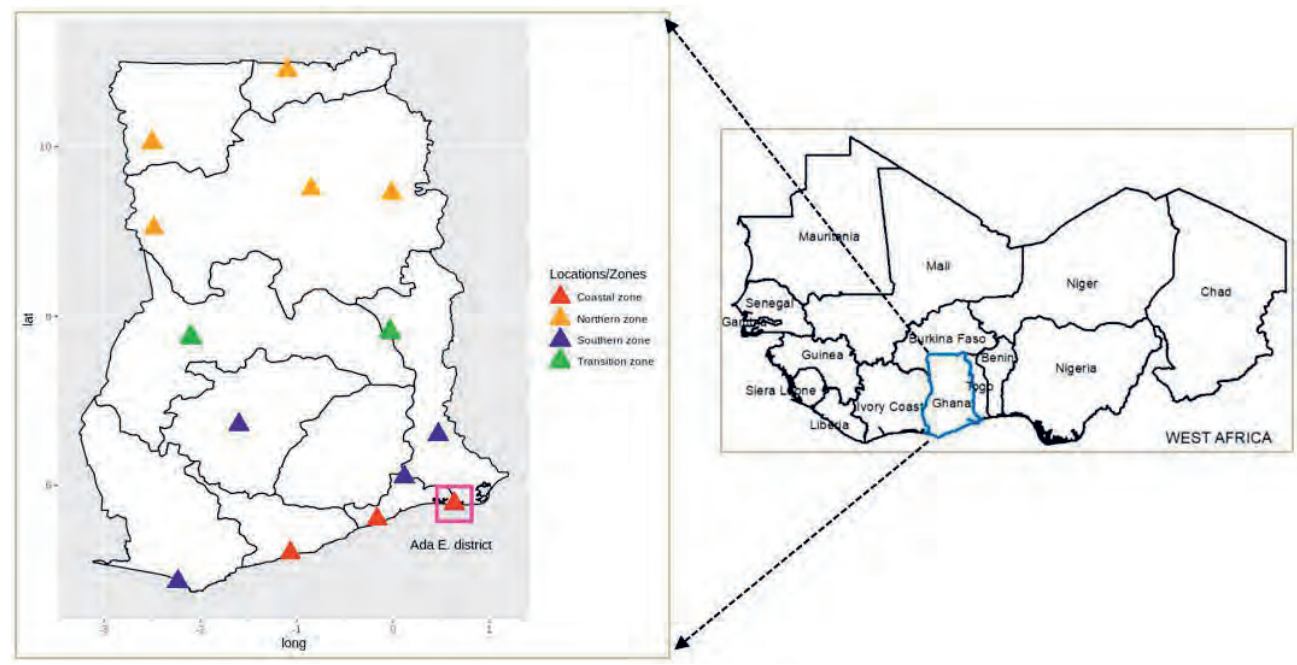

Fig. 1.1: Map of the study area showing (i) the locations/stations per agroecological zone in Ghana where scientific, model-based forecasts were interpolated and evaluated; and (ii) Ada East district, which was the pilot site of the Waterapps project, where the the local forecasting knowledge system was explored and the coproduction experiment was carried out.

\subsubsection{Thesis outline and research design}

This dissertation is structured in six chapters. After this general introduction, the four research questions are addressed in four scientific articles, presented as chapters 2-5. Each chapter addresses one research question. Figure 1.2 presents the substance of these and their interconnections. Chapters 2 and 3 focus on tailoring scientific, model-based forecasts to farmers' needs in order to improve the quality and usefulness of the forecast information.

This research used a multimethodological approach for data collection and analyses. Figure 1.3 presents an overview of the research objectives, research questions and chapters with their corresponding methodological designs.

Chapter 2 addresses seasonal variability and predictability of agrometeorological indices of particular relevance to smallholder farmers, particularly rainy season onset dates. The need to tailor forecast information to smallholder farmers' needs emerged from the literature and my own field observations in relation to the cropping calendar. I developed two suitable definitions of the rainy 
season onset date and assessed trends in and variability of onset dates based on time series data from stations' observations. I then applied forecast verification metrics to explore the accuracy of the onset date estimates from scientific, model-based seasonal forecasts. The analyses were carried out for Ghana as a whole, though with an emphasis on two study sites, in coastal and northern Ghana, where the effects of climate variability and change are relatively more dominant.

Chapter 3 concerns rainfall and dry spell occurrence in Ghana, particularly trends, variability and seasonal predictions based on both dynamical and statistical models. The need for better, locally tailored predictions of these indicators was again identified based on the literature, supplemented with my field observations and the local cropping calendar. I analysed trends and interannual variability of these indicators to understand the challenges involved in producing accurate predictions of seasonal rainfall and dry spell occurrence at critical stages of crop production. I developed statistical forecasts based on the link with nearby and remote sea surface temperatures (SSTs) driven by the El Niño-Southern Oscillation (ENSO) phenomenon. Subsequently, I investigated the predictability of these agrometeorological indices using both scientific, modelbased dynamical forecasts and statistical forecasts to improve the quality of seasonal predictions.

Chapter 4 explores the potential for harnessing local forecasting knowledge on weather and climate in Ghana, and integrating it with scientific forecasting techniques. For this, I documented local forecasting knowledge (LFK) on weather and seasons, based on interviews, focus group discussions and a citizen science experiment. Using forecast evaluation metrics, I analysed the performance of LFK compared to scientific forecasting knowledge (SFK). Finally, I developed an integrated approach to predict daily rainfall occurrence and identified three other opportunities to integrate LFK and SFK for investigation in future research.

Chapter 5 explores the coproduction of weather forecast information with and for smallholder farmers in Ghana. Specifically, it evaluates a citizen science coproduction experiment in which farmers, extension agents and scientists participated in training, data collection and monitoring activities. I used expert observation and ex post evaluation to assess an ICT-based weather forecast information service designed with and for smallholder farmers and including both local and scientific forecast information. This allowed me to test the benefit of the joined-up approach to WCIS design and production and to derive design features required for effective WCIS tailored for vulnerable smallholder farmers. 


\section{Chapter I}

Chapter 6 recaps the methods and tools developed, the research results and the main conclusions. It begins by summarizing the answers to the four research questions, and then reflects on the methods developed to tailor scientific forecasts to farmers' needs, the approaches used to assess forecast performance and opportunities to combine local and scientific forecasting knowledge, as well as design parameters for an effective ICT-based climate information service tailored for smallholder farmers. The strengths and limitations of the research are then discussed, followed by an examination of, respectively, the scientific and societal significance of the research with regard to WCIS development for small-scale agriculture. Finally, recommendations are made for future research in the field.

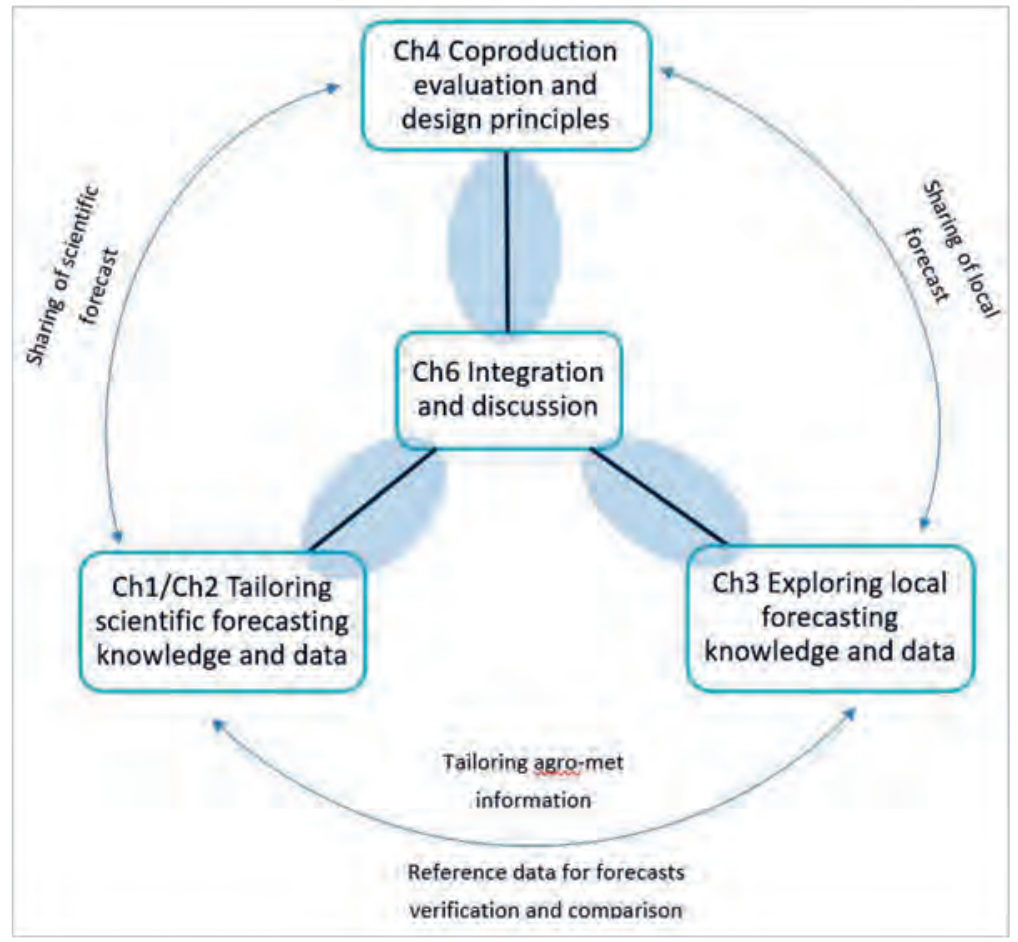

Fig 1.2: Outline of the thesis 


\section{General introduction}

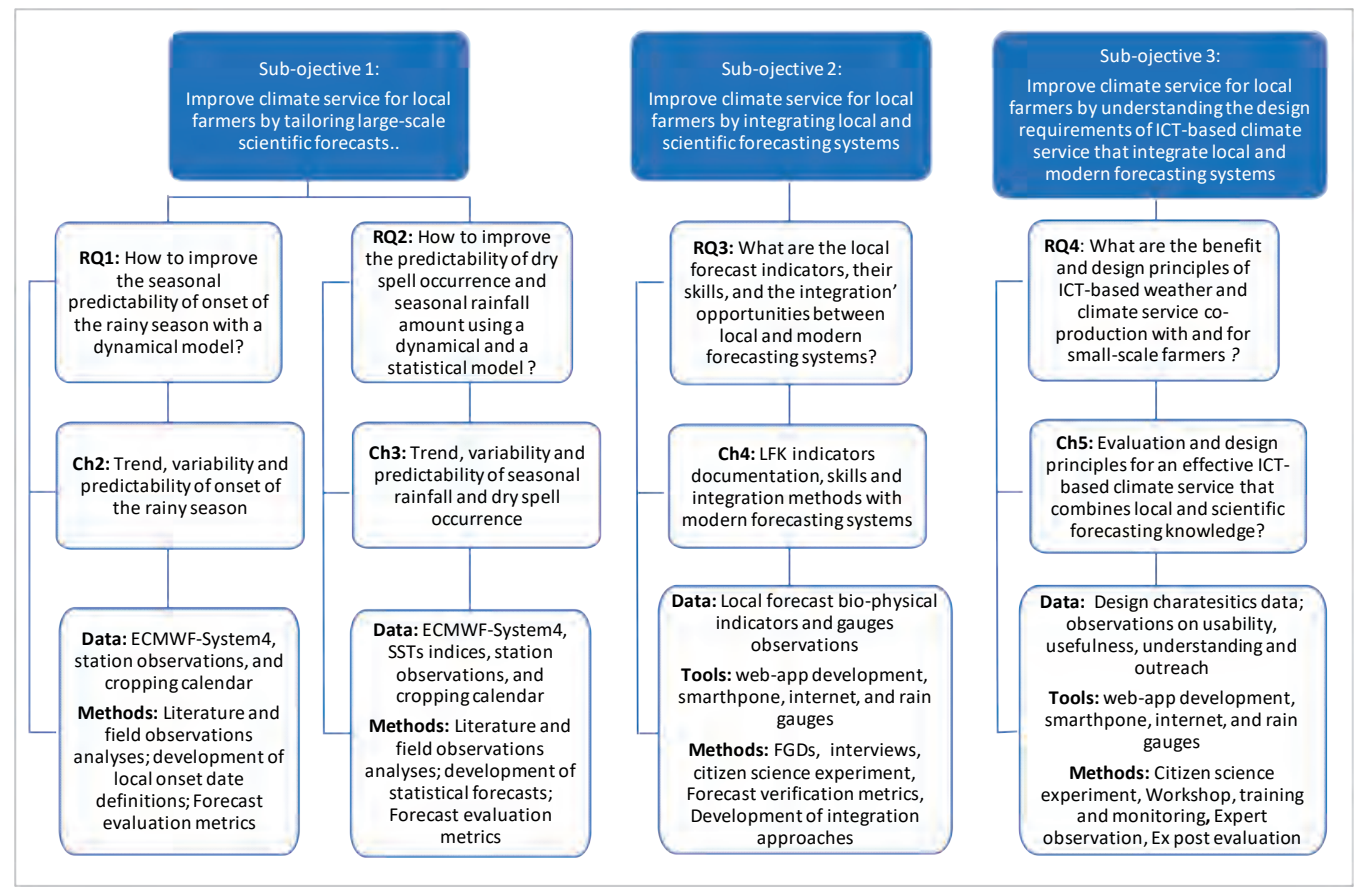

Fig 1.3: Research framework, research objectives and research questions, with their corresponding chapters in this thesis and the data, methods and tools applied. 


\title{
Chapter 2. Seasonal variability and predictability of agro-meteorological indices: Tailoring onset of rainy season estimation to meet farmers' needs in Ghana
}

\begin{abstract}
Reliable information on onset of the rainy season is important for local agriculture planning in Ghana. We examine the (i) trend and variability of onset in local observations to better understand the need for onset forecast information and (ii) performance of ECMWF System 4 seasonal climate forecast in reproducing this variability and discriminating tercile categories of onset dates across Ghana. The analyses focused on two pilots locations of interest among the fourteen synoptic stations studied, namely Ada and Tamale located in the coastal savanna and in northern Ghana. Two different onset date definitions were tested to suite with uncorrected and bias-corrected forecasts in order to test the predictability. The definitions were tailored to suit with forecast start dates, local climate data availability and cropping calendar. Results show a significant decreasing trend in historical onset dates towards more recent times (i.e 1986-2010) at Tamale station. Also, historical onset dates exhibit a significant increasing variability towards more recent time at Ada station. System 4 shows some ability for reproducing local onset variability with significant correlational relationship between forecasted and observed onset dates at some locations including Ada station. The forecasting system also has significant skill in predicting early and late onset dates categories (i.e H-K score > 0) at the pilot stations. In conclusion, the use of onset agrometeorological index, based on System 4 as climate service in Ghana, has a potential value for decision making when considering categorical based forecasts.
\end{abstract}

Published as:

Gbangou, T., Ludwig, F., van Slobbe, E., Hoang, L., \& Kranjac-Berisavljevic, G. (2019). Seasonal variability and predictability of agro-meteorological indices: tailoring onset of rainy season estimation to meet farmers' needs in Ghana. Climate Services, 14, 19-30. https://doi.org/10.1016/j.cliser.2019.04.002 


\section{Practical Implications}

Seasonal crop production in Ghana is subjected to important challenges due to the changing climatic conditions. These challenges are often related to poor understanding of climate variability and low access to tailored climate information that affect farmers' decision making and induces crop failure and yield reduction. This paper addresses this issue by estimating monsoon onset dates trend, variability and predictability. Onset dates agrometeorological information is highly valuable for local agricultural production, especially for small scale rainfed farmers in Ghana whose crop production depend mainly on rainfall. It can help farmers improve their decision-making about the selection of crop types and varieties. Informed farmers can also reduce the risks and costs related to the re-sowing or re-planting process.

This research proposes and applies methods for transforming seasonal climate forecasts relateddata into relevant climate information tailored to end-users needs in Ghana. To this end, monsoon onset dates forecast information is estimated and verified (evaluated) against local observations (local stations data) as a way to represent better local-scale experience and thereby increase the information value. Furthermore, local cropping calendar time-scale are taken into account in the verification process to ensure that onset dates information is tailored to farmer's specific locations and climatic conditions. The significant forecast skills found for the early and late onset dates show promises for provision of tailored forecast onset dates information to local farmers. Thus, prior to each growing season, farmers could use this information to make the right decision. For instance, forecasts starting in March and April respectively for Ada and Tamale could be used to inform farmers on whether rain will start early or late.

The research reflects on uptake of appropriate methods for ensemble seasonal forecasts verification processes by water managers from national meteorological agencies or any institution/programme involved in climate information services provision. This is in view of filling the gap of climate forecasts information creation and access in Ghana based on ECMWF seasonal climate forecasting system. A case application of new seamless monsoon onset definitions and forecast evaluation methods are used in the paper and can help improve forecast usefulness, usability and uptake. Moreover, the probabilistic nature of the forecast assessment offers the benefit of taking into account uncertainties by exploring different potential future realizations or ensemble members. 


\section{Chapter 2}

Owing to a high spatial and temporal variability of monsoon onset dates, famers have problems to decide when to start with the sowing preparations and to optimize investments despite the use a range of traditional coping strategies. Seasonal onset dates forecast information can back up the traditional methods and strategies used by local farmers. The categorization of onset dates in the form of early, normal and late onset dates classes can facilitate the understanding even by local farmers. This format of information can equally give room for future integration with traditional knowledge and can built a roadmap for co-production of climate services.

\subsection{Introduction}

Understanding climate variability is a key concern to achieve food security in West African countries. There is evidence that rainfall variability will increase under climate change (Morris et al., 2009, Sylla et al., 2016, Salack et al., 2016). As a result of this variability, many small scale farmers are facing challenges because they depend, largely, on rain-fed agriculture (Cooper et al., 2008, Wani et al., 2009). In rain-fed farming, rainfall fluctuations induce variability in soil moisture which can limit plant growth and yield. Especially, the inter-annual variability in onset dates can lead to crop failure and yield reduction (Rockstrom, 2000, Ingram et al., 2002, Ochola and Kerkides, 2003, Barron, 2004, Usman and Reason, 2004). For example, delay planting due to late onset of rains may result in reduced yield, while planting following a "false" onset of the growing season may lead to failure and the need for expensive replanting (Ingram et al., 2002, Wetterhall et al., 2015, Dunning et al., 2016). The ability to cope with uncertainty in rainfall and water availability is vital for all farmers. Farming in Ghana is no exception to this uncertainty (Yaro, 2013) as traditional knowledge is often no longer enough to make appropriate decisions (Codjoe et al., 2014). Seasonal forecasts of the onset of the growing season is important for farmers' decision making. Predicting onset of the rainy season can help local farmers plan on when and what to plant. It can also help water managers and authorities plan good seasonal policies towards food security. Understanding onset variability and predictability based on local data is also an important step to fully (i) understand the needs for rains onset information and (ii) the potential for predicting it.

Previous research has shown that skilful seasonal climate prediction can provide meaningful information several months ahead to support decision-makers (Charney and Shukla, 1981, Slingo 
and Palmer, 2011, MacLeod, 2018) despite the chaotic nature of weather. It follows that cropping calendar' decisions for different crops with growing lengths falling totally or partially within 7 months period can potentially benefit from the seasonal climate forecasts information. However, there are still major issues regarding the prediction of onset dates especially for local farmers. Seasonal onset forecasts are shown to have little value to forecast users in West Africa as forecast models tend to under-predict the variability of onset dates across the region, especially when using the wrong onset definitions and observation dataset (Vellinga et al., 2013, Fitzpatrick et al., 2015).

Previous studies carried out on onset seasonal prediction in West Africa (including Ghana) have mostly used large-scale observational products as reference for comparison or for bias correction (Fitzpatrick et al., 2015, Vellinga et al., 2013, Wetterhall et al., 2015) instead of local station data. This is a limitation because global data does not often give a representation of what is experienced on local scale (Wetterhall et al., 2015, Gbangou et al., 2018). For example, Sylla et al. (2013) identified significant differences between satellite and gauges merged observations. Important discrepancies were also found between gauge-based observations and satellite products by Nikulin et al. (2012) and Diallo et al. (2013). Therefore, rigorous validation of climate model outputs using high quality observations remains a challenge Diallo et al. (2016). Moreover, Manzanas et al. (2014a) raised a warning regarding the use of global data, especially, in Ghana as most of the products fail to reproduce the complex rainfall regime in the country (Owusu and Waylen, 2009). These studies use also regional definitions of onset dates instead of local definitions which are locally calibrated and represent local climate conditions (Fitzpatrick et al., 2015).

The importance of a tailored (i.e. specific to local climate and cropping calendar) rainy season onset definition has been proven to be relevant at local scale by previous studies (Janicot et al., 2011, Codjoe et al., 2014, MacLeod, 2018). The surveys on farmers information needs carried out by the Waterapps project ${ }^{1}$ in Ghana has also confirmed a high demand for local specific agro-climatic information. Exploring patterns of local onset trends and variability can provide a clear insight on the factors that drive current challenges faced by traditional knowledge (Ingram et al., 2002), formerly used by farmers to make agro-climatic predictions including onset of the rainy season.

\footnotetext{
${ }^{1}$ Surveys have been conducted locally in Ada East District, Ghana under the WaterApps (www.waterapps.net) project on farmers information needs.
} 


\section{Chapter 2}

This paper aims to optimize the approach for assessing the trend, variability and predictability of growing season onset timing by (i) using local station observations as reference and (ii) adopting a locally tailored definition of the season onset. In doing so, onset information need is ascertained and its predictability is verified with long range seasonal forecasts.

The study area covers the whole Ghana focusing on two pilot stations namely Ada and Tamale (Figure 2.1) located in the coastal savanna and in Northern Ghana respectively. These are locations with a high demand for climate information to support agriculture and where the Waterapps project (www.waterapps.net) is actively involved. Moreover the two stations are located both within a savannah climate conditions where climatic change and variability remains a challenge for agriculture.
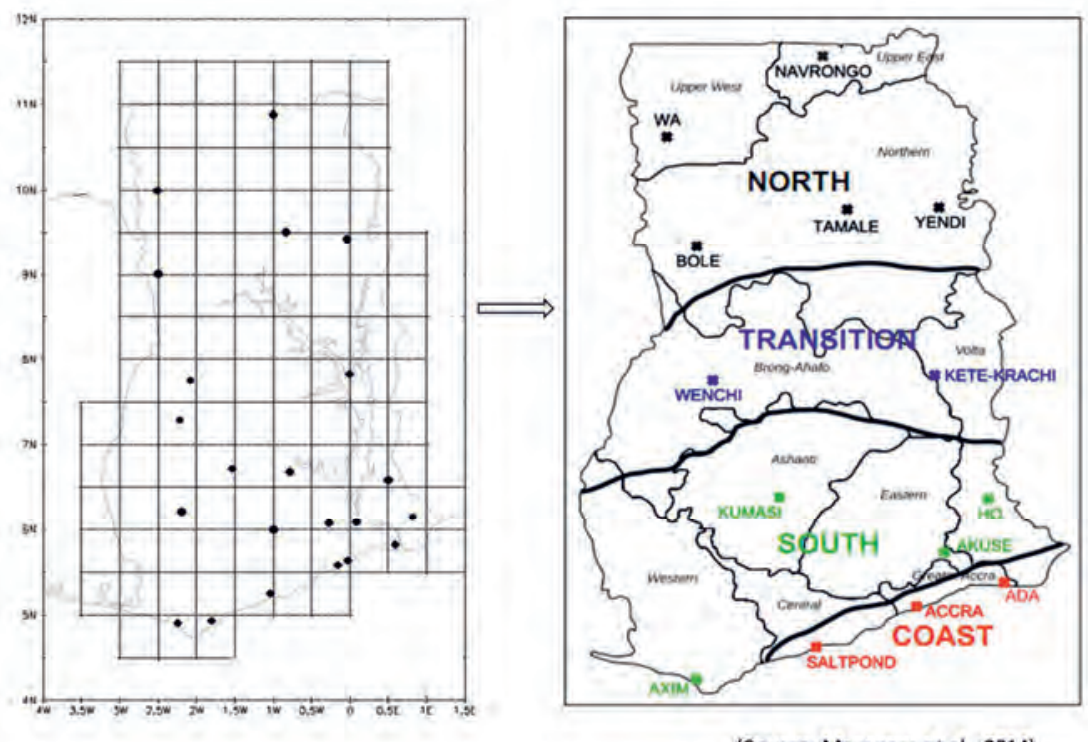

(Source: Manzanas et al., 2014)

Figure 2.1: Map of Ghana showing the location the 22 gauges stations (left) collected from GMet and sorted into 14 gauges stations (right) across the four main agro-ecological zones previously used in Owusu and Waylen $(2009,2013)$.

\subsection{Datasets}


This section give the description of seasonal forecast and stations dataset used in to the study.

\subsubsection{ECMWF seasonal climate forecasts}

The European Centre for Medium-Range Weather Forecasts (ECMWF) seasonal forecasts System 4 was used in the current study. The forecasting system has 51 ensemble members, with initial date on $1^{\text {st }}$ of each month, and then run daily for 7 months (i.e Lead-months). The 51 ensemble members are made up with one control member initialised by ERA-Interim and 50 ensembles in which the initial conditions (ocean and atmosphere) combined with stochastic schemes in the model physics of the atmospheric model (Molteni et al., 2011). The re-forecasts (also referred to as hindcasts) for System 4 consists of forecasts starting also on the $1^{\text {st }}$ of every month over the years 1981-2010 with an ensemble size of 15 members. The hindcasts can be used to calibrate the real-time forecasts in combination with the observed weather and climate. In this study, hindcasts acquired from the ECOMS User Gateway ((Magariño Manero et al., 2014); http://meteo.unican.es/ecoms-udg) are used to verify the performance of System 4 to reproduce local onset dates. Lead-month 0,1 and 2 of System 4 forecasts were selected considering lead time needs ${ }^{2}$ as described in Table 2.1 bellow.

Table 2.1: System 4 lead months selection per agro-ecological zones

\begin{tabular}{cll}
\hline Leadtime & Costal\&Southern zone & Transition\&Northern zone \\
\hline Leadmonth 0 & $\begin{array}{l}\text { Forecast start date is } 1^{\text {st }} \text { March and } \\
\text { MAM season is considered }\end{array}$ & $\begin{array}{l}\text { Forecast start date is } 1^{\text {st }} \text { April and } \\
\text { AMJ season is considered }\end{array}$ \\
Leadmonth 1 & $\begin{array}{l}\text { Forecast start date is } 1^{\text {st }} \text { February } \\
\text { and MAM season is considered }\end{array}$ & $\begin{array}{l}\text { Forecast start date is } 1^{\text {st }} \text { March and } \\
\text { AMJ season is considered }\end{array}$ \\
Leadmonth 2 & $\begin{array}{l}\text { Forecast start date is } 1^{\text {st } J a n u a r y} \\
\text { and MAM season is considered }\end{array}$ & $\begin{array}{l}\text { Forecast start date is } 1^{\text {st }} \text { February and } \\
\text { AMJ season is considered }\end{array}$ \\
\hline
\end{tabular}

\subsubsection{Stations datasets}

A 50 years (1961-2010) rainfall dataset for 14 gauges with less than 2\% missing values (Figure 2.1) were used to (i) characterize historical trend and interannual variability of rainy season onset and (ii) serve partly as reference for the skill assessment of System 4 seasonal climate forecast

\footnotetext{
${ }^{2}$ Lead time needs is based on the cropping calendar (Supplementary S2.3) and surveys conducted in situ
} 


\section{Chapter 2}

described above. These datasets were acquired from Ghana Meteorological Agency (GMet). Considering that Ghana has an area of $238,535 \mathrm{~km}^{2}, 14$ stations correspond to a coverage of about $17,038 \mathrm{~km}^{2}$ per station. This is considered as spare coverage according to Masinde et al. (2012b) as some model gridded data (e.g. System 4 has $0.75 \times 0.75$ grid size) may not have a station within its grid-cell (Figure 2.1). Therefore, instead of interpolating point station rainfall to grid format, which requires a well distributed synoptic stations over Ghana, we rather extracted (interpolated) gridded data for each of the 14 stations. This was done by applying the nearest neighbour interpolation as described by Manzanas et al. (2014a). As mentioned earlier in the introduction, local stations were taken as reference observations for forecasts bias-correction and skill assessment. This is because large-scale products mostly fails to represent local experience, especially at coastal areas with two rainy seasons (Dunning et al., 2016).

\subsection{Methods}

The predictability of rainy season onset is shown to be dependent on (i) lead-time, (ii) definition of onset (iii) the presence of model biases and (iv) the spatial averaging scale of prediction (Wetterhall et al., 2015). We therefore consider adopting adequate definitions and thresholds to check the predictability of this index over Ghana. The bias-correction methodology is also presented in this section.

\subsubsection{Onset date definitions}

Rainy season onset definitions ranges from (i) regional to local definitions and from (ii) rainfallevapotranspiration to rainfall-only related definitions (Ati et al., 2002, Laux et al., 2008, Fitzpatrick et al., 2015). The local definition based on 'rainfall-evapotranspiration that can detect false onset date' seems to be most adequate for onset prediction as it accounts for both local scale experience, and includes environmental water losses through evapotranspiration (Gbangou et al., 2018). However it requires the inputs of several climate variables to calculate evapotranspiration. Thus, two onsets definitions based on 'rainfall-related' definitions namely "isochrone" and "agronomic" were adopted due to lack of data to fully compute evapotranspiration. The isochrone and agronomic method being respectively adequate for (i) raw model runs and (ii) bias-corrected model runs. The two definitions are described below: 
- An adjusted onset definition presented by Vellinga et al. (2013) and often called 'isochrone method' was adopted and applied to both raw System 4 and GMet datasets. They define onset date as the date when a given percentage of cumulative season rainfall has fallen, here $25 \%$ of the normalized seasonal (e.g: MAM or AMJ) rainfall was considered as calibrated threshold (Supplementary S2.2). The threshold is chosen to reflect the agronomic onset definition which is a rainfall-evapotranspiration definition of Benoit (1977). Although, this definition is only a rainfall-related, in contrast to rainfall-evapotranspiration related definition, and it remains relevant for the purpose of this study. This method is particularly useful when dealing with raw System 4 outputs because it is not sensitive to models biases (Vellinga et al., 2013). This is because the definition uses a relative number as a threshold instead of an absolute rainfall amount.

- An agronomic onset date definition (based on absolute rainfall value) was adopted for biascorrected System 4 outputs. For example at Ada district (coastal zone) onset is defined as follow : starting from $1^{\text {st }}$ March, onset of growing season is when average 4 days rainfall exceeds $10 \mathrm{~mm}$. The definition was motivated by the study of Huho et al. (2012) based on cropping calendar in Kenya. The threshold of $10 \mathrm{~mm}$ is chosen after validation with the full rainfall-evapotranspiration onset definition of Benoit (1977) (see Supplementary S2.2, figure S2.2).

The definitions were chosen to reflect the local farmers cropping calendar ${ }^{3}$ and the northward evolution in rainfall distribution across Ghana. The forecasts start dates were selected based the cropping calendar at Ada district, taken as reference for the coastal savannah and considering the northward rainfall distribution in Ghana as described in previous (Manzanas et al., 2014a, Owusu and Waylen, 2009). Therefore, MAM (March-April-May) and AMJ (April-March-June) seasons were selected for Coast-South and Transitional-North agro-ecological zones respectively (Figure 2.1).

Both methods were validated using Benoit (1977) 'rainfall-evapotranspiration related onset definition', which is 'false onset'-sensitive, over years and stations where data were available. This was done in order to avoid false starts related to prolonged dry spells that can cause serious damage

\footnotetext{
3 The general cropping calendar in Ada East district is presented Appendix 3
} 


\section{Chapter 2}

to crops (Ati et al., 2002, Marteau et al., 2009, Dunning et al., 2016). At Ada, relatively good correlations 0.71 and 0.72 were found, respectively, between (i) Benoit (false-onset sensitive) and the agronomic (absolute value) definitions used in this paper and (ii) Benoit (false-onset sensitive) with the isochrone methods (see Supplementary, S2.2). These correlations indicate that there are differences in onset dates among the definitions. However this is not surprising given that local/agronomic definitions usually have discrepancies among them unlike regional definitions which can predict homogeneous onset dates (Fitzpatrick et al 2015). When considering the Benoit (1977) definition as reference, we identified 4/31 cases of false onset starts for the absolute value agronomic definition and $3 / 31$ of false onset starts with the isochrone definition (see Supplementary, Figure S2.2). These false onset dates can be assumed to be rare.

\subsubsection{Bias-correction and lead-time selection}

Bias-correction was applied on the System 4 seasonal climate forecasts using GMet observations as reference. The quantile mapping bias-correction method (Panofsky et al., 1958) was used (see full methodology in Supplementary S2.4). The method adjusts the forecasted rainfall (System 4) to the observed rainfall (GMet) by matching the cumulative density function (CDF) of daily rainfall at each station. The method is proven to be successful in many hydrological and climate impact studies (Maurer and Hidalgo, 2008, Li et al., 2010, Jakob Themeßl et al., 2011, Wetterhall et al., 2012) as well as medium-range (Voisin et al., 2010) and seasonal forecasts (Wood et al., 2002). We consider forecast starting in March and April for (i) Coast -South and (ii) Transitional-North agro-ecological zones respectively in order to account for bimodal, unimodal as well as the northward shift in rainfall distribution across Ghana (Sultan and Janicot, 2003).

\subsubsection{Skill metrics}

The onset dates derived from System 4 ensemble forecasts were verified against GMet observations using Pearson' correlation coefficient (PCC) and Hanssen-Kuipers (H-K) skill score discriminant for the categories (Hanssen and Kuipers, 1965). PCC, presented in Equation 2.1, measures how well the forecast anomalies correspond to the observed anomalies over the hindcast period 19812010 at each station. Hence, PCC stands as a measure of variability. This H-K score (Equation 2.2) has been widely used for many years to evaluate precipitation forecasts (Accadia et al., 2003, Stephenson, 2000, Tartaglione, 2010, Gsella et al., 2014, Fekri and Yau, 2016, Singh et al., 2017) 
against observations. Hanssen and Kuipers' discriminant score is universally acceptable and give the best in evaluating yes/no forecasts for decision making purpose (Woodcock, 1976). The score measures the ability of the forecasts to discriminate (correctly classify) events and non-events. The events are considered here as early, near average, and late onset dates. Onset dates (i) before average corresponds to the lower tercile or lower third $\left(\leq 33^{\text {rd }}\right)$ of the onset dates over the full hindcast period, (ii) near average corresponds to middle tercile, or central third of the onset dates and (iii) later than average corresponds to upper tercile or top third $\left(\geq 66^{\text {th }}\right)$ of the onset dates.

$\mathrm{PCC}=\frac{\frac{1}{M} \sum\left(F_{m}-\bar{F}_{m}\right)\left(o_{m}-\bar{o}_{m}\right)}{\sqrt{\frac{1}{M} \sum\left(F_{m}-\bar{F}_{m}\right)^{2} \cdot \frac{1}{M} \sum\left(o_{m}-\bar{o}_{m}\right)^{2}}} \quad$ (Equation 2.1)

Where: $F_{m}$ and $O_{m}$ are respectively the forecasted and observed indices for year m; $\bar{F}_{m}$ and $\bar{O}_{m}$ is the time mean of $F_{m}$ and $O_{m}$ respectively ; and $\mathrm{M}$ is the number of hindcast years; PCC is the correlation coefficient.

$\mathrm{H}-\mathrm{K}=\mathrm{POD}-\mathrm{POFD}$ with POD $=\mathrm{a} /(\mathrm{a}+\mathrm{c})$ and POFD=b/(b+d) (Equation 2.2)

Where: $\mathrm{H}-\mathrm{K}$ is the Hanssen-Kuipers discriminant or Pierce Skill Score (Hanssen and Kuipers, 1965); POD and POFD represent respectively the probability of detection or hit rate and the probability of false detection or false alarm rate; HK ranges from -1 to $1 ; \mathrm{H}-\mathrm{K} \leq 0$ indicates no skill, $\mathrm{H}-\mathrm{K}=1$ is the perfect score; $\mathrm{a}, \mathrm{b}, \mathrm{c}$ and $\mathrm{d}$ are described in Table 2.2.

$\mathrm{FAR}=\mathrm{b} /(\mathrm{b}+\mathrm{a})($ Equation 2.3$)$

Where: FAR is the false alarm ratio and ranges from 0 to $1, F A R=0$ is the perfect score.

Table 2.2: Contingency table for categories of events.

\begin{tabular}{llll}
\hline & Event-observed & Event-not observed & Total \\
\hline Event-forecasted & Hits (a) & False alarms $(\mathrm{b})$ & $\begin{array}{l}\text { Yes forecasted (a } \\
+\mathrm{b})\end{array}$ \\
Event-not forecasted & Misses (c) & Correct rejection $(\mathrm{d})$ & $\begin{array}{l}\text { No forecasted (c } \\
+\mathrm{d})\end{array}$ \\
Total & Yes observed $(\mathrm{a}+\mathrm{c})$ & No observed $(\mathrm{b}+\mathrm{d})$ & Total forecasts (n)
\end{tabular}

Hit rate (POD, Equation 2.2), false alarms ratio (FAR, Equation 2.3), and false alarm ratio (POFD, Equation 2.2) were subsequently analyzed to facilitate the use for forecast for decision making. POD measures the fraction of the observed "yes" events that were correctly forecasted and ranges 


\section{Chapter 2}

from 0 to 1 where the perfect score is 1 . FAR measures the fraction of predicted "yes" events that did not occur and ranges from 0 to 1 with 0 as perfect score. POFD measures the fraction of the observed "no" events were incorrectly forecast as "yes" and ranges from 0 to 1 with 0 as perfect score. We recall that the 'event' here indicates early, normal or late onset dates. POD and POFD are measures of discrimination while FAR is a measure of reliability. These metrics can facilitate decision making, even for non-scientific, and were computed for the best leadtimes found after the H-K skill scores analyses at Ada and Tamale pilot stations of interest.

\subsubsection{Statistical Analyses}

Patterns of onset starting date trend and variability were analyzed for P1: 1961-1985 and P2: 19862010 over the 14 stations including Ada and Tamale pilots stations. P1 and P2 periods are set to represent past and more recent time climate conditions following the work of Manzanas et al. (2014a) on precipitation trend and variability in Ghana. The analysis over these separate periods help to account for changes in trend and variability in Ghana. Moreover, the equal-length of the cut-off years prevents from the effect of sample size on the significance tests.

Statistical tests were performed for the trend and variability of historical onset dates over the P1 and P2 periods. The Mann-Kendall test analysis of linear trend significance was carried out. This method has been used in many previous studies across the world (Partal and Kahya, 2006, Obot et al., 2010, Manzanas et al., 2014a). The analysis of onset date variability significance was performed using F-test to test whether there is a difference in variability between P1 to P2 periods. An additional evidence on the change in variability was carried out using the Fligner-Killeen test (Fligner and Killeen, 1976, Hettmansperger and McKean, 2010) which is robust and nonparametric (see supplementary, Table S2.3).

Statistical significance tests were also carried out on the forecasts skill assessment over the hindcast period of 1981-2010 using t-test. The significance tests were applied to the (i) correlation between GMet and System 4 and the (i) H-K skill scores.

\subsection{Results}

\subsubsection{Trend and variability in onset dates from GMet observations}


The inter-annual variability of onset dates for Ada (coastal savannah) and Tamale (northern Ghana) stations under the isochrone and agronomic methods are presented on Figure 2.2. The figure clearly show that onset dates vary from year to year for both P1 and P2 periods at the two stations. Julian days at Tamale are generally higher than Ada implying that onset occurs later in the northern although both have a savanna type of climate. Differences in onset dates also exist between the two local onset definitions. At Ada station, there is a non-significant decreasing and increasing linear trend over P1 and P2 periods respectively for both onset definitions (Figure 2.3a). However, at Tamale, there is a significant $(\mathrm{P}<0.10)$ decreasing linear trend for $\mathrm{P} 1$ and $\mathrm{P} 2$ periods respectively under the two onset definitions (Fig 2.3b). Using the isochrone method, the trend towards an earlier date is even significant at $\mathrm{P}<0.05$ for Tamale. These results imply that, towards more recent time, there is no significant change in trend for onset starting dates at Ada. At Tamale, however, there is a clear change pattern that indicate an earlier start of rainy season towards present day. The results for other stations also show a general trend towards an earlier date over the majority of stations located at the transition and northern Ghana compared to those located in the Coastal and Southern Ghana (Figures 2.3a and 2.3b). For example, stations like Wa and Yendi show a significant decreasing trend at $95 \%$ confidence level.

At Ada, there is an increase variability of the onset of the rainfall. The standard deviation of both the isochrone and agronomic (Figures 2.4) definitions are significantly increasing. At Tamale, the figures show a reduction of standard deviation with no-significant decrease in variability and under the isochrone and agronomic definitions. These findings show that there is a higher variability in onset dates occurring at Ada towards more recent time whereas at Tamale, le variability is small. Under the isochrone method (Figure 2.4 ), the majority (10 over 14 stations) of the stations exhibit an increasing variability over P2 in relation to P1 period. Under the agronomic method (Figure 2.4), half of the stations show an increasing variability. However, both methods consistently predicted with $90 \%$ confidence a significant increasing variability at 3 stations namely Ada, Saltpond, Kete-Krachi, Wa and Yendi. At 95\% confidence level, both methods consistently predicted an increased variability at Kete-Krachi station only.

In summary, the results show that at Tamale the rainfall season has started earlier over the last decades indicated by significant trends for the 1986-2010 period. In Ada there has not been a significant change in the onset of the rainfall season. In Ada, however, the variability of the onset 


\section{Chapter 2}

has increased during both periods. At Tamale there was no significant change in the variability of the onset of the rainfall season.

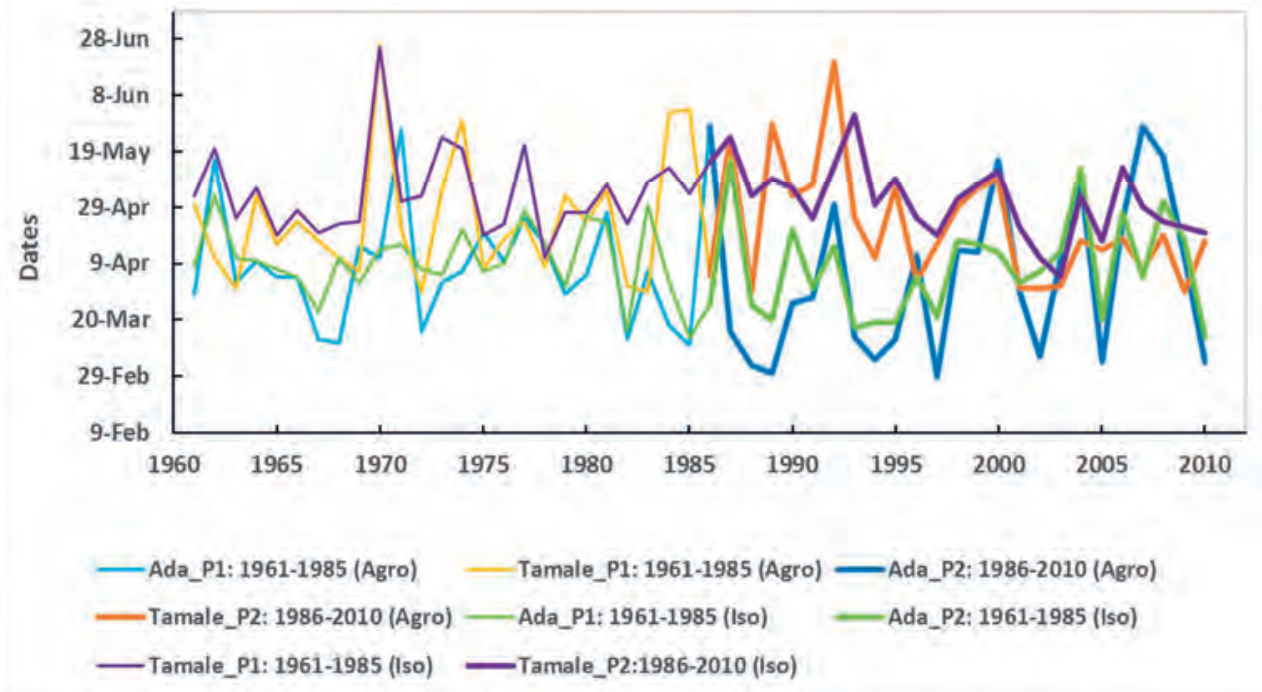

Figure 2.2: Interannual variability of onset dates in GMet observations for the two different periods: P1:1961-1985 and P2: 1986-2010 for Ada and Tamale stations. Onset dates were calculated using the isochrone (iso) and agronomic (agro) methods. 


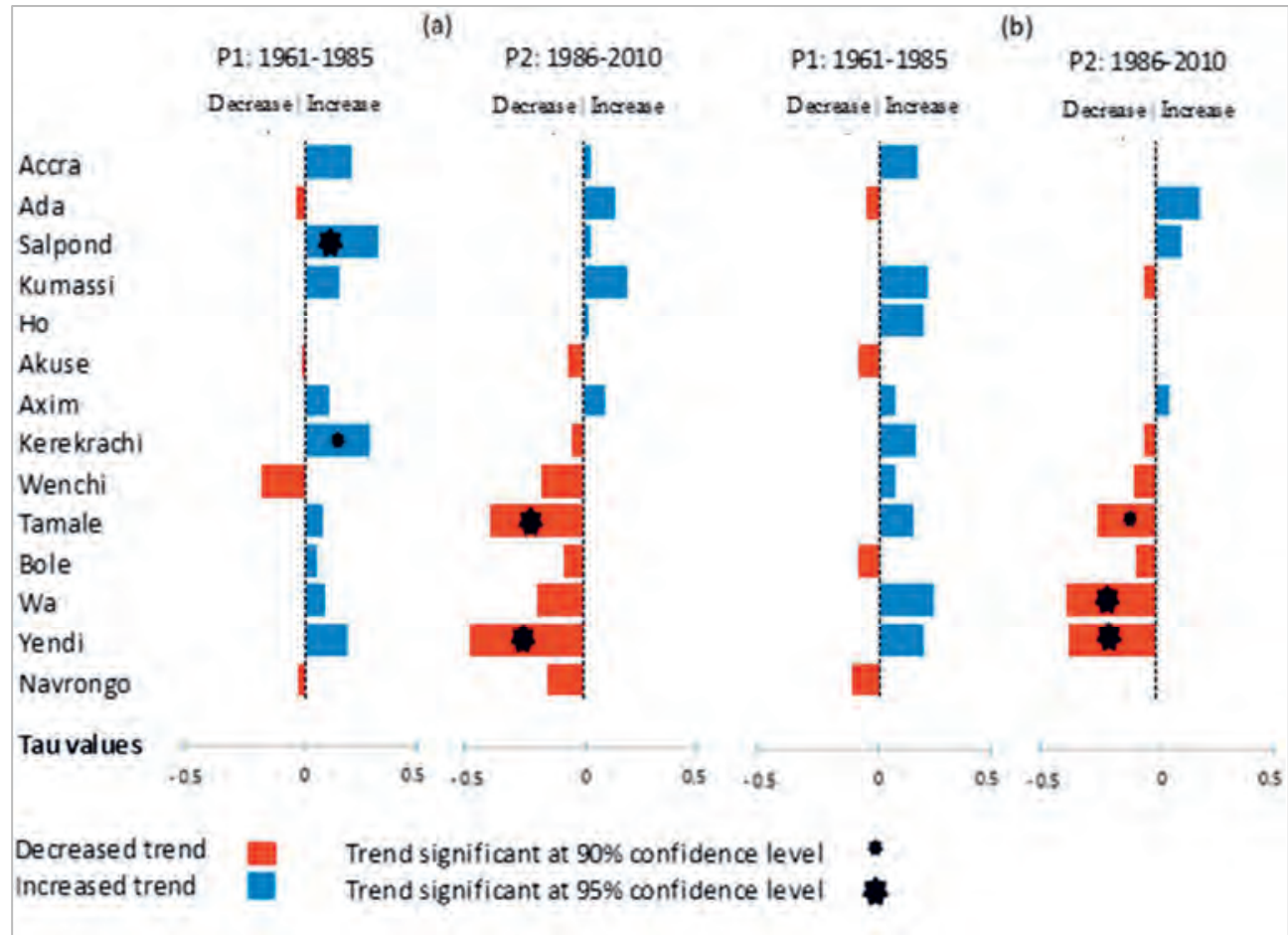

Figure 2.3: Linear trend of onset dates for all the stations and for the isochrone (a) and agronomic (b) definitions. The small and big asterisks indicate, respectively, significance in trend at $90 \%$ and $95 \%$ confidence levels based on Mann-Kendall test. The decreasing and increasing trends are indicate by the tau values of the statistical test.

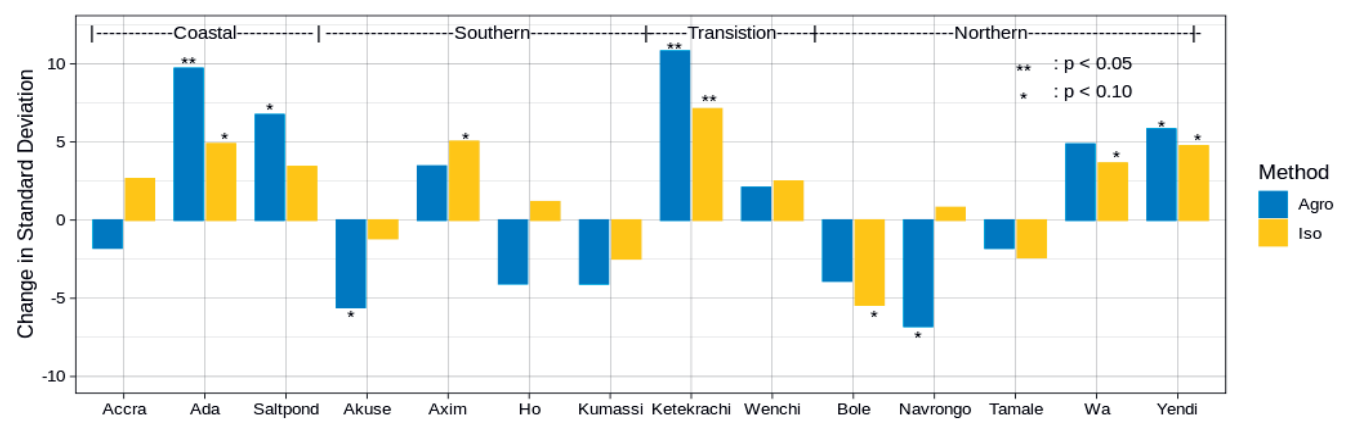




\section{Chapter 2}

Figure 2.4 : Change in the standard deviation of onset dates across the 14 stations in Ghana for periods P1:1961-1985 and P2: 1986-2010. (*) and (**) asterisks indicate, respectively, significance changes in variability at $90 \%$ and $95 \%$ confidence level based on F-test. Iso and Agro indicate the isochrone and agronomic onset definitions respectively. The stations are also grouped by agroecological zones.

\subsubsection{Ability of System 4 for the reproduction of local onset variability}

This section analyses findings on the ability of system 4 to reproduce the variability in observed onset dates, focusing on correlations. Results on the correlational analysis is presented in Figures $2.5 \mathrm{a}$ and $2.5 \mathrm{~b}$ for the isochrone and agronomic onset definitions respectively over the 14 stations. The correlation relationship plot between GMet and System 4 ensemble mean onset dates is presented for lead month 0,1 and 2 (i.e $1^{\text {st }}$ March, $1^{\text {st }}$ February, and $1^{\text {st }}$ January forecast starting dates for the South-Coast and $1^{\text {st }}$ April, $1^{\text {st }}$ March, and $1^{\text {st }}$ February forecast starting dates for the Transition-North zones respectively). The correlation coefficient ranges from 0 to 0.42 and from 0 to 0.49 for the agronomic and isochrone methods respectively. Globally, correlation for leadmonth 0 performs better than the others for both onset definitions. In terms of correlation strength, these coefficients are weak but there are, interestingly, significant positive correlational relationships for some stations. For example, at Ada station and under leadmonth 0, the correlation is positively weak (i.e PCC is less than 0.5) but significant at $95 \%$ confidence level under the two onset definitions. With the isochrone definition at Leadmonth 0 , there are 9/14 stations with significant relationship at $90 \%$ confidence level and $6 / 14$ at $95 \%$ confidence level. Under the agronomic definition, only $7 / 14$ of the stations show a significant correlation at $90 \%$ confidence for leadmonth 0,1 and 2 put together and 4/14 stations significant at 95\% confidence level for leadmonth 0 and 1. In term of agro-ecological zones, higher correlations are generally found over the CoastSouthern zone in comparison to the Transition-Northern zone.

Figure 2.6 presents the interannual variability of onset dates at Ada and Tamale from GMet and System 4 ensemble forecasts for the 15 members over the hindcast period and for the isochrone and agronomic methods using boxplots. Each boxplot measures onset dates distribution over the hindcast period 1981-2010 by highlighting the central tendency and its variability. The figure also shows the median and mean (red asterisk). Additional detailed analyses at individual member level 
were presented in the supplementary material (see Supplemental S2.6). This was done by resampling interannual variability across the hindcasts years and for each ensemble member. Under the isochrone definition, Figure 2.6 shows that the magnitude of observed onset date variability is under-estimated by System 4 at Ada. Interestingly, this correspond to period where high variability has been observed earlier in section 2.4.1. However, at Tamale, where a reduced onset variability has been observed, the magnitude of variability is better reproduced. In contrast, the agronomic definition over-estimate the observed variability.

The results on significance correlational relationship (see Figure 2.5), shows weak correlation coefficients range from 0 to 0.49 but significant at some stations like Ada. The inter-annual variability findings (see Figure 2.6) show that system 4 usually under-estimate the variability at station where high onset variability is occurring based on the isochrone method. With the agronomic, which is based on bias-corrected forecast, the variability is generally over-estimated in all cases.
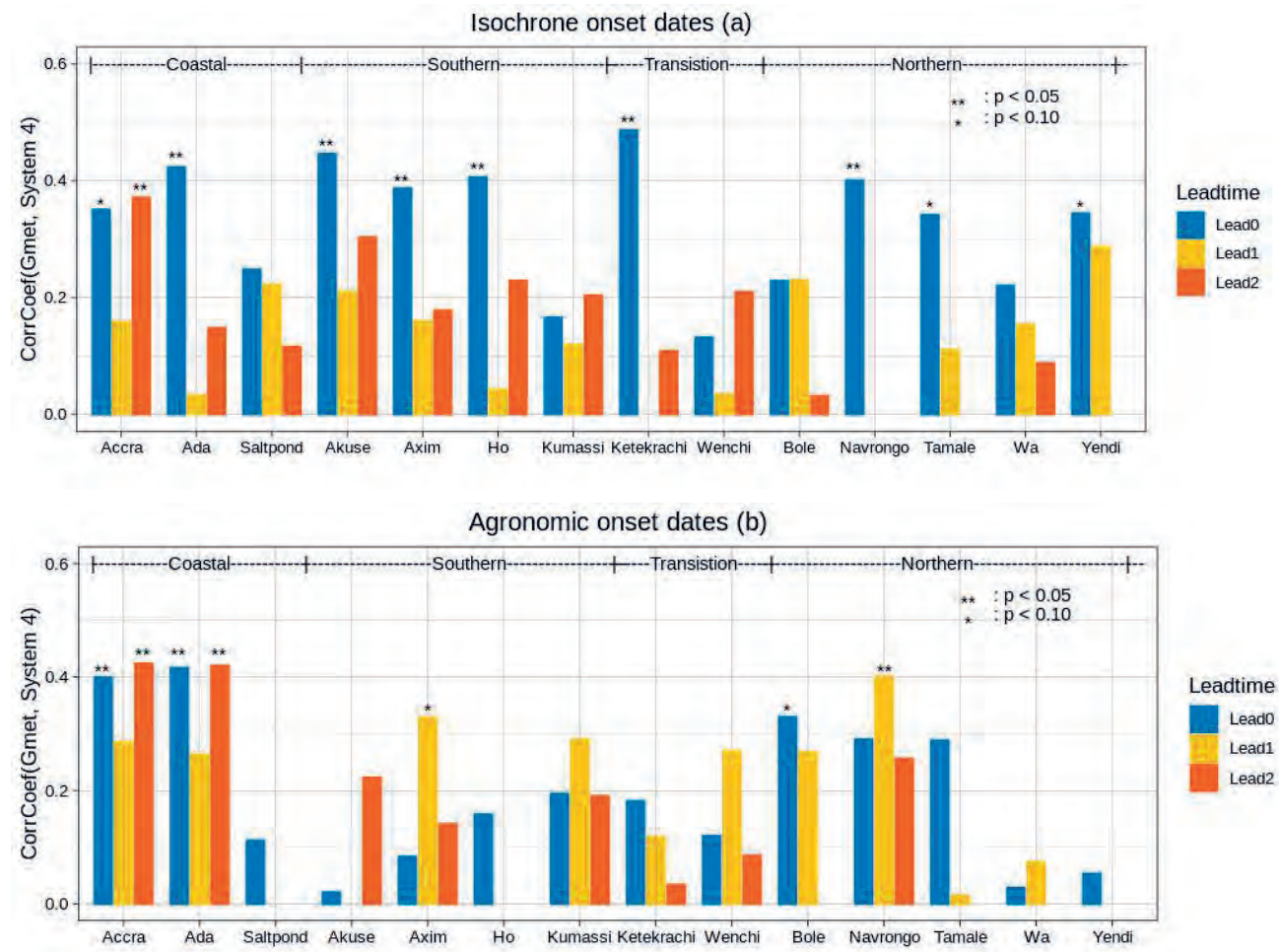


\section{Chapter 2}

Figure 2.5: Anomaly correlation coefficients between onset dates GMet and System 4 ensemble mean for the (a) isochrone and (b) agronomic methods. The agronomic definition are applied on bias-corrected forecasts. The ensemble mean being computed for lead time 0,1 and 2. (**) and (*) indicate significant correlation at 0.05 and 0.10 confidence level respectively. Stations are grouped by agro-ecological zones.
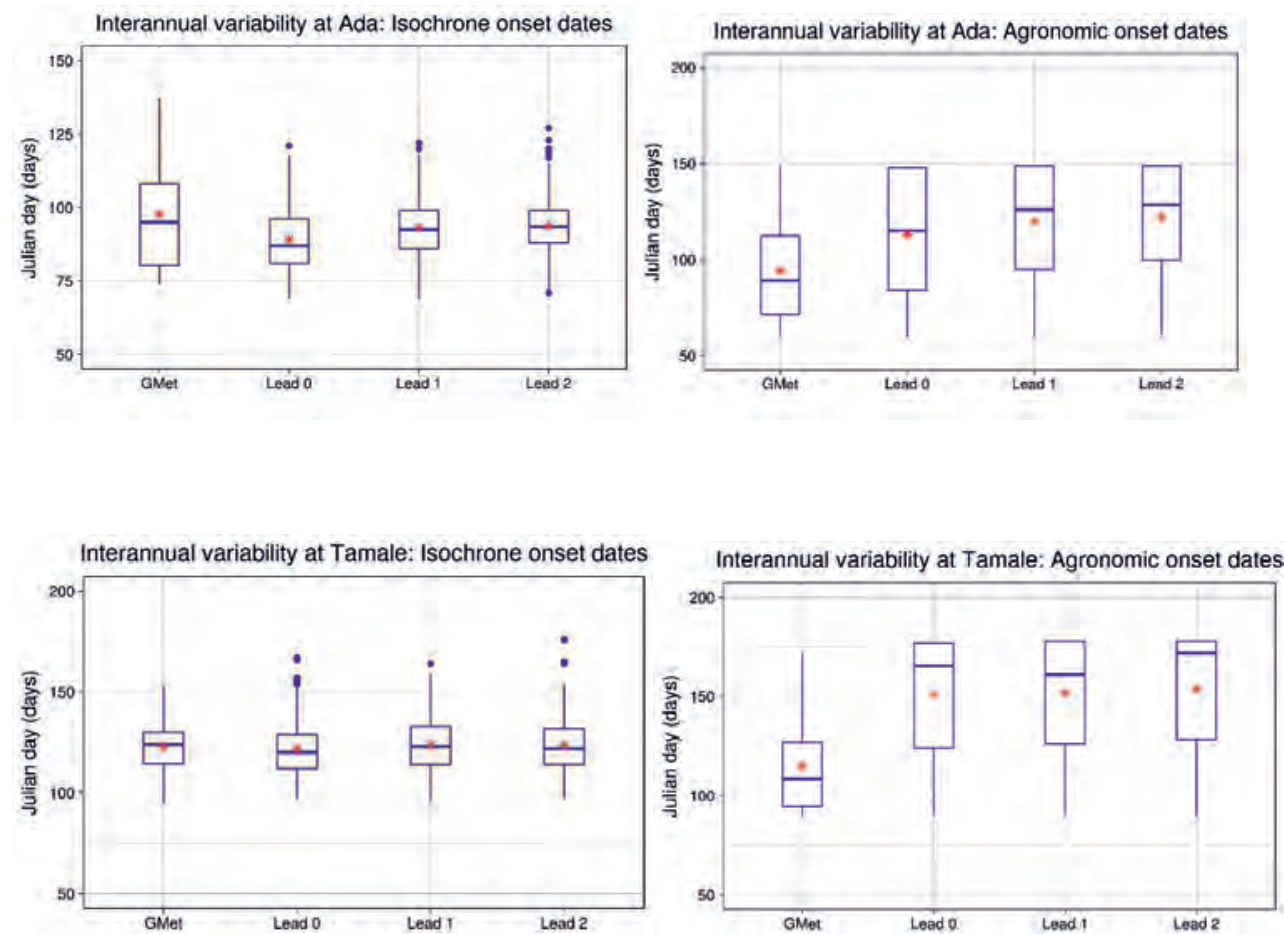

Figure 2.6: Inter-annual variability of onset dates over the hindcasts period 1981-2010 for Ada and Tamale stations. Edges of Box show 25 and 75 percentiles with the line within the box showing the median. Error bars show 10 and 90 percentiles and dots indicate individual outliers. The red asterisk represents mean. Lead 0,1,2 represent the forecasts starting in (i) March, February, and January for Ada, and (ii) April, March, and February for Tamale.

\subsubsection{Ability of system 4 to reproduction categories of local onset}


Results on the skill test of System 4 ensemble forecasts in classifying early, normal and late onset are presented in this section for Ada and Tamale pilot stations and for the two onset definitions. The analysis for all 15 members and the ensemble mean for Leadmonth 0,1 and 2 and for each category are presented in Figure 2.7 together with the significance test results at $95 \%$ and $99 \%$ confidence levels. Under lead-month 0 , the median and mean fall above H-K score $=0$ for the early and late onset categories. These two categories also show significant scores at the two stations when using the isochrone method (see Figure 2.7). However, under the agronomic definition, only the late category has significant score at lead-month 0 . The other lead-months, with exception of the late category of lead-month 1 at Tamale, show non-significant skillful scores. Therefore Leadmonth 0 has better skill than Learmonth 1 and 2 for both definitions at the two pilot stations. The figure also shows that System 4 is able, at some extent, to discriminate better early and late rain onset dates than those at near average (normal) categories. Moreover, the isochrone definition performance slightly better than the agronomic definition at Learmonth 0 with higher skill scores value around the central tendency.

In conclusion, System 4 seasonal climate forecast has skills in reproducing onset date categories especially for low and higher tercile categories and for Learmonth 0 which corresponds to March and April forecasts for Ada and Tamale respectively. The next section presents results discussion of all findings.
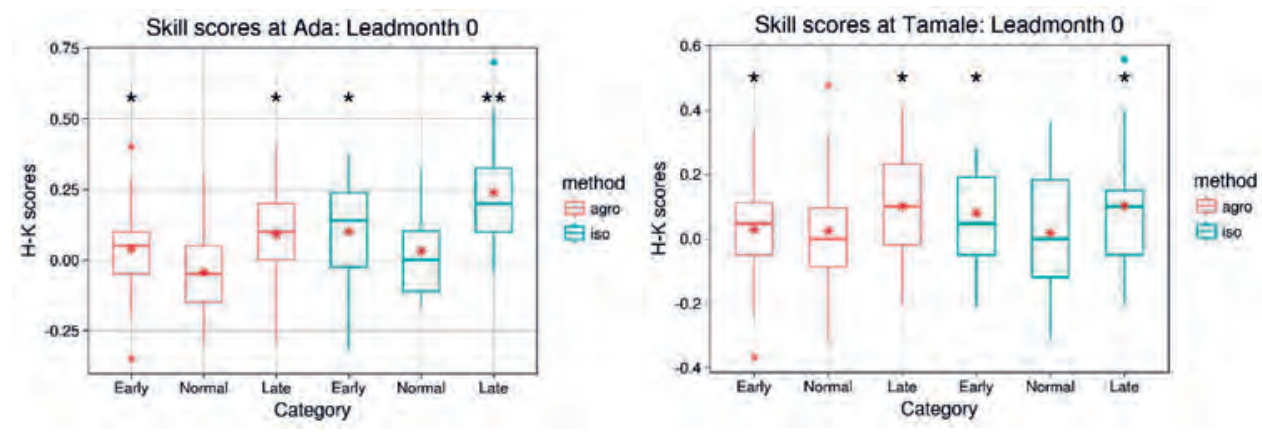


\section{Chapter 2}
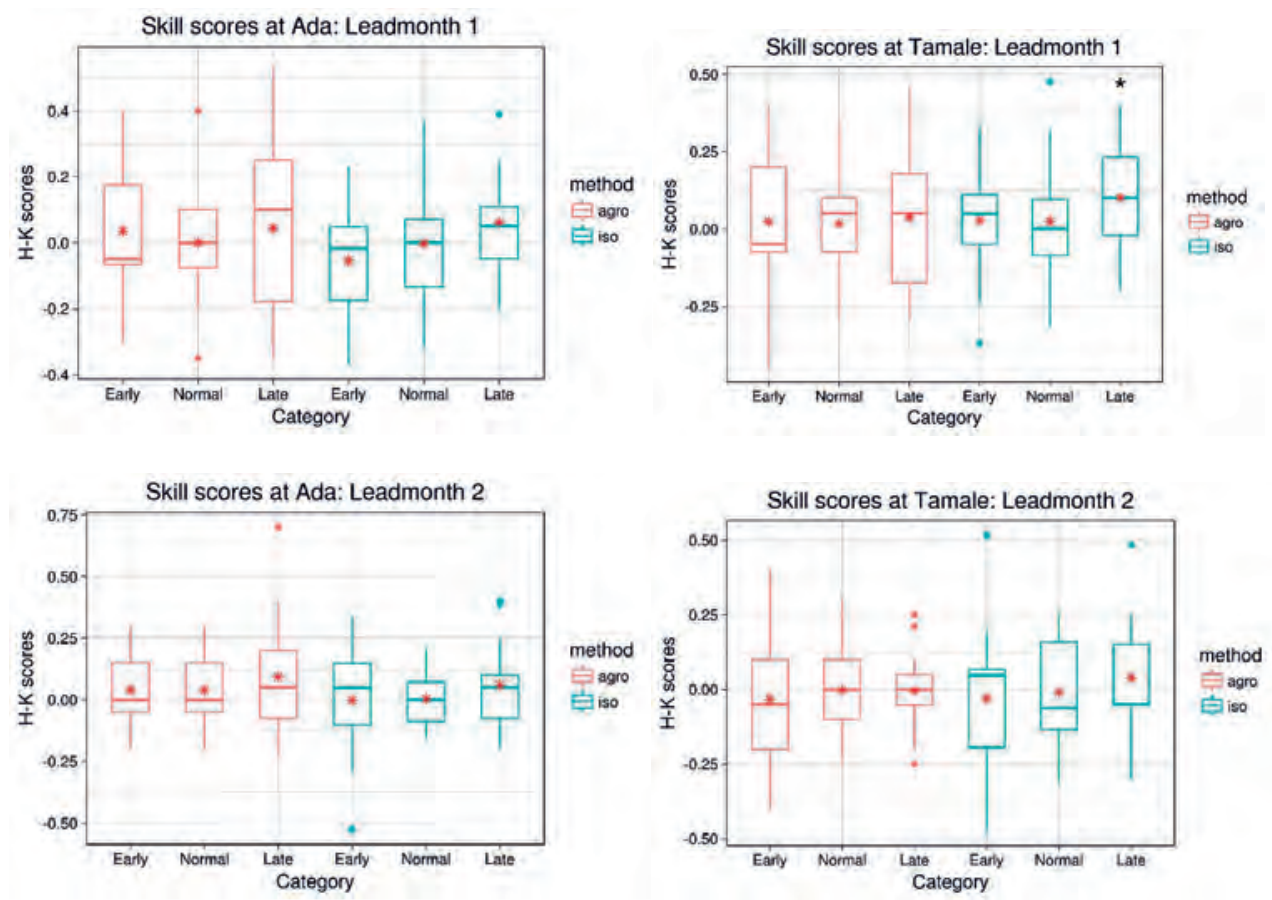

Figure 2.7: Skill in onset date categories for lead-month 0,1, and 2 at Ada and Tanmale stations. Edges of Box show 25 and 75 percentiles with the line within the box showing the median. Error bars show 10 and 90 percentiles and dots indicate individual outliers. The red asterisk indicates the skill in the ensemble mean. The single and two black asterisks show lead-months and categories where the skill is respectively significant at $95 \%$ and $99 \%$ confidence levels based on t-test. The isochrone dates are presented in pink and agronomic in blue.

Analyses of hit rate (POD), false alarms ratio (FAR), and false alarm rate (PODF) for Leadtime 0 are presented in Table 2.3 and 2.4 for Ada and Tamale stations. These are meant to facilitate the use the forecasts information for decision making. Based on the ensemble results for Ada and for the isochrone method, Table 2.3 indicates that 56\% (i.e. POD) of the observed late-onset events were correctly predicted while $45 \%$ (i.e. FAR) of the predicted 'yes' late-onset events did not occur; and only $27 \%$ (i.e. POFD) of the forecasted 'no' late onset event was incorrectly 'yes'. As for early onset event with the same station and method, the table indicates that $40 \%$ of the observed earlyonset events were correctly predicted while $60 \%$ of the predicted 'yes' early-onset events did not 
occur; and only $30 \%$ of the forecasted 'no' early onset event was incorrectly 'yes'. Recalling that the best case for decision making is when POD, FAR, and POFD are respectively close to 1,0, and 0 , late onset forecast are more reliable compared to early onset date. Both can discriminate onset categories and for that reason are still better than random guesses. With the agronomic definition, hit rates were found to be lower than the false alarm ratio (e.g. POD of $36 \%$ and $45 \%$ against FAR of $64 \%$ and $55 \%$ for the early and late onset respectively) although the false alarm rate is still relatively good (i.e low with $31 \%$ and $27 \%$ for the early and late onset dates). This further confirmed that the isochrone method perform better compared to the agronomic definition. Similar analysis for Tamale show that late onset date forecasts are more reliable than early onset category, although both categories are discriminated by the forecasts. Some of the best ensemble members do show good reliability (e.g. at Ada under the isochrone method, $\mathrm{POD}=80 \%$ and $\mathrm{FAR}=20 \%$ for late onset date event ).

Table 2.3 : Analysis of hit rate, false alarm ratios and false alarm ratio at Ada station to facilitate forecast interpretation for decision making. Leadtime 0 is considered.

\begin{tabular}{|c|c|c|c|c|c|c|}
\hline $\begin{array}{c}\text { Onset } \\
\text { definition }\end{array}$ & $\begin{array}{c}\text { Best } \\
\text { Leadtime } \\
\mathrm{s}\end{array}$ & $\begin{array}{c}\text { Best } \\
\text { Categorie } \\
\mathrm{s}\end{array}$ & $\begin{array}{c}\text { Ensemble } \\
\text { forecast }\end{array}$ & $\begin{array}{l}\text { POD (hit } \\
\text { rates) }\end{array}$ & $\begin{array}{l}\text { FAR (false } \\
\text { alarm ratio) }\end{array}$ & $\begin{array}{c}\text { POFD (false } \\
\text { alarm rate) }\end{array}$ \\
\hline \multirow{4}{*}{ Isochrone } & \multirow{4}{*}{ Lead 0} & \multirow{2}{*}{$\begin{array}{c}\text { Early } \\
\text { onset date }\end{array}$} & Ensemble & $36 \%$ & $60 \%$ & $30 \%$ \\
\hline & & & $\begin{array}{c}\text { Best } \\
\text { member }\end{array}$ & $55 \%$ & $40 \%$ & $21 \%$ \\
\hline & & \multirow{2}{*}{$\begin{array}{l}\text { Late onset } \\
\text { date }\end{array}$} & Ensemble & $56 \%$ & $45 \%$ & $27 \%$ \\
\hline & & & $\begin{array}{c}\text { Best } \\
\text { member }\end{array}$ & $80 \%$ & $20 \%$ & $30 \%$ \\
\hline \multirow{4}{*}{$\begin{array}{l}\text { Agronomi } \\
\text { c }\end{array}$} & \multirow{4}{*}{ Lead 0} & & Ensemble & $36 \%$ & $64 \%$ & $31 \%$ \\
\hline & & onset date & $\begin{array}{c}\text { Best } \\
\text { member }\end{array}$ & $60 \%$ & $40 \%$ & $20 \%$ \\
\hline & & \multirow{2}{*}{$\begin{array}{l}\text { Late onset } \\
\text { date }\end{array}$} & Ensemble & $49 \%$ & $55 \%$ & $27 \%$ \\
\hline & & & $\begin{array}{c}\text { Best } \\
\text { member }\end{array}$ & $81 \%$ & $21 \%$ & $30 \%$ \\
\hline
\end{tabular}




\section{Chapter 2}

Table 2.4: Analysis of hit rate, false alarm ratios and false alarm ratio at Tamale station to facilitate forecast interpretation for decision making. Leadtime 0 is considered.

\begin{tabular}{|c|c|c|c|c|c|c|}
\hline $\begin{array}{c}\text { Onset } \\
\text { definition }\end{array}$ & $\begin{array}{c}\text { Best } \\
\text { Leadtime } \\
\mathrm{s}\end{array}$ & $\begin{array}{c}\text { Best } \\
\text { Categorie } \\
\text { s }\end{array}$ & $\begin{array}{c}\text { Ensemble } \\
\text { forecast }\end{array}$ & $\begin{array}{l}\text { POD (hit } \\
\text { rates) }\end{array}$ & $\begin{array}{l}\text { FAR (false } \\
\text { alarm ratio) }\end{array}$ & $\begin{array}{c}\text { POFD (false } \\
\text { alarm rate) }\end{array}$ \\
\hline \multirow{4}{*}{ Iso } & \multirow{4}{*}{ Lead 0} & \multirow[b]{2}{*}{$\begin{array}{c}\text { Early } \\
\text { onset date }\end{array}$} & Ensemble & $40 \%$ & $58 \%$ & $30 \%$ \\
\hline & & & $\begin{array}{c}\text { Best } \\
\text { member }\end{array}$ & $55 \%$ & $45 \%$ & $26 \%$ \\
\hline & & \multirow{2}{*}{$\begin{array}{c}\text { Late } \\
\text { onset date }\end{array}$} & Ensemble & $49 \%$ & $54 \%$ & $33 \%$ \\
\hline & & & $\begin{array}{c}\text { Best } \\
\text { member }\end{array}$ & $86 \%$ & $17 \%$ & $30 \%$ \\
\hline \multirow{4}{*}{ Agro } & \multirow{4}{*}{ Lead 0} & \multirow{2}{*}{$\begin{array}{c}\text { Early } \\
\text { onset date }\end{array}$} & Ensemble & $33 \%$ & $68 \%$ & $33 \%$ \\
\hline & & & $\begin{array}{c}\text { Best } \\
\text { member }\end{array}$ & $50 \%$ & $50 \%$ & $25 \%$ \\
\hline & & \multirow{2}{*}{$\begin{array}{c}\text { Late } \\
\text { onset date }\end{array}$} & Ensemble & $60 \%$ & $56 \%$ & $44 \%$ \\
\hline & & & $\begin{array}{c}\text { Best } \\
\text { member }\end{array}$ & $86 \%$ & $25 \%$ & $49 \%$ \\
\hline
\end{tabular}

\subsection{Discussions}

The study set up the aim to understand patterns of trend and variability in onset dates and to explore the ability of System 4 seasonal forecasts in reproducing this variability. In this process, the need and provision of onset forecast information can be better understood especially for the two pilot stations of interest.

\subsubsection{Trend and variability implication for local farming}

Our findings show that, over the more recent period 1986-2010, the rainfall season has started earlier in Tamale while at Ada there has not been a significant change in onset of the rainfall season. There is (i) no significant change in trend and (ii) a significant decreasing trend for Ada and Tamale respectively. Equally, from P1 (1961-1985) to P2 (1986-2010) periods there is (i) a significant increasing variability at Ada and (ii) a non-significant decreasing variability at Ada and Tamale respectively. The two onset definitions generally predict similar patterns on trend and variability despite some differences in significance. 
These patterns of increasing/decreasing trend and variability in onset support the study of Manzanas et al. (2014a) over the two stations using GMet data. Although these authors studied only seasonal rainfall, the current study found similar patterns of trend and variability for onset dates over P1 and P2 periods. However, results on variability for some stations in Ghana do support with cautiousness the general statement about the increasing climate variability over West Africa (Salack et al., 2016, Morris et al., 2009, Sylla et al., 2016) since this is not always valid for local onset date variability towards more recent time. These stations include Tamale, Kumassi, Bole and Akuse where there are no signals of increasing variability. The differences in onset dates found between the two local definitions were expected because Fitzpatrick et al. (2015) show that local onset definitions have high spatial, interannual, and interdefinition variability. This explains the discrepancies between the two definitions. A possible explanation for the occurring high variability in rain onset dates at Ada could be related to complex series of coastal/oceanic and atmospheric interactions (Acheampong, 1982, Owusu and Waylen, 2009, Manzanas et al., 2014a, Philippon et al., 2010) which have increased with climate change.

There are several implications for local farming in Ada and Tamale especially. At Ada, the increase variability of seasonal rainfall is likely to increase the risk of rainfed crop systems. One of the problems is the costs associated with the need to re-plant due a late start of the rainy season. At the same time (too) late planting reduces the yield potential. This increasing variability can also have an impact on the effectiveness of traditional prediction (formerly) used by farmer's to appreciate the monsoon start (Yaro, 2013, Ingram et al., 2002). At Tamale station, where there is no increase variability but a trend towards an earlier date in onset. Here, farmers need information about whether this earlier onset is permanent or only a temporary situation. Supporting local farmer's knowledge with skillful modern forecasts information can help them mitigate the risks related to climate variability and change both in Southern and Northern Ghana.

\subsubsection{Forecast skill and implication for local farming}

The analyses of correlational relationship significance between GMet and System 4 show weak correlations of 0.0-0.49 but significant at some stations. These results reflects those from Vellinga et al. (2013) who also found correlations between 0.15 and 0.4 using seasonal forecasting system of the UK Met Office (GloSea4). This is already encouraging as it may imply that there is a potential for the forecast to correctly classify locally observed onset categories. The higher 


\section{Chapter 2}

correlations found in the Coast-South agro-ecological zone suggest a stronger influence of the sea surface temperature on rainfall variability (Philippon et al., 2010). The comparison of the interannual variability between GMet and System 4 show that System 4 usually under-estimates the variability at station were high onset variability is occurring if the isochrone method is used. With the agronomic definition, which is based on bias-corrected forecasts, the variability is generally over-estimated. It is surprising that isochrone definitions applied to raw forecasts capture twice better the observed central tendency (e.g mean and median) better than the agronomic definition which is based on bias-corrected forecast. In general, the results support the suggestion that seasonal forecasts is not very useful in reproducing the magnitude of variability in the monsoon onset over West African region (Fitzpatrick et al., 2015).

The skill analyses for categorizing onset dates show that System 4 can reproduce onset date categories. This is, especially the case for low and higher tercile categories and for Learmonth 0 which corresponds to March (Ada) and April (Tamale) forecasts. This is because the skill of the seasonal forecast generally decrease as the lead-time increases (Wetterhall et al., 2015, Ogutu et al., 2017). In fact, since rains onset is defined based on 3 months period, by moving from Learmonth 0 to 2 , we also move towards the $3^{\text {rd }}, 4^{\text {th }}$, and $5^{\text {th }}$ months respectively. This corresponds to an increasing lead time towards the $7^{\text {th }}$ month, which explains the decrease in skills.

These results show promise for the provision of tailored forecast onset dates information to local farmers at least in terms of early and late categories. The forecasts starting in March and April respectively for Ada and Tamale could be used to inform farmers on whether rain will start early or late. This information can potentially support farmer' decision making. It can help them to reduce the risk for re-planting. Also, this could be a modern prediction of onset dates that can be combined or complemented with local traditional predictions. In this way the forecast information could be culturally accepted by farmers (Ingram et al., 2002).

\subsubsection{Importance of using local station observations and cautious interpretation of findings}

Using directly local observations for this particular study is a relatively new approach with it strength and challenges. Assessing trend and variability, and verifying seasonal forecasts with local observations offer the benefit to derive conclusions that are more tailored to farmers at Ada and 
Tamale. This is because large-scale observations (satellite and reanalyses) cannot capture local micro-climatic processes. For example, a quick comparison of WATCH-Forcing-Data-ERAInterim (WFDEI) (Weedon et al., 2014) between the most suitable large-scale reanalysis product (Manzanas et al., 2014a) and GMet rainfall data shows some important discrepancies (see supplementary S2.1) especially for Ada. It is also important to consider some of the limitations related to the datasets and methodology. Although the observations have been carefully checked in order to keep stations that have low percentage of missing, the residual missing values might still affect the prediction of onset dates. Also, the neighbor weighted interpolation technic used to interpolate the forecast at each point station is still a form of averaging approximation that can also have an effect on the results.

The potential use of the forecasts for decision making also depends on the ECMWF System operational forecast release timing restriction. Operational forecast would not actually be available on first of each month as applied in this paper using hindcasts. For instance, System 4 is released on $8^{\text {th }}$ of the month while the new System 5 is released on the $5^{\text {th }}$. In addition to that, one must further consider the processing and communication time between ECMWF, the local Met agency and farmers. This delay can potentially impact on the use of the forecasts since farmers may not be informed in time (e.g. case of early onset dates occurrence that may occur close or event after the release date). Therefore, future research and application with operational forecast should consider the forecast release time lag.

\subsection{Conclusions}

The purpose of the current study was to assess the trend, variability and predictability of onset of the rainy season by (i) using local station observations as reference and (ii) adopting two tailored local definitions. The analyses focused on Ada and Tamale stations which are two pilot stations of interest.

The study has identified changes in the onset of the rainy season. At Ada (coastal savannah), there is a an increasing onset variability that can increase rainfed crop production risks. At, Tamale, there is, rather, a decreasing trend implying an earlier start of the wet season towards more recent time.

The analysis of predictability shows that System 4 has little benefit for reproducing the magnitude of local variability of onset dates, especially where there is an observed high variability. This means 


\section{Chapter 2}

that the system does not have enough benefit for giving exact/precise onset date information to local farmers. However, System 4 is proven to have skills for categorizing early and late onset dates especially for forecast starting in March and April for Ada and Tamale respectively. The use of onset agro-meteorological index based on System 4 as climate services in Ghana can have a potential value for decision making when considering categories. These results give promise for the provision of tailored forecast onset dates information to local farmers at least in term of categories.

Considering the time lag restriction in the release of operational forecast, future research or applications of seasonal forecast is recommended to always take into account this time lag in order to optimize the utility of the forecast information for decision making. The additional time related to the processing and communication between, for instance, ECMWF, National Met agency and farmers need also to be considered as much as possible. Organizations promoting forecast-based climate services (e.g. ECMWF, National Met Agencies and others projects) are encouraged to reduce the release time in future forecasting systems and the communication timing to the endusers. The improvement on the quality and availability of station observations for better improved skill assessment of operational forecasts is also a priority.

Future analyses of seasonal climate forecast performance on additional agro-meteorological indices such as dry spell occurrence are also an important climate information for crop production in Ghana. Potential predictability of this index is highly demanded by local as climate information in order to avoid crop failure during plant's critical growth. For future studies, it might also be interesting to look at methods that integrate (e.g. combination or complementarity) modern (scientific) onset prediction with the traditional ones. In that process, the value of onset information for local agriculture might increase.

\section{Acknowledgement}

This research is fully funded by the Netherlands Organization for Scientific Research (NWO) under the urbanizing deltas of the world program (UDW) and WaterApps (www.waterapps.net) project. My sincerest gratitude goes Ghana Meteorological Agency (GMet) for providing gauge observations to the WaterApps project. I express my special thanks to Dr. Hutjes Ronald, Dr. Supit Iwan, Dr. Wouter Greuell, and Mr. Franssen Wietse from the Water System and Global change group, Wageningen University, for their contribution to the paper. 


\title{
Chapter3. Rainfall and dry spell occurrence in Ghana: trends and seasonal predictions with a dynamical and a statistical model
}

\begin{abstract}
Improved information on the distribution of seasonal rainfall is important for crop production in Ghana. The predictability of key agro-meteorological indices, namely, seasonal rainfall, maximum dry spell length (MDSL), and dry spell frequency (DSF) was investigated across Ghana [with an interest on the coastal savannah agro-ecological zone]. These three variables are relevant for local agricultural water management. A dynamical model (i.e. European Centre for Medium-Range Weather Forecasts (ECMWF) System 4 seasonal forecasts) and a statistical model (i.e. response to sea surface temperatures (SST)) were used and analysed using correlation and other discrimination skill metrics. ECMWF-System 4 was bias-corrected and verified with 14 local stations' observations. Results show that differences in variability and skills of the agrometeorological indices are small between agro-ecological zones as compared to the differences between stations. The dynamic model System 4 explains up to $31 \%$ of the variability of the MDSL and seasonal rainfall indices. Coastal savannah exhibits the highest level of discrimination skills. However, these skills are generally higher for the below and above normal MDSL and seasonal rainfall categories at lead-time 0. Similarity in skills for the agro-meteorological indices over the same zones and stations are found both for the dynamical and statistical models. Although System 4 performs slightly better than the statistical model, especially, for dry spell length and seasonal rainfall. For dry spell frequency and longer lead-times dry spell length, the statistical model tends to perform better. These results suggest that the agro-meteorological indices derived from System 4' updated versions, corrected with local observations, together with the response to SST information, can potentially support decision-making of local smallholders farmers in Ghana.
\end{abstract}

Published as:

Gbangou, T., Ludwig, F., van Slobbe, E., Greuell, W., \& Kranjac-Berisavljevic, G. (2020). Rainfall and dry spell occurrence in Ghana: trends and seasonal predictions with a dynamical and a statistical model. Theor Appl Climatol 141, 371-387. https://doi.org/10.1007/s00704$020-03212-5$ 


\section{Chapter 3}

\subsection{Introduction}

In Ghana, West Africa, demands for operational predictions of rainfall and related indices are growing to support rural communities (Vitart et al., 2017, Gbangou et al., 2019, Nyadzi et al., 2019). This is especially true where rainfed smallholder farmers are affected by climate variability and change (Mendelsohn et al., 2006, Codjoe et al., 2014, Gbangou et al., 2019). Provision of forecasts of water availability indicators with sufficient accuracy and appropriate lead-time can potentially improve management for rainfed or semi-rainfed farming systems in Ghana. Seasonal forecast of the likelihood of the growing season' water availability can help inform farmers with long-term planning. For example, the Waterapps research project (www.waterapps.net) aims to develop tailored water information services with and for farmers in peri-urban areas in the urbanising deltas of Accra, Ghana to improve the water and food security. The project focusses on Ghana's urbanising delta because of agricultural intensification, water availability issues and the increasing possibilities of farmers to use ICT for climate information service. Also risks in terms of crop failure due to unexpected rainfall events are growing and hence the need for improved rainfall forecasts is growing too. Therefore, this study focusses on the coastal savannah agroecological zone along the delta area (Figure 3.1).

There is a need for agro-meteorological forecast information about seasonal rainfall and dry spells occurrence for West African farmers in general (Usman and Reason, 2004, Codjoe et al., 2014, Yaro, 2013) and more specifically in the coastal savannah of Ghana delta area (Gbangou et al., 2019). This information can help to improve specific decision-making of many local farmers by optimising the selection of crop types/varieties, reducing the cost of land preparation and avoiding crops failure due to premature or late planting time. Dry spells during the growing season have a large impact on crops and the cumulative rainfall does not fully explain impacts on agriculture, because a few heavy rainfall events may lead to an erroneous impression that a growing season is good (Usman and Reason, 2004). According to Usman and Reason (2004), crops are more likely to do well with uniformly spread 'light' rains compared to a few 'heavy' rainfall events interrupted by dry periods. So, the timing of breaks in rainfall events (dry spells) relative to the cropping calendar rather than total seasonal rainfall is fundamental to crop viability and production.

West African rainfall is highly variable on interannual and decadal time scales and is highly correlated with sea surface temperature (SST) (Zhang et al., 2015). Globally, dry conditions over 
the Sahel and wet conditions over Guinea are associated with positive El Niño-Southern Oscillation (ENSO) SST anomalies of the eastern tropical Pacific, with positive SST anomalies of the Southern Hemisphere Atlantic, and with negative anomalies of the Northern Hemisphere Atlantic (the Atlantic dipole), and positive SST anomalies of the tropical Indian Ocean (Folland et al., 1986, Janicot et al., 1998, Rowell, 2001, Matthews, 2004). The majority of these studies have focused on large areas (eg. Sahel and Guinea) of West Africa. Hence, the mentioned rainfall teleconnection may not account for the considerable variability at a more local scale (Diro et al., 2011).

Additionally, global-gridded rainfall products have been shown to exhibit clear ENSO signals over West Africa (Jury et al., 2002, Joly and Voldoire, 2009, Alizadeh-Choobari et al., 2018). However, the societal effects of rainfall characteristics are often felt on local scales (Gbangou et al., 2018, Matthews et al., 2013, Wetterhall et al., 2015). For example, small-scale rain-fed agriculture in Ghana or local industrial operations may be crucially dependent on the rainfall in the immediate vicinity but not directly connected to large-scale aggregated rainfall patterns. Hence, the question of whether a large-scale system such as ENSO is "felt" at the local level and for a specific season of interest can be an important one. No study has yet addressed precisely ENSO effects on dry spells agro-met indices during critical growing seasons in Ghana using local station data.

There are also some limitations on seasonal forecast evaluation approaches for the purpose of local communities. More often, large-scale observational products are used as reference for comparison or for bias correction (Fitzpatrick et al., 2015, Vellinga et al., 2013, Wetterhall et al., 2015, Joly and Voldoire, 2009) instead of local station data. Although these approaches are often justified by the recurent lack of consistent local observations over West Africa, including Ghana (Owusu and Waylen, 2009, 2013), findings at large-scale level may have litle benefit for smallholder farmers.

Localized data analysis on dry spells occurrence and seasonal rainfall is important from the point of view of farmers. Farmers need information on these indicators, especially in the first three rainy season months. This type of analysis is yet lacking. March-April-May (MAM) and April-May-June (AMJ) seasons over the Coast-South and Transition-North agro-ecological zones respectively (see Figure 3.1, Table 3.1) have been given minimal attention compared to other seasons in Ghana. However, for agricultural applications, these are critical seasons during crops' growing stages as they are highly sensitive to onset, dry spell occurrence and rainfall totals (Gbangou et al., 2019). 


\section{Chapter 3}

This paper examines the skill of ECMWF-System 4 seasonal climate forecasts, a dynamical model, in reproducing the variability of seasonal rainfall and dry spells agro-meteorological indices, and explores the effect of pre-rainy season SST on these indices over Ghana using local station observations as reference and focusing its analysis on the coastal zone. The response to SST is being considered as a statistical model. Trend and variability in historical observations are explored prior to skill assessment in order to ascertain the climatic conditions and the challenges related to the predictability of the indices.

The study area is Ghana's coastal savannah area, but to identify possible difference between local stations and agro-ecological zones, we covered the entire of Ghana focussing on 14 stations (Figure $3.1)$.
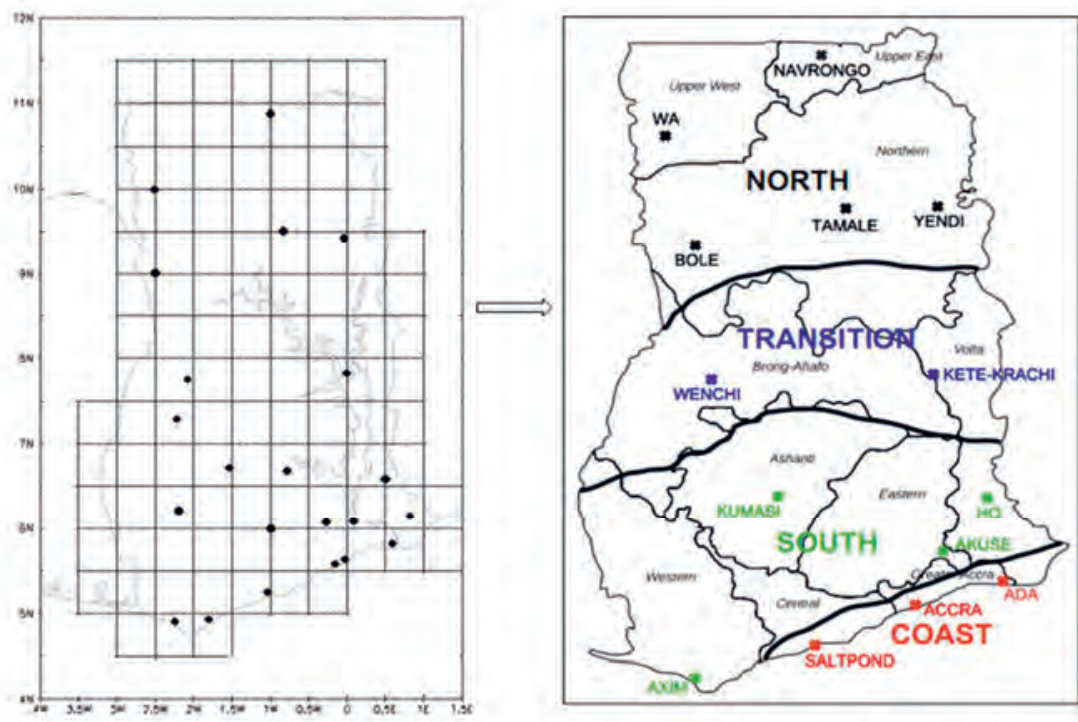

(Source: Manzanas et al., 2014)

Figure.3.1: Map of Ghana showing the location of the 22 gauges stations (left) collected from GMet and sorted into 14 gauges stations (right) across the four main agro-ecological zones previously used in Owusu and Waylen $(2009,2013)$.

\subsection{Data}




\subsubsection{ECMWF-System 4 seasonal climate hindcasts}

ECMWF-System 4 seasonal climate reforecasts were used. They consist of 15 ensemble members, with initial date on the 1 st of each month, and then run for 7 months (i.e leadmonths). The reforecasts (also referred to as hindcasts) extend over the 1981-2010 period. They were acquired from the ECOMS User Gateway (Cofiño et al. (2018); http://meteo.unican.es/ecoms-udg) and used to verify the performance of System 4 to reproduce dry spell occurrence and seasonal rainfall. Forecasts for periods starting in March and April (i.e MAM and AMJ seasons) were considered for stations located respectively within the (i) Southern and Coastal and (ii) Transition and Northern agro-ecological zones (Table 3.1). These seasons were selected considering the local cropping calendar and the northward shift with the time of rainfall across Ghana (Sultan and Janicot, 2003, Gbangou et al., 2019).

Considering that Ghana has an area of $238,535 \mathrm{~km}^{2}, 14$ stations correspond to a mean of 17,038 $\mathrm{km}^{2}$ per station (Figure 3.1). This is considered as sparse coverage, according to Masinde et al. (2012a) as many models gridded cells (e.g. System 4 has $0.75 \times 0.75$ grid size) may not contain any station within their grid-cell area (Figure 3.1). Therefore, instead of interpolating point station rainfall to grid format, which requires a well distributed synoptic stations over Ghana, we rather extracted model gridded data for each of the 14 stations. This was done by applying the nearest neighbour interpolation as described by Manzanas et al. (2014a). Hence, this technique provides relatively good estimates of forecasts time series at each station.

Table 3.1: System4 lead months selection per zone (Gbangou et al. 2019)

\begin{tabular}{lll}
\hline Leadtime & Costal\&Southern zone & Transition\&Northern zone \\
\hline Leadmonth 0 & $\begin{array}{l}\text { Forecast start date is } 1^{\text {st }} \text { March and } \\
\text { MAM season is considered }\end{array}$ & $\begin{array}{l}\text { Forecast start date is } 1^{\text {st }} \text { April and } \\
\text { AMJ season is considered }\end{array}$ \\
Leadmonth 1 & $\begin{array}{l}\text { Forecast start date is } 1^{\text {st }} \text { February } \\
\text { and MAM season is considered }\end{array}$ & $\begin{array}{l}\text { Forecast start date is } 1^{\text {st }} \text { March and } \\
\text { AMJ season is considered }\end{array}$ \\
Leadmonth 2 & $\begin{array}{l}\text { Forecast start date is } 1^{\text {st } J a n u a r y ~ a n d ~} \\
\text { MAM season is considered }\end{array}$ & Forecast start date is $1^{\text {st }}$ February and \\
& & AMJ season is considered \\
\hline
\end{tabular}




\section{Chapter 3}

\subsubsection{Local station data}

Primary data used in this study are the time series of daily rainfall totals from rain gauges at 14 stations out the 22 synoptic stations in Ghana (Figure 3.1) over 30 years (1981-2010). These data were used to assess the skill of the forecasts and assess the response to SSTs anomalies. Datasets were acquired from Ghana Meteorological Agency (GMet). The stations have been grouped according to the four main agro-ecological zones in Ghana (Figure 3.1).

\subsubsection{Sea surface temperature data}

SST data for February, January, December and for March, February, January lagged-months were used to assess the response of the agrometeorological indices during MAM and AMJ seasons respectively. This was done on purpose to explore longer lag time teleconnection and to be consistent with lead-months from System 4 (see Table 3.1). The South Atlantic Tropical SST index (SAT), the Tropical Southern Atlantic index (TSA) and Niño3.4 SST were acquired from NOAA website (https://stateoftheocean.osmc.noaa.gov/sur/) (Reynolds et al., 2002). Niño3.4 SSTs are widely used to characterize ENSO conditions (Huang et al., 2015). The SSTs are averages for the areas shown in Figure 3.2. The data cover the seasonal System 4 hindcasts period, i.e. 1981-2010. For the remote Niño3.4 SSTs, we also performed analyses much longer lead times i.e. SSTs for September, October and November and for October, November, and December were related to the MAM and AMJ agrometeorological indices, respectively. However, these results are only presented in the supplemental.

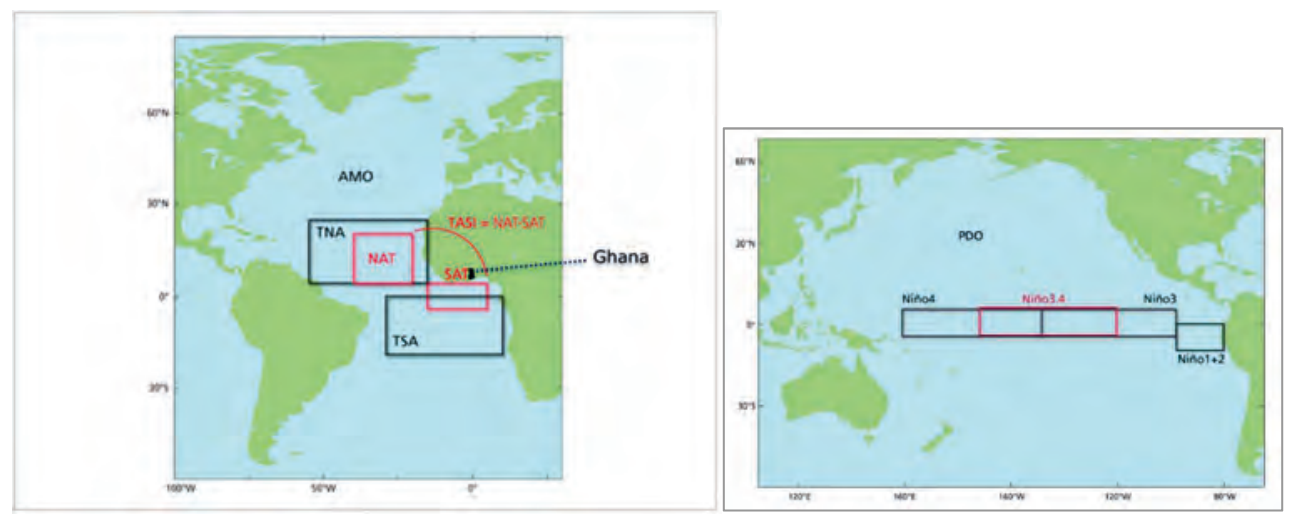


Fig 3.2: South Atlantic Tropical SST index (SAT), Tropical Southern Atlantic index (TSA) and Niño3.4 SST box locations. SAT-SST anomalies are in the box $15^{\circ} \mathrm{W}-5^{\circ} \mathrm{E}, 5^{\circ} \mathrm{S}-5^{\circ} \mathrm{N}$. TSA-SST anomalies are in the box $30^{\circ} \mathrm{W}-10^{\circ} \mathrm{E}, 20^{\circ} \mathrm{S}-\mathrm{EQ}$. 4. Niño3.4 -SST anomalies are in the box $170^{\circ} \mathrm{W}$ $-120^{\circ} \mathrm{W}, 5^{\circ} \mathrm{S}-5^{\circ} \mathrm{N}$.

\subsection{Methods}

The area of interest for this study is the coastal savanna area. However, in order to analyse possible differences between large (i.e. entire Ghana) and local (i.e. station and agroecological zones) scale, we compared outcomes with all selected stations in Ghana.

\subsubsection{Bias-correction}

System 4 seasonal hindcasts were bias-corrected against reference GMet observations following the quantile mapping bias-correction method. For each station, the method adjusts the forecasted rainfall (System 4) to the observed rainfall (GMet) by matching the cumulative density functions (CDF) of daily rainfall (Gudmundsson et al., 2012, Gudmundsson, 2016). The method is proven to be successful in many hydrological and climate impact studies (Maurer and Hidalgo, 2008, Li et al., 2010, Wetterhall et al., 2012, Themeß1 et al., 2012, Cooper, 2019) as well as in medium-range (Voisin et al., 2010) and seasonal forecasts (Wood et al., 2002).

Wetterhall et al. (2015) demonstrated that this bias-correction technique can improve the skill of dry spell length and frequency in comparison with the use of raw forecasts. In a previous study, Ogutu et al. (2017) showed that bias-correction does not necessarily improve the skill of rainfall prediction. Therefore, in order to check the bias-correction sensitivity, we also analysed uncorrected forecasts. The results were very similar compared to bias-corrected forecasts in terms of skills and were in agreement with the study of Manzanas et al. (2019). However, only biascorrected results are presented and discussed in this paper. Furthermore, we checked the need for frequency adaptation correction, which is required when the predicted frequency of dry days in the model is larger than the observed one (Themeß1 et al., 2012). In all of our cases, the frequency of dry days was higher in the model than in the observations, so this correction was not made in the present study (see Supplemental 3.2, Table S3.1).

\subsubsection{Definition of the agro-meteorological indices}




\section{Chapter 3}

The dry spell occurrence definition was adopted from Usman and Reason (2004). During the rainy season, it is not expected that precipitation will occur on a daily basis. However, when breaks in between rains spells are prolonged, plants may wilt and die or have reduced yield. Breaks of equal to or more than 15 days are considered serious anomalies (Adefolalu, 1988, Barron, 2004). Here, we define the number or frequency of dry spell and the longest or maximum dry spell length as follow:

- Longest/maximum dry spell: the largest number of consecutive days during which the rainfall is less than $1 \mathrm{~mm}$ /day over the season.

- Frequency/number of dry spells: the number of dry spells with a length of more than 5 days duringwhich precipitation is less than $1 \mathrm{~mm}$ /day over the season.

- Total seasonal rainfall: the sum of rainfall over the season.

Seasons are defined as March-April-May for the South-Coast and April-May-June for the Transition-North agro-ecological zones.

\subsubsection{Skill assessment metrics of the dynamical model}

Different metrics for assessing the forecasts usefulness for decision making were computed. Seasonal rainfall and dry spell occurrence agro-meteorological indices, derived from System 4 ensemble forecasts, were then verified against GMet observations using (i) Pearson' correlation with the ensemble mean (EnsCorr), (ii) the generalized discrimination score for ensemble forecasts (Ens2AFC) (Weigel and Mason, 2011), and (iii) relative operating characteristic skill score (ROCSS) computed from the ROC area (Jolliffe and Stephenson, 2012). All the three metrics, globally, show the discrimination ability of the forecasts. EnsCorr is a measure of variability and measures how well the forecast anomalies correspond to the observed anomalies over the hindcast period 1981-2010 at each station. Significant correlations indicate that System 4, at least partly, reproduced the variability of observed indices.

Ens2AFC quantified globally, whether a set of observed agro-meteorological indices can be correctly discriminated by the corresponding forecasts (i.e., it is a measure of the skill attribute of discrimination). Positively skilled forecasts will show Ens2AFC >0.5 (Mason, 2013). The ROCSS metric plays the same role as Ens2AFC but gives more details at tercile category level (i.e. below normal, normal and above normal categories). A ROCSS $>0$ for a specific category indicates 
forecasts with positive skill for discriminating forecast categories (i.e. better than the climatology) (Mason, 2013). The ROCSS metric is conditioned on the observations and often needs the reliability diagram, as a partner, which is conditioned on the forecast (i.e., given that an event was predicted, what was the outcome?). The reliability diagram measures how well the predicted probabilities of an event correspond to their observed frequencies.

All the skill metrics were computed using R-packages "Specs Verification" (Siegert, 2017) and "Easy Verification" (MeteoSwiss, 2017). These metrics and packages have been widely used to evaluate the skill of the climate predictions (Cofiño et al., 2018, Manzanas et al., 2018, Ogutu et al., 2017).

\subsubsection{Analysis of the skills of the statistical model}

The response of agro-meteorological indices (i.e MDSL, DSF and Seasonal rainfall) to SST was expressed using a statistical model (i.e. linear regression) driven by SSTs indices to assess the predictability. This was done using the (i) two SST indices of relatively nearby areas, namely the South Atlantic index (SAT) and the Tropical Southern Atlantic index (TSA), and (ii) one index of a more remote area, namely the Tropical Pacific Niño index (Niño3.4) (Figure 3.2). The statistical forecasts were obtained using a linear regression model between observed agrometeorological indices and SSTs for individual months (i.e. in a univariate mode). This regression was done in a leave-one-year-out cross-validation mode. Then, the observed agrometeorological indices from GMet were correlated with the forecasted ones derived from the statistical model over the period 1981-2010 and at individual stations across the agro-ecological zones. We recall that the agrometeorological indices were computed for MAM over the Coast-South and for AMJ season over the Transition-North agro-ecological zones. To assess the effect of lead time, SST data of February, January, December and for March, February, and January were considered for the Coast-South (i.e. MAM season) and Transition-North (i.e. AMJ season) agro-ecological zones, respectively.

\subsubsection{Statistical trend, variability and significance analyses}

Several statistical significance tests were applied. The Mann-Kendall test analysis of linear trend significance was carried out on observed agrometeorological indices. This method is proven to be robust for trend analyses of time series (Partal and Kahya, 2006, Obot et al., 2010, Manzanas et al., 2014a). The coefficient of variation (Cv) was used as a measure interannual variability as suggested 


\section{Chapter 3}

by Obarein and Amanambu (2018). The t-test was used to determine both the (i) significance of correlation relationships between the dynamical forecasts System 4 and GMet derived agrometeorological indices and the (ii) significance of correlation relationships between statistical forecasts driven by SST and GMet derived agro-meteorological indices. The relation is significant when, for an infinite number of tests, one out of 10 ( $p$ threshold of 0.10 ) is found.

The term "skilful" forecast is used for positive and significant EnsCorr and ROCSS throughout the paper. Considering that Ens2AFC metric does not have a build-in test for significance at individual stations as for the EnsCorr and ROCSS) (Weigel and Mason 2011), a binomial distribution test was used alternatively to identify lead-time with significant forecasts.

\subsection{Results}

\subsubsection{Observed trend and variability of dry spell occurrence and seasonal rainfall}

Observed trends of the agrometeorological indices, over 1981-2010 period, generally, show no clear significant decreasing and increasing patterns for MAM and AMJ seasons (Table 3.2) except for 4 stations out of the 14 stations. These 4 stations with significant trend are Ada, Akuse, Wa and Yendi. MDSL at Ada is significantly increasing implying that the prolonged dry spells have increased $(\mathrm{p}<0.10)$. DSF at Akuse shows a decreasing pattern with $90 \%$ confidence level as well, implying that the frequency of dry spells has reduced in that location. Seasonal rainfall significantly increased at Wa and Yendi.

The mean and relative variability of MDSL, DSF and seasonal rainfall varies by location and by agro-ecological zones (Figure 3.3 and Table 3.2). Average MDSL and DSF are higher along the coast and in northern Ghana compared to the South and Transition zones. Southern and transition zones have the highest average seasonal rainfall. MDSL in the overall Coastal and Northern Ghana have higher relative variability compared to the South and Transition zones. The coastal savannah also has the highest variability of seasonal rainfall.

Table 3.2: Mean, coefficient of variation, and trend significance test of the agrometeorological

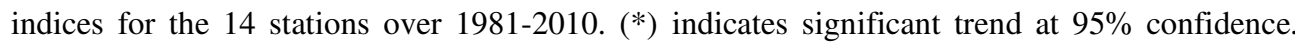
Positive (blue bar) and negative (i.e. red bar) tau indicate increasing and decreasing trends, respectively. Bold values indicate the average over each agro-ecological zone. 
Seasonal predictions of rainfall and dry spell occurrence

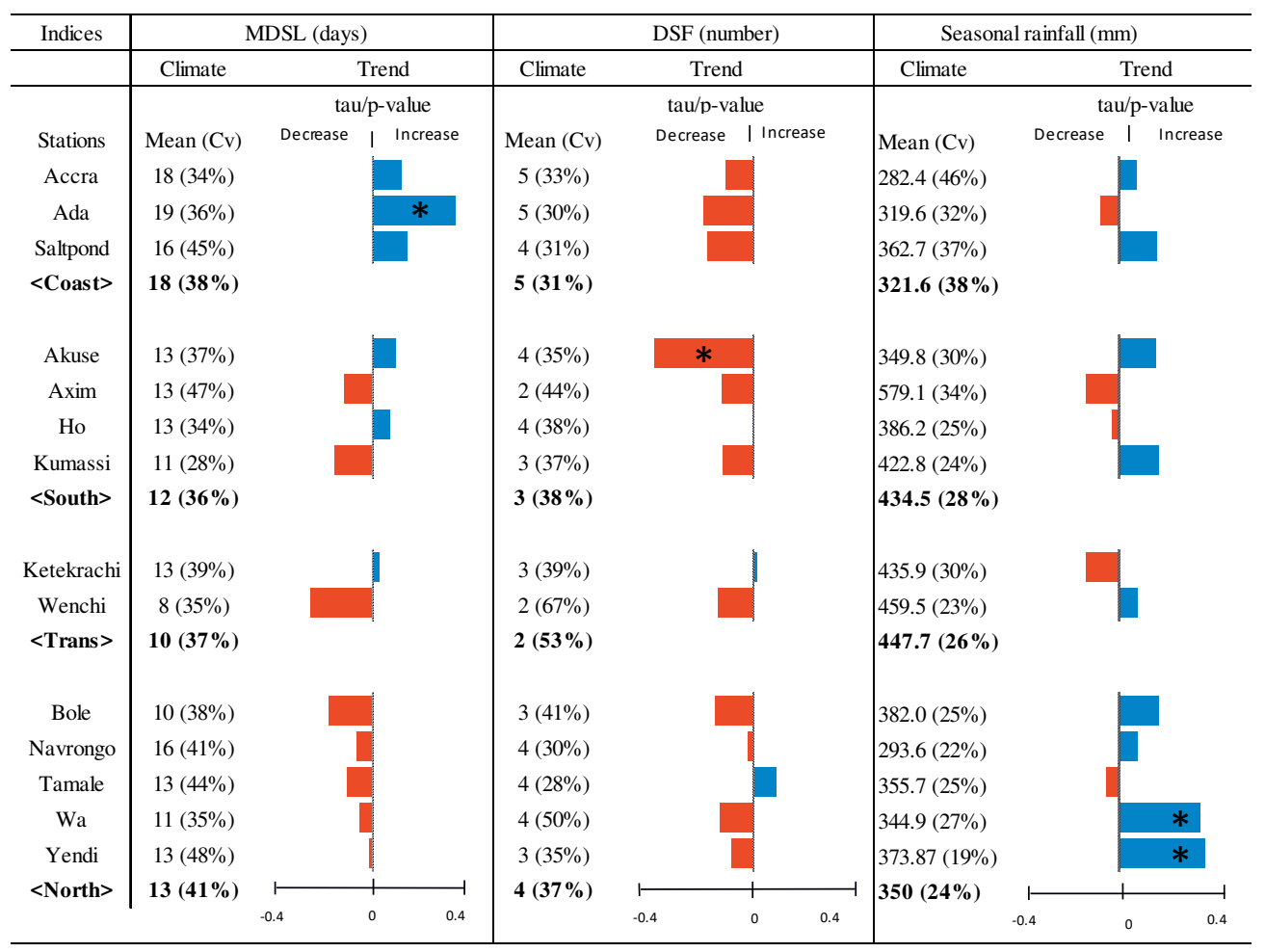




\section{Chapter 3}
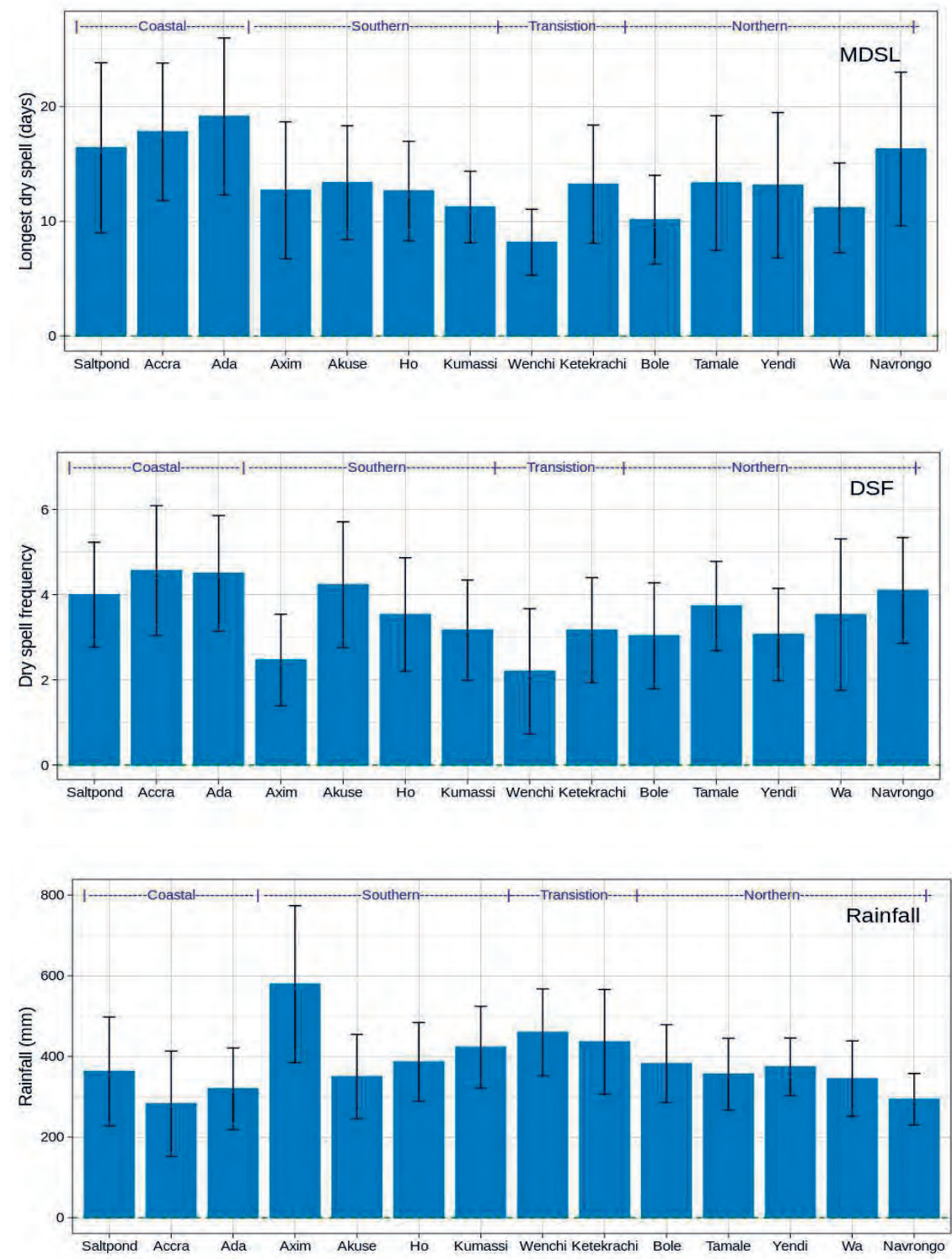

Figure 3.3: Spatial variation of the climatology for the MDSL, DSF and Seasonal rainfall across Ghana stations and agro-ecological zones. MAM and AMJ seasons are consider for Coast-South 
and Transition-Northern agro-ecological zones, respectively. Error bars represent standard deviation of annual values of the agro-meteorological indices at each station.

\subsubsection{Ability of System 4 in reproducing dry spell occurrence and seasonal rainfall (dynamical model)}

The EnsCorr for the three agro-met indices (i.e MDSL, DSF, and seasonal rainfall) range from 0.35 to 0.56 for different lead-times and different stations across Ghana (Figure 3.4). This range of values implies that the three observed indices (i.e. indices calculated from GMet data) have weak correlation relationship with predicted indices (i.e. agro-met indices derived from System 4 simulations). The significance test show, however, that some stations are significant. For MDSL, lead-time 0,1 and 2 have, respectively (i) 12/14, 8/14 and 10/14 fraction of stations with positive skill and (ii) 7/14, 2/14, and 2/14 fraction of stations with positive and significant skill (Figure 3.4). More positive and significant stations are found in Coast-South (4) as compared to the TransitionNorth zone (2) for MDSL.

In the case of DSF (Figure 3.4), lead-time 0,1 and 2 count, respectively (i) 4/14, 9/14 and 3/14 fraction of stations with positive skill and (ii) only one station with positive and significant skill. As for seasonal rainfall presented in Figure 3.4, Lead-time 0,1 and 2 have, respectively (i) 10/14, 11/14 and 13/14 fraction of stations with positive skills and (ii) 4/14, 1/14, and 4/14 fraction of stations with positive and significant skills. A large number of positive and significant stations are also found in the Coast-South (i.e. 4) as compared to the Transition-North zone (i.e. 3) for seasonal rainfall.

Summarizing, lead-time 0 , generally gives the highest positive and significant skills, especially for MDSL and seasonal rainfall. The coastal-south zone has a higher number of stations with positive and significant skills than the Transition-Northern zone for both MDSL and seasonal rainfall. DSF show the lowest positive and significant skills. Findings on the correlation relationship show that System 4 can explain up to $31 \%$ of the variability (i.e. correlation peaks at 0.56 ) of the indices, especially for MDSF at the coastal and southern zones. 


\section{Chapter 3}
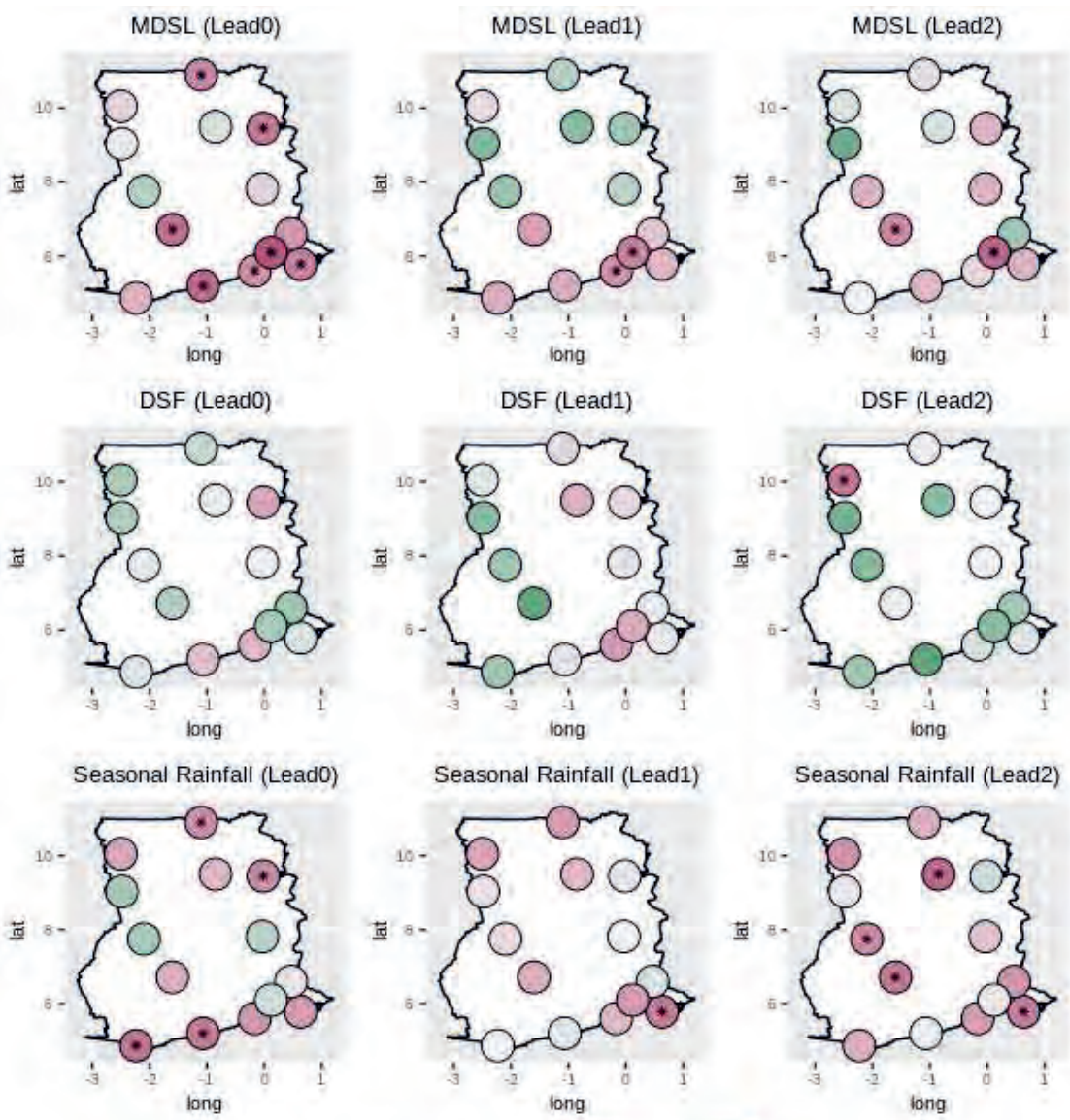

EnsCorr (GMet, System4)

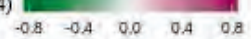

Figure 3.4: Ensemble correlation (EnsCorr) between GMet and the dynamical model System 4 forecasts for the maximum dry spell length (MDSL), dry spell frequency (DSF) and seasonal rainfall. Lead0, 1 and 2 represent initialisation in February (March), January (February), and December (January) considered for MAM (AMJ) seasons, respectively. (*) indicates the correlation significance at $\mathrm{p}<0.10$. The overall significant EnsCorr ranges from 0.30 to 0.56.

The generalized discriminant skill score over the 14 locations ranges from 0.37 to 0.66 over leadmonth 0, 1 and 2 (Figure 3.5). Figure 3.5 reveals that, for MDSL, lead-month 0, 1 and 2 have respectively 12/14, 8/14 and 7/14 fraction of stations where Ens2AFC $>0.5$. Recalling that 
significance for Ens2AFC cannot be tested at individual stations, the application of the binomial distribution test show that System 4 has significant skill at Lead-time 0 (see details in Supplementary S3.5, Table S3.2). Results for DSF and Seasonal rainfall are the same as for the ensemble correlation in terms of patterns of skills (i.e. skills in DSF are the lowest and skill in seasonal rainfall are similar to that of MDSL (see Supplementary 3.4, Figure S3.4). Coastal savannah area, including Ada, Accra, Saltpond and Akuse, a nearby station from the southern region, shows the highest skills.
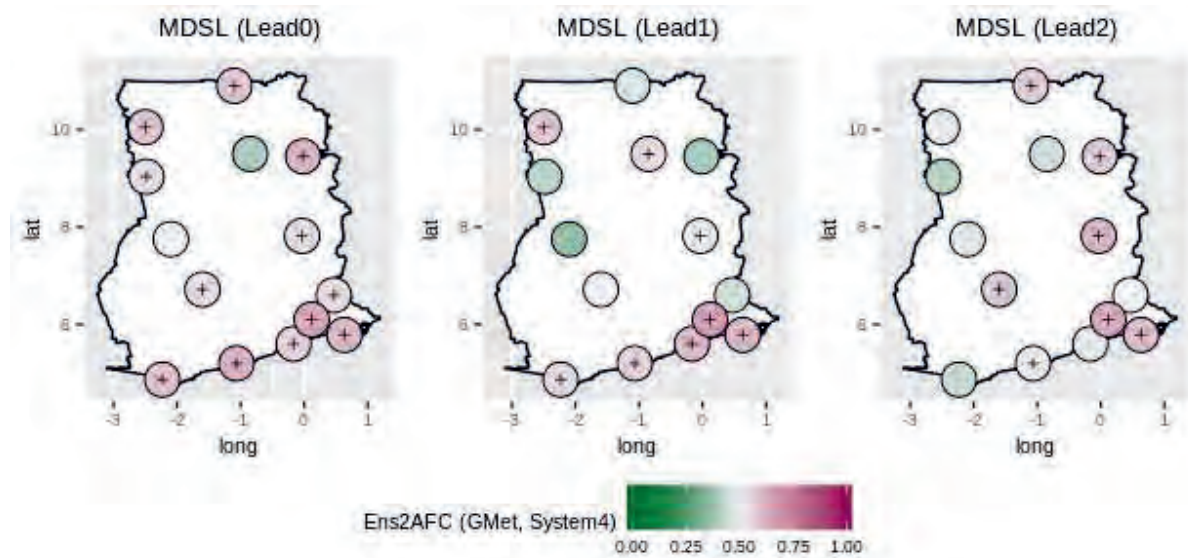

Figure 3.5 : Generalized discriminant score (Ens2AFC) between GMet and System 4 forecasts for the maximum dry spell length (MDSL). Lead0, 1 and 2 represent initialisation in February (March), January (February), and December (January) considered for MAM (AMJ) seasons, respectively. $(+)$ indicates the stations where Ens2AFC is greater than 0.5 (i.e. forecast better than random guessing). The overall Ens2AFC scores ranges from 0.37 to 0.66 .

At categorical level, skilful and non-skilful categories were found over different time leads and for different agro-meteorological indices. Positive ROCSS ranges from 0 to 0.58 for MDSL (Figure 3.6). The figure reveals that a large number of stations have positive skill (i.e. ROCSS $>0$ ) for the below and above normal categories (i.e. 13/14, 8/14, and 9/14 fraction of stations with positive skill for lead times 0,1 , and 2 respectively, for each category) in comparison to the near normal category (i.e. 9/14, 5/14, and 6/14 fraction of stations with positive skill for Lead-time 0,1 , and 2 respectively). Also, the number of stations with significant skills is higher for below (above) normal 


\section{Chapter 3}

categories (i.e. 5/14 (5/14), 4/14 (3/14), and 3/14 (5/14) for Lead-time 0, 1, and 2 respectively) when compared to the near normal category (i.e. $1 / 14,3 / 14$, and $5 / 14$ for Lead-time 0,1 , and 2 respectively). Additionally, the majority of stations with positive and significant skills are found in Coast-South (i.e. 6 and 7 for the below and above normal categories across the lead times) compared to the Transition-North zone (i.e. 4 for both below and above normal categories across the lead times) for MDSL. Results for DSF and Seasonal rainfall are also the same as for the ensemble correlation in terms of patterns of the skills (i.e. . i.e. skills in DSF are the lowest, whereas the skills for seasonal rainfall are similar to MDSL (see Supplementary S3.6, Figures S3.5 and S3.6). The reliability diagrams, constructed for two sample locations (Ada and Tamale) with skilful lead-times (see Supplementary S3.7, Figure S3.7) show some proximity of the curves with the perfectly reliable line and suggest that forecast probability and mean observed frequency have, relatively, good agreement. 

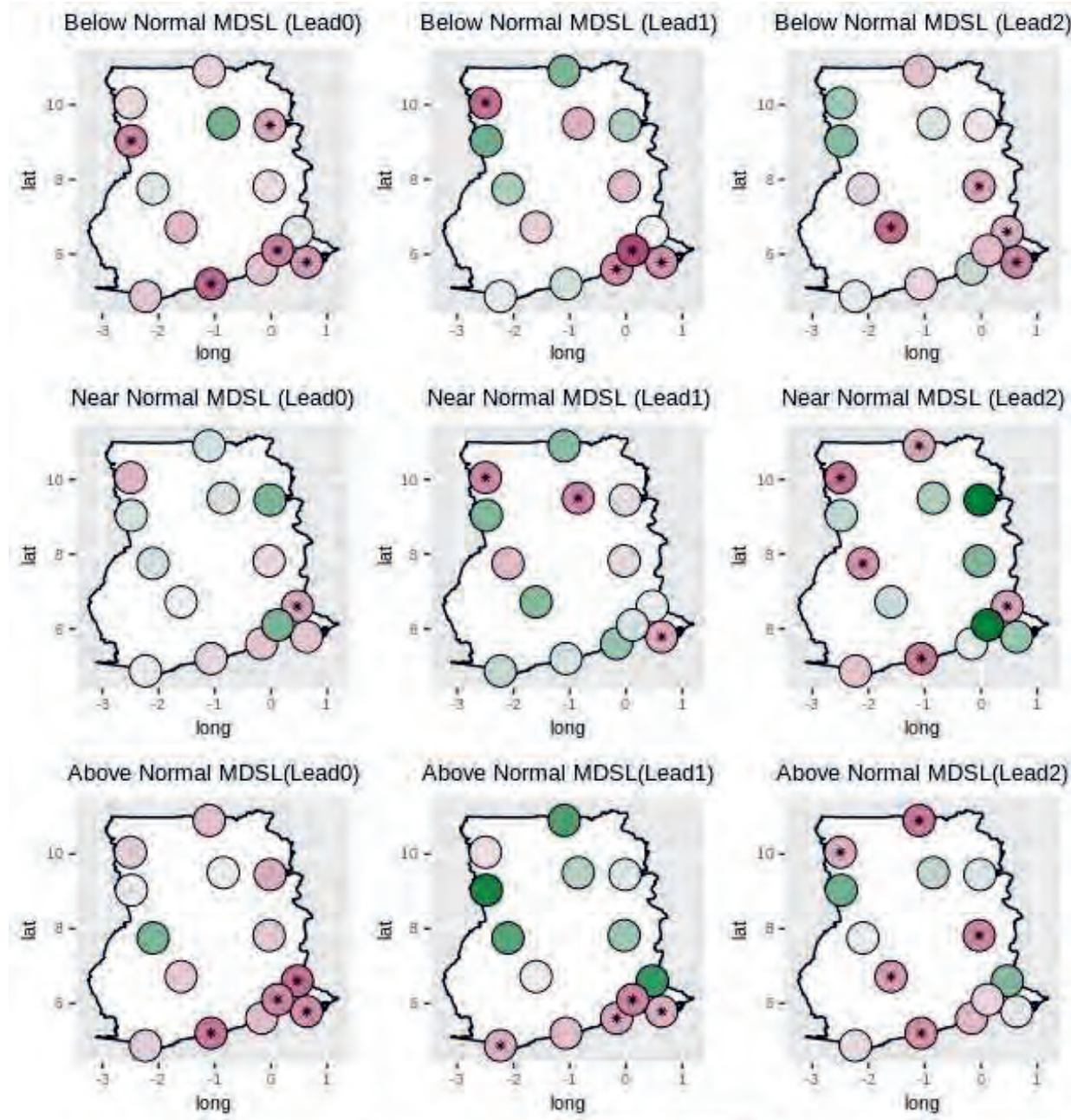

ROCSS (GMet, System4)

Figure 3.6 : ROCSS between GMet and the dynamical model System 4 forecasts for the maximum dry spell length (MDSL) and for the below normal, near normal, and above normal categories. Lead0, 1 and 2 represent initialisation in February (March), January (February), and December (January) considered for MAM (AMJ) seasons, respectively. (*) indicates the correlation significance at $\mathrm{p}<0.10$. The overall positive ROCSS ranges from 0 to 0.58 . 


\section{Chapter 3}

In conclusion, the generalized and categorical skills in discriminating prolonged dry spell and Seasonal rainfall are generally better than that of dry spell frequency over MAM and AMJ seasons in Ghana. System 4 performs better at distinguishing the bellow and above normal categories as it accounts a majority of positive and significant skilled stations in comparison to the near normal category. Lead-time 0 generally has the highest skills with the exception of seasonal rainfall where Lead-time 2 has, surprisingly, more skilful stations. Considering the agro-ecological zone together with the two best categories (i.e. bellow and above normal), the forecasts tend to perform better in the South-Coast compared to the North-transition zones especially for prolonged dry spell and the seasonal rainfall.

\subsubsection{Response of seasonal rainfall and dry spell occurrence to SSTs (statistical model)}

The response of agrometeorological indices to SAT, TSA and Niño3.4 SST is expressed as a statistical model (i.e. a linear regression model) and used to examine the seasonal prediction ability. Results presented in Figure 3.7 show the spatial variation of the correlational relationship between the observed agrometeorological indices and their statistical forecasts driven by the SSTs. SATSST tends to have weak and non-significant correlations (i.e. correlation ranging from 0 to 0.25 ) for the agro-meteorological indices with the exception of DSF which is significantly correlated with SAT-SST at (i) Ada, Tamale, Wenchi and Navrongo, (ii) Ada, Tamale and Navrongo; and (iv) Kumassi for lead-month 0, 1 and 2 (Figure 3.7). Compared to SAT-SST, the statistical model driven by Niño3.4-SST tends to have stronger and correlations and stations with significant correlation relationships (i.e. correlations ranging from 0.30 to 0.45 ) across lead-times and Ghana (Figure 3.8). This is especially the case for MDSL and applies to all lead times. Analysis for lead times longer than two months shows less skill (See Supplementary S3.8, Figure S3.9). The statistical forecasts for MDSL, DSF, and seasonal rainfall are all positively correlated with the observed ones across Ghana. At the agro-ecological zone levels, the statistical model driven by Niño3.4-SST has more stations with significant correlations over Coastal and Northern for MDSL as compared to other regions. Analyses for TSA-SST show similar results as for SAT-SST (see Supplementary S3.9, Figure S3.10), therefore, only SAT results are presented.

In summary, results show that the statistical model driven by Tropical Pacific SST (i.e. Niño3.4) has a better correlation relationship with local agrometeorological indices in comparison to the Tropical Atlantic SSTs (i.e. SAT or TSA). The statistical model can explain up to $20 \%$ of the 
variability (i.e. correlation peaks at 0.45 ) of the agro-meteorological indices, especially for MDSL in the coastal zones.

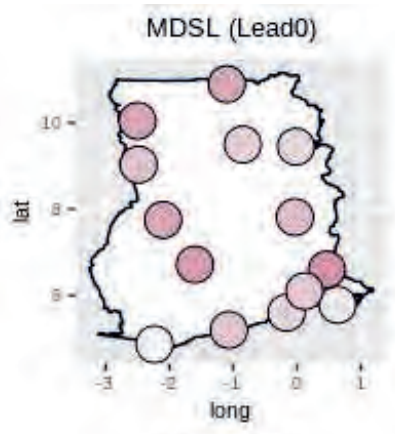

DSF (Lead0)

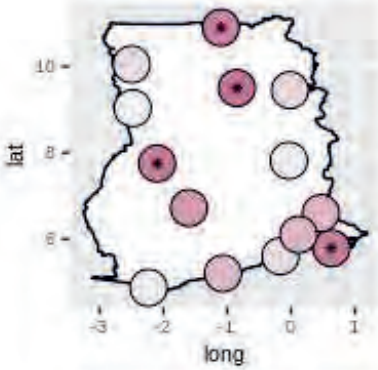

Seasonal Rainfall (Lead0)

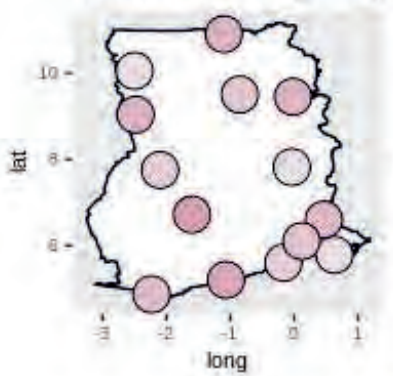

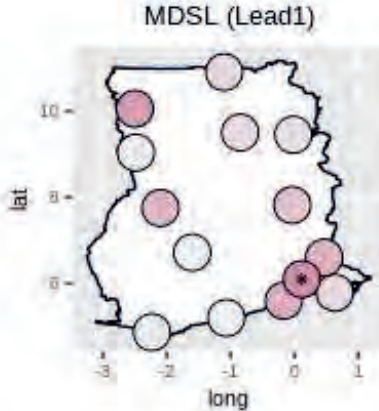

DSF (Lead1)

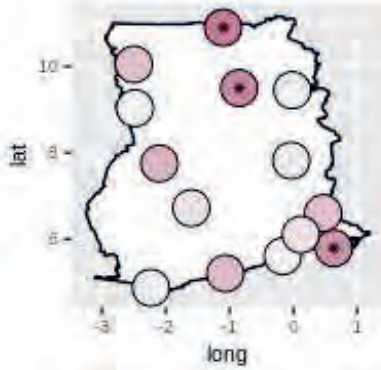

Seasonal Rainfall (Lead1)

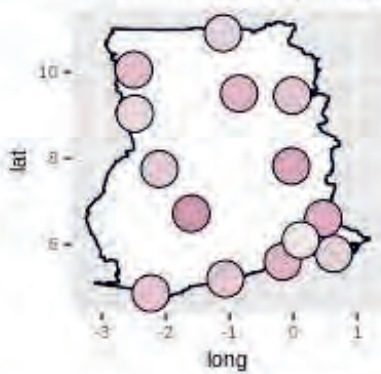

MDSL (Lead2)

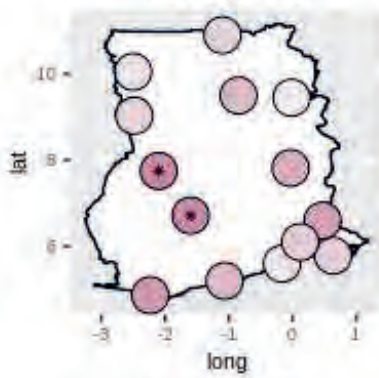

DSF (Lead2)

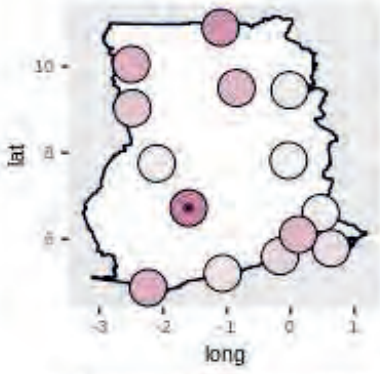

Seasonal Rainfall (Lead2)

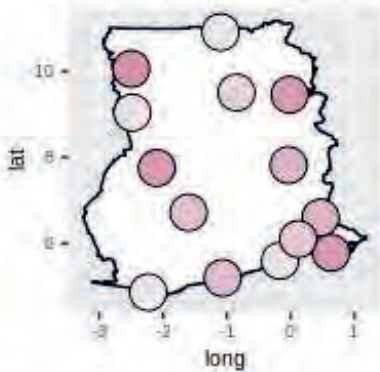

Corr (GMet, SM_SAT)

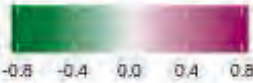

Figure 3.7: Correlation between GMet and the statistical model forecasts driven by SAT-SST (SM_SAT) for the maximum dry spell length (MDSL), dry spell frequency (DSF) and seasonal rainfall. Lead0, 1 and 2 represent the relation between SSTs for February (March), 


\section{Chapter 3}

January(February), and December(January) and agrometeorological indices considered for the MAM (AMJ) seasons, respectively. $(*)$ indicates significance at $\mathrm{p}<0.10$. The overall significant correlations coefficients range from 0.30 to 0.43 .
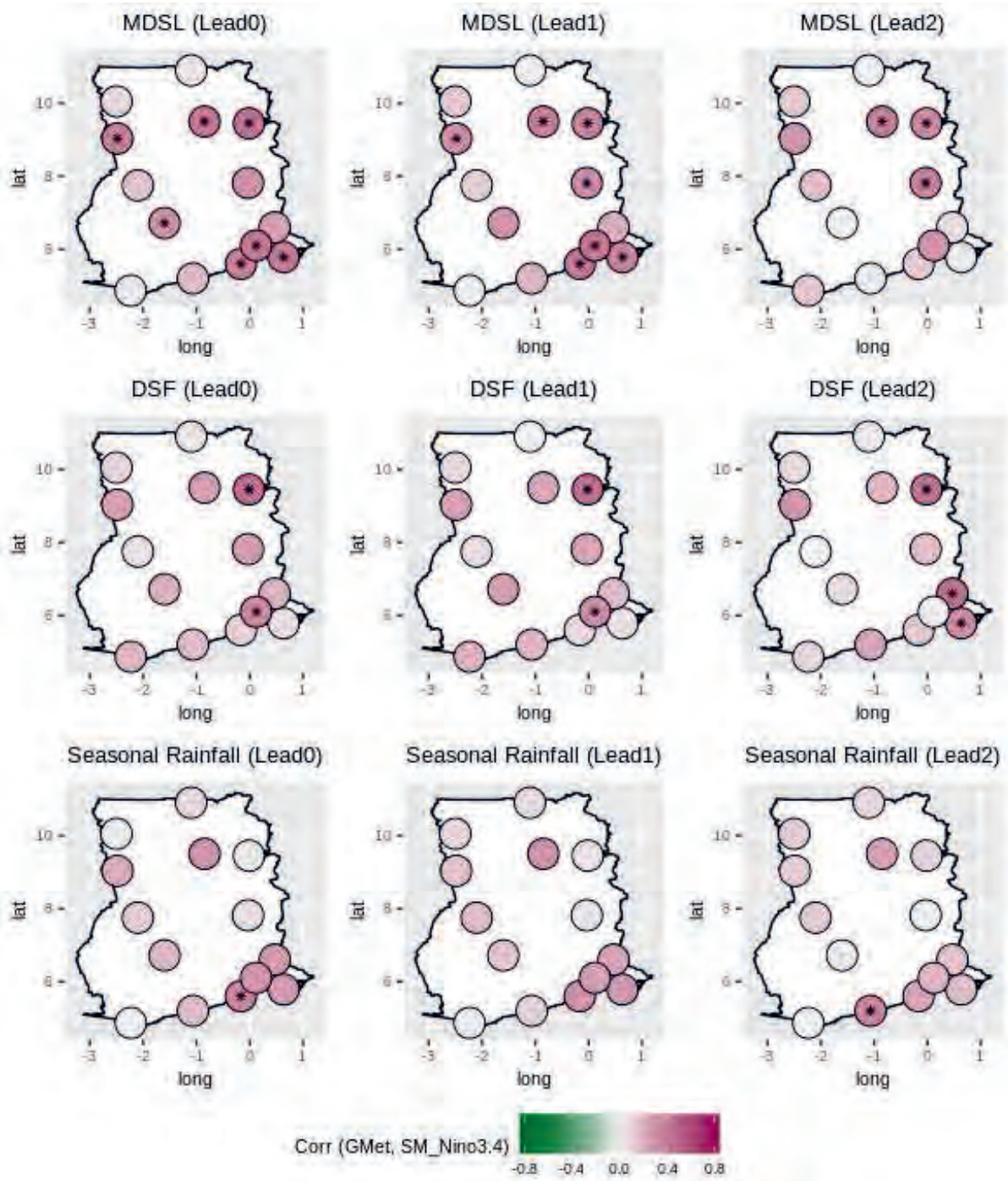
Figure 3.8: Correlation between GMet and the statistical model forecasts driven by Niño3.4-SST (SM_Niño3.4) for the maximum dry spell length (MDSL), dry spell frequency (DSF) and seasonal rainfall. Lead0, 1 and 2 represent the relation between SSTs for February (March), January(February), and December(January) and agrometeorological indices considered for MAM (AMJ) seasons, respectively. $(*)$ indicates significance at $\mathrm{p}<0.10$. The overall significant correlations coefficients from 0.30 to 0.45 .

\subsubsection{Comparing the predictability of the dynamical (System 4) with the statistical model (SSTs)}

The values of significant correlation coefficients for both the dynamical model (i.e. System 4) and the statistical model (i.e. response-to-SST) have more or less the same range across Ghana (see section 3.4.2 and 3.4.3). Although, the positive correlations peak at 0.56 and 0.45 for the dynamical and statistical models, respectively. Figure 3.9 shows the difference in correlation coefficients between the dynamical and the Niño3.4 driven statistical model. The figure indicates that the spatial distribution of significant correlations varies with lead times and agro-meteorological indices. For MDSL, the statistical model driven by Niño3.4 is more successful than the dynamical model with the exception of lead-time 0 where the both models have similar skill in terms of distribution of significant correlations coefficients. The statistical model is also more skilful than the dynamical one for DSF with a larger share of significant correlation coefficients. However, for seasonal rainfall, System4 largely dominates the statistical model for all three lead-months. The dynamical model is also more skilful than the statistical model driven by SAT for the agro-meteorological indices with the exception of DSF that has more significant correlation coefficients (see Supplementary S3.10, Figure S3.11).

The comparison reveals that the dynamical model (i.e. System 4) has, slightly, a higher predictive skill (i.e. in terms of difference in correlation coefficients) than the statistical model for MDSL and seasonal rainfall at short lead times (i.e. Lead0). For longer lead times, the statistical model driven by Niño3.4 tends to perform better for MDSL. Also, DSF is better predicted by the statistical model driven by both SSTs indices. 


\section{Chapter 3}
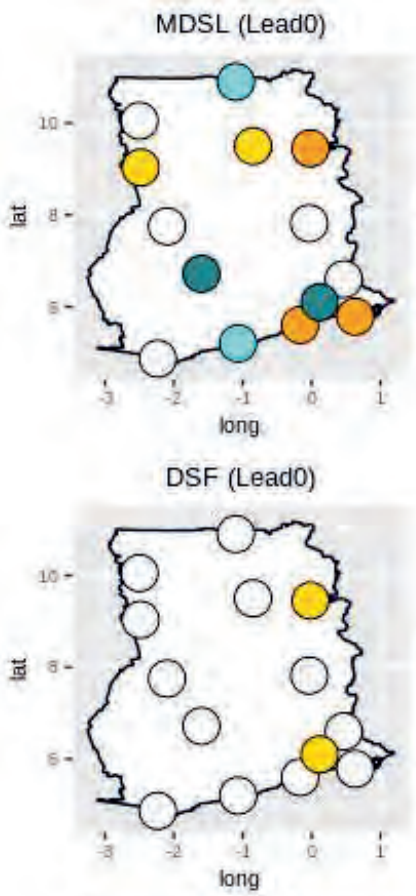

Seasonal Rainfall (Lead0)

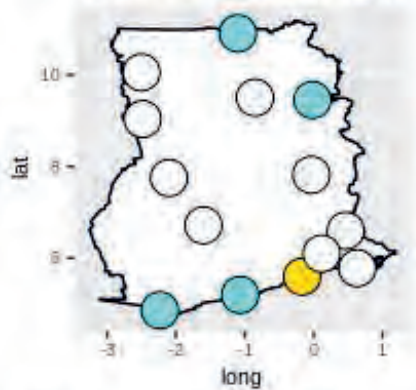

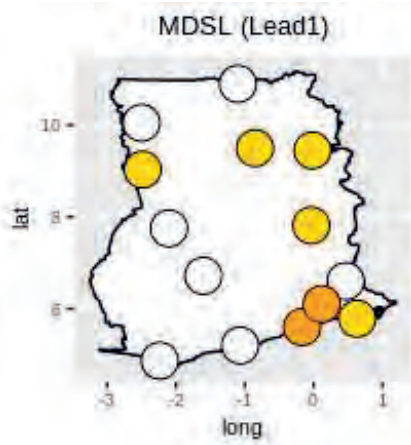

DSF (Lead1)

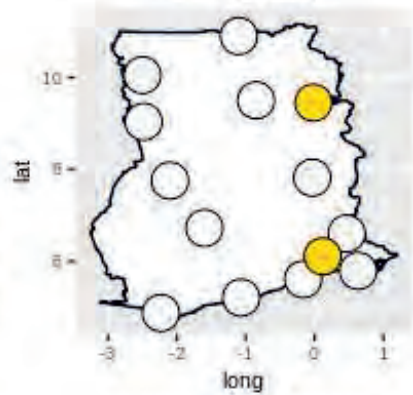

Seasonal Rainfall (Lead1)

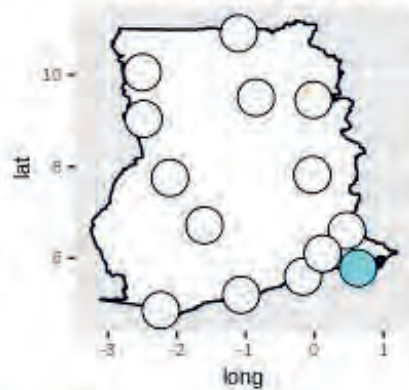

MDSL (Lead2)

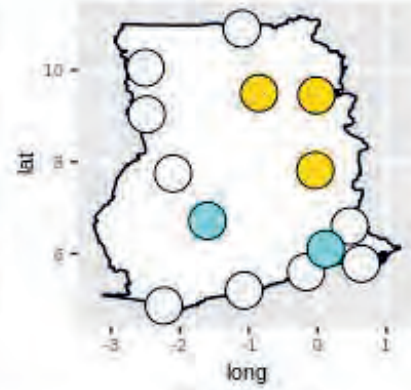

DSF (Lead2)

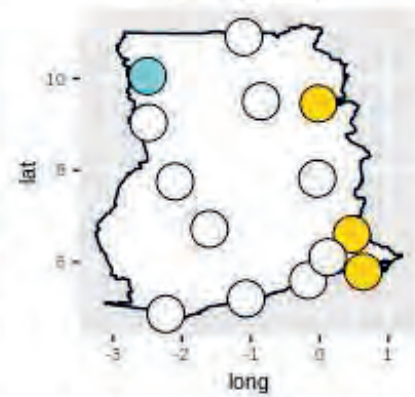

Seasonal Rainfall (Lead2)

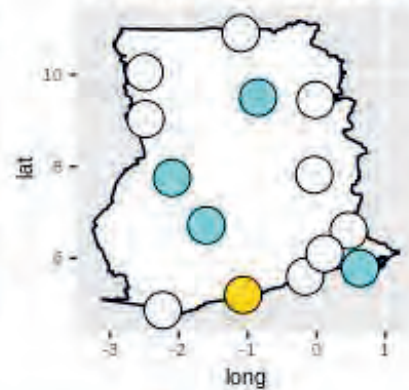

Cort.DM and SM nonsi. $\bigcirc$ Cort. DMonlysg. $\bigcirc$ Corr.sMonlysig.

Bath ourt. sig. whth DM $>$ SM Botr corr.sg- with $\mathrm{DM}<\mathrm{SM}$

Figure 3.9: Comparison of the predictive skill between the dynamical model System 4 (i.e. DM) and statistical model driven by Niño3.4 (i.e. SM) in terms of difference in the correlation relationships with GMet observed agro-meteorological indices. Lead 0, 1 and 2 represent the relation between SSTs for February (March), January (February), and December (January) and 
agrometeorological indices considered for MAM (AMJ) seasons, respectively. "Corr." and "sig." mean, respectively, correlation and significant.

\subsection{Discussion}

The aim of the current work was to assess the predictability of seasonal rainfall, dry spell length and frequency using local station observations as reference. In this process, both trend and interannual variability are first explored in view of ascertaining the climatic conditions prior the verification with the dynamical model (i.e. System4). The effects of SSTs on various agrometeorological indices are also examined as a statistical model.

\subsubsection{Trend, variability and predictability}

We showed that across Ghana and over the period 1981-2010, the coastal zone has the longest dry spells (i.e. MDSL) and the highest frequency of dry spells (i.e DSF) and the lowest mean rainfall during the rainy season (i.e. MAM). It is also interesting to note that variations of the agromet indices between zones are small in comparison to differences between stations. Both Coastal and Northern zones have higher variability for MDSL. Coastal zone has also the highest interannual variability in terms of seasonal rainfall. This variability ranging from 19-67\% (Table 3.2) for all indices is high with reference to the study of Obarein and Amanambu (2019). These results are broadly in agreement with more recent studies on rainfall patterns over this area with large-scale dataset (Baidu et al., 2017, Atiah et al., 2019). With such level of variability one can guess why local communities are facing challenges to make predictions based on their traditional knowledge. Over the coastal zone, the complex series of coastal/oceanic and atmospheric interactions contribute to this uncertainty (Acheampong 1982, Owusu and Waylen 2009, Manzanas et al. 2014).

The analyses also show higher correlations between System 4 and GMet for the dry spell length and seasonal rainfall as compared to the dry spell frequency (see section 3.4.2). The correlations found are generally weak over various stations and agro-ecological zones (i.e. correlations peaks at 0.56 ). This support the statement that seasonal forecast usually performs poorly in reproducing rainfall indices variability, including onset of the rainy season (Fitzpatrick et al., 2015, Gbangou et al., 2019). Interestingly, the Coastal area which has the highest dry spell length/lowest seasonal 


\section{Chapter 3}

rainfall, was found to have the highest level of predictability in terms of correlation relationships where System 4 was able to explain up to $31 \%$ of the variability of dry spell length.

The discrimination ability of System 4 is also confirmed by the results from the Ens2AFC and ROCSS (see section 3.4.3) especially for dry spell length and seasonal rainfall agrometeorological indices over the coast. Discrimination skills are shown to vary with the lead-times and categories. The below and above normal categories at the majority of stations tend to have higher skills than the near normal category, this is consistent with the findings of Manzanas et al. (2014b). Results on dry spell length are also consistent with those found over another African region by Wetterhall et al. (2015). These authors also find discrimination skills for dry spell agrometeorological indices. This implies that the use of System 4 agro-meteorological information for decision making remains better than the use of climatology or than guessing.

\subsubsection{Performance of the dynamical and statistical model}

Surprisingly, the statistical model (i.e. linear regression model) driven by the remote Tropical Pacific SSTs (i.e. Niño3.4-SST) showed higher correlations with local agro-meteorological indices as compared to the one driven by local (nearby) Southern Tropical Atlantic SST (SAT or TSA), especially, for MDSL and seasonal rainfall. Findings (i.e. level of correlations) with local SSTs are, however, consistent with a previous study on precipitation teleconnections over Ghana (Opoku-Ankomah and Cordery, 1994). The authors showed that the relationship of local SSTs with local rainfall is strong from July to September but very weak from March to June. Our findings suggest that during the most important seasons (i.e. MAM and AMJ) where correlations with local SST are weak, farm planning can rely on predictions based on the remote SST, namely Niño3.4SST. Although the correlations peak at 0.45 , the teleconnection is still strong enough to provide information to farmers on the likelihood of the indices during MAM and AMJ seasons (OpokuAnkomah and Cordery, 1994, Alhamshry et al., 2019).

The dynamical model explains up to $31 \%$ (i.e. correlation peaks at 0.56 ) of the variance of agrometeorological indices while the statistical model driven by Tropical Pacific SST can only explain $20 \%$ (i.e. correlation peaks at 0.45 ) of the variance (see sections 3.4.2 and 3.4.3). This implies that the dynamical performs, slightly, better than the statistical model. Although both models have the same patterns of skills, that is, the same zones and indices have generally 
significant skills, especially, for dry spell length and rainfall. Also, for dry spell frequency and for longer lead times dry spell length, the statistical model tends to perform better. Skills found for longer lead times are, particularly, useful for useful for operational purposes. The similarity in the level of skill between the response-to-SST with System 4 seasonal forecasting is probably justified, since the System 4 is also driven/initialized by SST. The difference between the dynamical and statistical models suggest that the joined use of both models can help generate more qualitative seasonal climate information.

\subsubsection{Importance of using local station observations and cautious interpretation of findings}

The use of local stations' observations for bias-correction and skill assessment of the seasonal forecasts in this paper is a relatively new approach with strengths and challenges. The approach offers the opportunity to explore differences in forecasts skills between local stations and agroecological zones. By using large-scale gridded data (e.g. satellite and reanalyses), we may miss some information on local variations due to micro-scale processes (Wetterhall et al., 2015, Gbangou et al., 2019). This is the case of most previous studies that used large scale dataset (Ogutu et al., 2017, Nyadzi et al., 2019). It is also important to consider some limitations related to the stations datasets and the methodology (Gbangou et al., 2019). The neighbour weighted interpolation technique used to interpolate the forecast at each point station is still a form of averaging approximation that can have an effect on the results.

For dry spell and seasonal rainfall information, derived from operational dynamical forecasts, to be valuable to local farmers and water managers, the release timing restriction of the forecasts needs to be taken into account. This is because, the operational forecasts from the new System (i.e. System 5) has a release date on the $5^{\text {th }}$ of each month. In addition, one should consider the processing and communication time between ECMWF, the local Met agency and end-users (e.g. local farmers in Ghana). Operational statistical and dynamical forecasts with skills at long lead times offer less time restriction for the processing and communication. It is equally important to explore the predictability with more shorter term forecasts, including sub-seasonal to seasonal forecasts (1-2 months) and also weather forecasts (1-14 days) to fully meet the need of local endusers, especially in Costal delta area of Ghana.

\subsubsection{Implication of the findings for local farming climate services development}




\section{Chapter 3}

With regards to farming, due to the high variability in dry spell length and frequency, and seasonal rainfall, risks of rainfed crop systems during MAM and AMJ critical growing seasons are large. One of the problems is the risk associated with crop failure during plant growing stages due to insufficient soil moisture. This can lead to a decrease in yield or generate additional costs for replanting. So far, farmers mostly relied on traditional predictions (Yaro, 2013, Ingram et al., 2002, Antwi-Agyei et al., 2012, Naab et al., 2019) to appreciate the likelihood of the wet and dry seasons. Introducing modern scientific forecasts of the agro-meteorological indices can help local farmers adapt agricultural practices and hence reduce crop failure and losses, particularly in Coastal and Northern Ghana where Waterapps project is actively involved.

Our results show promise for the provision of some degree of skilful dry spell and seasonal rainfall forecast for local farmers in Ghana, especially during critical growing seasons. Information derived from the forecasts starting from January, February, and March (coastal and southern zones) and from February, March, and April (transitional and northern zones) can potentially help end-users such as local water manager and farmers with making decisions. The below and above normal information being better discriminated over the costal savannah can help to reduce the risks and costs related to crop failure through an early crop types and varieties selection. For instance, during below normal dry spell and above normal rainfall year, farmers may expect a good year. They can thus plan for early farming activities and worry less about crop failure related to water scarcity. During above normal dry spell and below normal rainfall year, there is a risk for drought. Skilful predictions could also be complemented with local traditional predictions to some extent to facilitate its acceptability and uptake (Ingram et al., 2002, Gbangou et al., 2018). However, farmers need to be well informed on the limitations of the forecasts to avoid damages related to false alarms.

\subsection{Conclusions}

This study has shown that there are differences in variability and skills of the agrometeorological indices across different zones and stations that might not be noticed when using large-scale datasets for forecast verification. Variations in skills between stations are higher than those between the agro-ecological zones which is a new insight on forecast performance at local scale. Also, similarity in skills of the agro-meteorological indices over the same zones and stations are found both for the dynamical and statically models although System 4 slightly performs better, especially, for dry spell length and seasonal rainfall. For dry spell frequency and longer lead-time dry spell length, the 
statistical model tends to perform better. The closeness in the level of skill between the responseto-SST with System 4 seasonal forecasting is probably justified, since the System is driven/initialized by SST.

Important skills in the dry spell length and seasonal rainfall forecasts with reasonable lead-time are present in the coastal savannah zone. These skills are, specifically, higher for the below and above normal categories. This proves that the operational seasonal forecast from the updated System (e.g. System 5) and the response-to-SST can be used to provide useful information to end-users including local farmers and water managers. This finding is particularly of interest for the districts located in the coastal savannah around the delta area, namely, Ada districts, where the Waterapps project is experimenting with co-production of water information service. The provision of operational forecasts at appropriate leadtime and categories in combination with the response-toSST's information can help mitigate the effect of high variability in dry spell and seasonal rainfall during critical growing stages of crops.

This new approach and understanding of the predictability could help to verify and improve agrometeorological information in other regions affected by climate variability. Future research and application in climate services development are encouraged to explore both models (dynamical and statistical models) to improve the predictability of dry spell occurrence and seasonal rainfall information during MAM and AMJ growing seasons in Ghana.

\section{Acknowledgement}

This research is fully funded by the Netherlands Organization for Scientific Research (NWO/WOTRO) under the urbanizing deltas of the world program (UDW) and WaterApps (www.waterapps.net) project. My sincerest gratitude goes Ghana Meteorological Agency (GMet) for providing gauge observations to the WaterApps project. 


\title{
Chapter 4. Harnessing local forecasting knowledge on weather and climate in Ghana: documentation, skills and integration with scientific forecasting knowledge
}

\begin{abstract}
Improved weather and climate forecast information services are important to sustain small-scale crop production in many developing countries. Previous studies recognized the value of integrating local forecasting knowledge (LFK) with scientific forecasting knowledge (SFK) to support farming's decisions making. Yet, little work has focused on proper documentation, quality verification, and integration techniques. The skills of local and scientific forecasts were compared and new integration approaches derived over the coastal zone of Ghana. LFK-indicators were documented and farmers trained to collect indicators' observations and record rainfall in real-time using digital tools and rain gauges respectively in 2019. Dichotomous forecasts verification metrics were then used to verify the skills of both local and scientific forecasts against rainfall records. Farmers use a diverse set of LKF-indicators for both weather and seasonal climate timescale predictions. LFK-indicators are mainly used to predict rainfall occurrence, amount of seasonal rainfall, dry spell occurrence, and onset and cessation of the rainy season. The average skill of a set of LFK-indicators in predicting one-day rainfall is higher than individual LFK-indicators. Also, the skills of a set of LFK-indicators can potentially be higher than the forecasts given by the Ghana Meteorological Agency for Ada district. The results of the documentation and skills indicate that approaches and methods developed for integrating LFK and SFK can contribute to increase forecast resolution, skills, and reduce recurring tensions between the two knowledge systems. Future research and applications on these methods can help improve weather and climate information services in Ghana.
\end{abstract}

Published as :

Gbangou, T., Ludwig, F., van Slobbe, E., Greuell, W., \& Kranjac-Berisavljevic, G. (2020). Harnessing local forecasting knowledge on weather and climate in Ghana: documentation, skills and integration with scientific forecasting knowledge. Wea. Climate Soc., 13, 23-37, https://doi.org/10.1175/WCAS-D-20-0012.1. 


\section{Significance Statement}

Most African farmers still rely on local or traditional knowledge on weather and climate forecasts to manage climate variability and change, although much efforts are put in to reach farmers with the increasing availability of scientific forecasts and data. Exploring the potential of local forecasts and the possible integration with modern forecasts has been suggested as a path to reach out to farmers with more accessible and credible climate information services (CIS). We aimed to understand the contribution of this local knowledge by documenting and investigating its quality. We found that local forecast indicators used by farmers are diverse and their level of quality can potentially improve the development of CIS, especially when they are combined or integrated with scientific forecasts.

\subsection{Introduction}

There is a strong need for better and more accessible weather and climate information services to support, especially, small scale farmers in their decision making. In large parts of Africa, the climate is highly variable, and improved climate information services can potentially help farmers to manage climate variability and change. In Ghana, food production contributes substantially to the national economy, with $80 \%$ of total agricultural production of the country being attributed to smallholder farmers (Barnett et al., 2017). These farmers, predominantly, rely on rainwater for agricultural production. This dependence on rains makes the region vulnerable to climate change and variability such as shifts in onset of rains and amounts of seasonal rainfall, and dry spell occurrences (Owusu and Waylen, 2009, Yaro, 2013, Gbangou et al., 2019). As a result, local farmers struggle to meet food and income security. Improved and tailored forecast information on weather and climate can help them adapt and make better decisions to increase their crop yields (Derbile et al., 2016, Gbangou et al., 2018, 2019)

Although previous studies showed that African' farmers use both local and scientific forecasting knowledge on weather and climate across Africa (Orlove et al., 2010, Roudier et al., 2014, Codjoe et al., 2014), several limitations remain. Firstly, scientific forecast information often has limited skills and accuracy at high spatial resolution (i.e. local scale) (Derbile et al., 2016, Fitzpatrick et al., 2015, Vellinga et al., 2013). In addition, the understanding and acceptability of modern forecasts by farmers sometimes limit forecast usefulness and usability (Ingram et al., 2002). 


\section{Chapter 4}

Moreover, this knowledge is usually not tailored to end-users needs. Secondly, there are claims that local forecasting knowledge is subjected to a decrease in trust due to the loss of indicators probably caused by changing weather and climate conditions (Kalanda-Joshua et al., 2011, Ziervogel and Downing, 2004, Ziervogel, 2001). Local knowledge is also subject to skepticism due to replicability issues that limit knowledge spread in practical applications and science (Huntington, 2000, Pierotti and Wildcat, 2000, Gilchrist et al., 2005). According to Lebel (2013), the systematic assessment of the consistency and validity of local knowledge is still lacking.

In view of these constraints, there is a need to integrate local and scientific knowledge to provide improved information services (Riedlinger and Berkes, 2001, Luseno et al., 2003, Speranza et al., 2010). Speranza et al. (2010) showed that the density and diversity of local knowledge indicators used for weather and climate monitoring and prediction have the potential to improve meteorological forecasts. This study focusses on local knowledge (LFK) and scientific forecasting knowledge (SFK) on weather and climate. Scientific knowledge refers to the expert or modern knowledge based on rigorous methods through observation and experimentation (e.g. forecasts from large-scale models, station, or satellite observational data). LFK is a knowledge that is rooted in local culture and generally associated with long-settled communities that have strong ties to their natural environment (Ingram et al., 2002, Orlove et al., 2010, Codjoe et al., 2014, Derbile et al., 2016). This local knowledge, inherently, also follows a rigorous process based on observations of biophysical indicators, experimentation in its production and analysis to build trusted cause-effect relationships between indicators and their predictive outcomes in terms of current and future weather and climate conditions (Aronson, 2007, Gearheard et al., 2010, Balehegn et al., 2019).

Despite the increasing interest in the use and integration of LFK with SFK, there are only a few studies on the performance assessment of the LFK and its integration with SFK (Speranza et al., 2010). Studies that focused on integration hardly exist, especially in Ghana. The majority of the studies focused on understanding and interpreting local knowledge related to environmental and social impact assessments for climate change adaption and mitigation (Berkes and Ecology, Huntington, 2000, Nakashima and Roué, 2002, Olsson and Folke, 2001). Also, the few studies that assessed the performance of LFK, have done so, qualitatively (Crane et al., 2010, Radeny et al., 2019), and therefore can hardly be used for a quantitative comparison with scientific knowledge (see Figure 4.1). Until now, no attempt has been made to assess the skills of LFK and integrate it 
with the modern forecasting system in the peri-urban delta areas of Ghana. In order to explore these skills, proper documentation of the local forecast indicators, specific to this area, is also needed.

This paper attempts to bridge this gap by both documenting and assessing the skills of LFK, and comparing these skills with conventional forecasts and observations. The paper further discusses the possible integration of LFK and SFK. We stress that the paper intends to propose new approaches and methods for collecting and assessing the quality of local knowledge, and integrating both local and scientific forecasting knowledge systems. These approaches and methods being both qualitative and quantitative (Figure 4.1). Farmers in Ada East district, Ghana (see. the study area, Figure 4.2) have also recognized the decline in LFK confidence through evidence from the surveys conducted by the Waterapps research project (http://www.waterapps.net/). Assessing the quality in LFK against SFK with local observations as a reference can help increase the confidence in LFK for both farmers and scientists towards improved climate services.

The work was designed to answer the following questions in the case study:

i. What are the most frequently used indicators for predicting daily and seasonal rainfall by local farmers?

ii. What is the perceived reliability of local forecasting knowledge?

iii. How are the skills of local forecasting knowledge indicators compared to those of scientific forecasting?

iv. How can we integrate local with scientific forecasting knowledge for improvement? 
Chapter 4

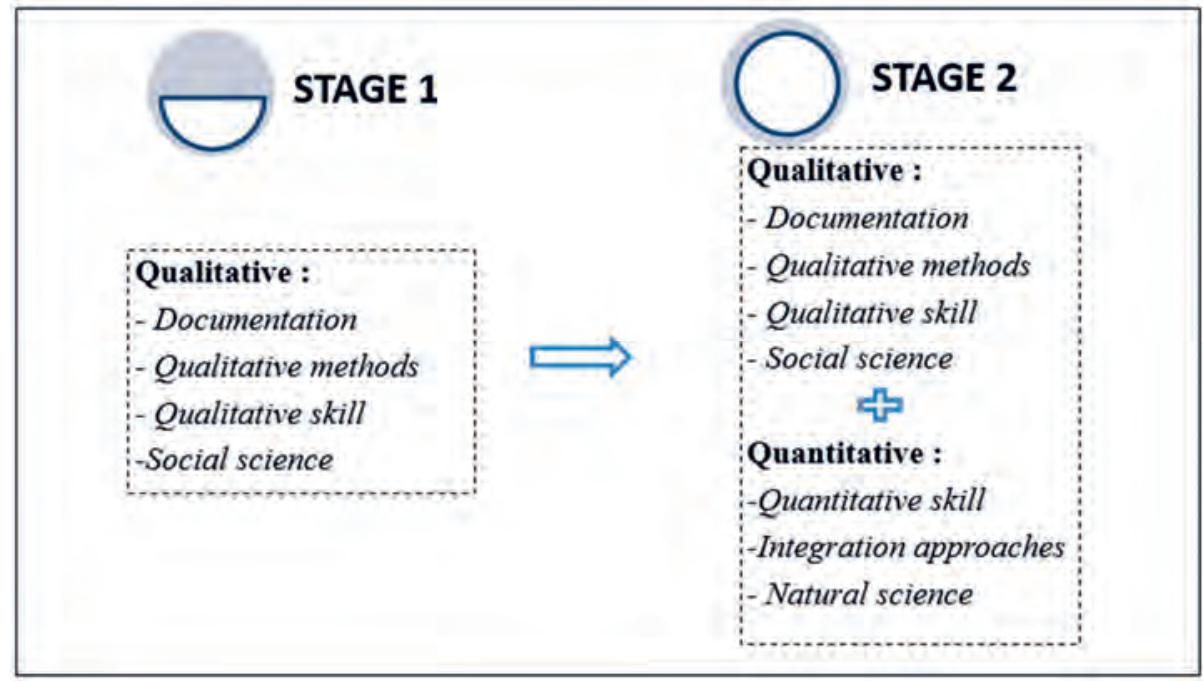

Figure 4.1. Framework showing current literature on LFK (stage 1) and the desired goal of the study presented (stage 2) 


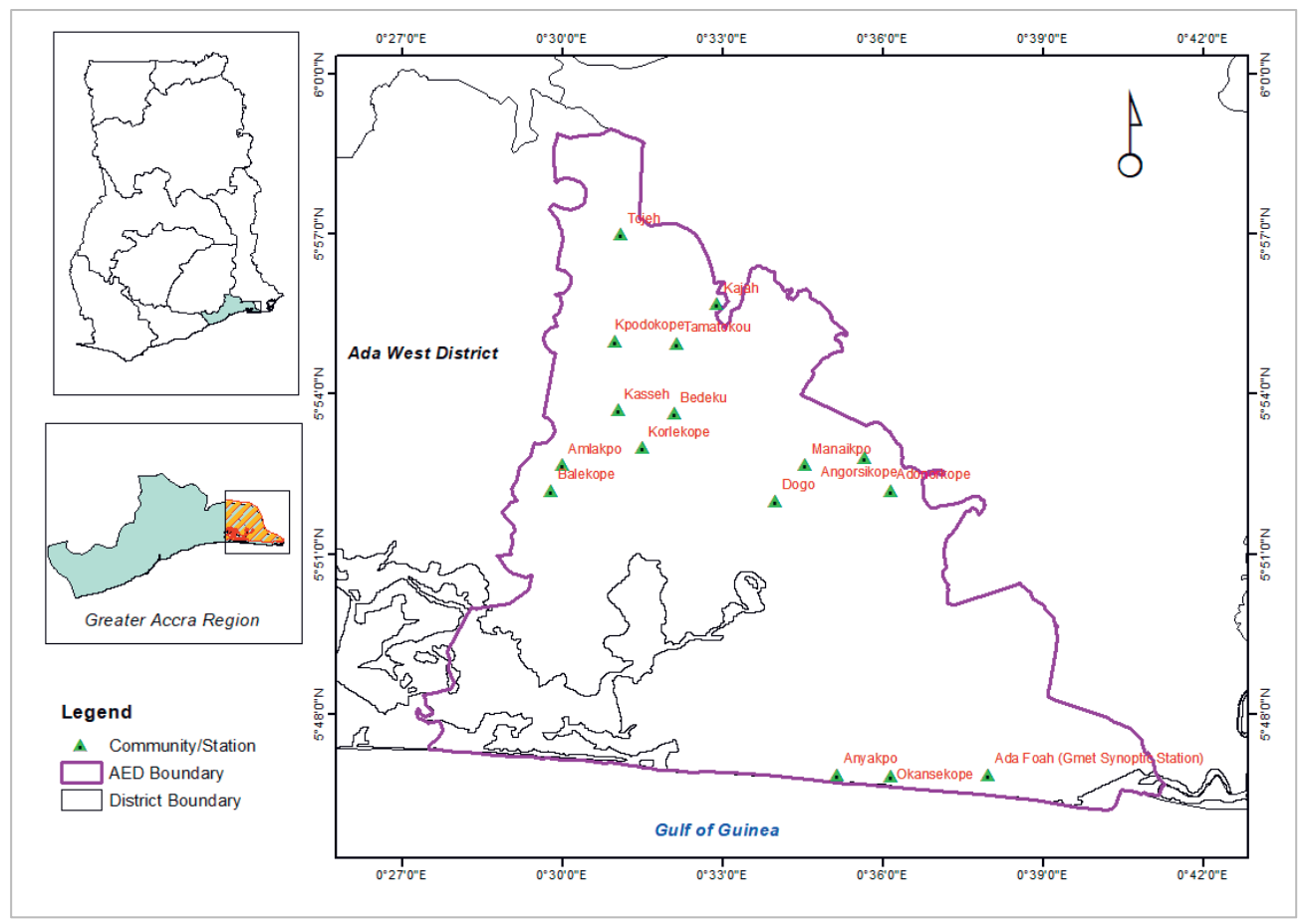

Figure 4.2: Map of the Study Area in Greater Accra Region, Ghana showing various communities of Ada East District.

\subsection{Study area}

The study was carried out in the Ada East District (AED) which is located in Ghana's coastal savannah along the delta area of the Volta River (Figure 4.1). A dry equatorial climate and coastal savanna vegetation are found in the area. AED is one of the hottest districts in Ghana with average temperatures ranging between $23^{\circ} \mathrm{C}$ and $28^{\circ} \mathrm{C}$ (Ghana Statistical Service, 2014). Average annual rainfall is about $750 \mathrm{~mm}$ (Lazar et al., 2015). AED is a peri-urban area, located within the Greater Accra Region of Ghana. The district produces mainly vegetables for big cities like Tema and Accra. According to Ghana Statistical Service (2014), the engagement of young adults in crop farming is a major boost to the district and the economy of Ghana. Also, the potential for digital technology to be adopted is high due to proximity to urban areas. The most economically important crops include cassava, pepper, rice, maize, and tomato (Amisigo et al., 2015). The majority of the 


\section{Chapter 4}

agricultural households are either into mono-cropping or intercropping type of farming (Ghana Statistical Service, 2012).

Crop production along the peri-urban delta area is vital to safeguard sustainable food production (Gbangou et al. 2019). This is because of agricultural intensification, water availability issues, and the increasing possibilities of farmers to use information and communication technology (ICT; e.g., cellular telephones, television, radio, and internet services) for climate information service. Also, risks of crop failure due to unpredictable rainfall events are growing and hence the need for improved rainfall forecasts.

\subsection{Methods}

This section presents the methodological approach for data collection and analysis.

\subsubsection{Data}

4.3.1.1.Documentation of local foresting knowledge data

Respondents for documenting of LFK were selected through purposeful non-random sampling which is the most adapted sampling method for collecting data from experienced targeted people as in this context (Santha et al., 2010). The sub-category snowball sampling (Quinn Patton, 2002) was adopted and focused on farmers that had local knowledge and experience in weather and climate forecasts across five communities of Ada East district (Figure 4.2), namely, Balekope, Amlakpo, Bedeku, Kasseh, and Korlekope (see demographic information in Figure 4.3a). With the help of agricultural extension agents, 32 respondents across communities were identified and indepth key informant interviews and five focus group discussions (FGDs) were carried out to collect the qualitative data. FGDs were done with a group of 5-9 farmers per community. Questions focused on identifying (i) indicators used for weather and climate predictions, (ii) their signals, (iv) the period, and (i) the corresponding outcomes (predictions) as described by Codjoe et al. (2014). The survey was carried out during the 2017 growing season before the real-time data collection at Ada East District during the 2019 season.

\subsubsection{Perceived reliability of local and scientific forecasts data}

Farmers' perceptions of the performance of local and scientific forecasts were investigated with 68 respondents also in 2017 (see demographic information in Figure 4.3b). Farmers who used both 
forecasting systems in their daily farming activities were, purposefully, identified by a pre-survey. And a random selection was performed to choose the final respondents across the communities of the district. Hence, this final sample could give a credible comparative appreciation of the reliability of local and scientific forecasting systems. This method allows to identify the population of interest and ensure the credibility of the findings even with small samples (Palinkas et al., 2015). The sampling focused on rainfed farmers who have used both local and scientific forecasts across Ada East district communities. Farmers were asked to rank the performance of each forecasting system in terms of reliability level: Not reliable, Somewhat reliable, and Reliable. Local forecasting knowledge comes from their own knowledge and experience while scientific knowledge comes from Ghana meteorological agency (GMet) through radio and television mainly.

\subsubsection{LFK-indicators observations data}

We also used a purposeful sample to select 22 farmers for collecting real-time LFK-indicators' observations (see demography in Figure 4.3c). For this stage, we selected individuals who had prior experience in local forecasting. We focused on the knowledge, availability, and willingness to participate, gender, and involvement of younger farmers in view to ensure the generational knowledge sharing and sustainability of the co-production process (see Figure 4.3c). In order to also ensure that those with less experience (e.g. younger farmers) in LFK can provide good observations, we trained all participants on the indicators' signals used and their outcomes. This was done during the 2018 and 2019 seasons. LFK-indicators' observations are based on the frequently used indicators documented during the 2017 season. We used a web-based application (Weatherapp, see Figure 4.4) tailored for the collection of LFK-indicators observations. LFKindicators' observations were subsequently converted into forecasts based on the database on indicators' signals and outcomes collected during the 2017 season (see section 4.3.1.1).

\subsubsection{Rainfall records data}

Farmers were provided with manual rain gauges (see supplementary, Figure S4.1) and trained by a meteorological extension agent from GMet on how to set up the gauges, measure, and record rainfall data from $5^{\text {th }}$ April to $17^{\text {th }}$ July 2019. A total number of twenty (20) manual rain-gauges were provided across communities (Figure 4.2). Rainfall data were recorded on a daily basis for 


\section{Chapter 4}

105 days starting from $5^{\text {th }}$ April 2019 until $17^{\text {th }}$ July 2019. These data were used as a reference to assess the skills (verify) both local and scientific forecasts from GMet and meteoblue. 

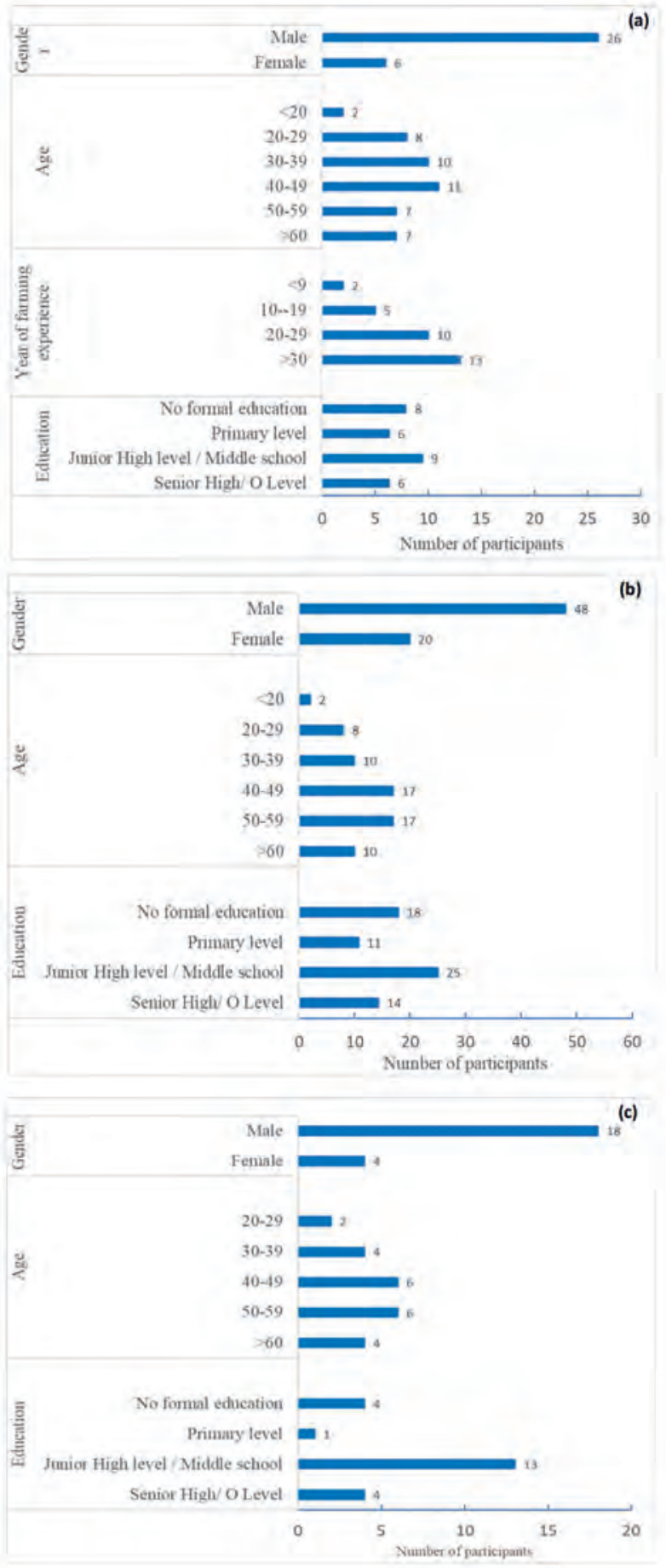


\section{Chapter 4}

Figure 4.3. Socio-demographic characteristics of (a) the 32 participants (farmers) involved in the focus group discussions and interviews for the documentation of local forecasting knowledge in 2017 season [including their level (years) of experience], (b) the 68 farmers involved on the assessment of the perceived reliability of local forecasting knowledge compared to the $24 \mathrm{~h}$-forecast from the Ghana Meteorological Agency (survey carried out in 2017 season), and (c) the 22 farmers who participated in the real-time collection of LFK-indicators observations in Ada East District from the 5th April to the 17th July 2019.

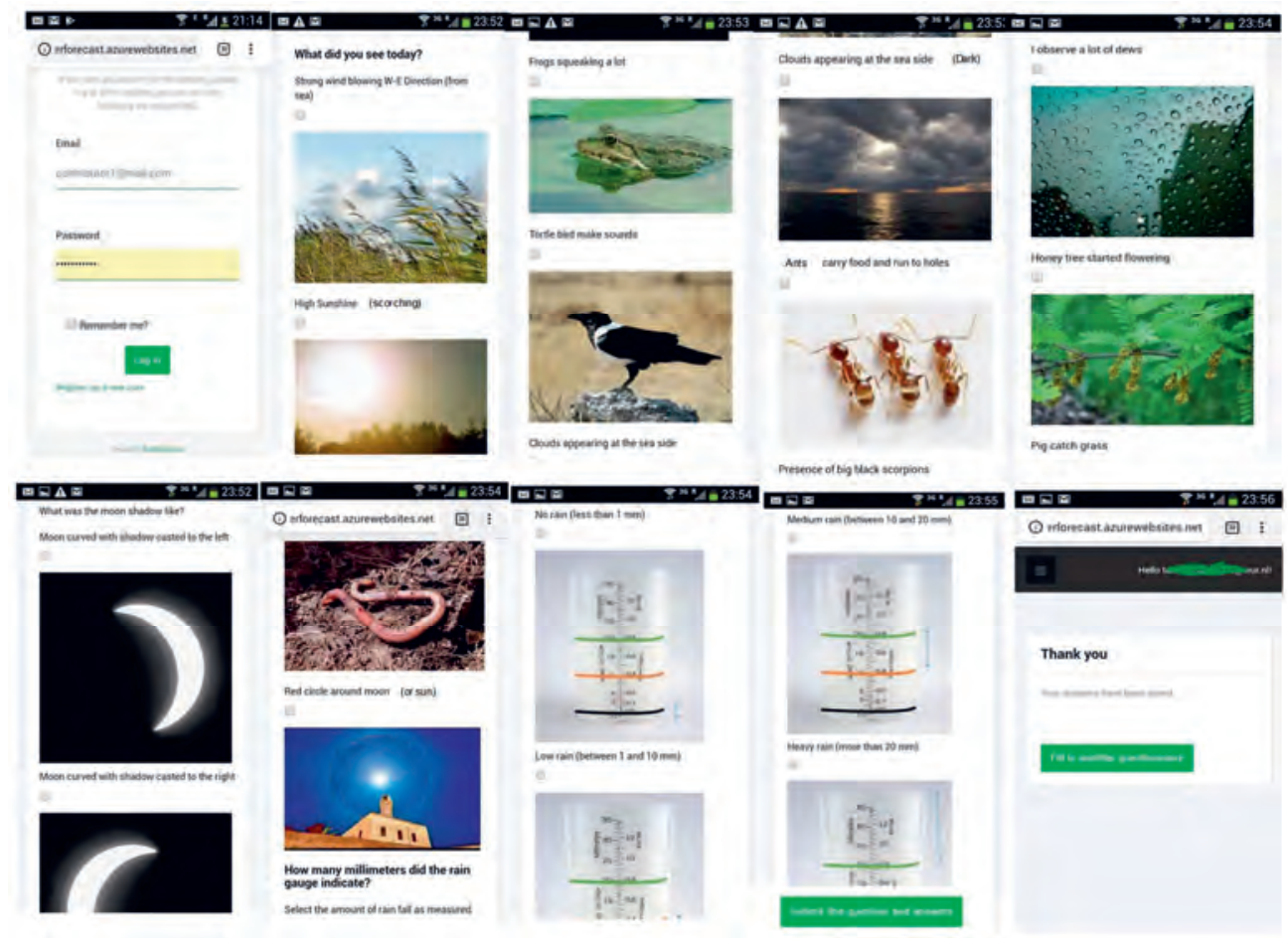

Figure 4.4. The interface of the WeatherApp of the web-application (http://waterappsweatherforecast.azurewebsites.net/Account/Login) showing some of the symbolic images of local weather indicators and data collection procedure. The WeatherApp was designed, tested and improved to collect Farmer's knowledge remotely from 2018 to 2019. More details on the application are described in a follow-up research output focusing on the evaluation of the coproduction experiment carried out in Ada East District under the Waterapps project. 


\subsubsection{GMet and meteoblue datasets}

Two scientific weather forecasts were used and compared with gauges data collected during the 105 days co-production experiment. These include GMet and meteblue 24h-forecast (i.e. daily) data. For consistency with the terms "LFK" and "SFK", daily forecast from GMet and meteoblue are named SFK-GMet and SFK-meteoblue respectively throughout the paper. GMet gives out the daily forecasts for different agro-ecological zones in Ghana (see Gbangou et al. 2019) that are much larger than the Ada East district area. Forecasts data for the coastal zone that contains the district was therefore considered. These forecasts are shared with the public through the official GMet website, social networks, TV, and Radio. Forecasts from meteoblue (https://www.meteoblue.com/) are raw simulations from the most appropriate (usually the one with the highest resolution) model, depending on location and period. They cover a spatial resolution of $30 \mathrm{~km}$ around Ada East District. These meteoblue forecasts are given for illustrative purposes only since the best guess forecast used cannot be known in advance. The skill of the meteoblue' real forecast that farmers can see in real-time might be much lower.

\subsubsection{Analysis of documentation and perceived reliability of local forecasting knowledge}

LFK-indicators were compiled, described and grouped into existing local knowledge spheres identified in previous studies (Codjoe et al., 2014, Speranza et al., 2010). The main spheres are atmospheric conditions, celestial elements, fauna, and flora. Indicators were also classified into weather and seasonal timescales. The perceived reliability was grouped into three categories using data on farmers' perceptions of the performance of local and scientific forecasts as applied in Radeny et al. (2019). These categories include: Not reliable ]0-33\%], Somewhat reliable ]33-66\%], and Reliable ]66-100\%]. These categories for the two forecasting systems were subsequently compared.

\subsubsection{Analysis of skills of local and scientific forecasting knowledge}

The actual (quantitative) skills of local and scientific forecasts for predicting rainfall occurrence were assessed using a contingency table (Table 4.1). In this table, the 'forecast' indicates LFKindicators, SFK-GMet, and SFK-meteoblue forecasts and the 'observation' refers to gauge observations measured by farmers (see details in Appendix A4.1 and Supplementary, Figure S4.1). The table was used to compute the most relevant skill metrics such as the hit rate (POD), the false 


\section{Chapter 4}

alarm ratio (POFD), the false alarm rate (FAR) and the Hanssen-Kuipers (H-K) discriminant skill score as described in Gbangou et al. (2019) (see Eq. 4.1, Eq. 4.2, and Table 4.1). This set of metrics allows for a complete analysis of the performance of forecast data (Gbangou et al., 2019). H-K skill measures the ability of the LFK-indicator or SFK-forecast to discriminate rainfall occurrence events. Skill scores were computed for both individuals LFK-indicators and the realization of combined LFK-indicators. All possible combinations of scenarios were derived using the formula presented in Eq. 4.3.

$\mathrm{FAR}=\frac{b}{(a+b)}($ Equation 4.1)

Where: FAR is the false alarm ratio and ranges from 0 to $1, F A R=0$ is the perfect score.

$\mathrm{H}-\mathrm{K}=\mathrm{POD}-\mathrm{POFD}$ with $\mathrm{POD}=\frac{a}{(a+c)}$ and $\mathrm{POFD}=\frac{b}{(b+d)} \quad($ Equation 4.2)

Where: H-K is the Hanssen-Kuiper's discriminant or Pierce Skill Score (Hanssen and Kuipers 1965); POD and POFD represent respectively the probability of detection or hit rate and the probability of false detection or false alarm rate; HK ranges from -1 to $1 ; \mathrm{H}-\mathrm{K} \leq 0$ indicates no skill, $\mathrm{H}-\mathrm{K}=1$ is the perfect score; $\mathrm{a}, \mathrm{b}, \mathrm{c}$ and $\mathrm{d}$ are described in Table 4.1.

$C_{n}^{k}=\frac{n !}{k !(n-k) !}($ Equation 4.3)

Where: $C_{n}^{k}$ is the possible combinations of k elements from the set of the element with size $\mathrm{n}$. The combinations are carried out without repetition (i.e. number of arrangements of $k$ from $n$ ). Here, $n$ is the total number of LFK-indicators tested.

Table 4.1: Contingency table for categories of events (Gbangou et al. 2019)

\begin{tabular}{llll}
\hline & Event-observed & Event-not observed & Total \\
\hline Event-forecasted & Hits $(\mathrm{a})$ & False alarms $(\mathrm{b})$ & Yes forecasted $(\mathrm{a}+\mathrm{b})$ \\
Event-not forecasted & Misses $(\mathrm{c})$ & Correct rejection $(\mathrm{d})$ & No forecasted $(\mathrm{c}+\mathrm{d})$ \\
Total & Yes observed $(\mathrm{a}+\mathrm{c})$ & No observed $(\mathrm{b}+\mathrm{d})$ & Total forecasts $(\mathrm{n})$ \\
& & & \\
\hline
\end{tabular}




\subsubsection{Analysis of skills of integrated forecasts (local and scientific)}

The word "integration" has several synonyms that include: combination, completion, connection, etc. Here, analyses focused on combining LFK and SFK. We, therefore, considered to alternate LFK and SFK systems (i.e. GMet and meteoblue) whenever suitable based on the statistical results from the analyses described above (section 4.3.3). We choose to call this integration approach, a " statistical integration" implying that the integration is based on statistical combination of local forecast indicators. This integration focused mainly on the prediction of daily rainfall occurrence.

Other approaches of integration (e.g. completion, connection) where identified from the results on the documentation and are only discussed for future research and application. These approaches aimed to help enrich both local and scientific forecasting knowledge. They include the approach (i) that uses specific weather and climate indicators from LFK to enrich SFK and vice versa were called "intuitive integration”, (ii) that explores the scientific/meteorological patterns of LFK based on scientific historical observations were called " patterns evidence from meteorological data", and (iii) that seeks to update some invariable LFK-indicators using scientific evidence was called “updating invariable LFK indicators”. Each approach was provided with an example.

Theoretically, the "Intuitive integration" is a judgmental approach as it uses expert or experience based judgment to derive the forecasts (Lawrence et al. 2006) while all other approaches are statistically related approaches for integrating local and scientific knowledge. The judgment or 'intuition' can be derived by the scientist, the farmers, or both (if they are working together to make a joint prediction).

\subsection{Results}

\subsubsection{Documentation of Local Forecasting Knowledge}

Several LFK-indicators used by farmers to monitor or forecast local weather and climate conditions are identified and documented in Tables 4.2 and 4.3 based on interviews and discussions with experienced local knowledge holders. Farmers from the five communities identified twenty-two (22) indicators related to weather timescale prediction (Table 4.2) and twelve (12) indicators used for seasonal timescale predictions (Table 4.3). The indicators documented pertain to different features of atmospheric conditions (wind, clouds, and dew), celestial elements (sun, moon, and sky), fauna (ants, frogs, goats, scorpions, worms, birds, and pigs) and flora (trees). Results showed 


\section{Chapter 4}

that the same indicator can have different signals and therefore indicates a different predictive outcome (see Table 4.2 and 4.3). Also, similar indicators can be found for the two timescales (i.e. weather and seasonal) but with different signals and predictions. Moreover, outcomes or predictions depend on the period the indicator is observed. This period expands from December until July which coincided with the major rainfall season's first and highest peak of the bimodal pattern of the rainy season.

Weather timescale indicators, listed in Table 4.2, give predictions of rainfall occurrence ranging from 1 to 14 days. The majority of the indicators are used to predict if it will rain within the coming three days. For instance, rainfall occurring within the next 1 to 3 days is predicted when farmers have observed: strong wind blowing from west to east direction; the Halo (red circle around the sun or moon); croaking of frogs; half of the moon visible at night; thick and dark clouds form in the eastern side; presence of dew; movement of ants, behavior of pig, and scorching sun. Some indicators give predictions about rainfall distribution: when the moon shape is curved such that the shadow is on the left side then rain is expected to occur inland, away, from the coast; if the shadow is on the right side then rain will occur inland close to the coast; and if the shadow is on the top, rain is expected in both locations (see Table 4.2). Other indicators give information about dry spell occurrence, for example, scorpions appearing frequently on the farm indicate that rains occur more frequently, in other words, frequency of dry spell and length is reduced during that season.

Sub-seasonal and seasonal timescale indicators are used to predict rainfall amounts, start and cease of the rainy season (Table 4.3). These indicators are used for predictions beyond the two weeks' timescale. Rainfall amount prediction refers to the below and above normal rainfall occurrence. For example, above-normal rainfall is expected when: a persisting strong wind is blowing at the start of the season (Feb/March) or one month before Easter; a feeling of cold weather is experienced during Feb-March, or big black scorpions are abundant on farms. Other indicators for below normal rainfall include: if heavy rainfall is occurring at the onset of the rainy season (March-April); when season falls on a leap year. Onset of the rainy season is also predicted to be early when: harmattan winds appear early.

In summary, a rich source of data on LFK exists in Ada, Ghana. A total number of 34 LFKindicators on weather and climate forecast were identified and documented. Results revealed that LFK-indicators are associated with weather forecast timescale in the majority (22 indicators) 
followed by sub-seasonal or seasonal climate forecast timescale (12 indicators). Most indicators are used during the major rainfall season in Ada East District.

Table 4.2: Documentation of Local Forecasting Knowledge indicators for the weather timescale in Ada East district

\begin{tabular}{|c|c|c|c|}
\hline $\begin{array}{l}\text { Indicators } \\
\text { name }\end{array}$ & Indicator' Signal & Month/period & Outcome (prediction) \\
\hline \multirow[b]{2}{*}{ Wind } & $\begin{array}{c}\text { When strong winds blow from } \\
\text { the sea (usually from West to } \\
\text { East direction) }\end{array}$ & $\begin{array}{l}\text { Rainy season } \\
\text { (March-July) }\end{array}$ & $\begin{array}{c}\text { Rain is expected within } 1 \text { to } \\
3 \text { days }\end{array}$ \\
\hline & $\begin{array}{l}\text { When the wind is blowing } \\
\text { from the sea carrying dust } \\
\text { (West-East direction) with } \\
\text { high intensity of the sun }\end{array}$ & Rainy season & $\begin{array}{l}\text { Rain expected within } 3 \\
\text { days, intensity depends on } \\
\text { the strength of wind } \\
\text { observed }\end{array}$ \\
\hline $\begin{array}{l}\text { Halo (around } \\
\text { the Sun) }\end{array}$ & $\begin{array}{l}\text { If at sunset there is a red } \\
\text { circle around the sun }\end{array}$ & $\begin{array}{l}\text { Rainy season } \\
\text { (March-July) }\end{array}$ & $\begin{array}{c}\text { Rain expected within } 1 \text { to } 3 \\
\text { days }\end{array}$ \\
\hline \multirow[b]{2}{*}{ Sun } & $\begin{array}{l}\text { If high intensity of sunshine is } \\
\text { observed }\end{array}$ & $\begin{array}{l}\text { Rainy season } \\
\text { (March-July) }\end{array}$ & $\begin{array}{c}\text { Rain expected within } 1 \text { to } 7 \\
\text { days }\end{array}$ \\
\hline & $\begin{array}{l}\text { If high intensity of sunshine } \\
\text { and dust-wind blowing (from } \\
\text { West to East) is observed }\end{array}$ & Rainy season & $\begin{array}{l}\text { Rain expected within 1-2 } \\
\text { days }\end{array}$ \\
\hline $\begin{array}{l}\text { Bird (Torle, } \\
\text { Clamator } \\
\text { jacobinus) }\end{array}$ & Make a lot of sounds & $\begin{array}{l}\text { At the entrance } \\
\text { of the rainy } \\
\text { season (from } \\
\text { Feb going) }\end{array}$ & $\begin{array}{c}\text { Onset of the rainy season is } \\
\text { expected in next } 1 \text { or two } \\
\text { weeks }\end{array}$ \\
\hline $\begin{array}{l}\text { Bird (Torle, } \\
\text { Clamator } \\
\text { jacobinus) }\end{array}$ & When making sounds & Rainy season & $\begin{array}{c}\text { Rain is expected within } 1 \text { to } \\
2 \text { weeks }\end{array}$ \\
\hline $\begin{array}{l}\text { Bird } \\
\text { (Gbonyu, } \\
\text { Ploceus } \\
\text { cucullatus) }\end{array}$ & Sings a lot & Rainy season & $\begin{array}{c}\text { Rain expected within } 1 \text { to } 2 \\
\text { days }\end{array}$ \\
\hline Frog & $\begin{array}{c}\text { When frogs start croaking a } \\
\text { lot }\end{array}$ & Rainy season & $\begin{array}{c}\text { Rain is expected within } 1 \text { to } \\
3 \text { days }\end{array}$ \\
\hline Pig & $\begin{array}{l}\text { When pigs catch the grass and } \\
\text { turning around it }\end{array}$ & Rainy season & $\begin{array}{c}\text { Rain is expecting within a } 1 \\
\text { day }\end{array}$ \\
\hline Goat & $\begin{array}{l}\text { When goat are gathered in the } \\
\text { evening and run together }\end{array}$ & Rainy season & $\begin{array}{l}\text { Rain is expected within a } \\
\text { day }\end{array}$ \\
\hline \multirow[t]{2}{*}{$\begin{array}{c}\text { Moon } \\
\text { (distribution) }\end{array}$} & $\begin{array}{l}\text { When the moon shape is } \\
\text { curved such that the shadow } \\
\text { is on the left side }\end{array}$ & Rainy season & $\begin{array}{l}\text { Rain is expected within two } \\
\text { (2) weeks' time inland }\end{array}$ \\
\hline & $\begin{array}{l}\text { When the moon shape is } \\
\text { curved such that the shadow } \\
\text { is on the right side }\end{array}$ & Rainy season & $\begin{array}{l}\text { Rain is expected within two } \\
\text { (2) weeks' time inland in } \\
\text { the coastal part }\end{array}$ \\
\hline
\end{tabular}




\begin{tabular}{|c|c|c|c|}
\hline & $\begin{array}{l}\text { When the moon shape is } \\
\text { curved such that the shadow } \\
\text { is on the top side }\end{array}$ & Rainy season & $\begin{array}{l}\text { Rain is expected within two } \\
\text { (2) weeks both inland and } \\
\text { coastal part }\end{array}$ \\
\hline \multirow{3}{*}{ Moon } & $\begin{array}{l}\text { When the moon disappears } \\
\text { and before its re-appears } \\
\text { (from the West) }\end{array}$ & Rainy season & $\begin{array}{c}\text { Rain expected generally } \\
\text { after } 3 \text { days }\end{array}$ \\
\hline & $\begin{array}{l}\text { At night, if you see that half } \\
\text { of the moon is visible }\end{array}$ & Rainy season & $\begin{array}{l}\text { Rain is expected within the } \\
\text { next } 2 \text { days }\end{array}$ \\
\hline & $\begin{array}{c}\text { At night, if you see a red } \\
\text { circle (like a rainbow) around } \\
\text { the moon }\end{array}$ & Rainy season & $\begin{array}{l}\text { It may rain within the next } \\
3 \text { days }\end{array}$ \\
\hline $\begin{array}{c}\text { Worm } \\
\text { (Abotele) }\end{array}$ & $\begin{array}{c}\text { Spread all over the grass after } \\
\text { a previous rain }\end{array}$ & After February & $\begin{array}{l}\text { It will rain again that same } \\
\text { day or within 1-week time }\end{array}$ \\
\hline Scorpion & $\begin{array}{l}\text { When big black scorpions } \\
\text { appear frequently on the farm }\end{array}$ & Rainy season & $\begin{array}{l}\text { More frequent rains event } \\
\text { are expected (that is less } \\
\text { dry spell) }\end{array}$ \\
\hline Clouds & $\begin{array}{l}\text { A thick cloud appears at the } \\
\text { eastern side of the sea }\end{array}$ & Rainy season & $\begin{array}{l}\text { It will rain on the same day } \\
\text { or within } 3 \text { days, but the } \\
\text { distribution can be different }\end{array}$ \\
\hline Ants & $\begin{array}{c}\text { Carry their food or eggs to } \\
\text { their holes }\end{array}$ & Rainy season & $\begin{array}{l}\text { Rain expected within next } \\
\text { the two days }\end{array}$ \\
\hline Dew & $\begin{array}{l}\text { If from mid-night to the } \\
\text { following morning there is a } \\
\text { lot of dews falling }\end{array}$ & & $\begin{array}{c}\text { No rain is expected the next } \\
\text { day (sunny day) }\end{array}$ \\
\hline
\end{tabular}

Table 4.3: Documentation of Local Forecasting Knowledge indicators for the sub-seasonal and seasonal timescale in Ada East district

\begin{tabular}{|cccc|}
\hline $\begin{array}{c}\text { Indicators } \\
\text { name }\end{array}$ & Indicator' Signal & Month/period & Outcome (Prediction) \\
\hline Wind & $\begin{array}{c}\text { When early persisting, } \\
\text { strong winds appear } \\
\text { (harmattan winds). }\end{array}$ & $\begin{array}{c}\text { During February } \\
\text {-March }\end{array}$ & $\begin{array}{c}\text { Onset of the rainy season is } \\
\text { expected to be early as well }\end{array}$ \\
\hline Sun & $\begin{array}{c}\text { If a scorching sun is } \\
\text { observed (i.e. above } \\
\text { normal temperature) }\end{array}$ & $\begin{array}{c}\text { During the } \\
\text { Christmas period } \\
\text { (Dec) }\end{array}$ & $\begin{array}{c}\text { The upcoming season is likely } \\
\text { to be good (i.e. above normal } \\
\text { rainfall with regular rains is } \\
\text { expected) }\end{array}$ \\
\hline $\begin{array}{c}\text { When feeling or } \\
\text { pemperature } \\
\text { patterns }\end{array}$ & $\begin{array}{c}\text { experiencing cold } \\
\text { weather condition (i.e. } \\
\text { below normal } \\
\text { temperature) }\end{array}$ & $\begin{array}{c}\text { During the two } \\
\text { months to Easter } \\
\text { (February- } \\
\text { March) }\end{array}$ & $\begin{array}{c}\text { The upcoming season is likely } \\
\text { to be good (above normal } \\
\text { rainfall with regular rains is } \\
\text { expected) }\end{array}$ \\
\cline { 2 - 5 } & $\begin{array}{c}\text { If chilling weather (cold) } \\
\text { is experienced }\end{array}$ & Middle of June & $\begin{array}{c}\text { Cessation of the rainy season } \\
\text { is likely to be early }\end{array}$ \\
\hline
\end{tabular}




\begin{tabular}{|c|c|c|c|}
\hline $\begin{array}{l}\text { Rainfall } \\
\text { patterns }\end{array}$ & $\begin{array}{l}\text { When it rains heavily at } \\
\text { the onset (March-April) }\end{array}$ & $\begin{array}{l}\text { At the beginning } \\
\text { of the growing } \\
\text { season }\end{array}$ & $\begin{array}{l}\text { Cessation of the rainy season } \\
\text { is expected to be early }\end{array}$ \\
\hline Leap year & $\begin{array}{l}\text { If the season falls on a } \\
\text { leap year }\end{array}$ & $\begin{array}{l}\text { Rainy season } \\
\text { (March-July) }\end{array}$ & $\begin{array}{l}\text { The upcoming season will not } \\
\text { be good (i.e. below normal } \\
\text { rainfall expected with } \\
\text { important dry spells) }\end{array}$ \\
\hline $\begin{array}{l}\text { Insect } \\
\text { (Manubi- } \\
\text { Tetey) }\end{array}$ & $\begin{array}{l}\text { When they are abundant } \\
\text { on farms }\end{array}$ & rainy season & $\begin{array}{c}\text { The season is likely to be good } \\
\text { (above normal rainfall } \\
\text { expected with regular rains) }\end{array}$ \\
\hline Dew & If there is a lot of dews & $\begin{array}{l}\text { At the beginning } \\
\text { of rainy season } \\
\text { (March-April) }\end{array}$ & $\begin{array}{l}\text { Onset of the rainy season is } \\
\text { expected to be late }\end{array}$ \\
\hline Sky & $\begin{array}{l}\text { If there are a lot of stars } \\
\text { in the sky }\end{array}$ & $\begin{array}{l}\text { From March } \\
\text { ongoing }\end{array}$ & $\begin{array}{c}\text { Onset of the rainy season is } \\
\text { expected to be late }\end{array}$ \\
\hline $\begin{array}{l}\text { Moon } \\
\text { (Traditional } \\
\text { lunar } \\
\text { calendar) }\end{array}$ & $\begin{array}{l}\text { Counting } 7 \text { months from } \\
\text { September }\end{array}$ & $\begin{array}{l}\text { September till } \\
\text { March/April }\end{array}$ & $\begin{array}{l}\text { Onset of the rainy season is } \\
\text { expected in March 6th. When } \\
\text { rains starting before or after } \\
\text { this date then onset is } \\
\text { respectively early or late }\end{array}$ \\
\hline Scorpion & $\begin{array}{l}\text { When big-black scorpion } \\
\text { are abundant on farms }\end{array}$ & Rainy season & $\begin{array}{l}\text { It will rain heavily in that } \\
\text { particular year (e.g. above } \\
\text { normal rainfall expected) }\end{array}$ \\
\hline $\begin{array}{c}\text { Tree } \\
\text { (Odokpo, } \\
\text { honey tree) }\end{array}$ & $\begin{array}{c}\text { When start flowering } \\
\text { early }\end{array}$ & Rainy season & $\begin{array}{l}\text { Early onset of the rainy season } \\
\text { is expected }\end{array}$ \\
\hline
\end{tabular}

\subsubsection{Distribution of LFK-indicators observations collected}

The distribution of LFK-indicators observations collected using the WeatherApp is presented in Figure 4.5. The monthly distribution of indicators shows that the number of observations varies by month and with the indicator. It shows the monthly variation in local weather conditions. The difference in the distribution is also related to the number of days where observations on local indicators were collected differ per month. For example, during April data collection started on $5^{\text {th }}$ April while in July data were collected until $17^{\text {th }}$ July 2019. Over the 105 days of data collection, some indicators were seen more often than others (Figure 4.5). For instance, sun, clouds, birds, wind, dew, ants, frog, Halo were among the 8 most often observed indicators with more than 25 observations recorded; while the moon, worms, stars, pig, and scorpions were the least frequently observed indicators. Only the skills of the 8 most frequently observed indicators were analyzed. 


\section{Chapter 4}

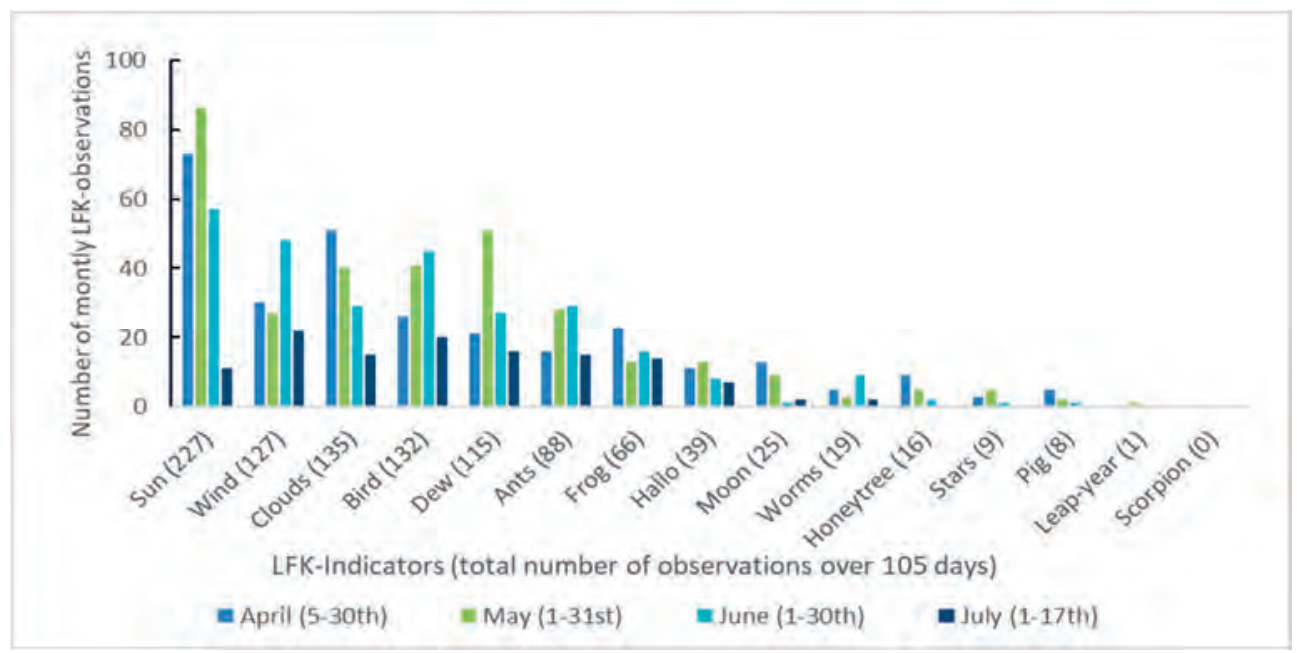

Figure. 4.5. Distribution of LFK-indicators observations collected for the period $5^{\text {th }}$ April to $17^{\text {th }}$ July 2019. Number of observation are presented (y-axis) and the total number over the whole period are shown in parenthesis (x-axis).

\subsubsection{Farmers' perception of the performance of local and scientific weather forecasts}

The perceived reliability of 24 hours local forecasts are compared with the national scientific forecasts (GMet) in Ada East District (Table 4.4). The largest share of farmers (40\% responses) believed that local forecasting knowledge is reliable compared with $22 \%$ for the national scientific forecasts. More than half of the farmers (67\%) thought scientific forecasts were somehow reliable, as compared with $45 \%$ for local forecasts. Very few and close share of farmers believed that both local (14\%) and scientific (11\%) forecast were not reliable. These results suggest that a large share of local farmers who are using both local and scientific forecasts believe that local forecasting knowledge is more reliable. Finding also implies that the majority of farmers believes the reliability of both systems is little or moderate.

Table 4.4: Farmers' perception on the reliability of daily local and scientific forecasts

\begin{tabular}{llll}
\hline Forecasting systems /Performance & Not Reliable & Somewhat Reliable & Reliable \\
\hline Local forecast (daily) & $14 \%$ & $45 \%$ & $40 \%$
\end{tabular}




\begin{tabular}{llll}
\hline Scientific forecast (daily) & $11 \%$ & $67 \%$ & $22 \%$
\end{tabular}

\subsubsection{Comparative skills between individual local and scientific forecasting systems}

Analyses of the probability of detection (POD), probability of false detection (POFD), False alarm ratio (FAR) and H-K skill score of LFK-indicators are presented together on Figures 4.6 and 4.7 for the 8 indicators. The skills of various indicators vary per month and per indicators (Figure 4.6). However, when the skill is aggregated over the 105 days period, the pattern of the best performing indicators becomes clear (see Figure 4.7). Results in Figure 4.7 show high probabilities of detection (ranging from 0.75 to 0.90 ) but also show an important level of false detection probabilities (i.e. 0.24 to 0.80 ) which contribute to reduce the skill score of the LFK-indicators. Halo, dew, frog, wind, ant, sun, and bird are respectively the most performing indicators with $\mathrm{H}-\mathrm{K}$ skill score $>0$. The highest score is the Halo with $\mathrm{HK}=0.56$.

Similar analyses for scientific forecasts from Ghana meteorological agency (SFK-GMet) and from meteoblue (SFK-meteoblue) are presented in Figure 4.7 over from $5^{\text {th }}$ April to $17^{\text {th }}$ July 2019 period. Skills in both scientific forecasting systems vary by month as in the case of LFK. SFKGMet shows an aggregated H-K skill score of 0.50 whereas the SFK-meteoblue has an overall skill of 0.59. This implies that the skill of meteoblue is higher than GMet in Ada with a difference of $\mathrm{HK}=0.09$. Also, the most performing LKF-indicator (i.e. the Halo with $\mathrm{H}-\mathrm{K}=0.56$ ) performs slightly better than SFK-GMet (i.e. H-K=0.50) but show a little less skill than SFK-meteoblue (i.e. $\mathrm{H}-\mathrm{K}=0.59$ ). 

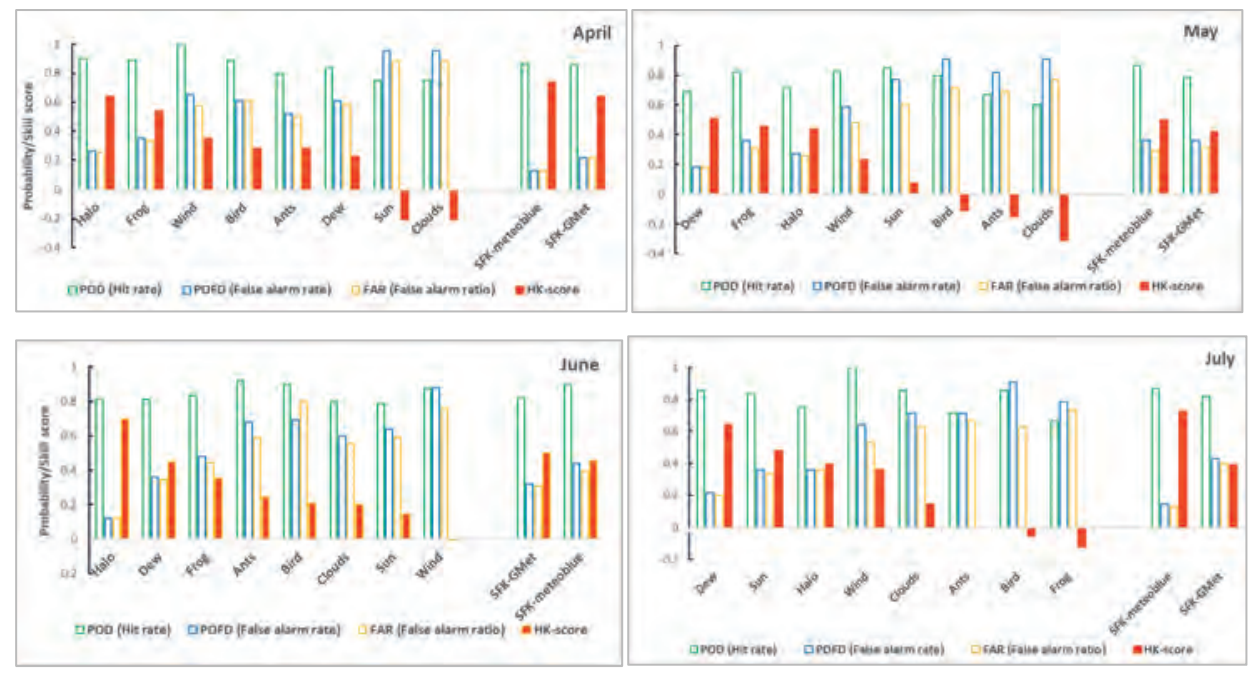

Figure 4.6. Skill of local forecast (LFK-Indicators) and scientific forecast (SFK-GMet, SFKmeteoblue) for April, May, June and July 2019. Hit rate, False alarm rate, and False alarm ratio are presented in different colors. LFK-indicator skills are assessed against gauge observations. Skills are classified from the highest to the lowest.

\subsubsection{Performance of combined LFK-indicators}

The skills of combined LFK-indicators are presented in Figure 4.8 for all possible combination scenarios together with the two scientific forecasting systems. H-K skill scores for each forecast are only presented here from the $5^{\text {th }}$ April to the $17^{\text {th }}$ July 2019 period. The figure shows that the more indicators are combined, the higher the aggregated (average) skill is. For example, the skill of individual LFK-indicators presented above (see Figure 4.7) corresponds to $\mathrm{k}=1$ and that of all eight indicators corresponds to $\mathrm{k}=8$. By combining indicators, the average skill improves from 0.22 to 0.80 for the eight indicators tested. Also, the average skill of LFK-indicator starts to surpass national and meteoblue forecasts when combining $\mathrm{k}=3$ and $\mathrm{k}=4$ elements respectively. The figure also shows that the average number of days (i.e. frequency), where a set of indicators is used simultaneously, decrease as the combination of $\mathrm{k}$ elements increases. In other words, scenarios of combined indicators with higher skills were less frequently observed by local farmers. 
Together these results provide important insights on the monthly distribution and overall performance of LFK-indicators in comparison to SFK from GMet and meteoblue. Results suggest that combined LFK-indicators can compete or often surpass scientific forecasts from GMet and meteoblue which are given for much broader area.

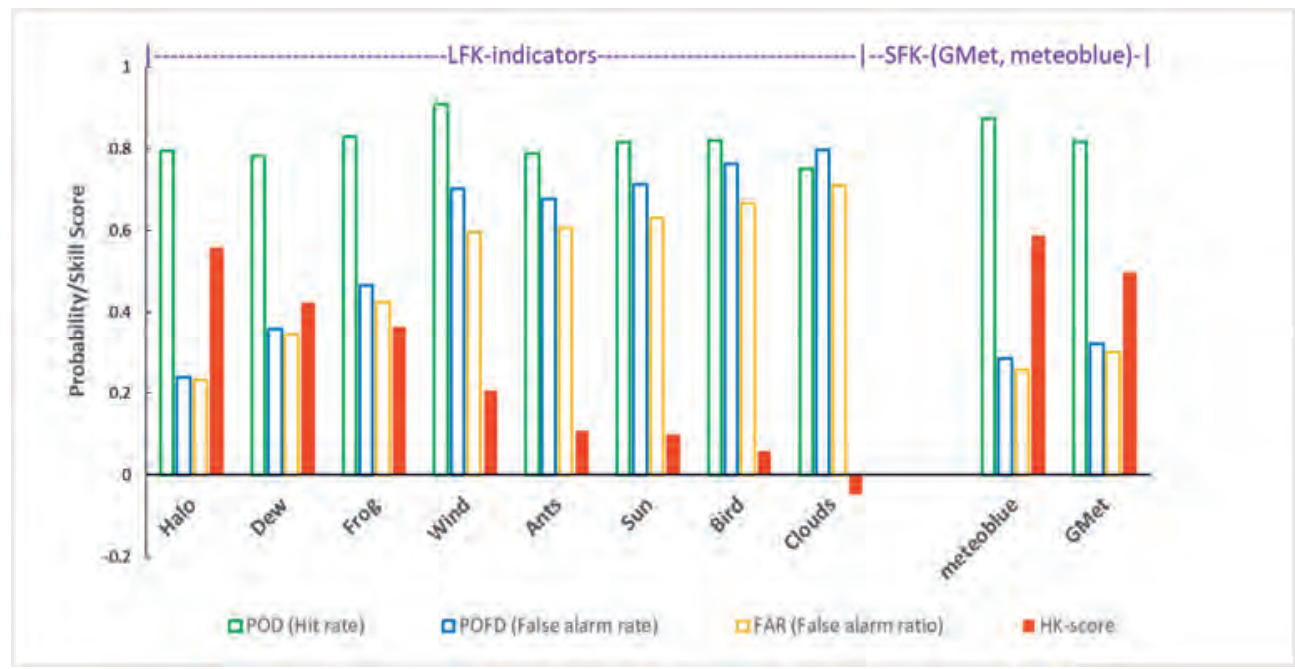

Figure 4.7. Overall skills of local forecast (LFK-Indicators) and scientific forecasts (GMet, meteoblue) over from $5^{\text {th }}$ April to $17^{\text {th }}$ July 2019 period. Hit rate, False alarm rate, and False alarm ratio are presented in different colors. Local and scientific forecasts skills are assessed against gauge observations. Skills are classified from the highest to the lowest. 


\section{Chapter 4}

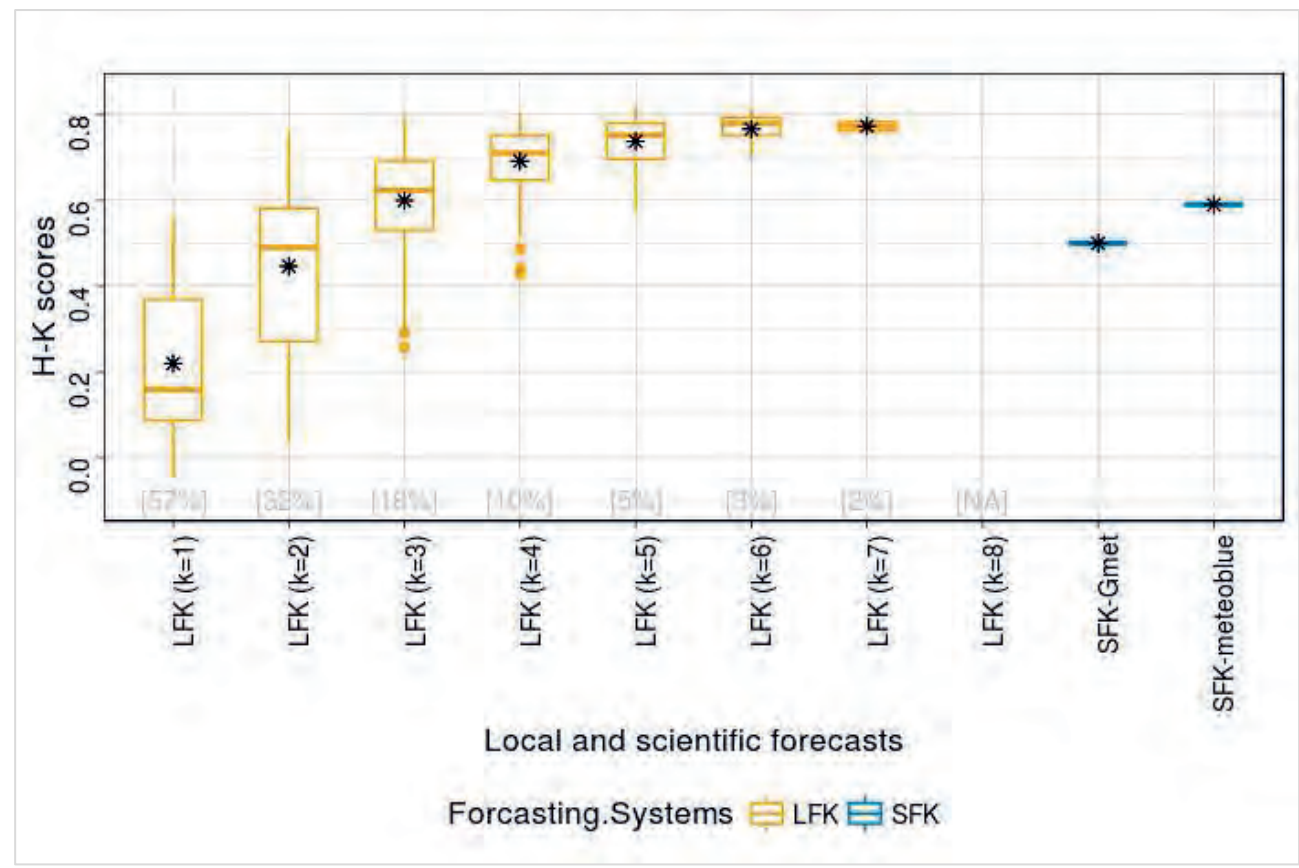

Figure 4.8. Skills of combined LFK-indicators compared with the skills of scientific forecasts from GMet and meteoblue from $5^{\text {th }}$ April to $17^{\text {th }}$ July 2019 period. $K=1,2,3,4,5,6,7$, and 8 indicate the possible combination of eight LFK-indicators observed; the combination is carried out without repetition and generate $8,28,56,70,56,28,8$, and 1 scenarios respectively. Also Boxplots represent the skill of these scenarios. (*) indicate the average skill of each scenarios. The square brackets $[\mathrm{X} \%]$ indicates the frequency (i.e. average number of days over the whole period) at which each scenario of combined indicators was observed simultaneously by local farmers. NA indicates that the scenario was not observed.

\subsection{Discussion}

\subsubsection{Documentation and skills of LFK}

Documentation of LFK showed a rich source of data in terms of amount, diversity, and forecast timescales that include both weather and seasonal timeframe. The performance of weather timescale indicators in discriminating daily rainfall occurrence varies depending on whether an individual or a set of indicators is used. If a set of several LFK-indicators is used, LFK can 
potentially predict daily rainfall occurrence better than national forecast and meteoblue that are given for a much broader area. Although scenarios in which local farmers observe several LFKindicators tend to have higher skills, such scenarios occur less frequently. These results are in agreement with the perceived reliability of local weather forecasts when compared with the national daily forecast.

The diversity of indicators is comparable to those found in other regions of Africa (Roncoli et al., 2009, Speranza et al., 2010, Radeny et al., 2019) and more particularly in Ghana (Codjoe et al., 2014). However, results achieved surpass the earlier work in Ghana (Codjoe et al., 2014) in terms of amount and diversity of indicators documented as they pertain not only to the weather but also to sub-seasonal and seasonal climate timescale predictions. Moreover, LFK outcomes (see Table 4.2 and 4.3) provide insights on tailored forecast information needs in the district: rainfall occurrence, categorical season rainfall amount, dry spell occurrence, onset and cessation of the rainy season (Gbangou et al., 2019, Nyadzi et al., 2019).

Findings on the skills imply that some LFK-indicators still stand and can even compete with advance modern forecasting systems despite the decrease in the reliability of local knowledge due to climate change and variability and due to the fast urbanization that has resulted in the loss of some local forecast indicators (Ziervogel, 2001, Ziervogel and Downing, 2004, Kalanda-Joshua et al., 2011, Balehegn et al., 2019). Hence, this study supports evidence from previous observations that local weather forecasting is still valuable for local farmers (Balehegn et al., 2019, Chisadza et al., 2015, Green et al., 2010).

\subsubsection{Integration opportunities between local and scientific forecasting knowledge}

\subsubsection{Method used to integrate local and scientific daily rainfall occurrence forecast}

Based on the statistics found for individual and combined skills of LFK-indicators (see section 4.4.5), an approach that we called "statistical integration" can be used to optimize local and modern forecasts performance by alternating both systems whenever suitable (Table 4.5). The table shows that farmers can alternate the choice of local and modern forecasting system based on the set of local indicators that are observed. For instance, with a set of more than three specific indicators observed, farmers would choose the local forecast instead of the scientific one, and, when less than three specific indicators are observed, then they would go for the scientific forecast (Table 4.5). 


\section{Chapter 4}

This approach can contribute to increment the skill for predicting daily rainfall occurrence despite the difference in scale and configuration of the two knowledge systems. It does not require the two systems to have a similar spatial resolution to make sense as in modern forecasting systems. In that sense, this integration approach offers an added value in accordance with Speranza et al. (2010) as it helps farmers select the most appropriate forecasts depending on the set of data observed/collected at the local scale. This is particularly useful when scientific forecast information available to farmers covers much larger areas and/or has fewer skills than local knowledge.

Summarizing, the 'statistical integration' which refers to an integration based on the statistics that combine a set of several indicators, was developed and applied in this study. This integration approach suggests that local and modern forecasts can be alternated on the basis of the set of local indicators observed by local farmers. This approach can improve the quality in daily weather forecast information for local farmers in Ada East District, Ghana.

Table 4.5: Proposed approach for integrating weather of local and scientific for daily rainfall occurrence in Ada East District (approach tested in this study and called the 'statistical integration'). The approach alternates local and modern daily forecasts based on the combination of a set of local forecast indicators $(\mathrm{k})$ observed by local farmers.

\begin{tabular}{ll}
\hline Number of elements combined $(\mathrm{k})$ & Choice of the weather forecasting system \\
\hline $2 \leq \mathrm{LFK}$-indicators are observed $(\mathrm{k} \leq 2)$ & $\begin{array}{l}\text { Farmers are advised to adopt the scientific forecasts } \\
\text { for decision making } \\
\text { 3 LFK-indicators are observed }(\mathrm{k}=3)\end{array}$ \\
$\begin{array}{l}\text { Farmers can adopt either local or scientific forecasts } \\
\text { for decision making }\end{array}$ \\
$\begin{array}{l}\text { Farmers are advised to adopt the local forecasting } \\
\text { system for decision making }\end{array}$ \\
\hline
\end{tabular}

4.5.2. Other integration possibilities between local and scientific forecasting systems

The rich diversity and performance of LFK-indicators create opportunities for more different integration approaches with the scientific forecasts (albeit not applied in this study). Based on the above-mentioned results, three additional approaches for integration were identified and discussed. These include (i) an intuitive integration, (ii) a patterns evidence analyses, and (iii) an updating of 
invariable LFK indicators. Table 4.6 summaries the three other recommended approaches with an example.

The "Intuitive integration" consists of complementing each knowledge system using the strength and weaknesses of the other to derive improved forecast information (Table 4.6). In this integration, scientific information on large-scale weather and climate dynamics, which is often not visible to farmers is used to enrich local knowledge. Inversely, observations on local-scale dynamics that are not visible to meteorologists can enrich scientific knowledge. The "Intuitive integration" approach can provide a much richer forecast outcome since it uses specific information available from each forecasting system to enrich the other. This can result in a higher predictive skill especially for weather timescale predictions of one or the other knowledge systems. Each knowledge system can benefit from a piece of punctual information or indicator from the other system to enhance its skills. However, it is important to recognize that intuitive forecasting is subjective and comes with limitations (Daan and AH, 1982). Therefore, good judgmental forecast requires close collaboration between well experienced local and scientific forecasters in the area to inform and update each other in time (Lawrence et al., 2006). This can be facilitated through the co-production of climate services with and for farmers.

The "Patterns evidence method" uses historical meteorological data to assess patterns in weather and climate conditions identified by local farmers through experience (Table 4.6). This can bring new discoveries of relationships and time lag-teleconnections (correlations) between local weather variables and agro-meteorological indices at a local scale. Insights from this integration approach can be useful to improve seasonal predictions by identifying, scientifically, existing lagcorrelations claim by local forecasters.

The "Updating invariable LFK-indicators" approach seeks to adjust LFK static indicators to the changing weather and climatic conditions (Table 4.6). It has similarities with the pattern evidence approach as it uses meteorological data to give insights on variability and changes related to some LFK static indicators in order to update and improve this knowledge. The method can allow taking into account indicators that have changed as a result of the climate change and variability mentioned in the previous works (Kalanda-Joshua et al., 2011, Ziervogel and Downing, 2004, Ziervogel, 2001). 


\section{Chapter 4}

All said, exploring these integrations methods can help to reduce the recurring tensions that exist between local and scientific knowledge (Briggs, 2005, Wohling, 2009) and increasing the replicability and spread of local knowledge in practice and in science.

Table 4.6: Proposed approaches opportunities (albeit not tested in this study) for integrating local and scientific forecasting knowledge.

\begin{tabular}{lll}
\hline Recommended & & \\
integration & Description & Examples \\
approaches & & \\
\hline
\end{tabular}

\begin{tabular}{|c|c|c|}
\hline $\begin{array}{l}\text { Intuitive } \\
\text { integration }\end{array}$ & $\begin{array}{l}\text { An intuitive approach consists of } \\
\text { supporting local forecasting } \\
\text { knowledge with insights from } \\
\text { scientific forecasting knowledge } \\
\text { and vice versa. This is because } \\
\text { the coastal area in Ghana is more } \\
\text { subjected to strong atmospheric- } \\
\text { sea-land interactions (Gbangou et } \\
\text { al. 2019). Ada being at a coastal } \\
\text { area, the district is affected by } \\
\text { local land-sea breeze interactions } \\
\text { due to the heating or pressure } \\
\text { gradient. Also, remote large-scale } \\
\text { disturbances such as storms or } \\
\text { thunderstorms can move towards } \\
\text { coastal zone and affect Ada } \\
\text { district. }\end{array}$ & $\begin{array}{l}\text { For example, local farmers are often unable } \\
\text { to perceive storm clouds forming far away } \\
\text { (e.g. from Nigeria or Benin) as well as its } \\
\text { momentum (See Supplementary, Figure } \\
\text { S4.2 for details). When such a strong storm } \\
\text { is located in those regions and moving } \\
\text { towards Ada, farmers might not observe } \\
\text { the cloud indicator from their location. } \\
\text { Satellite imagery data can help informed } \\
\text { local knowledge by estimating a storm } \\
\text { cloud speed and direction moving towards } \\
\text { the Ada district environment. } \\
\text { Similarly, observations on LFK-indicators } \\
\text { such as the halo, wind, and dew can be used } \\
\text { as a piece of real-time additional } \\
\text { information to informs modern weather } \\
\text { forecasts for Ada location. For instance, } \\
\text { dew observation is connected with } \\
\text { atmospheric stability (i.e. clear skies, light } \\
\text { winds) and therefore implies an absence of }\end{array}$ \\
\hline
\end{tabular}


turbulence, vertical motion, clouds, and thunderstorm precipitation.

For example, in the LFK system, cold weather experienced during the Feb-Mar period indicates an above-normal rainfall season; or if the cold weather is

(2)

Patterns

evidence from meteorological data
This approach consists of exploring hidden patterns on weather and climate conditions, identified by local forecasting knowledge, using historical scientific observations. normal seasonal rainfall; or if early cessation is associated with below-normal temperature in June. LFK indicator on rain patterns indicated that heavy rains observe in March-April is a sign of early cessation.

An interesting example, in this case, is the traditional calendar indicator used by farmers to predict a fixed date of onset by counting 7 months from September. The work done by Gbangou et al (2019) can help inform farmers that, because of climate variability and change, there has been an important shifts in the mean onset date as well as an increased variability in the year to year onset dates. This can be applied to the leap-year indicator as well. 


\section{Chapter 4}

\subsubsection{Limitation and cautious interpretation of the results}

A number of limitations are applicable to this new approach for documentation, quantitative skill assessment and integration of local and scientific forecasting knowledge. The most important one relates to LFK-indicators' observations and rainfall records that were collected during one single rainy season, and therefore do not allow for a multi-year analysis that will give more insights on the performance of LFK in Ada. However, these results reflect well farmer's long-term perception of the reliability of their indicators. To further validate our results and test the long term skills of LFK-indicators including significance tests, longer-term historical data are needed.

In this study, the performance of local and scientific forecasts are compared although they are not on the same scale or resolution. For instance, LFK is provided for the Ada East district level, while SFK-GMet forecast is provided for the coastal agro-ecological zone level (see Figure 4.2). Similarly, SFK-meteoblue is valid for a spatial resolution of $30 \mathrm{~km}$. This is because the scientific forecasts used in the area are not yet available at a finer spatial resolution. However, this does not affect the outcome of the study as findings intend to show the value of documenting and integrating LFK with modern forecast towards downscaling and improvement of forecast information.

Results of the indicators and skills cannot easily be transferred to other regions. This is because a different region/community can have different weather patterns and indicators with different performances in predicting rainfall occurrence. In other words, an LFK-indicator performing in Ada may not be present or have similar performance elsewhere. Further documentation of indicators for different regions is needed. However, the approaches for the quantitative assessment of the skills and integration can be adapted and applied anywhere.

Also, in this study, we have mainly used a scientific approach (e.g. skills assessment metrics, validation with rainfall measurements, etc.) to analyze the performance of both the local and scientific forecasting systems. And we recognize that we could have also used in the other way round a local approach to evaluate both the local and scientific forecasts performance (Balehegn et al., 2019). Further research should be undertaken to investigate the approaches for local forecast quality assessment, specific to the location of interest, and use this local method to get further insights on the performance. This can contribute to further stimulate the reconciliation between the two knowledge systems. 


\subsubsection{Practical implication for local farming and the development of climate services}

Our study shows similar results as Codjoe et al. (2014) indicating that LFKs have several practical applications for local farmers and can also contribute to improve scientific knowledge. Adopting the integration approaches of local and scientific forecasts support the idea of Deloria (1996) that scientific research can benefit from more or sometimes better weather and climate information. This can be done through a better collaboration of local and scientific communities through a coproduction process of weather and climate information. Such collaboration requires appropriate infrastructures, capacity building, and user-friendly environmental monitoring tools such as interactive mobile apps (Buytaert et al., 2014, Nyadzi et al., 2018) to facilitate the exchange, understandable and acceptability (Ingram et al., 2002).

Our work shows potential for exploring new approaches and methods to deal with challenges related to weather and climate information especially for farmers in the developing countries where meteorological observations are not often available or accessible. Moreover, collecting LFK observations can be used for continuous improvement of farmers' forecasts through the process of verification alike hindcasts used for scientific forecasting systems. If these data are collected for several years, they can help build LFK-hindcasts datasets for future studies and provide better insight for both weather and seasonal timescale predictions. This approach is built on citizen science approaches, thus the performance of local forecasts may be dependent on the education levels, experiences, engagement and motivation of the farmers involved. Therefore, local forecasts performance/quality can be improved through better engagement and training of local farmers. Improving the tools used for data collection and exchange is also important to facilitate and get qualitative data.

Documenting local forecasting has helped to reveal local forecast information' needs that can help farmers enhance their decision-making. Although this study tested only daily rainfall occurrence, many other agrometeorological indices can be predicted by LFK (e.g. onset, cessation, and dry spell) and can be used in future studies as well.

\subsection{Conclusions}

This study provides new insights into the diversity and performance of farmers' contribution to weather and climate forecasting in the Ada case study. New approaches for integrating local and 


\section{Chapter 4}

scientific forecasting knowledge are identified for future research and applications in climate service development. Local forecasting knowledge is proven to go beyond the weather time scale as it includes also sub-seasonal or seasonal time scale prediction indicators. Besides, this knowledge focusses on forecasting tailor-made agro-meteorological indices such as rainfall occurrence and amount, dry spell occurrence, onset, and cessation. In that sense, it also contributes to understanding local information needs for weather and climate service development.

The level of skills found also reveals that the local forecasting system can potentially compete with modern forecasting systems with regards to the prediction of rainfall occurrence. This is especially applicable when local knowledge indicators are combined. More importantly, local and scientific forecasting can enrich each other through several integration approaches. Although further research and development are necessary to bring more evidence and insights. Such integrated forecast information can help in developing improved climate services for and with farmers towards a better adaptation to climate change and variability in Ghana and other regions of the world. Integration can reduce the recurrent tensions between the two knowledge systems and foster the acceptability by both farmers and scientists.

\section{Acknowledgements}

This research is fully funded by the Netherlands Organization for Scientific Research (NWO/WOTRO) under the urbanizing deltas of the world program (UDW) and WaterApps (www.waterapps.net) project. My sincerest gratitude goes to Mr. Tsatu, a meteorologist from Ghana Meteorological Agency (GMet) who has been working in Ada for many years and whose experience in local weather and climate patterns has enriched this study. We also thank the Ghana Ministry of Food and Agriculture (MOFA) extension office in Ada East district for their support in organizing, translating and participating in various fieldwork activities. Finally, we would like to thank meteoblue for providing the necessary data for Ada to include in this work and in general to the WaterApps project.

\section{Appendix}

Appendix A4.1. Notes on the analysis of the skills of local forecasting knowledge indicators in predicting one-day rainfall occurrence. 
The skills of LFK-indicators are based on indicators observations and rainfall records. We looked at indicators observed by farmers and the rainfall occurrence $(\mathrm{P}>1 \mathrm{~mm})$ recorded by farmers within the next 24 hours (i.e. daily). For instance, when an indicator or a set of indicators is/ is not observed and rainfall has/has not occurred respectively within the next $24 \mathrm{~h}$, then it is a hit. Both LFKindicators and rain observations are aggregated on a daily basis. 


\title{
Chapter 5. Coproducing Weather Forecast Information with and for Smallholder Farmers in Ghana: Evaluation and Design Principles
}

\begin{abstract}
Many West African farmers are struggling to cope with changing weather and climatic conditions. This situation limits farmers' ability to make optimal decisions for food and income security. Developing more useful and accessible weather and climate information services (WCIS) can help small-scale farmers improve their adaptive capacity. The literature suggests that such WCIS can be achieved if forecast information is produced jointly by farmers and scientists. To test this hypothesis and derive design requirements for effective WCIS, we evaluated the outcomes of an experimental coproduction of weather forecasts in Ada, Ghana. The experiment involved a userdriven design and testing of information and communications technology (ICT)-based digital (smartphones and apps) and rainfall monitoring tools by 22 farmers. They collected data and received weather forecasts during the 2018/2019 study period. The results showed a positive evaluation of the intervention, expressed by the level of engagement, the increase in usability of the tools and understanding of forecast uncertainty, outreach capacity with other farmers, and improved daily farming decisions. The success of the intervention was attributed to the iterative design process, as well as the training, monitoring, and technical support provided. We conclude that the application of modern technology in a coproduction process with targeted training and monitoring can improve smallholder farmers' access to and use of weather and climate forecast information.
\end{abstract}

Published as:

Gbangou, T., Sarku, R., Slobbe, E. V., Ludwig, F., Kranjac-Berisavljevic, G., \& Paparrizos, S. (2020). Coproducing Weather Forecast Information with and for Smallholder Farmers in Ghana: Evaluation and Design Principles. Atmosphere, 11(9), 902. https://doi.org/10.3390/atmos11090902 


\subsection{Introduction}

Agriculture is a key source of food and income security in many sub-Saharan African countries (Shimeles et al., 2018, Rockström and Falkenmark, 2015). However, the sector is heavily impacted by climate variability and change (Sultan et al., 2020, Sultan and Gaetani, 2016, Gbangou et al., 2018). Future projections suggest significant risks to agriculture, even if global warming remains below the limits set by the Paris Agreement (Sultan et al., 2020, IPCC, 2019). Moreover, people involved in different agricultural water use systems throughout sub-Saharan Africa are unevenly impacted by climate variability and change (Jalloh et al., 2013, Atta et al., 2015).

Climate variability and change prompted increased demand for early warning systems for weather and climate risks, especially in developing countries, where the climate is already highly variable and threatens food security, and where adaptation capacities are low (Sultan et al., 2020, Yobom, 2020, Gbangou et al., 2019). In West African countries like Ghana, where crop production depends largely on smallholder farming and rainwater, the need for better weather and climate information systems is significant (Cooper et al., 2008, Wani et al., 2009, Vaughan et al., 2019, Sultan et al., 2020, Gbangou et al., 2019). Although much effort is made by governments and other organizations to provide such information services to farmers and water managers, the resulting systems are often of limited usefulness for local smallholders (Sultan et al., 2020, Masinde et al., 2012a). This is because many smallholder farmers in Africa need information to be more tailored to their specific needs (Gbangou et al., 2020a, van der Burgt et al., 2018, Vogel et al., 2017). Among the climate information services currently available to West African farmers, the majority are hampered by information irrelevance, incompleteness, uncertainty, and the lack of user training for a better understanding of the required technology (Vaughan et al., 2019, Sultan et al., 2020). Hence, the design of information systems needs not only to be based on the provider's ideas and principles but also to integrate local farmers' needs and knowledge in a user-driven design approach (Masinde et al., 2012a, Buytaert et al., 2014, Nyadzi et al., 2018).

The coproduction of information systems is a potential strategy for attaining adequate interaction between information producers and users, as well as to foster knowledge sharing (Byerlee et al., 2008, Lemos et al., 2018). Regarding weather and climate information systems, coproduction is increasingly recognized as a potential path to success, with several positive outcomes already documented (Zebiak, 2019, van der Burgt et al., 2018, Masinde et al., 2012a). The current study 


\section{Chapter 5}

uses the term "coproduction" to refer to participatory engagement between researchers and a group of farmers and extension agents in the design of tools and the production of weather data and forecasts (Vedeld et al., 2019). By definition, the coproduction process is built according to user engagement and needs and, thus, can facilitate the development of and access to climate services, i.e., the production, translation, and use of weather and climate information in a way that assists users in terms of decision-making and policy planning (CSP, 2011, GFCS, 2016). Such services are crucial for smallholder farmers, who are particularly vulnerable to climate variability and change because of their reliance on rainfall for farming and their limited adaptive capacity (Sarku et al., 2020, Gbangou et al., 2019).

Interactions with local farmers in Ada East District, Ghana (Figure 5.1) helped to define and predict relevant, tailor-made agrometeorological indices, such as the onset of the wet season, dry spell occurrence, and total seasonal rainfall, to support farming decision-making (Gbangou et al., 2019, 2020a). Previous research undertaken as part of the Waterapps project (www.waterapps.net) in Ada found that, due to the lack of location-specific information and limited understanding of modern forecasts (Vaughan et al., 2019, Sultan et al., 2020, van der Burgt et al., 2018), local farmers rely mainly on traditional knowledge for farming decisions. The coproduction of forecast knowledge with and for farmers can help foster trust and increase the local uptake of scientific model-based forecasting knowledge (Ingram et al., 2002). Furthermore, collecting and integrating local or traditional knowledge with scientific data can help increase credibility and improve access (Nyadzi, 2020, Gbangou et al., 2020b). Good local information can help to enhance usefulness and skills of model-based forecasts (Nyadzi, 2020). For instance, information about crop types, cropping calendars, and other local specific needs can be incorporated into models to derive relevant forecast information to enable adaptation to climate variability. Similarly, harnessing local forecasts can potentially be combined with the model's forecasts to synergize the accuracy of the combined weather and climate forecast information (Radeny et al., 2019, Nyadzi, 2020, Crane et al., 2010). As in many West African countries, Ghana's current climate information services are based on long-term modeled trends and resilience planning, regional agrometeorological bulletins, and weather forecasts at grid scales that are often too coarse to be useful for location-specific predictions (Gbangou et al., 2018, Gbangou et al., 2019). 
In this regard, modern digital technology offers opportunities for developing innovative climate information services. For example, information and communications technology (ICT) such as mobile phones, smartphones, apps, and the internet can serve as supportive tools at all stages of climate information service provision, including production, transfer, and use by end-users (Sultan et al., 2020, van der Burgt et al., 2018). The ICT interface can be designed with and for farmers to facilitate effective data collection, feedback, and interaction (Nyadzi et al., 2018). Farmers can also be engaged as citizen scientists to monitor daily and seasonal climate observations and share these with peer farmers and scientists (O'Grady et al., 2016, Rutten et al., 2017, Tinati et al., 2017, Turreira-García et al., 2018). Despite the overall limited use of ICT by local communities (Naab et al., 2019), there is evidence of a rapidly increasing digital literacy that indicates promise for ICT adoption in West Africa, particularly in Ghana (Aker, 2011, Aker and Mbiti, 2010, Zibi, 2009). The coproduction of weather and climate information services (WCIS) using digital tools could be an important means to enhance adaptive capacity and resilience of smallholder farmers in the face of climate variability. Nonetheless, there is limited practical evidence on smallholder farmers' use of ICT-based technology in coproduction processes in West Africa (Beza et al., 2017, Phillips et al., 2018, Sultan et al., 2020). Practical evidence regarding the coproduction of climate information services could orient knowledge and policy to better support vulnerable smallholder farmers (Field, 2014, Vaughan et al., 2019).

This paper reports on an ICT-based weather information service coproduction process involving farmers, extension workers, and scientists in Ada East District, Ghana (Figure 5.1), on the testing of the codesigned WCIS and evaluation of the experiment's results. Based on the evaluation findings, design criteria for such services are proposed. Extracting the design principles will help improve future WCIS for smallholder farmers in Ghana and elsewhere. The current study focuses on aspects of WCIS implementation, particularly testing of design features and the associated training, monitoring, and support provided during the testing phase of the coproduction experiment. 


\section{Chapter 5}

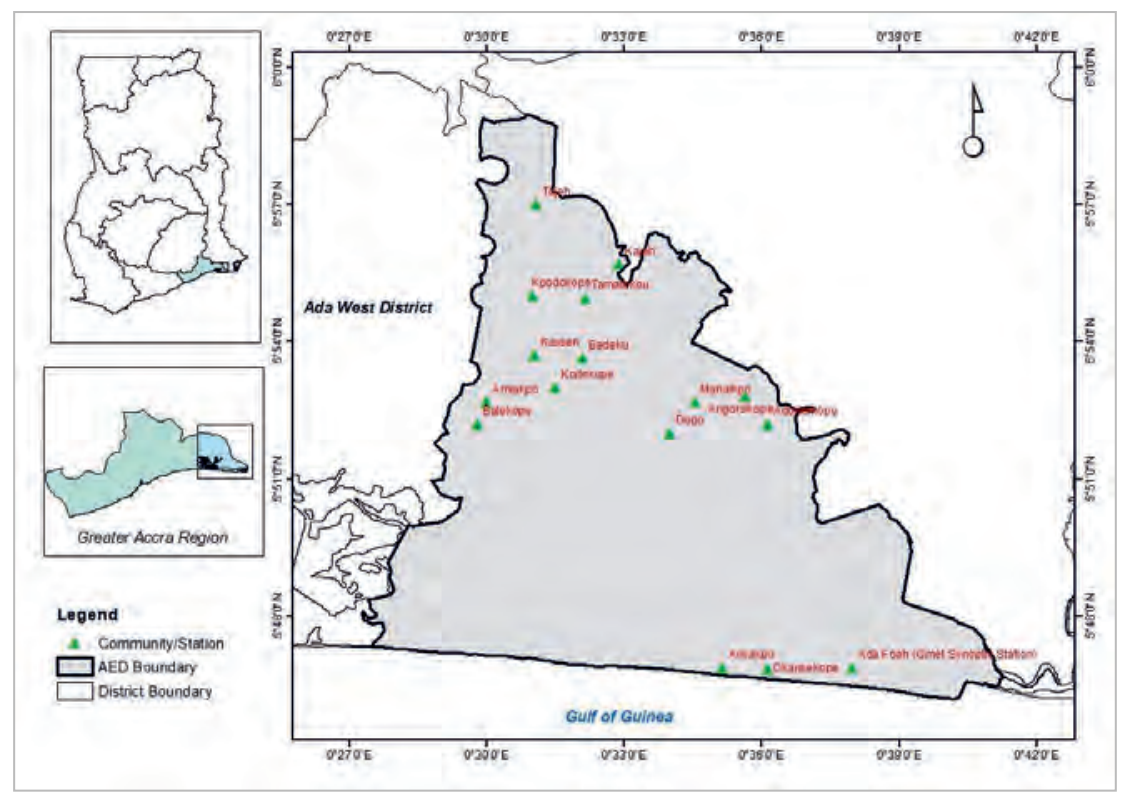

Figure 5.1. Map of the study area in the Greater Accra Region, Ghana, showing the various communities of Ada East District (Gbangou et al., 2020b).

\subsection{Materials and Methods}

This section details the methodological approach for coproduction implementation, data collection, and analysis. Figure 5.2 presents a general methodological flowchart, including the participants, inputs, and processes, as well as the outcomes evaluated. The various components of the figure are addressed below. Other results from the field study, for instance, regarding local forecast performance and motivations and barriers for farmer participation, are presented elsewhere (Gbangou et al., 2020b, Sarku et al., Accepted) and, therefore, not included in the current paper. Similarly, before the design and testing phase, farmers' agrometeorological information needs and local forecasting indicators were assessed under the Waterapps project. Results of those presurveys were discussed in Reference (Gbangou et al., 2020b). 


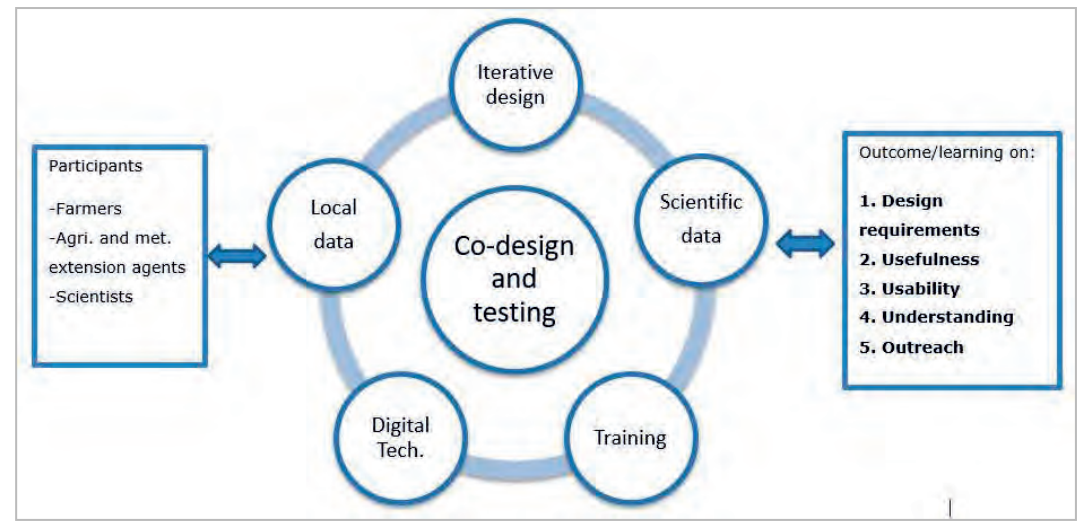

Figure 5.2. Codesign and testing of agrometeorological information services: methodological flowchart showing the cyclical and iterative process of knowledge development. Local data refer to farmers' forecasts (based on locally used biophysical indicators) and scientific data refer to model-based forecasts. Digital technology includes information and communications technology (ICT; smartphones, apps, and the internet) used for knowledge exchange and collection of rainfall monitoring data.

\subsubsection{Study Area and Participants}

Our study was carried out in the Ada East District (AED) of Ghana, which is a peri-urban district located in the Volta Delta, a coastal savanna subregion. The map in Figure 5.1 shows the location of communities with field study participants. In this region, crop growth is affected by changing climatic conditions, including greater variability in the onset date of the rainy season, more erratic total seasonal rainfall, and dry spells (Gbangou et al., 2020a, 2019, Addo et al., 2018). Unpredictable early and late onset dates and dry spell occurrence affect AED farmers' decisionmaking strategies (Sarku et al., 2020). Unlike many farmers in Northern Ghana, who have access to private weather forecast services in addition to national forecasts (Nyadzi et al., 2019, Nyamekye et al., 2019), AED farmers only occasionally receive (mainly via radio and television (TV)) daily national weather forecasts that are given for the entire coastal region and are, thus, too coarse for location-specific farming decisions (Jost et al., 2016, Limantol et al., 2016, Gbangou et al., 2019). Hence, local farmers in the area are among the most vulnerable to climate variability in Ghana. Crop production in the district mainly includes cassava, pepper, rice, maize, and tomato. These 


\section{Chapter 5}

products represent an important source of food for urban markets, especially in nearby major cities like Accra and Tema in Ghana, as well as Lomé in Togo. The district's proximity to urban areas also suggests a potential for adoption of ICT-based digital technology by farmers. Developing location-specific, tailored ICT-based forecast information services could help farmers improve their daily farming decisions and adaptive capacity.

Study participants were selected using a purposive sampling method based on experience with local forecasts, availability, gender, and willingness to participate. A group of 22 farmers, five agricultural extension agents, and one meteorological extension agent was selected. This was considered representative and sufficient for the experiment in WCIS codesign and testing, which took place in 2018-2019. Figure 5.3 presents the socio-demographic characteristics of participants, including gender, age, and education levels. In our sample there were 18 male and four female farmers. Participant ages ranged from 20 to over 60, thus including both young and older farmers. Education levels varied from no formal education to high school level, with the majority of farmers having attended middle school. Extension agents were considered key participants, as they worked with farmers in different communities and, thus, had greater outreach potential. Although the extension agents did not collect primary data, they saw, shared, and interacted with the forecasts and data collected by the farmers and scientists. The extension agents were also asked to give their opinions in evaluating the coproduction experiment.

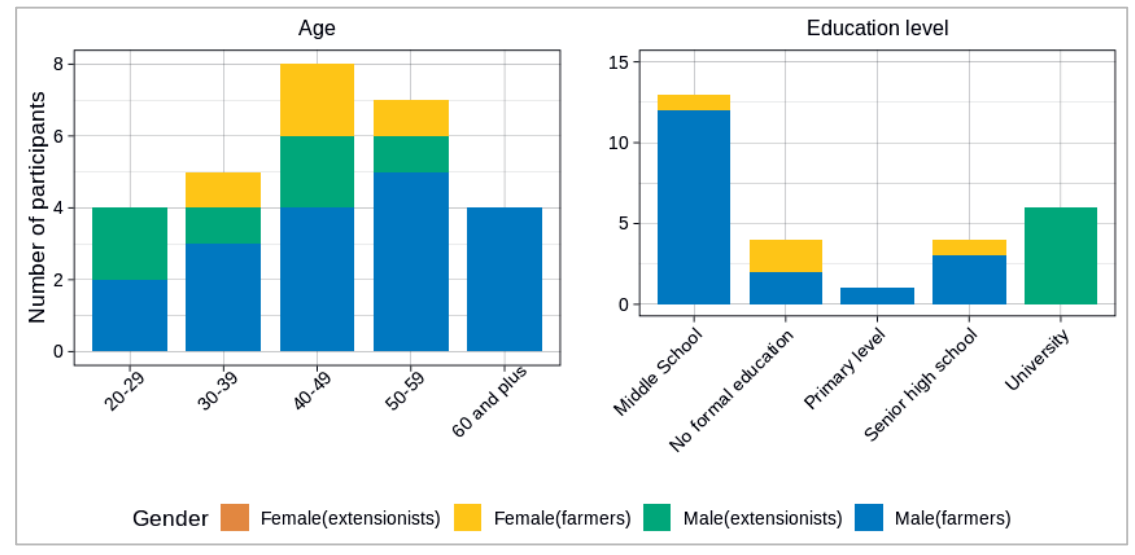

Figure 5.3. Age, education level, and gender of farmers and extension agents participating in coproduction experiment for weather and climate information in Ada East District, Ghana. 


\subsubsection{Digital and Rainfall Monitoring Tools}

Modern technology, including web-connected smartphones, mobile applications (apps), and the internet, was used to facilitate the coproduction process. We provided a smartphone with an internet data bundle from a local telecommunication company to each of the 22 participating farmers and to extension agents who did not already have one. Each phone contained (i) a weather app (http://waterapps-weatherforecast.azurewebsites.net/Account/Login) for collecting local forecast indicators and rainfall observation data, and (ii) WhatsApp (a smartphone chat app) for disseminating forecasts prepared by scientists for farmers and to enable interaction among the participants. Although this dual-app set-up was satisfactory for the coproduction experiment, future applications might seek ways to integrate data collection, dissemination, and interaction into one ICT tool. To measure daily rainfall, a total of 20 manual rain gauges were distributed to farmers from the 15 communities involved (see Figure 5.1). We ensured that each community had at least one rain gauge.

\subsubsection{Data Collection and Sharing}

Data collected by local farmers included daily local weather forecast indicators (see Table S5.1, Supplementary Materials) and daily rainfall observations (Table 5.1). Farmers collected these on a real-time basis, sharing them with the research team via the weather app. These data were then processed into daily forecasts (for details see Gbangou et al. (2020b)) and shared with all participants via the WhatsApp group. Similarly, daily scientific model-based weather forecasts (from www.meteoblue.com) were simplified and shared via the WhatsApp group. This sharing was done in real time and on a daily basis from April to July 2019.

Table 5.1. Data collected and shared via the digital tools.

\begin{tabular}{|c|c|c|}
\hline Digital Tools & & Data Collected and Shared \\
\hline $\begin{array}{l}\text { Weather } \\
\text { (collection) }\end{array}$ & app & $\begin{array}{l}\text { Daily biophysical local forecast indicators as observed and reported by } \\
\text { farmers in their various locations } \\
\text { Daily rainfall observations as measured by farmers using the provided } \\
\text { rain gauges }\end{array}$ \\
\hline $\begin{array}{l}\text { WhatsApp } \\
\text { (sharing) }\end{array}$ & group & $\begin{array}{l}\text { Daily local forecasts based on the processed and aggregated local forecast } \\
\text { indicators (Gbangou et al., 2020b) } \\
\text { Daily local forecasts derived from scientific sources (e.g., meteoblue) } \\
\text { (Gbangou et al., 2020b) } \\
\text { Daily rainfall observations as measured with the provided rain gauges }\end{array}$ \\
\hline
\end{tabular}




\section{Chapter 5}

\subsubsection{Workshops, Training, and Monitoring}

Several workshop sessions were conducted to learn from farmers what forecast indicators they typically used and to codesign the digital tool interface for the weather app. This was done following a user-driven design approach (Zulkafli et al., 2017). Hence, the researchers learned from farmers and extension agents and, with them, jointly defined and redefined features of the apps, including visuals, symbols, texts, and format. Farmers were also trained in use of the digital tools, including the smartphones, apps, internet handling, and installation and use of the rainfall monitoring tools. They were also educated on the probabilistic nature of the forecasts shared via WhatsApp group. Throughout the four-month data collection period (April to July 2019), monitoring was carried out, including field visits with farmers. A final evaluation of the whole experiment was conducted at the end of the rainy season, in July 2019. Figure 5.4 summarizes the chronology, activities, and methods used. Activities carried out in the rainy season of 2017 on local agrometeorological information needs and local forecasting indicators are outside the scope of the present study (details on these can be found in Reference (Gbangou et al., 2020b). Nonetheless, this step is included in Figure 5.4 to show the flow of the project and the link to local information needs and forecasting indicators. 


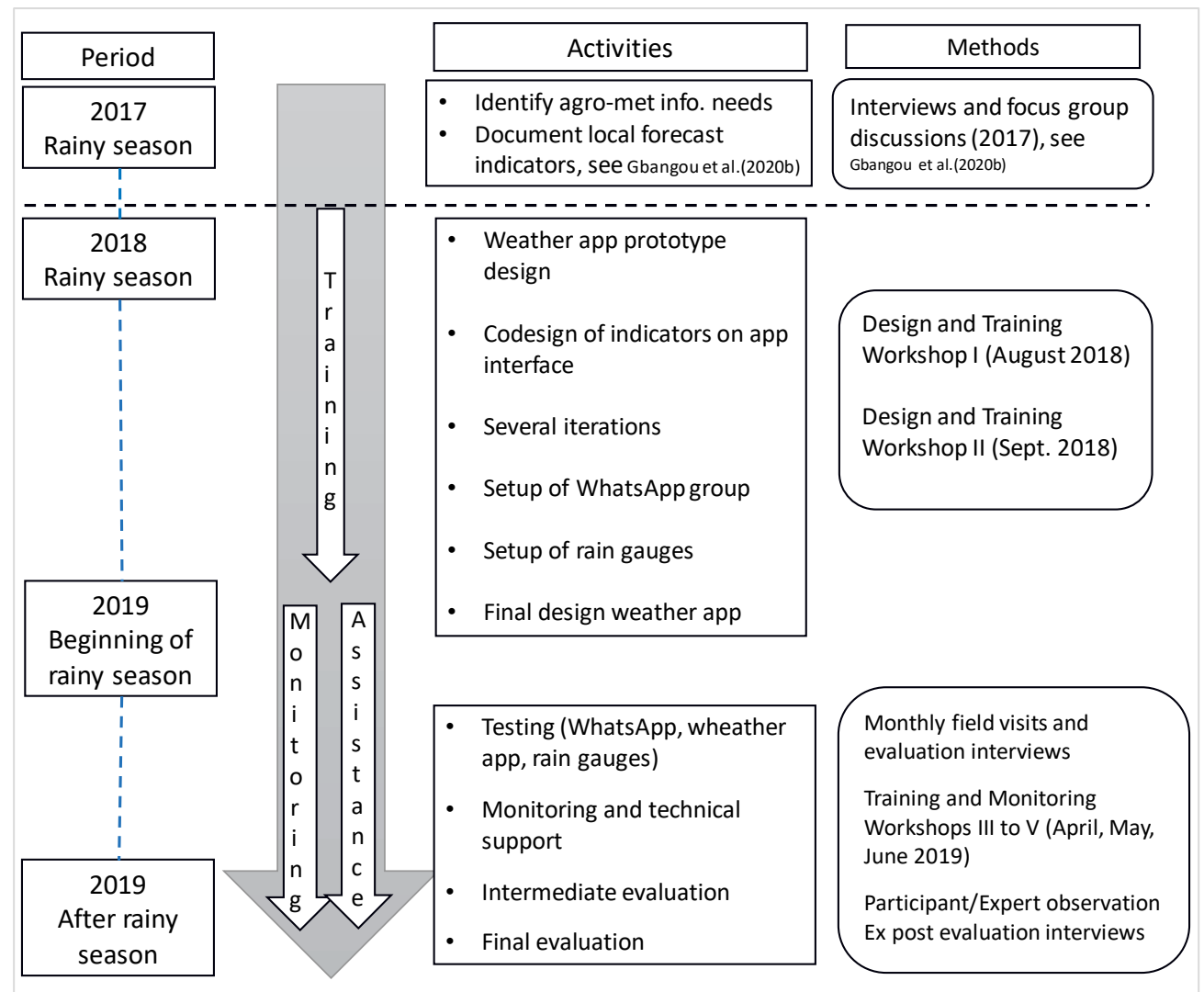

Figure 5.4. Chronology of the coproduction work carried out in Ada East District, Ghana. Activities and methods for the 2017 rainy season, above the horizontal dashed line, are covered in previous studies, as part of the Waterapps project. They are, therefore, not included in the present study.

\subsubsection{Analysis of Design and Lessons Learned}

Since the aim of this study was to improve the quality and effectiveness of weather and climate information services in the study area, an ex post evaluation approach was adopted (Tall et al., 2018). This approach was deemed suitable for the actual intervention and sought to document and analyze participants' behavior and the impacts of climate information service delivery (Tall et al., 2018, Vaughan et al., 2019). Note that the focus of the current study was on evaluating farmers' engagement and the usability and usefulness of the weather information system introduced to them, 


\section{Chapter 5}

not on examining the impacts of the intervention in terms of farming outcomes (like changes in cropping practices or yields). To determine the usability and usefulness of the WCIS and the extent to which farmers' understanding and daily management decisions improved or changed following access to the weather and climate information, we used answers to a set of descriptive questions. These covered the ability of farmers to use the information service (i.e., its usability (Collier and Dercon, 2014)), estimation of the potential relevance of the service for farmers (i.e., its usefulness (Sonwa et al., 2017)), and identification of elements of design and implementation that could lead to better outcomes (i.e., design criteria (Collier and Dercon, 2014, Sonwa et al., 2017)). The evaluation questions were posed in interviews conducted with both the participating farmers and the extension agents. Considering our small sample size, a binomial distribution approach was used to test the significance of the results. Expert (participant) observation (Bowden and Ciesielska, 2016, Chandra et al., 2017) was also applied, to better understand differences between sociodemographic groups (age, gender, and literacy) in challenges encountered by farmers during the testing phase. Based on the evaluation results and expert judgments, design principles for an effective ICT-based weather information service coproduction process were derived.

\subsection{Results}

\subsubsection{Design Phase of the Digital and Rain Monitoring Tools}

The co-development process began in 2017, with an initial exploration, by researchers, of the forecast information needs and challenges faced by Ada East District farmers in using weather and climate information (Sarku et al., 2020, Gbangou et al., 2019). ICT-based tools appropriate for weather and climate information sharing and rainfall monitoring were then designed with and for farmers and extension agents in 2018. Table 5.2 presents design features, which were iteratively adjusted and refined by participants at design workshops. The main tools used were a web-based weather app, a WhatsApp group, and rain gauges (see Figure 5.5 for illustration).

The weather app was designed to be user-friendly and allow for collection of local forecast observations and rainfall data from local farmers. These local observations included indicators that farmers typically paid attention to when assessing daily weather (see Reference Gbangou et al. (2020b)). These indicators were represented by symbols agreed upon with local farmers. The weather app also contained pictures illustrating various intensities of rainfall; these could be selected by participants (farmers) to record the amounts of rainfall observed at their locations. Each 
picture was complemented with a short descriptive text, as the majority of farmers could read (Figure 5.5a). The weather app required a login step for security purposes, although it offered the option of remembering the user's log-in details. Its interface offered easy selection of options, scrolling, and submission of data with a confirmation message sent to verify successful data submission.

The WhatsApp mobile application was installed on participants' smartphones, and a WhatsApp chat group was created so they could receive both local and scientific forecasts and interact with one another (Table 5.2). Participants received training to help them understand and interpret the probability of rainfall occurrence represented by the simple pie charts that were shared (see Figure $5.5 \mathrm{~b}$ for illustration). Farmers could also write messages or use emojis to interact with other members of the WhatsApp group. Farmers unfamiliar with WhatsApp were trained in its aim and usage. Farmers were free to share their opinions on forecast quality. They could also share their rainfall data in the WhatsApp group to help others understand rainfall distribution across the district. Both apps required participants to use the mobile internet connection included in their smartphone subscription (e.g., they needed to be able to turn mobile data on and off).

Participants were also trained by a meteorological extension officer to install, read, and record rainfall data using the manual rain gauges provided (Figure 5.5c). Only farmers were asked to record daily rainfall at their locations, which they submitted via the weather app, the WhatsApp group, or notebook records. Farmers were asked to not only be attentive and report the rainfall amount and category (low, medium, and high; see Figure 5.5a) but also to note the beginning and end times of rainfall events when these occurred.

Summarizing, the coproduction tools were designed with and for farmers to be user-friendly, and consensus on design features was sought with the study participants. The design features agreed upon with farmers in 2018 were tested in real time during the rainy season of 2019, from April to July. At the end of the rainy season, in July 2019, an evaluation was carried out.

Table 5.2. Design aspects considered in coproduction of ICT-based digital and rain monitoring tools. 


\begin{tabular}{|c|c|c|}
\hline Digital Tools & Features & Important Characteristics \\
\hline \multirow{4}{*}{$\begin{array}{l}\text { Weather app } \\
\text { (for collection of daily } \\
\text { observations on local } \\
\text { forecast indicators and } \\
\text { rainfall data) }\end{array}$} & Images & $\begin{array}{l}\text { Images for local forecast indicators were chosen } \\
\text { and refined with farmers and presented on the } \\
\text { app interface. }\end{array}$ \\
\hline & Symbols & $\begin{array}{l}\text { Symbols were used for easy selection of options, } \\
\text { such as heavy, light, low, or no rain and } \\
\text { confidence levels (see Figure 5.5a). }\end{array}$ \\
\hline & Text & $\begin{array}{l}\text { Most farmers could read (see socio-demographic } \\
\text { details in Figure 5.3); thus, short phrases were } \\
\text { used to describe, for example, signal indicators, } \\
\text { rainfall levels, and farmer forecasts. }\end{array}$ \\
\hline & $\begin{array}{l}\text { App } \\
\text { manipulation }\end{array}$ & $\begin{array}{l}\text { The app was designed for easy scrolling, } \\
\text { selection, and submission of data, with a } \\
\text { confirmation message sent upon successful } \\
\text { submission. A training session helped farmers to } \\
\text { quickly master it. }\end{array}$ \\
\hline \multirow{3}{*}{$\begin{array}{l}\text { WhatsApp } \\
\text { (for sharing daily local } \\
\text { and scientific forecasts, } \\
\text { and daily rainfall data) }\end{array}$} & Forecast graphs & $\begin{array}{l}\text { To illustrate the probabilistic nature of both local } \\
\text { and scientific forecasts, simple pie charts were } \\
\text { used to show the probability of, for example, rain } \\
\text { or no rain (see Figure 5.5b). }\end{array}$ \\
\hline & Text & $\begin{array}{l}\text { Chats among farmers, extension agents, and } \\
\text { scientists required that each participant be able to } \\
\text { read and write. Most farmers could do so. Low- } \\
\text { literacy farmers were assisted by relatives at } \\
\text { home. }\end{array}$ \\
\hline & $\begin{array}{l}\text { App } \\
\text { manipulation }\end{array}$ & $\begin{array}{l}\text { Most farmers had never used this app; thus, } \\
\text { training was provided to help them find the app, } \\
\text { launch it, and read and write messages. }\end{array}$ \\
\hline $\begin{array}{l}\text { Internet } \\
\text { (medium for transmitting } \\
\text { digital weather forecasts } \\
\text { and data) }\end{array}$ & $\begin{array}{l}\text { Set-up } \\
\text { handling }\end{array}$ & $\begin{array}{l}\text { Internet connections were preconfigured on each } \\
\text { smartphone with a subscription from a local } \\
\text { provider in Ghana. Farmers were trained in how } \\
\text { to turn mobile data on and off. }\end{array}$ \\
\hline \multirow{3}{*}{$\begin{array}{l}\text { Rain gauges } \\
\text { (for measuring } \\
\text { rainfall amounts) }\end{array}$} & $\begin{array}{l}\text { Set-up of manual } \\
\text { rain gauges }\end{array}$ & $\begin{array}{l}\text { An experienced meteorologist from the Ghana } \\
\text { Meteorological Agency trained farmers to set up } \\
\text { conventional rain gauges on their farms or near } \\
\text { their homes (Figure } 5.5 \mathrm{c} \text { ). }\end{array}$ \\
\hline & $\begin{array}{l}\text { Recording of } \\
\text { daily rainfall } \\
\text { amounts }\end{array}$ & $\begin{array}{l}\text { Farmers were trained to record daily rainfall } \\
\text { amounts at 9:00 a.m. and to specify the start and } \\
\text { end times and dates of each rainfall event }\end{array}$ \\
\hline & $\begin{array}{l}\text { Reporting of } \\
\text { daily rainfall } \\
\text { amounts }\end{array}$ & $\begin{array}{l}\text { Farmers could report the data collected in several } \\
\text { ways, including the weather app, WhatsApp, or } \\
\text { a notebook (e.g., if internet service was } \\
\text { unavailable or the telephone battery was dead). }\end{array}$ \\
\hline
\end{tabular}




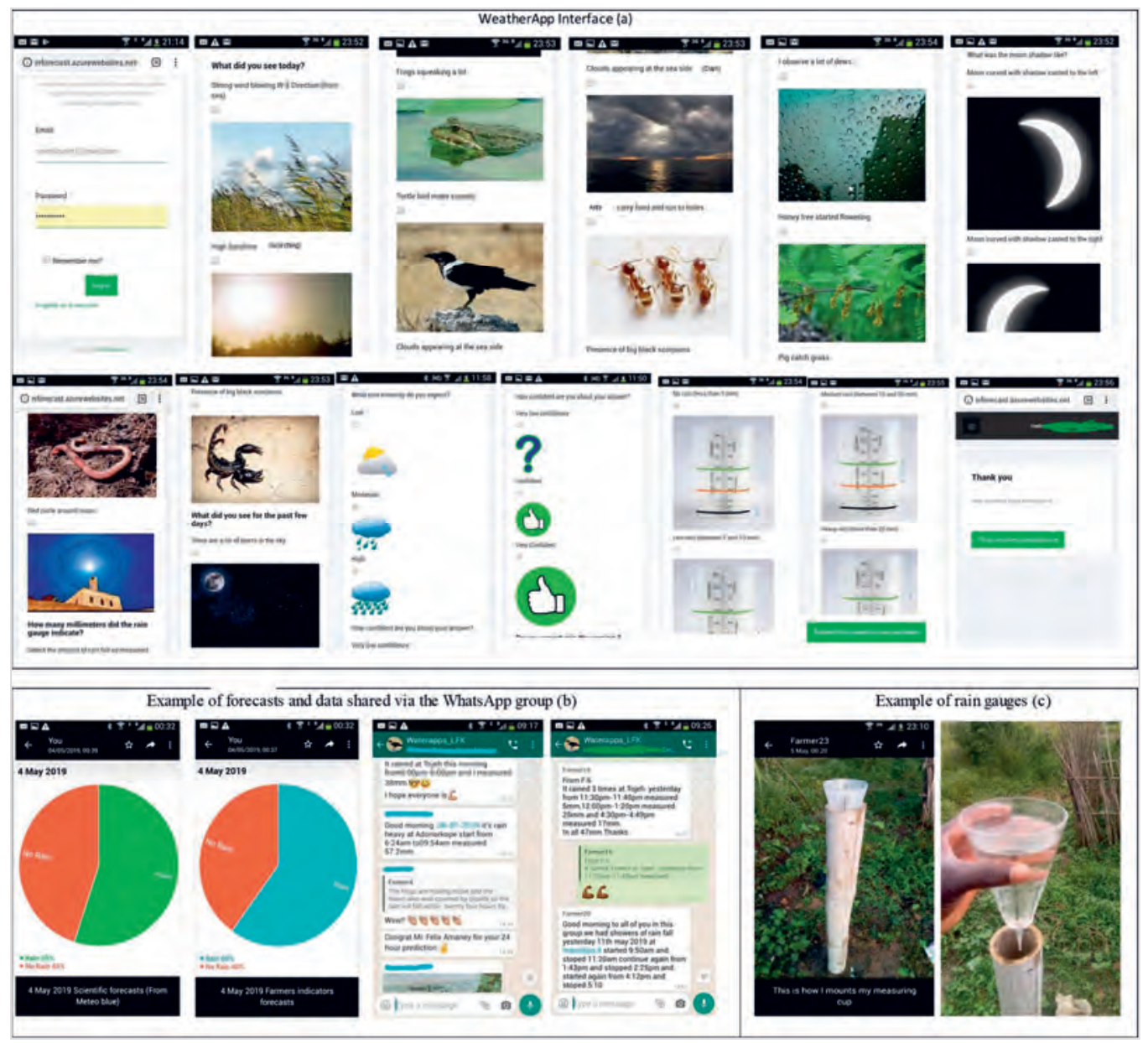

Figure 5.5. The mobile applications and rain gauges used during the coproduction experiment. These included (a) a weather app used by farmers to collect real-time data on local forecast indicators and rainfall (see Table 5.2), (b) a WhatsApp group used by participants to share data on rainfall, as well as to disseminate both local and scientific forecasts in simple pie chart format and also to interact (see Table 5.2), and (c) manual rain gauges used by farmers to record rainfall amounts (see Table 5.2).

\subsubsection{Evaluation of the Testing Phase}

\subsubsection{Participant Engagement}




\section{Chapter 5}

During the testing phase, from April to July 2019, engagement of the farmers and extension agents varied in terms of their data inputs and participation (Figure 5.6). Based on the frequency of data collection and interaction, we ranked engagement levels into three categories: low $(<33 \%)$, medium, and high ( $>66 \%$ ). Some $76 \%$ of farmers fell into the medium to high range during the four-month testing period. The high-level engagement category grew over time. Extension agents' engagement remained constant over time, meaning that they were consistently active in monitoring activities, providing feedback, and sharing knowledge with farmers beyond those involved in the experiment.

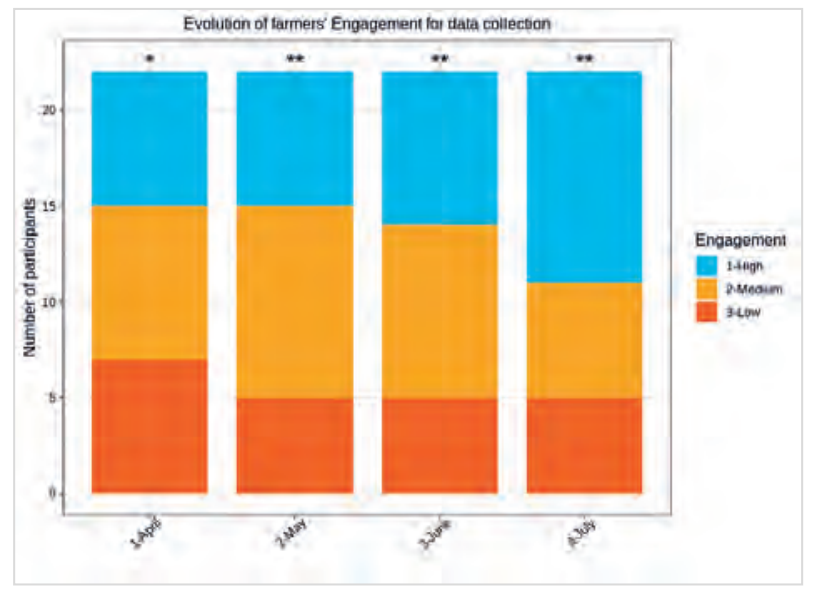

Figure 5.6. Evolution of participants' engagement based on their frequency of data collection and interaction via the digital and rain monitoring tools. Asterisks $(*$ and $* *)$ indicate the significance of the results for the combined "medium and high engagement" category at, respectively, $p<0.05$ and $p<0.01$, based on a binomial distribution test.

\subsubsection{Usability of the Digital Technology}

Farmers' ability to use the digital and rain monitoring tools was evaluated throughout the testing phase. Figure 5.7 shows participants' assessments of the usability of the various tools, before and after four months of practice. Usability of all the tools improved considerably. Nonetheless, the figure indicates some design aspects that, although improved, still needed further refinement. These included the mobile internet connection, inputting text in the WhatsApp, recording rainfall data, 
and submitting reports. A small percentage of farmers $(<23 \%)$ did not answer because they did not know or dropped out of the experiment due to low motivation or other barriers.

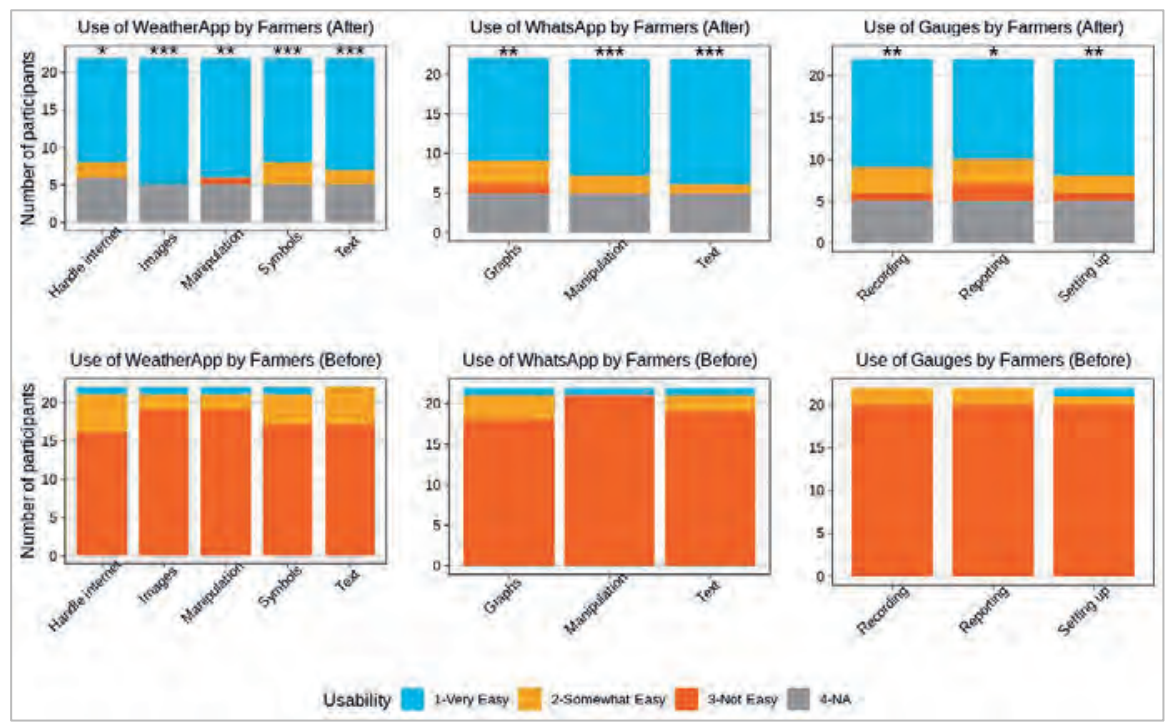

Figure 5.7. Usability of the digital and rain monitoring tools throughout the testing phase. "Not applicable (NA)" indicates participants who did not answer or dropped out of the experiment. Asterisks (*,**, and ***) indicate the significance of the results for the combined "somewhat and very easy" category at, respectively, $p<0.05, p<0.01$, and $p<0.001$, based on a binomial distribution test.

\subsubsection{Usefulness of Tools, Weather Forecasts, and Data}

The usefulness of the tools, weather forecasts, and data was also evaluated. Figure 5.8 presents farmers' and extension agents' opinions on the relevance of each component to farmers in the study area. Most participants confirmed that the design tools (i.e., mobile internet, the rain gauges, smartphones, the weather app, and WhatsApp) were at least somewhat relevant as communication tools for weather forecast information (compared to traditional channels like radio and TV). Similarly, the majority thought the local and scientific weather forecasts and data produced and shared were highly relevant to their daily farming decisions. However, some digital technology 


\section{Chapter 5}

items (e.g., mobile internet) were less appreciated by participants. This was mainly due to the low internet coverage in remote locations of the study district, which prevented some participants from using the apps effectively.

Both farmers and extension agents observed that the experiment helped farmers improve their understanding of rainfall distribution and forecast uncertainties. Furthermore, farmers' decisionmaking was said to have improved, compared to previous years (see daily decisions in Table S5.2, Supplementary Materials). Most participants noted that their understanding and decisions improved, at least somewhat (Figure 5.9).

In summary, although further improvements were still called for, the evaluation pointed to positive outcomes regarding engagement of farmers, usability and usefulness of the tools, understanding of the tools, and farming decisions. These results are significant at the $95 \%$ confidence level, considering a binomial distribution for the medium and high response categories, except for the internet category (see details in Tables S5.3 and S5.4, Supplementary Materials).

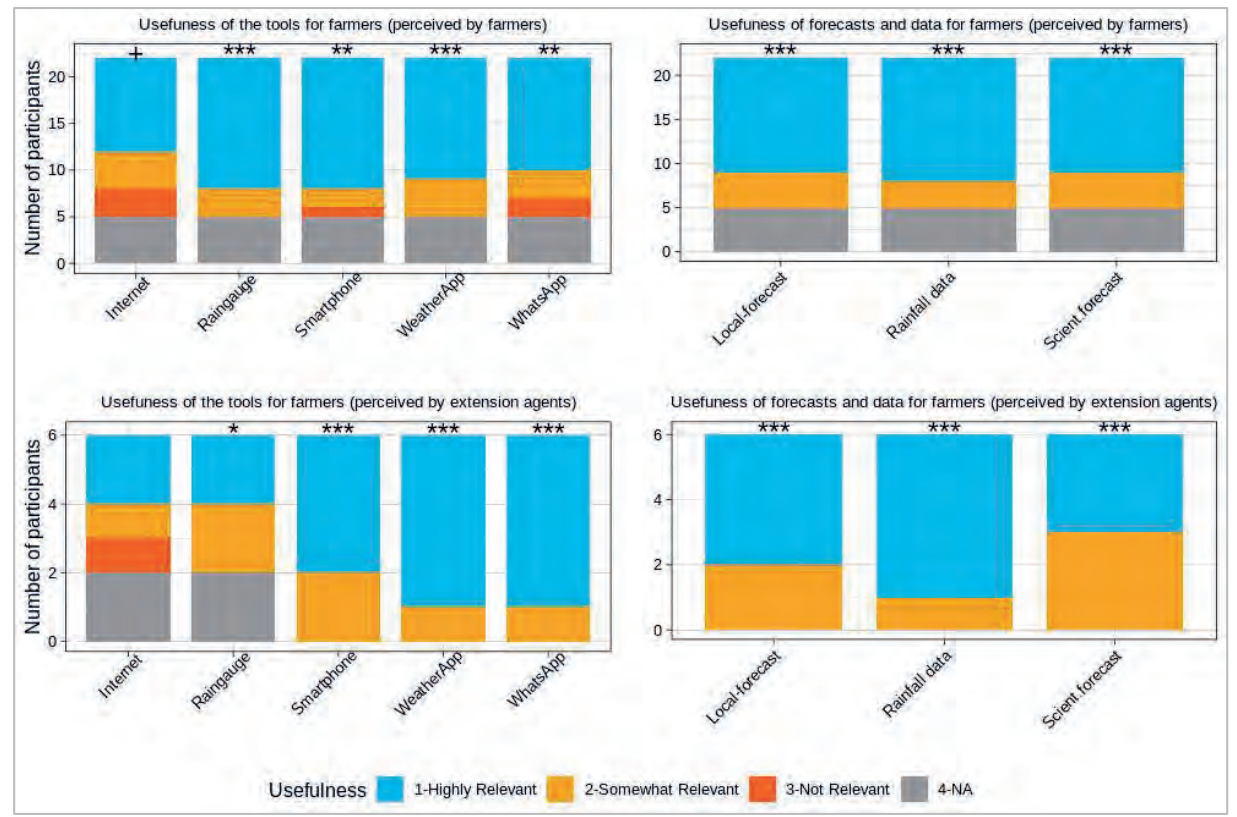

Figure 5.8. Farmers' perceptions of the relevance or usefulness of the digital tools and weather forecast information and data shared compared to channels formerly used for dissemination of 
forecast data. "NA" indicates the share of participants who abstained from answering the question or dropped out of the experiment. Farmers were asked how useful the tools and information were, while extension agents were asked to confirm this usefulness. Various symbols $(+, *, * *$, and $* * *)$ indicate the significance of the results for the combined "somewhat and highly relevant" category at, respectively, $p<0.1, p<0.05, p<0.01$, and $p<0.001$, based on a binomial distribution test.

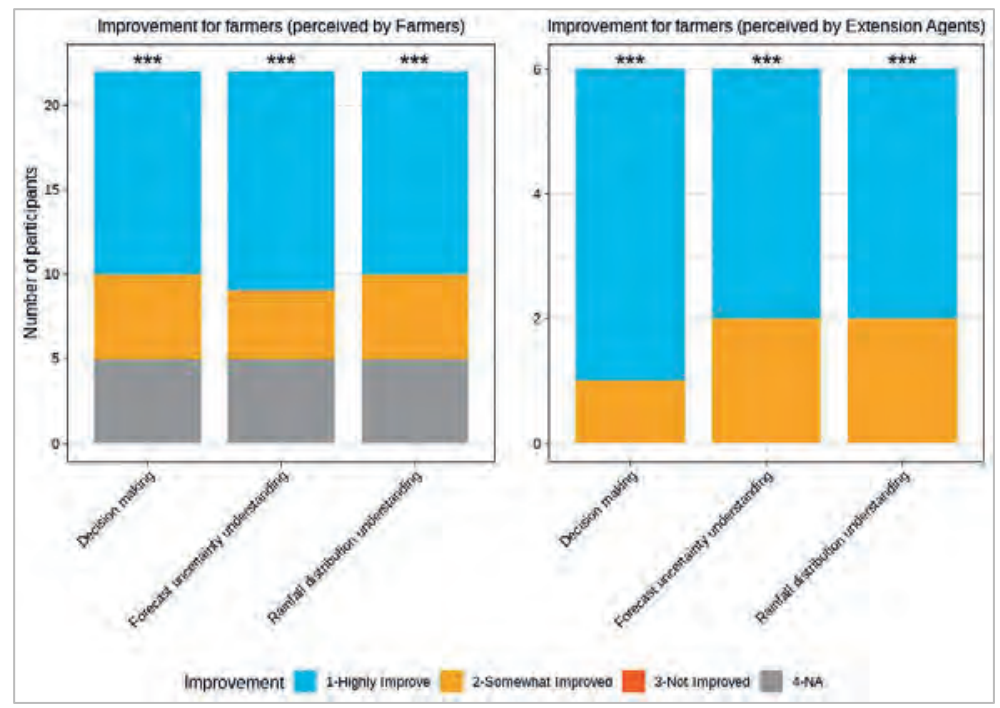

Figure 5.9. Perception of improvement in farmers' decision-making, as well as understanding of forecast uncertainty and rainfall distribution, as compared to previous seasons. Farmers were asked if their decisions and understanding improved, while extension agents were asked if they perceived any such improvement. Asterisks (***) indicate the significance of the result for the combined "somewhat and highly improved" category at $p<0.001$, based on a binomial distribution test.

\subsubsection{Outreach to Other Farmers}

The coproduction experiment reached more farmers in Ada East communities beyond those directly involved in the experiment. Table 5.3 presents the numbers of farmers with whom experiment participants (i.e., both farmers and extension agents) shared data and what they learned. In total, farmers indicated having shared their data and knowledge with more than 350 fellow farmers, while the extension agents, who were in constant contact with farmers throughout Ada East, indicated they reached out to more than 504 farmers. This implies that all participants can 


\section{Chapter 5}

spread the knowledge coproduced. It also demonstrates the importance of involving agricultural and meteorological extension agents, as they have larger networks and can transmit the coproduced knowledge to many farmers not involved in the experiment.

Table 5.3. Numbers of farmers reached indirectly, via participants in the coproduction experiment (both farmers and extension agents).

\begin{tabular}{ccc}
\hline & Farmers & $\begin{array}{c}\text { Extension } \\
\text { Agents }\end{array}$ \\
\hline $\begin{array}{c}\text { Number of participants in coproduction experiment } \\
\text { Number of farmers with whom forecast information and/or data } \\
\text { were shared. }\end{array}$ & $350+$ & $504+$ \\
\hline
\end{tabular}

\subsubsection{Monthly Monitoring and Assistance Activities}

Continuous monitoring was carried out during the testing phase to support farmers in their usage of the tools and to ensure the quality of the data collected. Table 5.4 lists several adjustments made during the process, alongside observations on lessons learned regarding design principles. Primary adjustments were to increase the frequency of tool maintenance (e.g., replacing broken rain gauges and defective phone batteries), correcting rainfall recording and reporting techniques, and advising some farmers on how to work around internet instability. These activities generated a workload for scientists of a half-day per week and one full day each month on average.

We also observed differences between the socio-demographic categories of participants that helped us to adjust and target our monitoring and assistance efforts (Table 5.4). For example, older farmers had better knowledge of local forecast indicators (see Table S5.6, Supplementary Materials) but faced more technical challenges in using the tools compared to younger farmers. Moreover, literate farmers tended to have less difficulty in handling the tools. Female and male farmers invested similar levels of time and effort in their participation in the coproduction experiment activities.

As noted, mobile internet stability varied across the district, and this particularly affected data collection and interaction of farmers in the most remote communities. Adjustments were made to 
help them address the issue. For instance, they were advised to try to reconnect on an elevated surface or, alternatively, to use a notebook to record rainfall data and local forecast indicators, and to call one of the scientists to submit their data.

Both apps (the weather app and WhatsApp) were essential for data collection and participant interaction. However, the double tools generated increased workload for both the farmers and the scientists. For instance, farmers had to keep track of two separate tools, which effectively doubled the technical challenges some faced. Researchers, for their part, had to manually process the data input via the weather app for sharing on WhatsApp.

Table 5.4. Observations from the monitoring and assistance activities during the testing phase (April-July 2019).

\begin{tabular}{|c|c|c|}
\hline Period & $\begin{array}{l}\text { Monitoring and Technical } \\
\text { Assistance Provided during the } \\
\text { Testing Phase }\end{array}$ & $\begin{array}{l}\text { Observations from the Monitoring and } \\
\text { Assistance during the Testing Phase }\end{array}$ \\
\hline Monthly/Weekly & $\begin{array}{l}\text { Weekly coaching and support } \\
\text { for farmers facing technical } \\
\text { issues related to the digital tools } \\
\text { (e.g., smartphone repairs, } \\
\text { replacement of batteries and } \\
\text { chargers, work-arounds for } \\
\text { internet and app problems). } \\
\text { Monthly field visits to check } \\
\text { the state of the rain gauges and } \\
\text { issues with their set-up, data } \\
\text { recording, and reporting (e.g., } \\
\text { two broken gauges were } \\
\text { replaced and reporting errors } \\
\text { were corrected, such as } \\
\text { emphasis on the need to specify }\end{array}$ & $\begin{array}{l}\text { - In terms of workload, the field } \\
\text { visits generated about one day of } \\
\text { work per month for the scientists } \\
\text { involved. Providing the weekly } \\
\text { technical support/coaching } \\
\text { generated about a half-day of work } \\
\text { per week. Nonetheless, these } \\
\text { monitoring and assistance activities } \\
\text { were essential to ensure continuous } \\
\text { functioning and good use of the } \\
\text { tools and to safeguard the quality of } \\
\text { the data collected. } \\
\text { Reliability of mobile internet } \\
\text { service varied across the Ada East } \\
\text { District, depending on the }\end{array}$ \\
\hline
\end{tabular}




\section{Chapter 5}

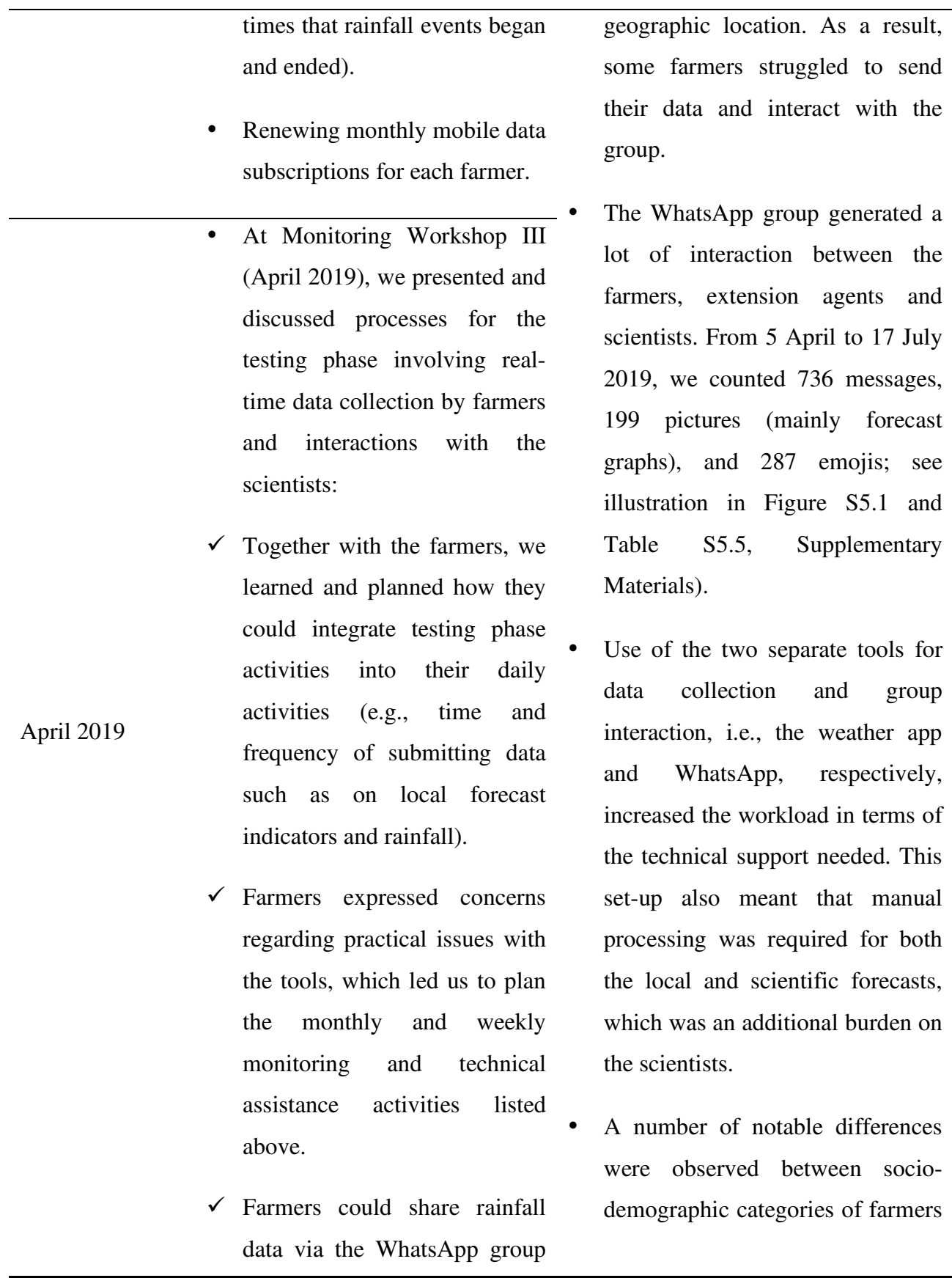


and interact that way with the participating scientists, extension agents, and fellow farmers.

- During Monitoring Workshop IV (May 2019), we reflected on the use of the coproduction tools and introduced the sharing of both local forecasts and scientific model-based forecasts via the WhatsApp group:

$\checkmark$ We determined that older and low-literacy farmers were having more difficulties and needed

May 2019

\author{
* (see supporting analyses in Table \\ S6, Supplementary Materials): \\ (a) Differences by age
}

The younger farmers generally had fewer technical difficulties (difficulty ratio of 2.92) in using the tools, compared to older farmers (difficulty ratio of 5.7). Older farmers demonstrated good knowledge and awareness of local forecast indicators.

(b) Differences by literacy level

The more literate farmers were more adept at using the tools (difficulty ratio of 3.18) compared to the low-literate farmers (difficulty ratio of 5.4)

(c) Differences by gender We decided to pay more attention to them by providing more frequent coaching during the weekly and monthly activities listed above.

$\checkmark$ A few farmers had unreliable internet coverage due to their remote location. We advised them to use a notebook to document rainfall data and, if
Although there were fewer female farmers (only 4) among the 22 farmer participants, female and male farmers were equally engaged participants (though no female farmers dropped out of the experiment), and women and men reported proportionally very similar levels of technical difficulty (difficulty ratios of 4.22 and 4.0 for male and female farmers, respectively). 


\section{Chapter 5}

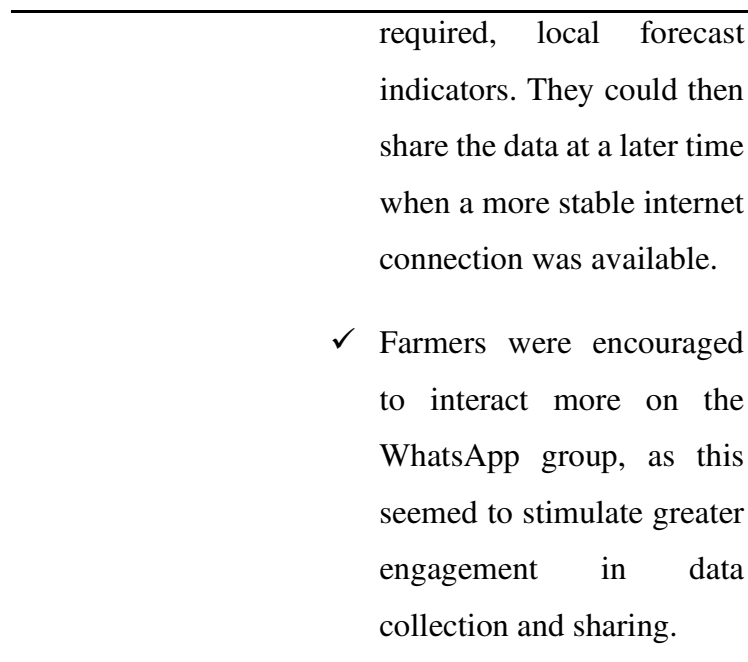

- During Monitoring Workshop

V (June 2019), we reflected on the use of the coproduction tools:

June 2019

$\checkmark$ Difficulties were similar to those identified at previous monitoring workshops, but with fewer technical challenges. Thus, we maintained the same procedures as in May.

July 2019

- We maintained the same procedures as in June.

(*) These observations are based on expert (participant) observation during the workshops and analysis of technical issue reports.

\subsection{Discussion}


The objective of this study was to evaluate a coproduction experiment and extract lessons on design principles for an ICT-based WCIS that combines local and scientific forecasting knowledge and is tailored to the needs of smallholder farmers. This section discusses the evaluation results and draws lessons on design criteria. In our evaluation of the experiment, we drew on participants' engagement in the coproduction experiment, the usability and usefulness of the tools, the weather forecasts and data coproduced, and improvements in farmer decision-making and understanding of rainfall distribution and forecast uncertainty. Our focus was on the design process, as the aim was to define critical design criteria/principles for effective ICT-based WCIS. We did not evaluate impacts in terms of farming outcomes, like changes in cropping practices or yields.

\subsubsection{Evaluation of the Coproduction Experiment}

The results include the level of engagement (i.e., $76 \%$ of farmers with medium and high levels of engagement) and the usability of the designed tools that were found to increase over time. In addition, most farmers and extension agents expressed appreciation for the relevance of the features and functionality of the tools (i.e., the weather app, the WhatsApp group, and the rain gauges) and the coproduced information (i.e., weather forecasts and rainfall data). A large share of the participants indicated that their understanding of rainfall distribution, forecast uncertainty, and farm decisions improved. Moreover, the coproduction experiment reached many farmers beyond those directly involved. A next step could be to evaluate the impacts of the coproduction experiment, for example, in terms of changes in cropping practices and yields. This was beyond the scope of the current experiment, as it would require a longer-term intervention.

Capacity building proved to be a key factor in the success of the experiment, alongside the continuous monitoring and technical support provided throughout the design and testing phases. This includes the joint definition and refinement of the app interfaces with farmers during the design phase, as well as several adjustments made during the testing phase of the experiment (see Table 5.4). The participants' engagement and interaction allowed the research team to identify and address challenges early and ensured the continuity of the experiment activities. Both farmers and scientists learned from each other as they defined the features and functionalities of the tools together. The scientists followed up by providing the participating farmers individualized coaching and technical assistance (see Table 5.4). Despite the intensive interactions between the scientists and farmers, a small portion of farmers still dropped out of the experiment. 


\section{Chapter 5}

At the start of the intervention, most of the participating farmers had no prior experience with mobile internet and smartphones, as they were still using basic mobile phone services, such as text alerts and voice messaging. The choice to use smartphones in our experiment meant that greater effort would be required to achieve the goals of the coproduction. However, the decision not to limit our experiment to the level of technology currently in use, but instead to jump ahead to the next level (smartphones) reflects our expectation of the fast development of digital technology in sub-Saharan Africa, and especially Ghana, in the near future (Aker, 2011, Aker and Mbiti, 2010, Zibi, 2009). ICT services, including internet service providers and telecommunication companies, have huge investments planned for the coming years in Ghana (Musters, 2017). The cost of mobile devices, including mobile data subscriptions, is also dropping, making them more accessible to peri-urban farmers and even to rural ones (Intelligence, 2016, Smith, 2014, Zibi, 2009). Digital devices like smartphones with mobile apps have much more power to generate interaction between scientists and farmers than short message service (SMS)-based alert services (David-West, 2011).

In line with our results, many previous studies found that coproduction is an efficient way to reach out to and engage smallholder farmers and build trust and user confidence (van der Burgt et al., 2018, Lemos et al., 2018, Nyadzi, 2020). Consistent with the literature, our results suggest that capacity building is essential to the success of coproduction (Rao et al., 2015, Vogel et al., 2017, van der Burgt et al., 2018). Capacity building is particularly important for interventions involving the testing of an innovative approach (Rao et al., 2015, Gertler et al., 2016).

Application of our findings could add value to existing climate information systems in Ghana. Indeed, today's information systems in Ghana still apply a traditional top-down approach, referred to as "one-directional". In these first-generation climate information services, researchers create and transfer knowledge and/or technology to end-users (e.g., farmers) and assume that farmers will access, understand, and adopt the information provided for improved decision-making (Musters, 2017, Nyadzi et al., 2018). This applies to the forecast information provided by the Ghana Meteorological Agency and by private information services such as Esoko and Farmerline (Nyamekye et al., 2019, Nyadzi et al., 2018). Our study went beyond this traditional approach. It used a holistic or second-generation methodology that acknowledges farmers as active participants in the production of knowledge and the codesign of innovative technology (Karpouzoglou et al., 2016, Nyadzi et al., 2018). This approach additionally promotes processes of intense collaboration 
between researchers and dedicated groups of farmers and extension agents, to build a strong foundation for technology design, weather forecast production, and dissemination of knowledge to the wider community.

The concept of joint, intensive collaboration with farmers for provision of location-specific knowledge is not new in West Africa (Kniveton et al., 2015, Tall et al., 2014a). Nonetheless, our findings extend existing scholarship (Vaughan et al., 2019, Field, 2014) by providing practical evidence that coproduction of climate information services can advance science and policies on smallholder agriculture within and outside Ghana. Our experiment showed the codesign of ICTbased tools, which harness real-time local/traditional weather forecasting knowledge, to be a significant step forward, particularly in the development of climate services that integrate traditional forecasting systems and scientific model-based forecasts. Availability of such combined services can foster acceptance and use of climate information by smallholder farmers (Roncoli et al., 2002, Roncoli et al., 2009). This could, in turn, enhance the adaptive capacity and resilience of smallholder agriculture in developing countries in the face of climate variability and change

Although implementing this approach requires efforts to build a strong collaboration with local farmers (especially during the development phase), once codesigned, the information service can be scaled up relatively quickly. Another limitation is the need for traditional forecasting knowledge to be local-specific, meaning that, while the information service designed may be good for the target community, it may not be wholly transferable to other regions within or outside Ghana.

Our overall results suggest that the use of modern technology in a coproduction process, with targeted training, can improve access to and use of weather forecasts by smallholder farmers. Currently, such an approach is mainly applicable in peri-urban areas of Ghana, like the Ada East District, or in rural areas with basic ICT infrastructure, particularly internet service and electricity. However, implementation in other remote rural communities will likely be possible in the near future, considering the fast growth of ICTs and internet access in Ghana and West Africa overall (Zibi, 2009).

\subsubsection{Design Criteria for Weather and Climate Information Services for Smallholders}




\section{Chapter 5}

Our research demonstrates that digital and rainfall monitoring tools can be codesigned with userfriendly features (e.g., visualization with symbols, Table 5.5) and tailored to smallholder farmers' needs. It also highlights the importance of appropriate training and monitoring throughout the design and testing of information systems for farmers, particularly if target farmers differ in literacy levels, ages, and locations (see Figures 5.1 and 5.3). Our coproduction experiment's use of two different apps and multiple data sources proved to be hectic for both scientists and farmers. In the future, we recommend combining the functionality of the weather app and WhatsApp in a single app that offers users the ability to both record data and interact. An additional improvement would be to process the forecasts and data from both local sources and scientific models by algorithms integrated into the back-end design of the single app. This would reduce the data processing, training, and monitoring workload. Nonetheless, for the purpose of this experiment, and considering limitations of time, the current set-up was sufficient for learning design principles for an effective WCIS. Additionally, involving young farmers and balancing gender would seem important for sustainable knowledge sharing. Particularly, mixing age groups can foster knowledge transmission between generations.

In designing a WCIS, it is important to focus on a smaller but dedicated group of intensive users who will form the basis for wider dissemination in their communities. This is especially because of the workload and the cost related to tool training, monitoring, and assistance, which require the coproduction investments to be optimized to ensure sustainability in future applications. The focus can then be on a representative but an optimal sample size of participants (especially farmers who are collecting the data, as well as extension agents) and with attention paid to the good use of tools and quality of the data (Table 5.5). Coproduction requires investment of sufficient resources to allow for targeted technical support to ensure the continued engagement of participants and guarantee the quality of the data collected. The coproduced information can then be made publicly available in the district. Regarding outreach, the current study found that extension agents had bigger networks and were good disseminators of forecast information. Although "extension-tofarmer" outreach was higher than "farmer-to-farmer" outreach in our case, the latter remains an important channel for reaching other farmers in the community. Farmer-to-farmer dissemination has the potential to spread agricultural technologies among smallholder farmer communities (Kiptot et al., 2006). However, more research is needed to understand and determine the impact 
and effectiveness of the "farmer-to-farmer" dissemination route for weather and climate information.

The lessons drawn from the coproduction approach used in this experiment are transferable to other regions under certain conditions (Table 5.6). Internet availability is an important one, as the realtime collection of forecast indicators and rainfall data from remote locations requires reliable internet coverage. This was one of the reasons why we selected a peri-urban region as our study area. Furthermore, the indicators used by farmers to forecast the weather and climate will differ depending on the region/district studied and, therefore, need to be adjusted for each.

Results from the current study advance research on the development and application of WCIS for smallholder farmers. Our coproduction experiment also contributes to other ongoing studies and to mobile app development for smallholder farmers. It demonstrates how local or traditional forecasting knowledge can be harnessed in real time and combined with scientific model-based forecasts for Ada East District, Ghana (Gbangou et al., 2020b). Additionally, the study helps to examine and understand the motivation and barriers to the engagement of local farmers for the same district in a follow-up study (see Reference Sarku et al. (Accepted)). Moreover, the design lessons learned from this coproduction experiment, combined with related research outputs, will help to further optimize the design of the two-way information systems within a single app, which is now under development and provisionally called "FarmerSupport" (http://www.waterapps.net/en-us/ghana-updates/farmersupport-mobile-app-now-online/).

Defining a strategy to sustain the coproduction process was found to be a critical design principle (Table 5.6). In this regard, it is important to reflect on WCIS sustainability and inclusiveness. For example, together with local authorities, roadmaps that can be adapted to local needs can be developed for establishing coproduction processes even in the absence of external research-driven projects. In the present study, we sought, with the acquiesce of local stakeholders such as the district assembly, extension department, and farmers (EVOCA and Waterapps, 2019), to create a sustainable business model. This was another factor that prompted our selection of a target farming community in proximity to an urban market outlet. Similar initiatives could involve collaboration between farmers and social enterprises. Moreover, local enterprises could elaborate a win-win business model around the coproduction process, connecting with partners such as government institutions, universities, agricultural insurance companies, and nongovernmental organizations to 


\section{Chapter 5}

ensure the sustainability of activities and outputs. However, this is not the only way to sustain the coproduction process. Prior research (Chandra et al., 2017, Oxfam, 2015) found that climateresilient field schools (CrFSs) provide a fruitful environment for the coproduction of locationspecific knowledge such as weather and climate information for smallholder farmers. CrFSs involve multilevel institutional actors (Chandra et al., 2017) that help to cover the costs of the coproduction process. However, barriers in terms of mismanagement and financial constraints need to be addressed for effective application of the farmer field school strategy (Chandra et al., 2017).

Table 5.5. Recommended design criteria or principles (development phase) for creating an effective weather and climate information system (WCIS) with and for smallholder farmers, combining local and scientific-based forecasting knowledge.

\section{Design Criteria Recommendations}

Defining the goal of the WCIS is important for design tailoring. The

(2) Goal of coproduction of a weather information service
WCIS designed in our experiment used ICT-based tools and engagement with farmers, extension agents, and scientists to collect local forecasts and weather indicators (with rainfall data for validation), combined with scientific model-based forecasts and group interaction.

The ICT-based tool should have a simple and clean design with emphasis on visualization. Consensus and visual design facilitate
(3) User interface of the application (front-end and back-end design) understanding by low-literacy farmers. Additional voice messages can be used to further facilitate farmers' understanding. The twoway information sharing system (i.e., both sending and receiving data and forecasts) could be integrated within a single application that uses algorithms in the back-end design which automatically process and display forecasts.

(4) Capacity building of both farmers and Training is necessary to learn from farmers and ensure appropriate research scientists design, good usage of tools, and the quality of the data collected. Training can be delivered through workshop sessions with farmers. 
(5) Monitoring and technical assistance during the development phase
During the development phase of the information service, monitoring and technical assistance are important to ensure appropriate use of tools and quality of the local forecast knowledge and data, as well as coaching to keep the participants motivated. Monitoring and technical assistance also helps in detecting problems and making the adjustments needed to solve the technical and non-technical issues that arise.

Sample size is important. At least one farmer should be included from each community targeted. This will help achieve a good

(6) Sample size of the distribution of the dataset across the district or area considered. We coproduction participants also learned that availability, knowledge, and engagement are more important for the quality of data than having a large number of farmers. However, the coproduced information can be shared with a larger group of farmers in the district.

We learned that it is important to include both older and younger farmers in the coproduction process and to balance gender as much

(7) Socio-demographic characteristics of the coproduction participants as possible. This facilitates knowledge harnessing, sharing, and transfer between generations. It is also important to include agricultural and meteorological extension agents in the coproduction process, as they are in contact with a large network of farmers and, thus, can boost sharing of the results.

Table 5.6. Recommended design criteria or principles (in the scaling-up phase) for creation of an effective weather and climate information system (WCIS) with and for smallholder farmers, combining local and scientific knowledge.

\section{Design Criteria Recommendations}

(1) Trade-off between

Costs are involved in the acquisition of tools (e.g., smartphones and rain gauges), in providing training sessions, and in monitoring and 


\section{Chapter 5}

\begin{tabular}{ll}
\hline cost (investment) and & lending assistance to farmers to ensure appropriate usage of tools \\
quality of intervention & and the quality of data and forecasts. To optimize these \\
& investments, we recommend intensifying the coproduction \\
& intervention within a limited but representative group of farmers \\
& and extension agents (see notes on sample size and socio- \\
& demographic characteristics in Table 5.5). This will help ensure the \\
& quality of the data and its continuous improvement. The \\
& coproduced information can be made available and disseminated \\
& publicly in the targeted district.
\end{tabular}

This case study found that extension agents played a key role in

(2) Dissemination of weather and climate information

(3) Transferability of the design criteria to other areas dissemination of weather forecast information, as they were in contact with a larger network of farmers. This demonstrates that both farmers and extension agents involved in the experiment can provide a base for sharing knowledge across the communities of the district.

The design principles can be applied to other areas where local or traditional forecasting knowledge exists and can be used to boost uptake of scientific model-based weather and climate information However, internet coverage is essential for real-time data collection. Moreover, location-specific information needs have to be identified first. Moreover, local forecast indicators will vary from place to place, and need to be identified for each new target community.

Regarding sustainability and inclusive development, it is important to reflect on the way forward with local authorities and to choose

(4) Sustainability and inclusiveness together an appropriate approach for scaling up. For example, as a follow-up to this study, we decided together with district authorities to create a business model for development of an app that combines the functionalities of the two apps used in this experiment. That app 


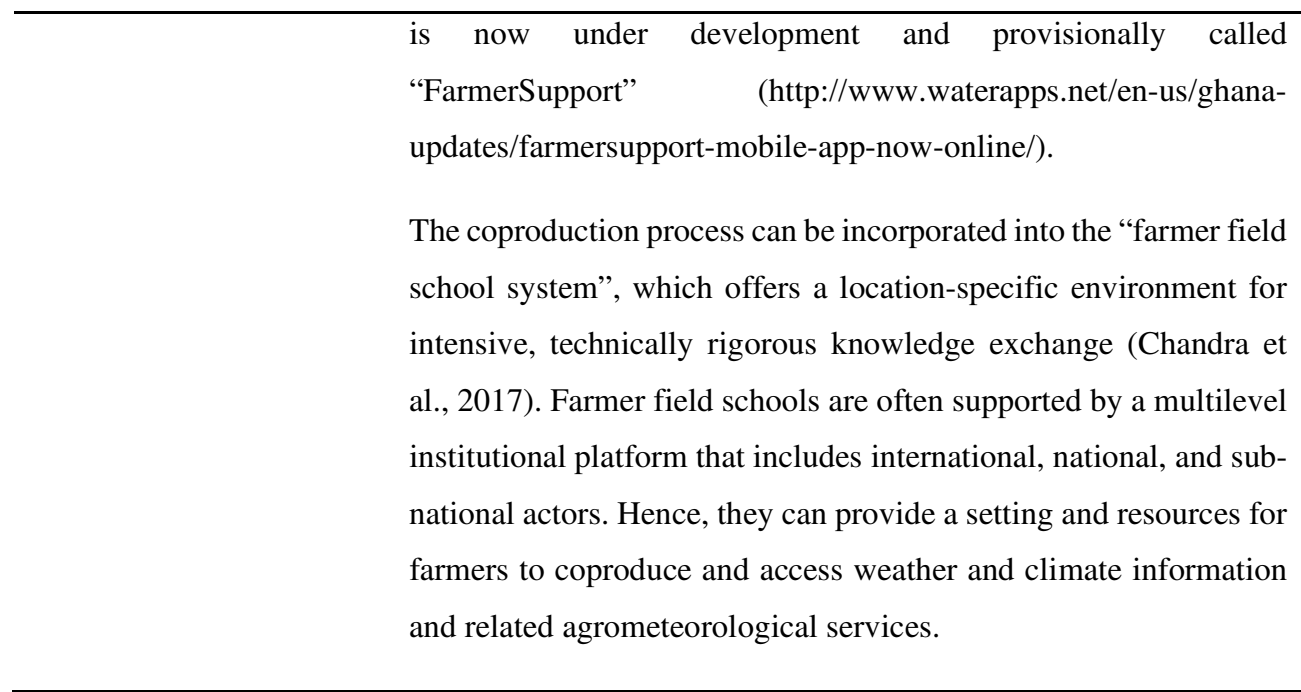

\subsection{Conclusions}

This study evaluated an experimental coproduction process for ICT-based weather forecast information services developed with and for smallholder farmers in Ada East District, Ghana. It also identified several lessons for similar interventions in the future. In particular, our research yielded two main insights related to the value of coproduction and its implementation. Firstly, the research demonstrated that digital tools (smartphones and apps) and rainfall monitoring tools with simple interfaces, designed with and for smallholder farmers, can lead to useful and usable weather forecast information services. The tools employed offered a unique opportunity for farmers and researchers to collaborate, for real-time collection of local or traditional forecasts and data, and for processing and combining local knowledge with scientific model-based forecasts. The Ada East case study further demonstrated that coproduction of a WCIS can facilitate farmers' access to and acceptance of weather and climate information and promote better understanding of forecast uncertainties, leading to improved farming decisions. However, longer-term changes in yields and livelihood assessments are needed to prove the real effectiveness of the coproduced WCIS. Our findings suggest that a coproduced information service is more likely to be accepted and used by vulnerable smallholder farmers in the study district. 


\section{Chapter 5}

Secondly, our study advanced understanding of design principles for a new generation of climate information services tailored for smallholder farmers. Coproduction of an ICT-based WCIS was found to require intensive collaboration between scientists and a dedicated group of farmers and extension agents. Capacity building was needed, alongside continuous monitoring and technical support during the design and testing phases. If a WCIS is built on both local and scientific forecast knowledge, it has more chance to be accepted, understood, and used by smallholder farmers. Integrating WCIS into agricultural policies and decision-making would further enhance the adaptive capacity of smallholder farmers in developing countries. These findings will also be of interest to the growing research community studying the integration of traditional forecasting systems into modern climate information services.

Supplementary Materials: The following are available online at www.mdpi.com/xxx/s1: Figure S5.1. Sample photos of the smartphones used by farmers and extension agents; Figure S5.2. Statistics on emojis shared in the WhatsApp group; Figure S5.3. Details on the integrated app developed under the Waterapps project (based on lessons from the present study), which is available on the Google Play store:

https://play.google.com/store/apps/details?id=com.spacewek.farmersupport ; Table S5.1. List of the local forecast indicators for the daily rainfall forecast at Ada East district used in the WeatherApp (adapted from Reference Gbangou et al. (2020b)); Table S5.2. Farming decisions that the coproduced information helped to support. It gives the percentage of decisions that were more of interest by the 28 participants (22 farmers and six extension agents); Table S5.3. Significance of the results on the engagement, usability, usefulness, understanding, and decision improvement when considering a binomial distribution for the medium and high categories of responses (farmers); Table S5.4. Significance of the results on the usefulness, understanding, and decision improvement when considering a binomial distribution for the medium and high categories of responses (extension agents); Table S5.5. Count of messages, pictures, and emojis exchanged via the WhatsApp group; Table S5.6. Analysis of the technical issues reported by age, gender, and literacy levels from a total of 92 technical issues recorded during the testing phase.

Author Contributions: Conceptualization, T.G., E.V.S., and F.L.; methodology, T.G. and E.V.S.; data collection and analysis, T.G. and S.R.; writing_original draft preparation, T.G.; writing- 
review and editing, T.G., S.R., E.V.S., L.F., G.K.-B., and S.P.; project administration, E.v.S., F.L., and G.K.-B. All authors read and agreed to the published version of the manuscript.

Funding: This research is part of the WATERAPPS project (http://www.waterapps.net/) and is funded by the Netherlands Organization for scientific research (NWO/WOTRO) under the Urbanizing Deltas of the World (UDW) program, grant number W 07.69.204.

Acknowledgments: This research was fully funded by the Netherlands Organization for Scientific Research (NWO/WOTRO) under the urbanizing deltas of the world program (UDW) and WaterApps (www.waterapps.net) project. Our sincerest gratitude goes to the farmers of Ada East District communities who contributed to local data collection and are the holders and custodians of this information. We also thank the Agriculture and Development Unit, Ada East, Ghana for their facilitation of the coproduction set-up. 


\section{Chapter 6}

\section{Chapter 6. Synthesis}

This chapter presents a general discussion and main conclusions of the research. Section 6.1 recaps the answers to the research questions. Section 6.2 reflects on (i) the methods developed to tailor scientific forecasts to smallholder farmers' needs, (ii) the methods and approaches used to assess forecast performance and to combine local and scientific forecasting knowledge, and (iii) design features and implementation of an effective ICT-based climate information service tailored for smallholder farmers. This is followed, in section 6.3 , by a discussion of the strengths and limitations of the research. Sections 6.4 and 6.5, respectively, reflect on the scientific and societal significance of the research with regard to WCIS development for smallholder agriculture in Ghana, and developing countries in general. Section 6.6 draws final conclusions, and makes recommendations for future research in the field.

\subsection{Introduction: Research objectives and main findings}

Smallholder agriculture is crucial for the food and income security of farmers in Ghana (Kanu et al., 2014). Currently, most smallholders have limited access to weather and climate information to support farm decision-making and to help them take appropriate action in the face of weather and climate shocks (Shimeles et al., 2018, Jost et al., 2016). The overall aim of the research presented in this thesis was to identify ways to improve the quality of weather and climate information for smallholder farmers, and to determine how such information could be made more accessible and useful for farmers. To this end, I formulated four research questions. The first two questions concerned the tailoring of scientific, model-based forecasts to meet local farmers' needs. The second two questions regarded the integration of local and scientific forecasting systems and design principles for an effective ICT-based climate information service tailored for smallholder farmers.

Each of these research questions was addressed in a separate scientific article, presented in this thesis as chapters 2-5. This section recaps the major findings from these chapters focused on tailoring scientific forecasts to local farmers' needs, integrating local and scientific forecasting knowledge and design principles for an effective ICT-based climate information service for smallholder farmers. Added to this discussion are reflections on the contributions of the findings from the different research questions towards the overall objective of the dissertation, which was 
to analyse the quality, accessibility and usefulness of weather and climate forecast information for supporting decision-making by smallholder farmers in Ghana.

\subsubsection{Main findings on tailoring scientific forecasts for local agriculture}

The first question was how and with what results a dynamical model could be used to tailor and improve predictions of the onset date of the rainy season (RQ1, Chapter 2). To this end, I proposed different definitions of the date of the rainy season onset and assessed the performance of seasonal forecast models (ECMWF System 4) in predicting these onset dates. Both definitions were suitable for the raw and bias-corrected ECMWF System 4 seasonal forecasts. I then assessed trends in observed rainy season onset, variability and prediction performance of the forecast models in Ghana with a focus on the coastal delta zone where the pilot station was located.

Results showed significant variation in season onset dates, particularly in the coastal savanna zone and northern Ghana. Nonetheless, the ECMWF System 4 seasonal forecasts were found to have considerable potential in categorical predictions (i.e., predicting whether conditions will be above or below normal), which were useful in supporting smallholder farmers' decision-making. The high observed variability of rainy season onset is indicative of the challenges faced by smallholder farmers in Ghana, and why they cannot rely solely on local forecasting knowledge systems. The two onset definitions developed were the 'isochrone' and 'absolute value' definitions. These were found to be, respectively, non-sensitive and sensitive to model biases. Hence, with appropriate season onset date definitions both raw and bias-corrected seasonal forecasts could be adopted to make predictions. The accuracy of onset date predictions was generally low across Ghana, though forecast performance that varied by lead times, categories (i.e. below-, near-, and above normal) and was generally higher for the coastal savanna zone. The Ada East district, which was a coastal pilot site for the Waterapps project, was among the areas with the highest variability in season onset dates, but was also the area with the highest potential for tailor-made scientific, model-based seasonal forecast information to support local farmers.

The next research question concerned how and with what results dynamical and statistical models could be employed to tailor and improve predictions of seasonal rainfall and dry spell length and frequency across Ghana, with a focus on the coastal savanna zone (RQ2, Chapter 3). Here, I used a dynamical model (ECMWF System 4) and a statistical model (a linear regression model based 


\section{Chapter 6}

on the influence of sea surface temperatures (SSTs)) to assess predictions of seasonal rainfall and dry spell occurrence using agrometeorological indices at critical stages of crop production in Ghana. Before the assessment, I investigated trends and variability of these indices.

Results showed that at critical stages in crop production, seasonal rainfall and dry spells were highly variable in both length and frequency, especially across the coastal savanna zone and northern Ghana. This, again, is indicative of the difficulties that local farmers face in predicting these key agrometeorological indicators. The accuracy of the predictions using the two scientific forecast methods differed across time (lead times), space (location) and categories (below-, near-, and above normal). Combining the dynamical model (ECMWF System 4) and the statistical model (SSTs-driven) provided better predictions of seasonal rainfall and dry spell occurrence across Ghana. This suggests that statistical and dynamical forecasts should be combined when and where appropriate to obtain greater accuracy and model-based predictions more tailored for smallholder farmers in Ghana.

The conclusions drawn from chapters 2 and 3 proved applicable to the Waterapps project site, in Ada East district, located in the coastal savanna zone of the Volta Delta. Ada is among the districts of Ghana with the highest variability in wet season onset, seasonal rainfall and dry spell occurrence. Nonetheless, significant potential was found to provide farmers tailor-made scientific, model-based seasonal forecast information. Chapter 3 explored the opportunities to integrate scientific and local knowledge systems for improved forecast performance in the Ada East district pilot location.

\subsubsection{Main findings on integrating local and scientific forecasting knowledge}

Chapter 4 investigated the forecast indicators used locally, and the accuracy of these and the potential for their integration with modern forecasting systems. The aim here was to improve weather and climate information for farmers in Ada, Ghana, by combining local forecasting knowledge (LFK) with scientific forecasting knowledge (SFK). Towards this objective, I followed three steps. First, I investigated and documented LFK, drawing mainly on findings from interviews and focus group discussions and data collected in real time using digital tools (smartphone apps). In the second step, I developed metrics and assessed the quality of LFK compared to SFK. In the last step, I developed four approaches to integrate LFK and SFK. Of these, one was tested in the current research, and the three others were detailed for investigation in future studies. 
Findings from the Ada pilot site suggest three main findings. First, local forecasting knowledge draws on a diversity of biophysical indicators and extends from the short-term, current weather to seasonal timescales. The local forecast indicators used provided information on the agrometeorological indices of key importance to smallholder farmers in Ada. Ghanaian farmers used LFK indicators mainly to predict rainfall occurrence, seasonal rainfall, dry spell occurrence and onset and cessation dates of the rainy season. Second, the accuracy of a set of LFK indicators in predicting one-day rainfall was greater on average than that of the individual LFK indicators. Third, combining farmers' observations on a set of local forecast indicators produced more accurate predictions of daily rainfall than the available national scientific forecasts, which covered the larger region surrounding Ada. The diversity and prediction accuracy of LFK indicators suggested several opportunities for integrating local and modern forecasts in climate information services.

Improving the quality of forecasts, either by improving and tailoring scientific forecasts or by integration of local and scientific forecasting knowledge, would result in information that is much more likely to be relevant to end-users (Roncoli, 2006, Coulibaly et al., 2015). The extent to which local farmers can access, understand and use the improved forecast information is also important (Sultan et al., 2020). This brings us to the fourth research question, regarding design principles for ICT-based WCIS coproduction with and for smallholder farmers.

\subsubsection{Main findings on design principles for WCIS integrating local and scientific knowledge}

Chapter 5 investigated the benefits of coproduction of an ICT-based climate information service with and for smallholder farmers, and the design principles for an effective WCIS. The aim was to experiment with design features, access and use of climate information services by smallholder farmers. The experimental coproduction approach engaged farmers, extension agents and researchers in a joined-up design, production and tool testing process for weather forecast information and data. Expert observations and ex post evaluation were used to understand the impact of the coproduction process and derive design criteria for future climate information services.

Results pointed to two main findings on the value and implementation of an ICT-based climate information service developed with and for smallholder farmers. First, co-designing a user-friendly digital tool (a smartphone app) and producing local and scientific forecasting knowledge with and 


\section{Chapter 6}

for farmers facilitated smallholders' access to tools and information for decision-making and their understanding and use of these tools and information. Second, climate information services need to be designed in an intensive process of collaboration between researchers and a dedicated group of farmers and extension agents to build a basis for information production and dissemination in the location of interest. Such collaboration should include a capacity building component, as well as monitoring and technical assistance, especially in the development phase. Third, selection of coproduction participants is important for appropriate use of the tools for collecting local forecast data and for disseminating forecast information within the community. Forecasting experience, age, gender and literacy level are among the socio-demographic characteristics that need to be considered.

\subsection{Connecting the dots}

This section reflects on the link between the research questions and broader perspectives on the results discussed above regarding the quality, accessibility and usefulness of climate information services.

\subsubsection{Tailoring modern forecasts for smallholder farmers}

There is growing interest in investigating the complex rainfall regime across the agroecological zones of Ghana to build a foundation for climate information service development (Owusu and Waylen, 2009, Manzanas et al., 2014a). As yet, however, there is a very limited amount of documented evidence on trends, variability and predictions of decision-relevant agrometeorological indices (Janicot et al., 2011, Codjoe et al., 2014, Baidu et al., 2017). Evidence is especially scarce at the local level. Chapters 2 and 3 examined location-specific methods for defining and predicting rainy season onset dates, rainfall amounts and dry spell occurrence. I demonstrated that the interannual variability of these agrometeorological indices represented a challenge for farmers, particularly in the coastal savanna zone and northern Ghana. Seasonal forecasts, both dynamical and statistical, proved to some extent valuable to local farmers. The analysis showed that, although the accuracy of categorical agrometeorological forecasts (probabilistic forecasts) varied over time and space, they performed better overall than predictions based on climatology, particularly throughout the coastal savanna zone. The categorical agrometeorological forecast format proved easy to understand for farmers and effective in 
communicating the uncertainties associated with decision-relevant agrometeorological information.

\subsubsection{Integrating local and modern knowledge systems}

Tailoring and improving the quality of scientific, model-based forecasts can foster their value and uptake, but the issue of their coarse temporal and spatial scale remains. Indeed, modern forecasts have limited location specificity and their usefulness depends on the lead times with which they reach farmers. Improving the resolution and accuracy of forecast information could enable smallholders to take action to avoid negative impacts of climate shocks (Masinde and Bagula, 2011, Ziervogel and Downing, 2004). A practical way to improve modern forecasts is to integrate local, traditional forecast knowledge into scientific, model-based forecasts (Tadesse et al., 2015, Plotz et al., 2017). Chapter 4 demonstrated that integrating local and modern knowledge systems can improve the overall accuracy of forecasts. Unlike modern forecasts, local forecast indicators do not have the limitations of coarse resolution and unsuitable release timing. Local indicators are collected by observation of biophysical markers in the environment and can be directly translated to forecast outcomes whenever such observations are made. Furthermore, the example presented in chapter 4, of the integration method called 'statistical integration', demonstrated that local and scientific knowledge need not be combined into a single integrated forecast, but instead can be used side by side, depending on the set of local indicators observed by local farmers. In other words, local and scientific forecasts can coexist, but must be used appropriately based on the criteria mentioned above. Chapter 4 proposed three additional opportunities whereby the local and scientific forecast systems could be integrated, to complement and enrich both. These integration opportunities could be explored in future research to improve forecast information at the farm level.

\subsubsection{Coproduction with and for smallholder farmers}

The accessibility and usefulness of climate information services for smallholder farmers rely on WCIS design, targeting and implementation (Zongo et al., 2016, Sonwa et al., 2017, Roudier et al., 2014, Vaughan et al., 2019). The ICT-based climate information platform evaluated in chapter 5 enabled farmers to gather data on local forecast indicators, which could then be combined with outcomes from the modern forecasting systems presented in chapter 4. Assessment of the 


\section{Chapter 6}

experiment demonstrated that coproduction fostered interaction between scientists and farmers and facilitated local understanding and use of climate information tools.

Moreover, several design criteria were found to be crucial for effective implementation, particularly in the development and scaling up phases. These design principles were found to ensure that data quality was maintained and that the forecast information remained accessible, understandable, beneficial for end-users. The ICT-based climate information service that was developed represents an advance on existing climate information services in Ghana, as it combined 'top-down' and 'bottom-up' approaches through a process of knowledge co-creation, to provide tailor-made, understandable, accessible and credible information to support smallholder farmers' decision-making. The seasonal agrometeorological forecast information derived in chapters 2 and 3 could also be included in the ICT-based climate information system presented in chapter 5 tailored for smallholder farmers.

\subsection{Strengths and limitations of the study}

The current researched used a multi-methodological approach to analyse the design of agrometeorological information services based on scientific and/or local forecasting knowledge systems. The aim was to identify areas of improvement with regard to the quality, accessibility and usefulness of climate information services for smallholders. This section reflects on the strengths and limitations of the study, with emphasis on the validity of the data, methods and tools.

Chapters 2 and 3 assessed the quality of seasonal forecasts, that is, their performance in reproducing observed variation in decision-relevant agrometeorological indices at the local level. I verified the performance of both dynamical forecasts (ECMWF System 4, Molteni et al. (2011)) and statistical forecasts (influence of SSTs) using correlation and other discriminant skill metrics. The quality of the reference observations used for forecast verification often presents a challenge. Use of independent observational datasets is crucial for robust forecast validation. Forecast verification commonly uses the large-scale gridded observations from the WATCH forcing dataset ERAInterim (WFDEI) (Vellinga et al., 2013, Manzanas et al., 2014a, Ogutu et al., 2017, Nyadzi et al., 2019). However, WFDEI and System 4 have similarities that might have influenced forecast accuracy, since both are built on the same atmospheric model (the Integrated Forecast System, Johnson et al. (2019)). Moreover, due to the complexity of the rainfall regime in Ghana, care is 
needed in the use of large-scale datasets such as WFDEI, as discrepancies can arise between these datasets and station observations (Manzanas et al., 2014a). In addition, information derived from comparing seasonal forecasts with large-scale observations may be of little usefulness at the local level, as variations on smaller scales may be missed (Wetterhall et al., 2015, Fitzpatrick et al., 2015, Gbangou et al., 2018). In the current study, I used independent observations from local stations instead of large-scale gridded data as my reference to assess forecast performance. This provided a more representative forecast performance assessment. Observations were gathered from 22 synoptic weather stations with consistent records (see (Owusu and Waylen, 2013, Manzanas et al., 2014a).

Two further limitations from chapters 2 and 3 warrant mention. A first and key limitation for forecast verification is the current research's use of the dynamical ECMWF System 4 model, which is no longer available. System 4 (Molteni et al., 2011) was an operational and competitive seasonal forecast system in the six years, but it was replaced by its successor, System 5, in November 2017 (Johnson et al., 2019). System 5 offers an upgraded version of the atmospheric and ocean models at a finer horizontal resolution (36 km, Johnson et al. (2019) compared to System 4 ( $80 \mathrm{~km}$, Molteni et al. (2011)). It also contains a prognostic sea ice model that did not exist in System 4 (Johnson et al., 2019). The resolution enhancement and better representation of ENSO events in System 5 (Johnson et al., 2019) suggest its better fit for seasonal forecasting compared to System 4. Produced by a global leader in forecasting, System 4 was still in use during this research (Weisheimer and Palmer, 2014). At the time of my research design, it represented the best observational and forecast data available.

The second limitation relates to the interpolation of System 4 seasonal forecasts at the local station level. Though widely accepted and applied in the literature (Manzanas et al., 2014a), interpolating large-scale model forecasts to a local station is still a form of averaging and approximation that can affect the results. However, this was the best option to derive representative forecast performance for the local farm scale, as opposed to using coarse and dependent observations (Wetterhall et al., 2015, Gbangou et al., 2018). Moreover, in this study, statistical forecasts were developed and used for seasonal predictions of the decision-relevant agrometeorological indices (chapter 3).

Up to now, scientific investigation and application of local forecasting knowledge has been limited due to issues of trust and replicability (Huntington, 2000, Pierotti and Wildcat, 2000, Gilchrist et 


\section{Chapter 6}

al., 2005). Chapter 4 presented robust tools and methods for collection of local forecast parameters, for gauging their quality and for integrating them with scientific forecasts. For example, the citizen coproduction experiment served as a vehicle for training, monitoring and technical assistance in forecast data collection and use, thus ensuring appropriate use of the ICT tools (smartphone app) and rain gauges and maintaining the quality of the collected data. Robust and established verification metrics (Gsella et al., 2014, Fekri and Yau, 2016, Singh et al., 2017) were also used to assess the performance of the local forecasting indicators. Nevertheless, unlike scientific forecast data, no long-term historical datasets could be acquired for local forecasts within the timeframe of the current research. Hence, no multi-year analysis could be carried out. Moreover, my assessment of local forecast performance was limited to the one-day rainfall forecasts. The tools and techniques developed can nonetheless serve for longer-term data collection and local forecast verification. Several additional integration approaches were also proposed that would be applicable to both short-term (weather) and longer-term (seasonal) forecasts.

Exploring forecast performance and integrating local and scientific forecasting systems is a key starting point for reducing tensions and reconciling local and scientific forecasting knowledge (Kniveton et al., 2015). The current study used only scientific forecast evaluation metrics to assess the quality of both local and scientific forecasts. This constitutes a logical point of reference for the scientific community. However, Balehegn et al. (2019) noted that local people have their own forecast verification techniques. Exploration and use of these local forecast evaluation metrics for forecast performance assessment is thus recommended as a next step towards full reconciliation of both knowledge systems. This step was beyond the scope of the current study.

The citizen science coproduction experiment provided an opportunity to implement and capture the benefits of an ICT-based climate information service combining local and scientific forecasting knowledge. The participatory approach allowed researchers, farmers and extension agents to learn from each other. The ex post evaluation of the climate information service, presented in chapter 5 , enabled examination of the real effectiveness of the information service, as opposed to an ex ante evaluation which would draw conclusions on effectiveness based on assumptions (Vaughan et al., 2019; Tall et al., 2018). The coproduction experiment provided evidence of the actual use and understanding of forecasts and the associated uncertainties and of the dissemination potential of the farmers and extension agents involved. The intensive collaboration process did prove laborious 
for the researchers. Here it bears mentioning that the local forecasting experiences and indicators and the design principles derived for the ICT-based climate information service tailored for smallholder farmers, were based on a single case study, in Ada East district, Ghana. Further insights might be obtained from direct comparisons of this case with similar experiments in other districts within and outside Ghana. To that end, the current study made recommendations regarding the transferability of the case study lessons.

\subsection{Scientific contributions}

Smallholder agriculture in developing countries like Ghana is severely affected by climate variability and change (Kanu et al., 2014, Barnett et al., 2017). Improved understanding of the prediction performance, accessibility and usefulness of agrometeorological forecasts is important to advance development of the needed climate information services. This section presents main contributions of the current research to the field.

Model-based climate information services are under construction in many developing countries, though they are currently mostly limited to the regional level. They thus provide general agrometeorological information with little direct bearing on the local level (Vincent et al., 2018; Vaughan et al., 2019). Existing studies on the accuracy of seasonal forecasts have similarly mainly been conducted over large areas (Vellinga et al., 2013, Dunning et al., 2016, Ogutu et al., 2017, Nyadzi et al., 2018). In this study, I explored the potential for defining and predicting decisionrelevant local agrometeorological indices, considering local data collection, the local cropping calendar and the lead time requirements for decision-making by smallholder farmers. I identified key agrometeorological forecast information in the study area to be onset dates of the rainy season, seasonal rainfall amounts and dry spell occurrence. Advancing methodologies to incorporate these indicators into scientific, model-based forecasts could add value to such forecasts for smallholder agriculture.

The impacts of ENSO events are a main source of seasonal climate predictability in much of the tropical zone (Kniveton et al., 2015, Nicholson, 2017, Johnson et al., 2019). Their influence on interannual variability of rainfall across West Africa is well documented (Zhang et al., 2015, Alizadeh-Choobari et al., 2018). However, there is much less understanding of how they affect local scale variation in rainfall (Diro et al., 2011, Wetterhall et al., 2015). Development and 


\section{Chapter 6}

verification of statistical agrometeorological forecasts based on SST indices provided an empirical understanding of how large-scale components of the climate system, such as ENSO events, are felt at the farm level. To the best of my knowledge, no study has yet investigated, precisely, the predictability of dry spell occurrence during critical growing seasons in Ghana using statistical forecasts driven by ENSO SSTs indices.

There is an emerging consensus in the literature regarding the potential of combining local and modern forecasting systems to increase forecast accuracy and acceptance (Ingram et al., 2002, Kalanda-Joshua et al., 2011, Lebel, 2013, Kniveton et al., 2015, Radeny et al., 2019). However, empirical evidence on integration techniques is still lacking. Additionally, existing studies on local forecast performance are mostly qualitative rather than quantitative, and methods for integrating local and scientific forecasts hardly exist. Hence, opportunities for replicating and comparing local and modern forecasts are limited (Gilchrist et al., 2005, Crane et al., 2010, Radeny et al., 2019). This study presented approaches and tools to allow the harnessing, quantitative evaluation and integration of local and scientific forecasting systems. The improvements in forecast performance that resulted from the integration of the two knowledge systems will advance the scientific debate on ways to synergize traditional and model-based forecasting systems for improved accuracy and usefulness. My research recognizes the contribution local knowledge systems can make to science and contributes to theory on how local forecasting knowledge can be integrated into climate information services in Ghana and elsewhere.

Weather and climate variability and change, now and in the future, pose a threat to the adaptive capacity of smallholder farmers (IPCC, 2018, 2019). Yet, empirical evidence on the design of climate information systems suitable for the most vulnerable farmers in developing countries remains limited (Vaughan et al., 2019; Vincent et al., 2018; Nyadzi et al., 2018). This study established design principles for local (rather than regional) climate information services that integrate traditional and scientific forecast information. The findings presented contribute towards the operationalization of climate information services tailored to the local level and integrating local forecasting knowledge. No other study, to my knowledge, has explored the real-time (actual) benefits and design features of ICT-based local climate information services tailored for smallholder farmers in Ghana. 
In particular, this work has already contributed to other studies and mobile application development for climate service coproduction in developing countries. Paparrizos et al. (2020) used the same methodological approach to tailor ECMWF-System 5 seasonal climate forecasts for local farming in Lower Ganges Delta, Bangladesh. This coproduction set up also helps a follow-up study examine and understand the motivation and barriers to smallholder farmers' engagement in the same Ada district, Ghana (Sarku et al., Accepted). Moreover, insights from designing principles of ICT-based tools supported the development of the FarmerSupport app that incorporates LFK, SFK, and hybrid forecasts for smallholder farmers (http://www.waterapps.net/en-us/ghana-updates/farmersupportapp-traingings-have-started/).

Overall, this research contributes to the literature on climate information service design. Particularly, it advances knowledge on the integration of bottom-up and top-down approaches to provide more useful, accessible but also actionable services.

\subsection{Societal contribution}

Demand for WCIS is growing as societies and governments seek means to respond to weather and climate shocks (Cane, 2010, Bowyer et al., 2015, Naab et al., 2019). In terms of societal relevance, my research makes a number of significant contributions in the field of climate information services for vulnerable smallholder farmers in Ghana and elsewhere.

First, considering that the climate information hitherto available to smallholder farmers was mostly limited to traditional knowledge (Antwi-Agyei et al., 2012, Naab et al., 2019), the current work provides tailored, model-based agrometeorological information responding to the specific needs of farmers in the study area. With improved quality and tailoring to the local situation, model-based forecasts can support decision-making by smallholder farmers and contributing to reduce the risk of crop failure and yield reduction. For instance, information on early or late onset of the rainy season, the probability of below or above average seasonal rainfall and dry spell occurrence, could be improved and targeted for smallholders in the coastal savanna zone of Ghana. This information can be provided in a format that non-scientists can easily understand, especially if basic training is provided. More importantly, categorical information (probabilistic forecasting) aptly expresses forecast uncertainties, which is an essential element in farmers' decision-making regarding seasonal farming operations (Patt and Dessai, 2005). Findings from the current study can also 


\section{Chapter 6}

promote appropriate and understandable methods of information collection and dissemination among water management and national meteorological agencies, within Ghana and elsewhere. These will help them deliver more useful seasonal predictions (both statistical and dynamical) for smallholder farmers.

Second, the presented evidence on the added value of combining local and scientific, model-based forecasts can foster farmer uptake of WCIS (Ingram et al., 2002, Patt and Gwata, 2002, Kniveton et al., 2015, Nyamekye et al., 2019). The integrated forecasting knowledge that was developed in this study provided improved spatial resolution of forecasts, which benefited local farm decisionmaking. In addition, generation of local forecasts by farmers themselves created a sense of ownership and inclusiveness in the knowledge production process, which fostered trust and acceptance of the information.

Third, lessons from the design and implementation of an ICT-based climate information platform tailored for smallholder farmers can advise policymakers and practitioners on ways to enhance access to and use of weather and climate information. Current channels for climate information communication are generally unsuitable for smallholder farmers, as they are too complicated with too many intermediaries and little opportunity for feedback (Antwi-Agyei et al., 2014, Jost et al., 2016, Naab et al., 2019). Promoting the co-design of WCIS with user-friendly modern technologies, like the internet and smartphone applications, can facilitate access and interaction with farmers. It can also shorten the dissemination route between WCIS producers and end-users. Considering the rapid growth of access to digital technology in West Africa, particularly in Ghana, use of ICT-based tools will likely be increasingly feasible in the near future. ICT-based tools facilitate provision of more useful and timely weather and climate information for the most vulnerable farmers.

The tailor-made ICT-based climate information system examined in this study engaged farmers, extension agents and researchers in a process of knowledge coproduction. The system acknowledged farmers' role as citizen scientists with their own unique forecasting expertise, which enriched modern forecasts. I demonstrated that both farmers and extension agents can contribute to disseminate forecast information with peer farmers in their communities. Inclusion of local knowledge in the current study fostered development of a WCIS that was culturally appropriate and locally relevant (Kniveton et al., 2015, Radeny et al., 2019). In addition, coproducing local 
forecasting knowledge with consideration of farmers' socio-demographic characteristics, such as age, literacy level and gender, strengthened knowledge transmission between generations and empowered women to access and use climate information. The findings of this research confirm that valuing local forecasting systems increases trust and preserves traditional knowledge of biophysical weather and climate indicators (Balehegn et al., 2019). As a wider audience starts to acknowledge the potential of local knowledge, more initiatives can be expected that push back against policies that directly or indirectly encourage abandonment of local knowledge systems.

The research outputs presented in this thesis support international and national initiatives for climate information service development in developing countries. International initiatives, such as the Global Framework on Climate Services (GFCS) and Climate Change, Agriculture and Food Security (CCAFS), advocate for development of climate information services in many developing countries (Bowyer et al., 2015, Naab et al., 2019). In Ghana, improving agricultural productivity is a key goal, as the country aims to achieve upper-middle-income status in the next decade (Barnett et al., 2017). In particular, Ghana's agricultural sector development policy (FASDEP II) focuses on development of smallholder farming, with international support from the European Union, the US Agency for International Development and Canada (Bowyer et al., 2015). An important and common challenge facing these initiatives is provision of useful climate information services for adaptive decision-making. Insights from the current study will advance the implementation of this agenda. Three key findings of this research warrant particular mention: (i) scientific forecasts need to be tailored to smallholder farmers' needs; (ii) integration of local forecasting knowledge can add value to scientific, model-based climate information services; and (iii) a tailor-made ICT-based weather and climate information platform can effectively deliver useful and actionable information to smallholder farmers while providing a vehicle for feedback.

\subsection{Future outlook}

With further research, scientific forecast information can be increasingly tailored for smallholder farmers in developing countries such as Ghana. Chapter 3 demonstrated that statistical predictions driven by SSTs were valuable for forecasting seasonal rainfall and dry spell occurrence, particularly if combined with dynamical predictions. In chapter 2, I tested only a dynamical model (ECMWF System 4) to predict rainy season onset dates. Thus, future research is recommended exploring the added value of dynamical statistical forecasts to enhance the performance of rainy 


\section{Chapter 6}

season onset date predictions. This is important because statistical forecasts based on SSTs can contribute to provide better forecasts with longer lead times, thus contributing to long-term planning in agriculture. This is especially the case for SST indices driven by ENSO events, as these are highly influential in the tropics (Kniveton et al., 2015, Nicholson, 2017). I additionally used a simple linear regression model to assess predictions of seasonal rainfall and dry spell occurrence at critical stages of crop production. Future research could test more advanced machine learning models to obtain further insights on the performance of statistical forecasts.

Further research is also recommended to deepen understanding of the potential of local forecast systems to contribute to local climate information service development. In chapter 4, I developed several integration approaches to synergize local and modern forecasting systems for improved accuracy. But only one approach was tested. Future research could explore the other integration opportunities, to potentially enrich both local and modern forecasting systems and advance local climate information service development. Further evidence on the performance of LFK and opportunities to integrate LFK and SFK using long-term datasets could enable stronger claims to be made regarding the added value of LFK and its integration with SFK systems. This study's performance assessment of weather forecasts was limited to daily rainfall forecasts. Future work could extend this line of inquiry to seasonal forecasts (1-2 months). Investigation of weather forecasts up to 14 days is also recommended, to meet the medium-range forecast needs of smallholder farmers in Ghana and elsewhere. In this study only science-based techniques were used explore the performance of local and scientific forecast systems. However, to fully reconcile the two knowledge systems, it is important to explore the traditional methods that local people use to evaluate forecasts.

In Chapter 5, I demonstrated the benefits and implementation criteria of ICT-based climate services tailored for smallholder farmers using experimentation during a rainy season. This allowed me to analyse farmers' access to weather and climate information, and explore how they used the information in farm decision-making, including their understanding of forecast uncertainty. However, to understand the real effectiveness and impacts of the system in terms of changes in cropping practices, yield and income, longer-term study is required. Testing such systems at different locations within and outside Ghana could provide further comparative insights on the benefit and implementation of climate information systems. 
Combining local and modern forecasts proved to have a huge potential for developing better local forecast information. Climate variability and change are not the only causes of the progressive abandonment and lack of generational transmission of traditional forecast knowledge (Masinde and Bagula, 2011, Gilberthorpe and Hilson, 2016, Balehegn et al., 2019). Current state policies and globalization have contributed to the degradation and decline in use of local forecasting knowledge in developing countries (Balehegn et al., 2019, Naab et al., 2019). Given the value of this knowledge, national, international policymakers are encouraged to adopt policies that stimulate development and inclusion of local forecasting knowledge in the climate information services currently under development. For example, ICT-based coproduction exercises could be introduced in farmer field schools focused on climate resilience (Chandra et al., 2017). Further, business models could be developed to preserve and help sustain local knowledge for the benefit of smallholder farmers and, indeed, for the scientific community as a whole. 


\section{References}

ACCADIA, C., MARIANI, S., CASAIOLI, M., LAVAGNINI, A. \& SPERANZA, A. 2003. Sensitivity of precipitation forecast skill scores to bilinear interpolation and a simple nearest-neighbor average method on high-resolution verification grids. Weather and Forecasting, 18, 918-932.

ACHEAMPONG, P. K. 1982. Rainfall anomaly along the coast of Ghana-Its nature and causes. Geografiska Annaler: Series A, Physical Geography, 64, 199-211.

ADDO, K. A., NICHOLLS, R. J., CODJOE, S. N. A. \& ABU, M. 2018. A biophysical and socioeconomic review of the Volta Delta, Ghana. Journal of Coastal Research, 34, 1216-1226.

ADEFOLALU, D. 1988. Precipitation trends, evapotranspiration and the ecological zones of Nigeria. Theoretical and applied climatology, 39, 81-89.

AKER, J. C. 2011. Dial "A" for agriculture: a review of information and communication technologies for agricultural extension in developing countries. Agricultural Economics, 42, 631-647.

AKER, J. C. \& MBITI, I. M. 2010. Mobile phones and economic development in Africa. Journal of economic Perspectives, 24, 207-32.

ALHAMSHRY, A., FENTA, A. A., YASUDA, H., SHIMIZU, K. \& KAWAI, T. 2019. Prediction of summer rainfall over the source region of the Blue Nile by using teleconnections based on sea surface temperatures. Theoretical and Applied Climatology, 1-11.

ALIZADEH-CHOOBARI, O., ADIBI, P. \& IRANNEJAD, P. 2018. Impact of the El Niño-Southern Oscillation on the climate of Iran using ERA-Interim data. Climate Dynamics, 51, 2897-2911.

AMEGNAGLO, C. J., ANAMAN, K. A., MENSAH-BONSU, A., ONUMAH, E. E. \& GERO, F. A. 2017. Contingent valuation study of the benefits of seasonal climate forecasts for maize farmers in the Republic of Benin, West Africa. Climate Services, 6, 1-11.

AMEKUDZI, L. K., YAMBA, E. I., PREKO, K., ASARE, E. O., ARYEE, J., BAIDU, M. \& CODJOE, S. N. 2015. Variabilities in rainfall onset, cessation and length of rainy season for the various agro-ecological zones of Ghana. Climate, 3, 416-434.

AMISIGO, B. A., MCCLUSKEY, A. \& SWANSON, R. 2015. Modeling impact of climate change on water resources and agriculture demand in the Volta Basin and other basin systems in Ghana. Sustainability, 7, 6957-6975. Doi:10.3390/su7066957

ANGELUCCI, F., ASANTE-POK, A. \& ANAADUMBA, P. 2019. Analysis of incentives and disincentives for rice in Ghana. Gates Open Res, 3.

ANTWI-AGYEI, P., FRASER, E. D., DOUGILL, A. J., STRINGER, L. C. \& SIMELTON, E. 2012. Mapping the vulnerability of crop production to drought in Ghana using rainfall, yield and socioeconomic data. Applied Geography, 32, 324-334.

ANTWI-AGYEI, P., STRINGER, L. C. \& DOUGILL, A. J. 2014. Livelihood adaptations to climate variability: insights from farming households in Ghana. Regional environmental change, 14, 1615-1626.

ARONSON, S. M. 2007. Local science vs. global science: Approaches to indigenous knowledge in international development, Berghahn Books.

ASANTE, F. A. \& AMUAKWA-MENSAH, F. 2015. Climate change and variability in Ghana: Stocktaking. Climate, $3,78-99$.

ATI, O., STIGTER, C. \& OLADIPO, E. 2002. A comparison of methods to determine the onset of the growing season in northern Nigeria. International journal of climatology, 22, 731-742.

ATIAH, W. A., AMEKUDZI, L. K., QUANSAH, E. \& PREKO, K. 2019. The Spatio-Temporal Variability of Rainfall over the Agro-Ecological Zones of Ghana. Atmospheric and Climate Sciences, 9, 527.

ATTA, S., LY, M., SALACK, S. \& GEORGE, D. A. 2015. Adapting to climate variability and change in smallholder farming communities: A case study from Burkina Faso, Chad and Niger. Journal of Agricultural Extension and Rural Development, 7, 16-27.

AUDIA, C. Interactions between local and scientific knowledge systems for weather and climate services. 2018.

BAIDU, M., AMEKUDZI, L. K., ARYEE, J. \& ANNOR, T. 2017. Assessment of long-term spatio-temporal rainfall variability over Ghana using wavelet analysis. Climate, 5,30 .

BALEHEGN, M., BALEHEY, S., FU, C. \& LIANG, W. 2019. Indigenous weather and climate forecasting knowledge among Afar pastoralists of north eastern Ethiopia: Role in adaptation to weather and climate variability. Pastoralism, 9, 8.

BARNETT, I., BATCHELOR, S., GILligAN, D., HADDAD, L., HIDROBO, M., LEDLIE, N., PALLONI, G., SCOTT, N. \& SHYAM, T. 2017. External evaluation of mobile phone technology-based nutrition and agriculture advisory services in Africa and South 
https://opendocs.ids.ac.uk/opendocs/bitstream/handle/20.500.12413/13465/mNutrition\%20Inception\%20Re port_for\%20publication\%20Nov17.pdf? sequence=1\&isAllowed $=y, 107 \mathrm{pp}$.

BARRON, J. 2004. Dry spell mitigation to upgrade semi-arid rainfed agriculture: Water harvesting and soil nutrient management for smallholder maize cultivation in Machakos, Kenya. Institutionen för systemekologi.

BENOIT, P. 1977. The start of the growing season in Northern Nigeria. Agricultural Meteorology, 18, 91-99. Doi:10.1016/0002-1571(77)90042-5

BERKES, F. 1999. Traditional Ecological Knowledge and Management Systems. Taylor and Francis, Philadelphia and London.

BERKES, F. \& ECOLOGY, S. Traditional Ecological Knowledge and Management Systems. Taylor and Francis, Philadelphia and London.

BEZA, E., STEINKE, J., VAN ETTEN, J., REIDSMA, P., FADDA, C., MITTRA, S., MATHUR, P. \& KOOISTRA, L. 2017. What are the prospects for citizen science in agriculture? Evidence from three continents on motivation and mobile telephone use of resource-poor farmers. PloS one, 12.

BOWDEN, A. \& CIESIELSKA, M. 2016. Ecomuseums as cross-sector partnerships: governance, strategy and leadership. Public Money \& Management, 36, 23-30.

BOWYER, P., BRASSEUR, G. \& JACOB, D. 2015. The role of climate services in adapting to climate variability and change. Handbook of Climate Change Adaptation. Springer.

BRIGGS, J. 2005. The use of indigenous knowledge in development: problems and challenges. Progress in development studies, 5, 99-114.

BUYTAERT, W., ZULKAFLI, Z., GRAINGER, S., ACOSTA, L., ALEMIE, T. C., BASTIAENSEN, J., DE BIÈVRE, B., BHUSAL, J., CLARK, J. \& DEWULF, A. 2014. Citizen science in hydrology and water resources: opportunities for knowledge generation, ecosystem service management, and sustainable development. Frontiers in Earth Science, 2, 26. Doi:10.3389/feart.2014.00026

BYERLEE, D., DE JANVRY, A., SADOUlET, E., TOWNSEND, R. \& KLYTCHNIKOVA, I. 2008. World development report 2008: Agriculture for development. The World Bank.

CAMPBELL, B. M., WAMUKOYA, G., KINYANGI, J., VERCHOT, L. V., WOLLENBERG, L., VERMEULEN, S. J., MINANG, P. A., NEUFELDT, H., VIDAL, A. \& LOBOGUERRERO RODRIGUEZ, A. M. 2014. The role of Agriculture in the UN climate talks.

CANE, M. 2010. Climate science: decadal predictions in demand. Nat. Geosci. 3, 231-232.

CHANDRA, A., DARGUSCH, P., MCNAMARA, K. E., CASPE, A. M. \& DALABAJAN, D. 2017. A study of climate-smart farming practices and climate-resiliency field schools in Mindanao, the Philippines. World Development, 98, 214-230.

CHARNEY, J. \& SHUKLA, J. 1981. Predictability of monsoons, Monsoon Dynamics edited by J Lighthill and RP Pearce. Cambridge University Press, Cambridge.

CHISADZA, B., TUMBARE, M. J., NYABEZE, W. R. \& NHAPI, I. 2015. Linkages between local knowledge drought forecasting indicators and scientific drought forecasting parameters in the Limpopo River Basin in Southern Africa. International Journal of Disaster Risk Reduction, 12, 226-233.

CODJOE, S. N. A., OWUSU, G. \& BURKETT, V. 2014. Perception, experience, and indigenous knowledge of climate change and variability: the case of Accra, a sub-Saharan African city. Regional Environmental Change, 14, 369-383.

COFIÑO, A., BEDIA, J., ITURBIDE, M., VEGA, M., HERRERA, S., FERNÁNDEZ, J., FRÍAS, M., MANZANAS, R. \& GUTIÉRREZ, J. M. 2018. The ECOMS User Data Gateway: Towards seasonal forecast data provision and research reproducibility in the era of Climate Services. Climate Services, 9, 33-43.

COLLIER, P. \& DERCON, S. 2014. African agriculture in 50 years: smallholders in a rapidly changing world? World development, 63, 92-101.

COOPER, P., DIMES, J., RAO, K., SHAPIRO, B., SHIFERAW, B. \& TWOMLOW, S. 2008. Coping better with current climatic variability in the rain-fed farming systems of sub-Saharan Africa: An essential first step in adapting to future climate change? Agriculture, Ecosystems \& Environment, 126, 24-35.

COOPER, R. T. 2019. Projection of future precipitation extremes across the Bangkok Metropolitan Region. Heliyon, $5, \mathrm{e} 01678$.

COUlibAlY, J. Y., MANGO, J., SWAMIlA, M., TALL, A., KAUR, H. \& HANSEN, J. 2015. Which climate services do farmers and pastoralists need in Malawi?

CRANE, T. A., RONCOLI, C., PAZ, J., BREUER, N., BROAD, K., INGRAM, K. T. \& HOOGENBOOM, G. 2010. Forecast skill and farmers' skills: Seasonal climate forecasts and agricultural risk management in the southeastern United States. Weather, Climate, and Society, 2, 44-59. 
CSP 2011. What are Climate Services? Available online: https://climate-services.org/about-us/what-are-climateservices/ (accessed on 0203 2020).

DAAN, H. \& AH, M. 1982. SUBJECTIVE PROBABILITY, FORECASTING IN THE NETHERLANDS: SOME OPERATIONAL AND EXPERIMENTAL RESULTS.

DAVID-WEST, O. 2011. Esoko Networks: facilitating agriculture through technology. Available online: http://growinginclusivemarkets.org/media/cases/esoko_summary.pdf(accessed on 01072020 ).

DELORIA, V. 1996. If you think about it, you will see that it is true. REVISION-CAMBRIDGE MA THEN WASHINGTON-, 18, 37-44.

DERBILE, E. K., ABDUL-MOOMIN, A. \& YAKUBU, I. 2016. Local Knowledge and Community-Based Assessment of Environmental Change in Ghana. Ghana Journal of Geography, 8, 59-83.

DIALLO, I., GIORGI, F., DEME, A., TALL, M., MARIOTTI, L. \& GAYE, A. T. 2016. Projected changes of summer monsoon extremes and hydroclimatic regimes over West Africa for the twenty-first century. Climate Dynamics, 47, 3931-3954. Doi:10.3389/fpls.2016.01262

DIALlO, I., SYLlA, M. B., GAYE, A. T. \& CAMARA, M. 2013. Comparaison du climat et de la variabilité interannuelle de la pluie simulée au Sahel par les modèles climatiques régionaux. Science et changements planétaires/Sécheresse, 24, 96-106.

DIRO, G., GRIMES, D. I. F. \& BLACK, E. 2011. Teleconnections between Ethiopian summer rainfall and sea surface temperature: part I-observation and modelling. Climate Dynamics, 37, 103-119.

DIXON, J. L. \& STRINGER, L. C. 2015. Towards a theoretical grounding of climate resilience assessments for smallholder farming systems in Sub-Saharan Africa. Resources, 4, 128-154.

DUBE, T., MOYO, P., NDLOVU, S. \& PHIRI, K. 2016. Towards a framework for the integration of traditional ecological knowledge and meteorological science in seasonal climate forecasting: The case of smallholder farmers in Zimbabwe. Journal of Human Ecology, 54, 49-58.

DUNNING, C. M., BLACK, E. C. \& ALLAN, R. P. 2016. The onset and cessation of seasonal rainfall over Africa Journal of Geophysical Research: Atmospheres, 121.

ELKHATIB, Y., BLAIR, G. S. \& SURAJBALI, B. Experiences of using a hybrid cloud to construct an environmental virtual observatory. Proceedings of the 3rd International Workshop on Cloud Data and Platforms, 2013. ACM, 13-18.

EVOCA \& WATERAPPS 2019. Wageningen University, partners launch apps to transform agricultural landscape. https://citinewsroom.com/2019/06/wageningen-university-partners-launch-apps-to-transform-agriculturallandscapel (accessed on 0203 2020).

FEKRI, M. \& YAU, M. 2016. An Information-Theoretical Score of Dichotomous Precipitation Forecast. Monthly Weather Review, 144, 1633-1647.

FIELD, C. B. 2014. Climate change 2014-Impacts, adaptation and vulnerability: Regional aspects, Cambridge University Press.

FITZPATRICK, R. G., BAIN, C. L., KNIPPERTZ, P., MARSHAM, J. H. \& PARKER, D. J. 2015. The West African monsoon onset: A concise comparison of definitions. Journal of Climate, 28, 8673-8694. Doi:10.1175/jcli-d15-0265.1

FLIGNER, M. A. \& KILLEEN, T. J. 1976. Distribution-free two-sample tests for scale. Journal of the American Statistical Association, 71, 210-213.

FOLLAND, C. K., PALMER, T. N. \& PARKER, D. E. 1986. Sahel rainfall and worldwide sea temperatures, 190185. Nature, 320, 602

GBANGOU, T., LUDWIG, F., VAN SLOBBE, E., GREUELL, W. \& KRANJAC-BERISAVLJEVIC, G. 2020a. Rainfall and dry spell occurrence in Ghana: trends and seasonal predictions with a dynamical and a statistical model. Theor and Appl Climatol, https://doi.org/10.1007/s00704-020-03212-5.

GBANGOU, T., LUDWIG, F., VAN SLOBBE, E., HOANG, L. \& KRANJAC-BERISAVLJEVIC, G. 2019. Seasonal variability and predictability of agro-meteorological indices: Tailoring onset of rainy season estimation to meet farmers' needs in Ghana. Climate Services, 14, 19-30.

GBANGOU, T., SYLLA, M. B., JIMOH, O. D. \& OKHIMAMHE, A. A. 2018. Assessment of projected agro-climatic indices over Awun river basin, Nigeria for the late twenty-first century. Climatic Change, 1-18.

GBANGOU, T., VAN SLOBBE, E., LUDWIG, F., GORDANA, K.-B. \& PAPARRIZOS, S. 2020b. Harnessing local forecasting knowledge on weather and climate in Ghana: documentation, skills and integration with scientific forecasting knowledge. Weather, Climate, and Society, 1-41.

GEARHEARD, S., POCERNICH, M., STEWART, R., SANGUYA, J. \& HUNTINGTON, H. P. 2010. Linking Inuit knowledge and meteorological station observations to understand changing wind patterns at Clyde River, Nunavut. Climatic Change, 100, 267-294. 
GEORGE, T., BAGAZONZYA, H., BALlAntYNE, P., BELDEN, C., BIRNER, R., DEL CASTELLO, R. \& TREINEN, S. 2011. ICT in agriculture: connecting smallholders to knowledge, networks, and institutions. Washington, DC: World Bank.

GERTLER, P. J., MARTINEZ, S., PREMAND, P., RAWLINGS, L. B. \& VERMEERSCH, C. M. 2016. Impact evaluation in practice, The World Bank.

GFCS 2016. Development and Delivery of Climate Services Research Dialogue. Available online: https://unfccc.int/files/science/workstreams/research/application/pdf/part2.1_wmo_dilley.pdf (accessed on 0203 2020).

GHANA METEOROLOGICAL AGENCY 2020. Retrieved from: https://www.meteo.gov.gh/.

GHANA STATISTICAL SERVICE 2012. 2010 population and housing census: summary report of final results. https://www.statsghana.gov.gh/gssmain/storage/img/marqueeupdater/census2010_summary_report_of_final results.pdf.

GHANA STATISTICAL SERVICE 2014. 2010 Population and Housing Census. District Analitical Report. Ada Est District. https://new-ndpc-static1.s3.amazonaws.com/CACHES/PUBLICATIONS/2016/06/06/Ada+East.pdf, 88pp.

GILBERTHORPE, E. \& HILSON, G. 2016. Natural resource extraction and indigenous livelihoods: Development challenges in an era of globalization, Routledge.

GILCHRIST, G., MALLORY, M. \& MERKEL, F. 2005. Can local ecological knowledge contribute to wildlife management? Case studies of migratory birds. Ecology and Society, 10.

GREEN, D., BILLY, J. \& TAPIM, A. 2010. Indigenous Australians' knowledge of weather and climate. Climatic Change, 100, 337-354.

GSEllA, A., DE MEIJ, A., KERSCHBAUMER, A., REIMER, E., THUNIS, P. \& CUVELIER, C. 2014. Evaluation of MM5, WRF and TRAMPER meteorology over the complex terrain of the Po Valley, Italy. Atmospheric Environment, 89, 797-806.

GUDMUNDSSON, L. 2016. Qmap: Statistical transformations for post-processing climate model output, version 1.04. R package.

GUDMUNDSSON, L., BREMNES, J., HAUGEN, J. \& ENGEN-SKAUGEN, T. 2012. Downscaling RCM precipitation to the station scale using statistical transformations: a comparison of methods. Hydrology and Earth System Sciences, 16, 3383-3390.

HANSEN, J. W. 2002. Realizing the potential benefits of climate prediction to agriculture: issues, approaches, challenges. Agricultural systems, 74, 309-330.

HANSEN, J. W., MISHRA, A., RAO, K., INDEJE, M. \& NGUGI, R. K. 2009. Potential value of GCM-based seasonal rainfall forecasts for maize management in semi-arid Kenya. Agricultural Systems, 101, 80-90.

HANSSEN, A. \& KUIPERS, W. 1965. On the Relationship Between the Frequency of Rain and Various Meteorological Parameters:(with Reference to the Problem Ob Objective Forecasting), Staatsdrukkerij-en Uitgeverijbedrijf.

HETTMANSPERGER, T. P. \& MCKEAN, J. W. 2010. Robust nonparametric statistical methods, CRC Press.

HOLT-GIMÉNEZ, E., SHATTUCK, A., ALTIERI, M., HERREN, H. \& GLIESSMAN, S. 2012. We already grow enough food for 10 billion people... and still can't end hunger. Taylor \& Francis.

HUANG, B., BANZON, V. F., FREEMAN, E., LAWRIMORE, J., LIU, W., PETERSON, T. C., SMITH, T. M., THORNE, P. W., WOODRUFF, S. D. \& ZHANG, H.-M. 2015. Extended reconstructed sea surface temperature version 4 (ERSST. v4). Part I: upgrades and intercomparisons. Journal of climate, 28, 911-930.

HUHO, J. M., NGAIRA, J. K., OGINDO, H. O. \& MASAYI, N. 2012. The changing rainfall pattern and the associated impacts on subsistence agriculture in Laikipia East District, Kenya. Journal of Geography and Regional Planning, 5, 198.

HUNTINGTON, H. P. 2000. Using traditional ecological knowledge in science: methods and applications. Ecological applications, 10, 1270-1274.

INGRAM, K., RONCOLI, M. \& KIRSHEN, P. 2002. Opportunities and constraints for farmers of west Africa to use seasonal precipitation forecasts with Burkina Faso as a case study. Agricultural systems, 74, 331-349. Doi:10.1016/s0308-521x(02)00044-6

INTELLIGENCE, G. 2016. The mobile economy Africa 2016. London: GSM Association.

IPCC 2018. Special Report on $1.5^{\circ}$ C. Jones, L., Dougill, A., Jones, R.G., Steynor,.

IPCC 2019. Special Report on $1.5^{\circ}$ C. Jones, L., Dougill, A., Jones, R.G., Steynor,

JAKOB THEMEßL, M., GOBIET, A. \& LEUPRECHT, A. 2011. Empirical-statistical downscaling and error correction of daily precipitation from regional climate models. International Journal of Climatology, 31, 1530-1544. 
JALLOH, A., NELSON, G. C., THOMAS, T. S., ZOUGMORÉ, R. B. \& ROY-MACAULEY, H. 2013. West African agriculture and climate change: a comprehensive analysis, Intl Food Policy Res Inst.

JANICOT, S., CANIAUX, G., CHAUVIN, F., DE COËTLOGON, G., FONTAINE, B., HALL, N., KILADIS, G., LAFORE, J. P., LAVAYSSE, C. \& LAVENDER, S. 2011. Intraseasonal variability of the West African monsoon. Atmospheric Science Letters, 12, 58-66.

JANICOT, S., HARZALLAH, A., FONTAINE, B. \& MORON, V. 1998. West African monsoon dynamics and eastern equatorial Atlantic and Pacific SST anomalies (1970-88). Journal of Climate, 11, 1874-1882.

JOHNSON, S. J., STOCKDALE, T. N., FERRANTI, L., BALMASEDA, M. A., MOLTENI, F., MAGNUSSON, L., TIETSCHE, S., DECREMER, D., WEISHEIMER, A. \& BALSAMO, G. 2019. SEAS5: The new ECMWF seasonal forecast system. Geoscientific Model Development, 12.

JOLLIFFE, I. T. \& STEPHENSON, D. B. 2012. Forecast verification, Wiley Oxford.

JOLY, M. \& VOLDOIRE, A. 2009. Influence of ENSO on the West African monsoon: temporal aspects and atmospheric processes. Journal of Climate, 22, 3193-3210.

JONES, L., DOUGILL, A., JONES, R. G., STEYNOR, A., WATKISS, P., KANE, C., KOELLE, B., MOUFOUMAOKIA, W., PADGHAM, J. \& RANGER, N. 2015. Ensuring climate information guides long-term development. Nature Climate Change, 5, 812-814.

JOST, C., KYAZZE, F., NAAB, J., NEELORMI, S., KINYANGI, J., ZOUGMORE, R., AGGARWAL, P., BHATTA, G., CHAUDHURY, M. \& TAPIO-BISTROM, M.-L. 2016. Understanding gender dimensions of agriculture and climate change in smallholder farming communities. Climate and Development, 8, 133-144.

JURY, M. R., ENFIELD, D. B. \& MÉLICE, J. L. 2002. Tropical monsoons around Africa: Stability of El NiñoSouthern Oscillation associations and links with continental climate. Journal of Geophysical Research: Oceans, 107, 15-1-15-17.

KADI, M., NJAU, L., MWIKYA, J. \& KAMGA, A. 2011. The State of Climate InformationServices for Agriculture and Food Security in East African Countries. CCAFSWorking Paper No. 5. Copenhagen, Denmark: CCAFS.

KALANDA-JOSHUA, M., NGONGONDO, C., CHIPETA, L. \& MPEMBEKA, F. 2011. Integrating indigenous knowledge with conventional science: Enhancing localised climate and weather forecasts in Nessa, Mulanje, Malawi. Physics and Chemistry of the Earth, Parts A/B/C, 36, 996-1003.

KANU, B. S., SALAMI, A. O. \& NUMASAWA, K. 2014. Inclusive growth: an imperative for African agriculture. African Journal of Food, Agriculture, Nutrition and Development, 14, A33-A33.

KARPOUZOGLOU, T., ZULKAFLI, Z., GRAINGER, S., DEWULF, A., BUYTAERT, W. \& HANNAH, D. M. 2016. Environmental virtual observatories (EVOs): prospects for knowledge co-creation and resilience in the information age. Current Opinion in Environmental Sustainability, 18, 40-48.

KHALIL, M. A., SMITH, P. L., DONGIER, P., SUDAN, R., ZHEN-WEI QIANG, C., SWANSON, E., D'COSTA, V. \& WELLENIUS, B. 2009. 2009 Information and communications for development: extending reach and increasing impact.

KIPTOT, E., FRANZEL, S., HEBINCK, P. \& RICHARDS, P. 2006. Sharing seed and knowledge: farmer to farmer dissemination of agroforestry technologies in western Kenya. Agroforestry systems, 68, 167-179.

KNIVETON, D., VISMAN, E., TALL, A., DIOP, M., EWBANK, R., NJOROGE, E. \& PEARSON, L. 2015. Dealing with uncertainty: Integrating local and scientific knowledge of the climate and weather. Disasters, 39, s35s53.

KNOX, J., HESS, T., DACCACHE, A. \& WHEELER, T. 2012. Climate change impacts on crop productivity in Africa and South Asia. Environmental Research Letters, 7, 034032.

KUMI, N., ABIODUN, B. J. \& ADEFISAN, E. A. 2020. Performance Evaluation of a Sub-seasonal to Seasonal Model in Predicting Rainfall Onset over West Africa. Earth and Space Science, e2019EA000928-T.

LACOMBE, G., MCCARTNEY, M. \& FORKUOR, G. 2012. Drying climate in Ghana over the period 1960-2005: evidence from the resampling-based Mann-Kendall test at local and regional levels. Hydrological Sciences Journal, 57, 1594-1609.

LAUX, P., KUNSTMANN, H. \& BÁRDOSSY, A. 2008. Predicting the regional onset of the rainy season in West Africa. International Journal of Climatology, 28, 329-342.

LAWRENCE, M., GOODWIN, P., O'CONNOR, M. \& ÖNKAL, D. 2006. Judgmental forecasting: A review of progress over the last 25 years. International Journal of forecasting, 22, 493-518.

LAZAR, A. N., NICHOLLS, R. J., PAYO, A., ADAMS, H., MORTREUX, C., SUCKALL, N., VINCENT, K., SUGATA, H., AMISIGO, B. A. \& RAHMAN, M. 2015. A method to assess migration and adaptation in deltas: A preliminary fast-track assessment. 
LEBEL, L. 2013. Local knowledge and adaptation to climate change in natural resource-based societies of the AsiaPacific. Mitigation and Adaptation Strategies for Global Change, 18, 1057-1076. Doi:10.1007/s11027-0129407-1

LEMOS, M. C., ARNOTT, J. C., ARDOIN, N. M., BAJA, K., BEDNAREK, A. T., DEWULF, A., FIESELER, C., GOODRICH, K. A., JAGANNATHAN, K. \& KLENK, N. 2018. To co-produce or not to co-produce. Nature Sustainability, 1, 722-724.

LI, H., SHEFFIELD, J. \& WOOD, E. F. 2010. Bias correction of monthly precipitation and temperature fields from Intergovernmental Panel on Climate Change AR4 models using equidistant quantile matching. Journal of Geophysical Research: Atmospheres, 115.

LIMANTOL, A. M., KEITH, B. E., AZABRE, B. A. \& LENNARTZ, B. 2016. Farmers' perception and adaptation practice to climate variability and change: a case study of the Vea catchment in Ghana. SpringerPlus, 5, 830.

LOURENÇO, T. C., SWART, R., GOOSEN, H. \& STREET, R. 2016. The rise of demand-driven climate services. Nature Climate Change, 6, 13-14.

LUSENO, W. K., MCPEAK, J. G., BARRETT, C. B., LITTLE, P. D. \& GEBRU, G. 2003. Assessing the value of climate forecast information for pastoralists: Evidence from Southern Ethiopia and Northern Kenya. World development, 31, 1477-1494.

MACLEOD, D. 2018. Seasonal predictability of onset and cessation of the east African rains. Weather and Climate Extremes.

MAGARIÑO MANERO, M. E., COFIÑO GONZÁLEZ, A. S., BEDÍA JIMÉNEZ, J., VEGA SALDARRIAGA, M., FERNÁNDEZ FERNÁNDEZ, J., GARCÍA MANZANAS, R. \& GUTIÉRREZ LLORENTE, J. M. 2014. The ECOMS User Data Gateway: homogeneous seasonal to decadal forecast data access for end users.

MANZANAS, R., AMEKUDZI, L., PREKO, K., HERRERA, S. \& GUTIÉRREZ, J. 2014a. Precipitation variability and trends in Ghana: An intercomparison of observational and reanalysis products. Climatic change, 124, 805-819.

MANZANAS, R., FRÍAS, M., COFIÑO, A. \& GUTIÉRREZ, J. M. 2014b. Validation of 40 year multimodel seasonal precipitation forecasts: The role of ENSO on the global skill. Journal of Geophysical Research: Atmospheres, 119, 1708-1719.

MANZANAS, R., GUTIÉRREZ, J., BHEND, J., HEMRI, S., DOBLAS-REYES, F. J., TORRALBA, V., PENABAD, E. \& BROOKSHAW, A. 2019. Bias adjustment and ensemble recalibration methods for seasonal forecasting: A comprehensive intercomparison using the C3S dataset. Climate Dynamics, 53, 1287-1305.

MANZANAS, R., GUTIÉRREZ, J., FERNÁNDEZ, J., VAN MEIJGAARD, E., CALMANTI, S., MAGARIÑO, M., COFIÑO, A. \& HERRERA, S. 2018. Dynamical and statistical downscaling of seasonal temperature forecasts in Europe: Added value for user applications. Climate Services, 9, 44-56.

MARTEAU, R., MORON, V. \& PHILIPPON, N. 2009. Spatial coherence of monsoon onset over Western and Central Sahel (1950-2000). Journal of Climate, 22, 1313-1324.

MASINDE, M. \& BAGULA, A. 2011. ITIKI: bridge between African indigenous knowledge and modern science of drought prediction. Knowledge Management for Development Journal, 7, 274-290.

MASINDE, M., BAGULA, A. \& MUTHAMA, N. J. 2012a. The role of ICTs in downscaling and up-scaling integrated weather forecasts for farmers in sub-Saharan Africa. Proceedings of the Fifth International Conference on Information and Communication Technologies and Development, ACM, 122-129.

MASINDE, M., BAGULA, A. \& MUTHAMA, N. J. The role of ICTs in downscaling and up-scaling integrated weather forecasts for farmers in sub-Saharan Africa. Proceedings of the Fifth International Conference on Information and Communication Technologies and Development, 2012b. ACM, 122-129.

MASON, S. J. 2013. Guidance on verification of operational seasonal climate forecasts. World Meteorological Organization, Commission for Climatology XIV Technical Report.

MATTHEWS, A. J. 2004. Intraseasonal variability over tropical Africa during northern summer. Journal of Climate, $17,2427-2440$.

MATTHEWS, A. J., PICKUP, G., PEATMAN, S. C., CLEWS, P. \& MARTIN, J. 2013. The effect of the MaddenJulian Oscillation on station rainfall and river level in the Fly River system, Papua New Guinea. Journal of Geophysical Research: Atmospheres, 118, 10,926-10,935.

MAURER, E. P. \& HIDALGO, H. G. 2008. Utility of daily vs. monthly large-scale climate data: an intercomparison of two statistical downscaling methods.

MENDELSOHN, R., DINAR, A. \& WILLIAMS, L. 2006. The distributional impact of climate change on rich and poor countries. Environment and Development Economics, 11, 159-178.

METEOSWISS 2017. EasyVerification: Ensemble Forecast Verification for Large Data Sets. R package version 0.4.2. URL: https://CRAN.R-project.org/package=easyVerification. 
MOFA, S. 2011. Agriculture in Ghana-Facts and figures (2010). Ministry of Food and Agriculture (MoFA)-Statistics, Research and Information Directorate (SRID).

MOLTENI, F., STOCKDALE, T., BALMASEDA, M., BALSAMO, G., BUIZZA, R., FERRANTI, L., MAGNUSSON, L., MOGENSEN, K., PALMER, T. \& VITART, F. 2011. The new ECMWF seasonal forecast system (System 4), European Centre for Medium-Range Weather Forecasts.

MORRIS, M. L., BINSWANGER-MIKHIZE, H. P. \& BYERLEE, D. 2009. Awakening Africa's sleeping giant: prospects for commercial agriculture in the Guinea Savannah Zone and beyond, World Bank Publications.

MUSTERS, D. 2017. An innovation systems approach to examine the organization of ICT-based IPs for extension services in Ghana. Master's Thesis, Wageningen University and Research: Wageningen, The Netherlands.

NAAB, F. Z., ABUBAKARI, Z. \& AHMED, A. 2019. The role of climate services in agricultural productivity in Ghana: the perspectives of farmers and institutions. Climate Services, 13, 24-32.

NAKASHIMA, D. \& ROUÉ, M. 2002. Indigenous knowledge, peoples and sustainable practice. Encyclopedia of global environmental change, 5, 314-324.

NICHOLSON, S. E. 2017. Climate and climatic variability of rainfall over eastern Africa. Reviews of Geophysics, 55, $590-635$.

NIKULIN, G., JONES, C., GIORGI, F., ASRAR, G., BÜCHNER, M., CEREZO-MOTA, R., CHRISTENSEN, O. B., DÉQUÉ, M., FERNANDEZ, J. \& HÄNSLER, A. 2012. Precipitation climatology in an ensemble of CORDEX-Africa regional climate simulations. Journal of Climate, 25, 6057-6078.

NYADZI, E. 2020. Best of both worlds : Co-producing climate services that integrate scientific and indigenous weather and seasonal climate forecast for water management and food production in Ghana. Wageningen University and Research.

NYADZI, E., NYAMEKYE, A. B., WERNERS, S. E., BIESBROEK, R. G., DEWULF, A., VAN SLOBBE, E., LONG, H. P., TERMEER, C. J. \& LUDWIG, F. 2018. Diagnosing the potential of hydro-climatic information services to support rice farming in northern Ghana. NJAS-Wageningen Journal of Life Sciences, 86, 51-63.

NYADZI, E., WERNERS, E. S., BIESBROEK, R., LONG, P. H., FRANSSEN, W. \& LUDWIG, F. 2019. Verification of Seasonal Climate Forecast toward Hydroclimatic Information Needs of Rice Farmers in Northern Ghana. Weather, Climate, and Society, 11, 127-142.

NYAMEKYE, A. B., DEWULF, A., VAN SLOBBE, E. \& TERMEER, K. 2019. Information systems and actionable knowledge creation in rice-farming systems in Northern Ghana. African Geographical Review, 1-18.

O'GRADY, M. J., MULDOON, C., CARR, D., WAN, J., KROON, B. \& O'HARE, G. M. 2016. Intelligent sensing for citizen science. Mobile Networks and Applications, 21, 375-385.

OBAREIN, O. A. \& AMANAMBU, A. C. 2019. Rainfall timing: variation, characteristics, coherence, and interrelationships in Nigeria. Theoretical and Applied Climatology, 1-15.

OBOT, N., CHENDO, M., UDO, S. \& EWONA, I. 2010. Evaluation of rainfall trends in Nigeria for 30 years (19782007). International Journal of Physical Sciences, 5, 2217-2222.

OCHOLA, W. \& KERKIDES, P. 2003. A Markov chain simulation model for predicting critical wet and dry spells in Kenya: analysing rainfall events in the Kano plains. Irrigation and drainage, 52, 327-342.

OECD/FAO 2016. OECD-FAO Agricultural Outlook 2016-2025. OECD Publishing, Paris.

OGUTU, G. E., FRANSSEN, W. H., SUPIT, I., OMONDI, P. \& HUTJES, R. W. 2017. Skill of ECMWF system-4 ensemble seasonal climate forecasts for East Africa. International Journal of Climatology, 37, 2734-2756.

OLANIRAN, O. 1984. The start and end of the growing season in the Niger River Basin Development Authority Area of Nigeria. Malaysian Journal of Tropical Geography (Malaysia).

OLSSON, P. \& FOLKE, C. 2001. Local ecological knowledge and institutional dynamics for ecosystem management: a study of Lake Racken watershed, Sweden. Ecosystems, 4, 85-104.

OPOKU-ANKOMAH, Y. \& CORDERY, I. 1994. Atlantic sea surface temperatures and rainfall variability in Ghana. Journal of Climate, 7, 551-558.

ORLOVE, B., RONCOLI, C., KABUGO, M. \& MAJUGU, A. 2010. Indigenous climate knowledge in southern Uganda: the multiple components of a dynamic regional system. Climatic Change, 100, 243-265.

OWUSU, A., TESFAMARIAM-TEKESTE, Y., AMBANI, M., ZEBIAK, S. E. \& THOMSON, M. C. 2017. Climate Services for Resilient Development (CSRD) Technical Exchange in Eastern Africa Workshop Report.

OWUSU, K. \& WAYLEN, P. 2009. Trends in spatio-temporal variability in annual rainfall in Ghana (1951-2000). Weather, 64, 115-120.

OWUSU, K. \& WAYLEN, P. R. 2013. The changing rainy season climatology of mid-Ghana. Theoretical and Applied Climatology, 112, 419-430.

OXFAM 2015. Community-based climate change action grants (CBCCAG) program activity completion report. Oxfam in The Philippines, Quezon City, The Philippines (2015). 
PALINKAS, L. A., HORWITZ, S. M., GREEN, C. A., WISDOM, J. P., DUAN, N. \& HOAGWOOD, K. 2015. Purposeful sampling for qualitative data collection and analysis in mixed method implementation research. Administration and policy in mental health and mental health services research, 42, 533-544.

PANOFSKY, H. A., BRIER, G. W. \& BEST, W. H. 1958. Some application of statistics to meteorology.

PAPARRIZOS, S., SMOLENAARS, W., GBANGOU, T., SLOBBE, E. V. \& LUDWIG, F. 2020. Verification of Weather and Seasonal Forecast Information Concerning the Peri-Urban Farmers' Needs in the Lower Ganges Delta in Bangladesh. Atmosphere, 11, 1041.

PARTAL, T. \& KAHYA, E. 2006. Trend analysis in Turkish precipitation data. Hydrological processes, 20, 20112026.

PATT, A. \& DESSAI, S. 2005. Communicating uncertainty: lessons learned and suggestions for climate change assessment. Comptes Rendus Geoscience, 337, 425-441.

PATT, A. \& GWATA, C. 2002. Effective seasonal climate forecast applications: examining constraints for subsistence farmers in Zimbabwe. Global environmental change, 12, 185-195.

PHILIPPON, N., DOBLAS-REYES, F. \& RUTI, P. M. 2010. Skill, reproducibility and potential predictability of the West African monsoon in coupled GCMs. Climate Dynamics, 35, 53-74.

PHILliPS, C., WALSHE, D., O’REGAN, K., STRONG, K., HENNON, C., KNAPP, K., MURPHY, C. \& THORNE, P. 2018. Assessing citizen science participation skill for altruism or university course credit: a case study analysis.

PIEROTTI, R. \& WILDCAT, D. 2000. Traditional ecological knowledge: the third alternative (commentary). Ecological applications, 10, 1333-1340.

PIRRET, J. S., DARON, J. D., BETT, P. E., FOURNIER, N. \& FOAMOUHOUE, A. K. 2020. Assessing the Skill and Reliability of Seasonal Climate Forecasts in Sahelian West Africa. Weather and Forecasting, 35, 1035-1050.

PLOTZ, R. D., CHAMBERS, L. E. \& FINN, C. K. 2017. The best of both worlds: a decision-making framework for combining traditional and contemporary forecast systems. Journal of Applied Meteorology and Climatology, 56, 2377-2392.

QIANG, C. Z.-W. 2009. Mobile telephony: A transformational tool for growth and development. Proparco's Magazine,(4), 7-9.

QUINN PATTON, M. 2002. Qualitative research and evaluation methods. Sage.

RADENY, M., DESALEGN, A., MUBIRU, D., KYAZZE, F., MAHOO, H., RECHA, J., KIMELI, P. \& SOLOMON, D. 2019. Indigenous knowledge for seasonal weather and climate forecasting across East Africa. Climatic Change, 156, 509-526.

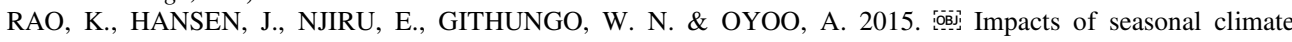
communication strategies on farm management and livelihoods in Wote, Kenya.

RASMUSSEN, L. V., MERTZ, O., RASMUSSEN, K., NIETO, H., ALI, A. \& MAIGA, I. 2014. Weather, climate, and resource information should meet the needs of Sahelian pastoralists. Weather, Climate, and Society, 6, 482-494.

REYNOLDS, R. W., RAYNER, N. A., SMITH, T. M., STOKES, D. C. \& WANG, W. 2002. An improved in situ and satellite SST analysis for climate. Journal of climate, 15, 1609-1625.

RIEDLINGER, D. \& BERKES, F. 2001. Contributions of traditional knowledge to understanding climate change in the Canadian Arctic. Polar record, 37, 315-328.

ROCKSTROM, J. 2000. Water resources management in smallholder farms in Eastern and Southern Africa: an overview. Physics and Chemistry of the Earth, Part B: Hydrology, Oceans and Atmosphere, 25, 275-283.

ROCKSTRÖM, J. \& FALKENMARK, M. 2015. Agriculture: Increase water harvesting in Africa. Nature, $519,283$. Doi: $10.1038 / 519283 a$

RONCOLI, C. 2006. Ethnographic and participatory approaches to research on farmers' responses to climate predictions. Climate Research, 33, 81-99.

RONCOLI, C., INGRAM, K. \& KIRSHEN, P. 2002. Reading the rains: local knowledge and rainfall forecasting in Burkina Faso. Society \&Natural Resources, 15, 409-427. Doi:10.1080/08941920252866774

RONCOLI, C., JOST, C., KIRSHEN, P., SANON, M., INGRAM, K. T., WOODIN, M., SOMÉ, L., OUATTARA, F., SANFO, B. J. \& SIA, C. 2009. From accessing to assessing forecasts: an end-to-end study of participatory climate forecast dissemination in Burkina Faso (West Africa). Climatic Change, 92, 433.

ROUDIER, P., ALHASSANE, A., BARON, C., LOUVET, S. \& SULTAN, B. 2016. Assessing the benefits of weather and seasonal forecasts to millet growers in Niger. Agricultural and Forest Meteorology, 223, 168-180.

ROUDIER, P., MUlLER, B., D’AQUINO, P., RONCOLI, C., SOUMARÉ, M. A., BATTÉ, L. \& SULTAN, B. 2014. The role of climate forecasts in smallholder agriculture: lessons from participatory research in two communities in Senegal. Climate Risk Management, 2, 42-55. 
ROUDIER, P., SULTAN, B., QUIRION, P. \& BERG, A. 2011. The impact of future climate change on West African crop yields: What does the recent literature say? Global environmental change, 21, 1073-1083.

ROWELL, D. P. 2001. Teleconnections between the tropical Pacific and the Sahel. Quarterly Journal of the Royal Meteorological Society, 127, 1683-1706.

RUTTEN, M., MINKMAN, E. \& VAN DER SANDEN, M. 2017. How to get and keep citizens involved in mobile crowd sensing for water management? A review of key success factors and motivational aspects. Wiley Interdisciplinary Reviews: Water, 4, e1218.

SALACK, S., KLEIN, C., GIANNINI, A., SARR, B., WOROU, O. N., BELKO, N., BLIEFERNICHT, J. \& KUNSTMAN, H. 2016. Global warming induced hybrid rainy seasons in the Sahel. Environmental Research Letters, $11,104008$.

SANTHA, S. D., FRAUNHOLZ, B. \& UNNITHAN, C. 2010. A societal knowledge management system: harnessing indigenous wisdom to build sustainable predictors for adaptation to climate change. International journal of climate change: impacts and responses, 2, 49-64. Doi:10.18848/1835-7156/CGP/v02i01/37293

SARKU, R., DEWULF, A., VAN SLOBBE, E., TERMEER, K. \& KRANJAC-BERISAVLJEVIC, G. 2020. Adaptive decision-making under conditions of uncertainty: the case of farming in the Volta delta, Ghana. Journal of Integrative Environmental Sciences, 17, 1-33.

SARKU, R., GBANGOU, T., DEWULF, A. \& SLOBBE, E. Accepted. Beyond 'experts knowledge': Locals and experts in a joint production of weatherApp and weather information for farming in the Volta Delta, Ghana. In Handbook of Climate Change Management, Springer Nature, New Delhi, India (Accepeted).

SHIMELES, A., VERDIER-CHOUCHANE, A. \& BOLY, A. 2018. Introduction: understanding the challenges of the agricultural sector in Sub-Saharan Africa. Building a Resilient and Sustainable Agriculture in Sub-Saharan Africa. Springer.

SIEGERT, S. 2017. SpecsVerification: Forecast Verification Routines for Ensemble Forecasts of Weather and Climate. R package version 0.5-2. URL: https://CRAN. R-project. org/package= SpecsVerification.

SINGH, H., ARORA, K., ASHRIT, R. \& RAJAGOPAL, E. N. 2017. Verification of pre-monsoon temperature forecasts over India during 2016 with a focus on heatwave prediction. Natural Hazards \& Earth System Sciences, 17.

SIVAKUMAR, M. 1988. Predicting rainy season potential from the onset of rains in Southern Sahelian and Sudanian climatic zones of West Africa. Agricultural and Forest Meteorology, 42, 295-305.

SLINGO, J. \& PALMER, T. 2011. Uncertainty in weather and climate prediction. Phil. Trans. R. Soc. A, 369, 47514767.

SMITH, D. 2014. Internet use on mobile phones in Africa predicted to increase 20-fold. Available online: http://www.theguardian.com/world/2014/jun/05/internet-use-mobile-phones-africa-predicted-increase-20fold (accessed on 0107 2020).

SONWA, D. J., DIEYE, A., EL MZOURI, E.-H., MAJUlE, A., MUGABE, F. T., OMOLO, N., WOUAPI, H., OBANDO, J. \& BROOKS, N. 2017. Drivers of climate risk in African agriculture. Climate and Development, 9, 383-398.

SPERANZA, C. I., KITEME, B., AMBENJE, P., WIESMANN, U. \& MAKALI, S. 2010. Indigenous knowledge related to climate variability and change: insights from droughts in semi-arid areas of former Makueni District, Kenya. Climatic change, 100, 295-315.

STEPHENSON, D. B. 2000. Use of the "odds ratio" for diagnosing forecast skill. Weather and Forecasting, 15, 221232.

STERN, R., DENNETT, M. \& GARBUTT, D. 1981. The start of the rains in West Africa. Journal of Climatology, 1, 59-68.

STRINGER, L. C., FRASER, E. D., HARRIS, D., LYON, C., PEREIRA, L., WARD, C. F. \& SIMELTON, E. 2020. Adaptation and development pathways for different types of farmers. Environmental Science \& Policy, 104, 174-189.

STRINGER, L. C., TWYMAN, C. \& GIBBS, L. M. 2008. Learning from the South: common challenges and solutions for small-scale farming. Geographical journal, 174, 235-250.

SULTAN, B. \& GAETANI, M. 2016. Agriculture in West Africa in the twenty-first century: climate change and impacts scenarios, and potential for adaptation. Frontiers in Plant Science, 7, 1262.

SULTAN, B. \& JANICOT, S. 2003. The West African monsoon dynamics. Part II: The "preonset" and "onset" of the summer monsoon. Journal of climate, 16, 3407-3427.

SUlTAN, B., LEJEUNE, Q., MENKE, I., MASKELL, G., LEE, K., NOBLET, M., SY, I. \& ROUDIER, P. 2020. Current needs for climate services in West Africa: Results from two stakeholder surveys. Climate Services, 18,100166 . 
SYLLA, M., GIORGI, F., COPPOLA, E. \& MARIOTTI, L. 2013. Uncertainties in daily rainfall over Africa: assessment of gridded observation products and evaluation of a regional climate model simulation. International Journal of Climatology, 33, 1805-1817.

SYLLA, M. B., ELGUINDI, N., GIORGI, F. \& WISSER, D. 2016. Projected robust shift of climate zones over West Africa in response to anthropogenic climate change for the late 21 st century. Climatic Change, 134, 241-253.

TADESSE, T., BATHKE, D., WALL, N., PETR, J. \& HAIGH, T. 2015. Participatory research workshop on seasonal prediction of hydroclimatic extremes in the Greater Horn of Africa. Bulletin of the American Meteorological Society, 96, ES139-ES142.

TALL, A., COULIBALY, J. Y. \& DIOP, M. 2018. Do climate services make a difference? A review of evaluation methodologies and practices to assess the value of climate information services for farmers: Implications for Africa. Climate Services, 11, 1-12.

TALL, A., HANSEN, J., JAY, A., CAMPBELL, B., KINYANGI, J., AGGARWAL, P. K. \& ZOUGMORÉ, R. 2014a. Scaling up climate services for farmers: Mission Possible. Learning from good practice in Africa and South Asia.

TALL, A., KRISTJANSON, P., CHAUDHURY, M., MCKUNE, S. \& ZOUGMORÉ, R. B. 2014b. Who gets the information? Gender, power and equity considerations in the design of climate services for farmers.

TARTAGLIONE, N. 2010. Relationship between precipitation forecast errors and skill scores of dichotomous forecasts. Weather and Forecasting, 25, 355-365.

THEMEßL, M. J., GOBIET, A. \& HEINRICH, G. 2012. Empirical-statistical downscaling and error correction of regional climate models and its impact on the climate change signal. Climatic Change, 112, 449-468.

TINATI, R., LUCZAK-ROESCH, M., SIMPERL, E. \& HALL, W. 2017. An investigation of player motivations in Eyewire, a gamified citizen science project. Computers in Human Behavior, 73, 527-540.

TURREIRA-GARCÍA, N., LUND, J. F., DOMÍNGUEZ, P., CARRILLO-ANGLÉS, E., BRUMMER, M. C., DUENN, P. \& REYES-GARCÍA, V. 2018. What's in a name? Unpacking "participatory" environmental monitoring. Ecology and Society, 23.

USMAN, M. T. \& REASON, C. 2004. Dry spell frequencies and their variability over southern Africa. Climate research, 26, 199-211.

VAN DER BURGT, F., VAN PELT, S. \& LOBBRECHT, A. 2018. Mobile weather services for small-scale farmers. Available online: https://www.weatherimpact.com/wpcontent/uploads/2019/10/MobileWeatherServicesforSmallScaleFarmers_WeatherImpact.pdf (accessed on $01072020)$.

VAUGHAN, C. \& DESSAI, S. 2014. Climate services for society: origins, institutional arrangements, and design elements for an evaluation framework. Wiley Interdisciplinary Reviews: Climate Change, 5, 587-603. Doi:10.1002/wcc. 290

VAUGHAN, C., HANSEN, J., ROUDIER, P., WATKISS, P. \& CARR, E. 2019. Evaluating agricultural weather and climate services in Africa: Evidence, methods, and a learning agenda. Wiley Interdisciplinary Reviews: Climate Change, 10, e586.

VEDELD, T., MATHUR, M. \& BHARTI, N. 2019. How can co-creation improve the engagement of farmers in weather and climate services (WCS) in India. Climate Services, 15, 100103.

VELLINGA, M., ARRIBAS, A. \& GRAHAM, R. 2013. Seasonal forecasts for regional onset of the West African monsoon. Climate dynamics, 40, 3047-3070.

VITART, F., ARDIlOUZE, C., BONET, A., BROOKSHAW, A., CHEN, M., CODOREAN, C., DÉQUÉ, M., FERRANTI, L., FUCILE, E. \& FUENTES, M. 2017. The subseasonal to seasonal (S2S) prediction project database. Bulletin of the American Meteorological Society, 98, 163-173.

VOGEL, J., LETSON, D. \& HERRICK, C. 2017. A framework for climate services evaluation and its application to the Caribbean Agrometeorological Initiative. Climate Services, 6, 65-76.

VOISIN, N., SCHAAKE, J. C. \& LETTENMAIER, D. P. 2010. Calibration and downscaling methods for quantitative ensemble precipitation forecasts. Weather and Forecasting, 25, 1603-1627.

WANI, S. P., ROCKSTRÖM, J. \& OWEIS, T. Y. 2009. Rainfed agriculture: unlocking the potential, CABI.

WEEDON, G. P., BALSAMO, G., BELLOUIN, N., GOMES, S., BEST, M. J. \& VITERBO, P. 2014. The WFDEI meteorological forcing data set: WATCH Forcing Data methodology applied to ERA-Interim reanalysis data. Water Resources Research, 50, 7505-7514.

WEIGEL, A. P. \& MASON, S. J. 2011. The generalized discrimination score for ensemble forecasts. Monthly Weather Review, 139, 3069-3074. 


\section{References}

WETTERHALL, F., PAPPENBERGER, F., HE, Y., FREER, J. \& CLOKE, H. 2012. Conditioning model output statistics of regional climate model precipitation on circulation patterns. Nonlinear Processes in Geophysics, $19,623-633$.

WETTERHALL, F., WINSEMIUS, H., DUTRA, E., WERNER, M. \& PAPPENBERGER, E. 2015. Seasonal predictions of agro-meteorological drought indicators for the Limpopo basin. Hydrology and Earth System Sciences, 19, 2577

WOHLING, M. 2009. The problem of scale in indigenous knowledge: a perspective from northern Australia. Ecology and Society, 14.

WOOD, A. W., MAURER, E. P., KUMAR, A. \& LETTENMAIER, D. P. 2002. Long-range experimental hydrologic forecasting for the eastern United States. Journal of Geophysical Research: Atmospheres, 107.

WOODCOCK, F. 1976. The evaluation of yes/no forecasts for scientific and administrative purposes. Monthly Weather Review, 104, 1209-1214.

WORLD AGROMETEOROLOGICAL INFORMATION SERVICE 2020. Retrieved from http://www.wamis.org/.

YARO, J. A. 2013. The perception of and adaptation to climate variability/change in Ghana by small-scale and commercial farmers. Regional Environmental Change, 13, 1259-1272. Doi:10.1007/s10113-013-0443-5

YOBOM, O. 2020. Climate change and variability: empirical evidence for countries and agroecological zones of the Sahel. Climatic Change, 1-20.

ZEBIAK, S. E. 2019. International Conference on Climate Services-5-An introduction. Elsevier.

ZHANG, Q., HOLMGREN, K. \& SUNDQVIST, H. 2015. Decadal rainfall dipole oscillation over southern Africa modulated by variation of austral summer Land-Sea contrast along the East Coast of Africa. Journal of the Atmospheric Sciences, 72, 1827-1836.

ZIBI, G. 2009. The African mobile phone market: Beyond the boom phase, between the promise and uncertainty of maturity. Private Sector \& Development, 4, 3-6.

ZIERVOGEL, G. Global science, local problems: Seasonal forecast use in a Basotho village. Open Meeting of the Global Environmental Change Research Community, Rio de Janeiro, 2001.

ZIERVOGEL, G. \& DOWNING, T. E. 2004. Stakeholder networks: improving seasonal climate forecasts. Climatic Change, 65, 73-101.

ZONGO, B., DIARRA, A., BARBIER, B., ZOROM, M., YACOUBA, H. \& DOGOT, T. 2016. Farmers' perception and willingness to pay for climate information in Burkina Faso.

ZULKAFLI, Z., PEREZ, K., VITOLO, C., BUYTAERT, W., KARPOUZOGLOU, T., DEWULF, A., DE BIEVRE, B., CLARK, J., HANNAH, D. M. \& SHAHEED, S. 2017. User-driven design of decision support systems for polycentric environmental resources management. Environmental Modelling \& Software, 88, 58-73. 


\section{Supplementary information}

Supplementary materials contain additional information to the following chapters of the PhD thesis:

- Supplementary Material Chapter 2 (published as Gbangou et al. 2019);

- Supplementary Material Chapter 3 (published as Gbangou et al. 2020a);

- Supplementary Material Chapter 4 (published as Gbangou et al. 2020b);

- Supplementary Material Chapter 5 (published as Gbangou et al. 2020c).

The text, figures and tables of the supplementary materials from published articles have been adjusted to the $\mathrm{PhD}$ thesis format (e.g., the numbering, formatting). This includes editorial changes for the consistency of presentation in the $\mathrm{PhD}$ thesis. The published versions of the supplementary manterials are available online with the published articles. 


\section{Supplementary Material Chapter 2}

\section{S2.1. Comparing WFDEI with GMet rainfall data}

Figures S2.1.a and S2.1.b present respectively inter-annual variability and annual cycle of rainfall for GMet and WFDEI at Ada and Tamale pilot stations. The figure shows that WFDEI does not always have a good agreement with local station data. WFDEI seems to reproduce well the patterns (relatively good correlation) at Tamale station however, important discrepancies are observed at Ada where WFDEI tends to over-estimate the magnitude of rainfall. Using WFDEI as alternative to station data for forecast verification may not be suitable in that location. Therefore, bias correction with station data was adopted in order to take into account climate processes experienced at the local scale.

(a)
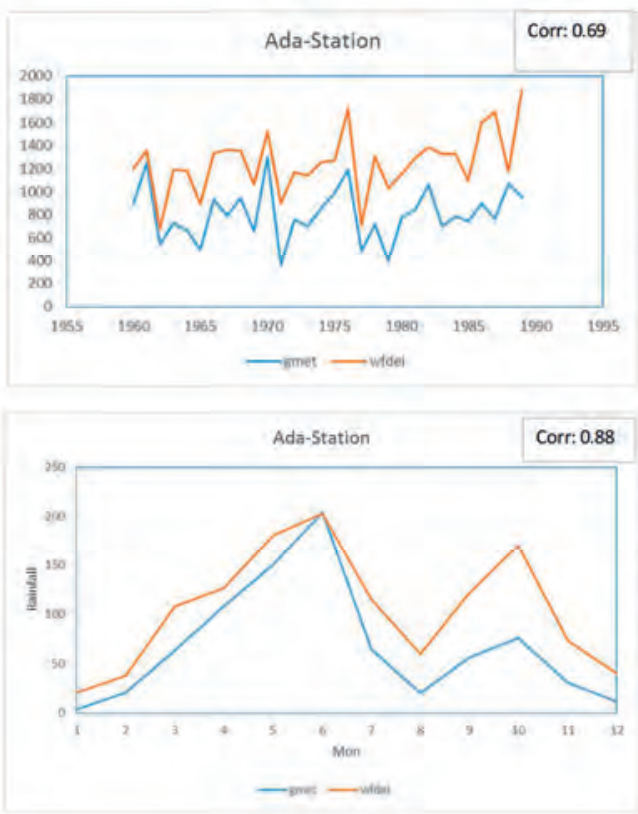

(b)
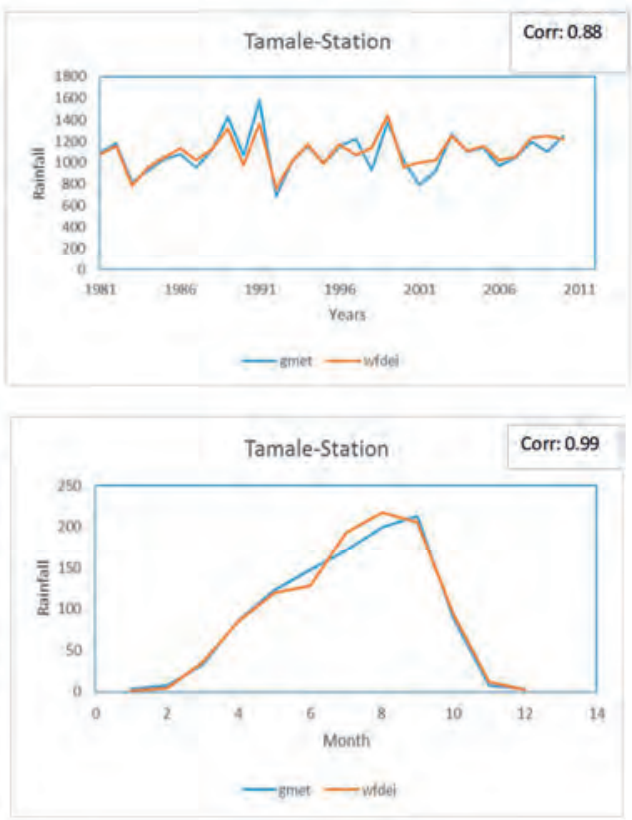

Figure S2.1: Comparing inter-annual rainfall and annual cycle of rainfall between GMet and WFDEI at Ada

\section{S2.2. Validation of onset definitions}


Using different thresholds $(30 \%, 25 \%, 24 \%, 23 \%, 22 \%, 21 \%$, and $20 \%)$ for the isochrones onset dates definition, we found that $25 \%$ threshold reproduces onset dates close to the rainfallevapotranspiration related definition of Benoit (1977) which is an agronomic 'false onset'-sensitive definition. Benoit (1977) defined the onset date as the date when accumulated daily rainfall (P) has exceeded $50 \%$ of accumulated potential evapotranspiration $\left(E T_{p}\right)$ i.e $\Sigma\left(P-0.5 * E T_{p}\right)>0$ for the remainder of the season, provided that no dry spell longer than 5 days occurs immediately after that date. This onset definition was chosen instead of many others (Olaniran, 1984, Stern et al., 1981, Marteau et al., 2009, Sivakumar, 1988) $)^{4}$ because it further include potential evapotranspiration (Gbangou et al., 2018). The definition has the benefit to ensure that the rain compensates water losses by evapotranspiration throughout the growing season. Hence, after the onset, the soil will keep enough moisture and protect crops from any plausible long dry spells which may occur during the growing season (Gbangou et al., 2018). The agronomic definition used in our study is not explicitly sensitive to false onset but was also calibrated with Benoit (1977) onset definition.

The comparison between the (i) isochrone and Benoit (1977) and between the (ii) absolute valuebased agronomic (i.e definition used in the study) and Benoit (1977) definitions at Ada show relatively good correlations of 0.72 and 0.71 respectively (Figure S2.2). The different methods also give close mean onset dates (i.e $1^{\text {th }}, 3^{\text {nd }}$ and $6^{\text {th }}$ of April for the agronomic-false-onsetsensitive, agronomic-absolute-value, and isochrone definitions respectively). There are 13/31 and 9/31 cases where isochrone and absolute-value agronomic onset dates does not match closely with

4

BENOIT P. 1977. The start of the growing season in Northern Nigeria. Agricultural Meteorology 18: 91-99.

GBANGOU T, SYLLA MB, JIMOH OD AND OKHIMAMHE AA. 2018. Assessment of projected agro-climatic indices over Awun river basin, Nigeria for the late twenty-first century. Climatic Change 151: 445-462.

MARTEAU R, MORON V AND PHILIPPON N. 2009. Spatial coherence of monsoon onset over Western and Central Sahel (1950-2000). Journal of Climate 22: 1313-1324.

OLANIRAN O. 1984. The start and end of the growing season in the Niger River Basin Development Authority Area of Nigeria. Malaysian Journal of Tropical Geography (Malaysia).

SIVAKUMAR M. 1988. Predicting rainy season potential from the onset of rains in Southern Sahelian and Sudanian climatic zones of West Africa. Agricultural and Forest Meteorology 42: 295-305.

STERN R, DENNETT M AND GARBUTT D. 1981. The start of the rains in West Africa. Journal of Climatology 1: 59-68. 


\section{Supplemental materials}

the Benoit false onset sensitive definition. This is not surprising given that that local/agronomic definitions usually show discrepancies among them unlike regional definitions that can predict similar onset dates (Fitzpatrick et al 2015). Considering the Benoit (1977) as reference, we can identify $4 / 31$ years of false onset starts for the absolute value agronomic definition and 3/31 of false onset starts with the isochrones definition. Therefore false onset dates can be assumed to be rare, thus the two methods used in the paper are acceptable.

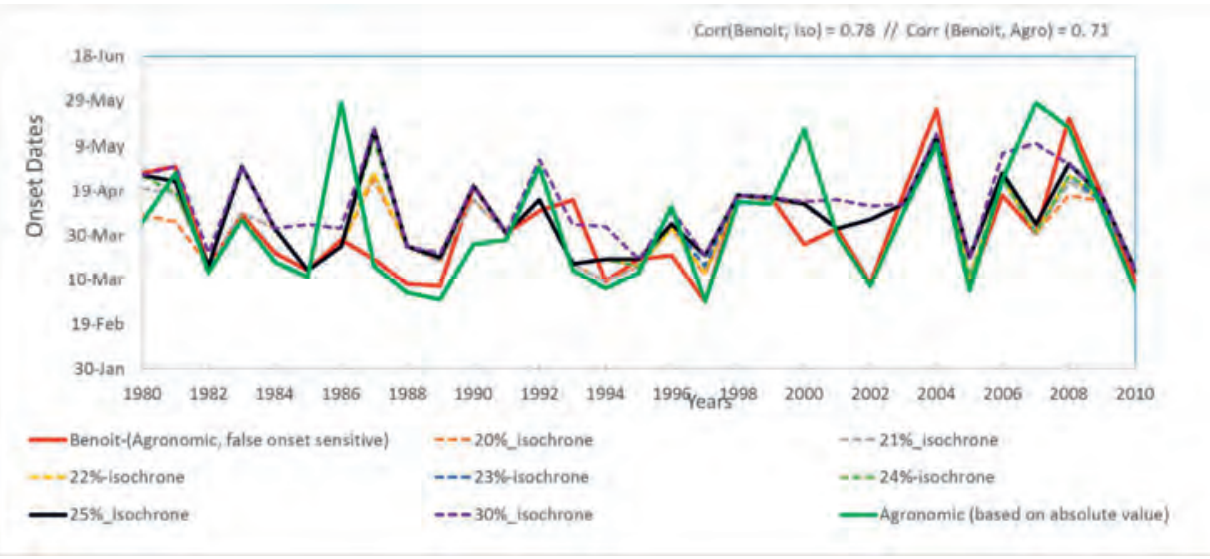

Figure S2.2: Comparison of isochrone, with the rainfall-evapotranspiration onset dates (agronomic) definition (Benoit, 1977) for different thresholds at Ada station. 25\% threshold presented with the black-bold line is the selected for the isochrones method used in the study.

\section{S2.3. General Cropping Calendar}

\begin{tabular}{l|l|l|l|l|l|l|l|l|l|l|l|l|}
\hline $\begin{array}{l}\text { Crop } \\
\text { type }\end{array}$ & Jan & Feb & Mar & Apr & May & Jun & Jul & Aug & Sep & Oct & Nov & Dec \\
\hline $\begin{array}{l}\text { Water } \\
\text { Melon }\end{array}$ \\
$\begin{array}{l}\text { Tomato } \\
\text { Pepper } \\
\text { Okro } \\
\text { Maize }\end{array}$ \\
\hline
\end{tabular}


Figure S2.3: Current cropping calendar decisions in Ada East district, Ghana. L= Land preparation, $\mathrm{P}=$ planting for the cropping cycle, $\mathrm{F}=$ fertilizer application and $\mathrm{H}=$ harvesting for cropping cycle and $\mathrm{W}=$ weeding.

\section{S2.4. Flowchart for bias-correction of seasonal forecasts with GMet observations}

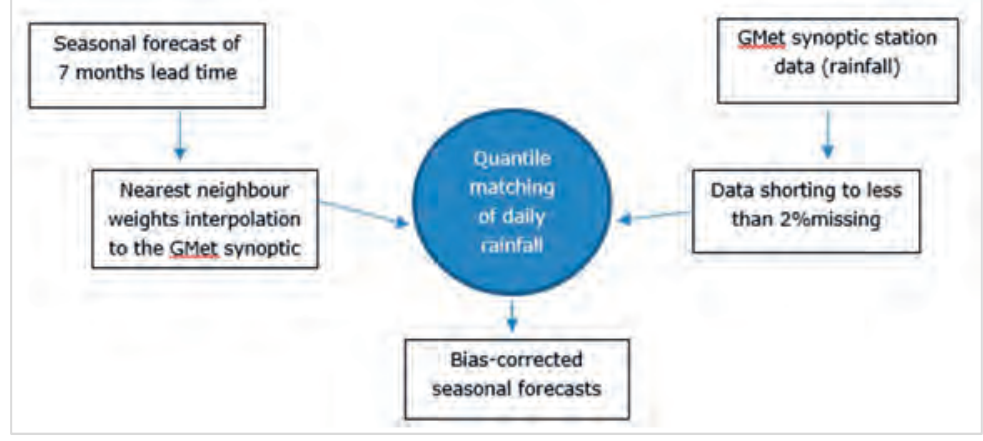

Figure S2.4: Flowchart for bias-correction of seasonal forecasts with GMet observations

\section{S2.5. Trend and variability significance in the observed onset dates for all the 14 stations}

Table S2.1: Trend significance for onset dates over the periods P1:1960-1984 and P2: 1985-2010. Positive tau values imply increasing trend while negative values imply decreasing trends.

\begin{tabular}{|c|c|c|c|c|c|c|c|c|c|}
\hline \multirow{3}{*}{$\begin{array}{l}\text { Agro-eco- } \\
\text { zones }\end{array}$} & \multirow{3}{*}{ Stations } & \multicolumn{4}{|c|}{$\begin{array}{c}\text { Trend Significance-Isochrone } \\
(0.05 \text { significance level })\end{array}$} & \multicolumn{4}{|c|}{$\begin{array}{c}\text { Trend Significance-Agronomic } \\
(0.05 \text { significance level })\end{array}$} \\
\hline & & \multicolumn{2}{|c|}{ P1: 1961-1985 } & \multicolumn{2}{|c|}{ P2: 1986-2010 } & \multicolumn{2}{|c|}{ P1: 1961-1985 } & \multicolumn{2}{|c|}{ P1: 1961-1985 } \\
\hline & & tau & p-value & tau & p-value & tau & p-value & tau & $\mathrm{p}$-value \\
\hline \multirow{3}{*}{ COAST } & Accra & 0.178 & 0.22386 & $\begin{array}{c}0.026 \\
8\end{array}$ & 0.87 & 0.134 & $\begin{array}{c}0.3621 \\
2\end{array}$ & 0.003 & 0.99 \\
\hline & Ada & 0.0336 & 0.83334 & 0.135 & 0.36159 & 0.0471 & $\begin{array}{c}0.7610 \\
4\end{array}$ & 0.174 & 0.23336 \\
\hline & Salpond & 0.294 & $\begin{array}{c}0.044026 \\
*\end{array}$ & $\begin{array}{c}0.023 \\
5\end{array}$ & 0.88847 & $\begin{array}{c}- \\
0.0033 \\
7\end{array}$ & 0.99 & 0.0975 & 0.5125 \\
\hline \multirow[b]{2}{*}{ SOUTH } & Kumassi & 0.128 & 0.38639 & 0.188 & 0.19839 & 0.179 & 0.2236 & 0.0473 & 0.76087 \\
\hline & Ho & $\begin{array}{c}0.0033 \\
7\end{array}$ & 0.99 & $\begin{array}{c}0.013 \\
6\end{array}$ & 0.94386 & 0.158 & $\begin{array}{c}0.2819 \\
3\end{array}$ & $\begin{array}{c}- \\
0.0067 \\
8\end{array}$ & 0.9813 \\
\hline
\end{tabular}




\begin{tabular}{|c|c|c|c|c|c|c|c|c|c|}
\hline & Akuse & $\stackrel{-}{0.0101}$ & 0.96271 & $\begin{array}{c}- \\
0.067 \\
3\end{array}$ & 0.65664 & $\begin{array}{c}- \\
0.0805\end{array}$ & $\begin{array}{c}0.5906 \\
8\end{array}$ & $\begin{array}{c}0.0033 \\
4\end{array}$ & 0.99 \\
\hline & Axim & 0.0875 & 0.55837 & $\begin{array}{c}0.087 \\
3\end{array}$ & 0.55888 & 0.061 & $\begin{array}{c}0.6904 \\
3\end{array}$ & 0.0504 & 0.74335 \\
\hline \multirow{2}{*}{$\begin{array}{c}\text { TRANSITIO } \\
\mathrm{N}\end{array}$} & $\begin{array}{l}\text { Kerekrac } \\
\text { hi }\end{array}$ & 0.245 & 0.09215 & $\begin{array}{c}- \\
0.053 \\
9\end{array}$ & 0.72557 & 0.131 & $\begin{array}{c}0.3744 \\
2\end{array}$ & $\begin{array}{c}- \\
0.0473\end{array}$ & 0.76075 \\
\hline & Wenchi & $\begin{array}{c}- \\
0.1691\end{array}$ & 0.251421 & $\begin{array}{c}- \\
0.187\end{array}$ & 0.19871 & 0.0586 & $\begin{array}{c}0.7064 \\
7\end{array}$ & $\begin{array}{c}- \\
0.0881\end{array}$ & 0.55809 \\
\hline \multirow{5}{*}{ NORTH } & Tamale & 0.0641 & 0.67356 & $\begin{array}{c}- \\
0.409\end{array}$ & $\begin{array}{c}0.0046688 \\
*\end{array}$ & 0.125 & $\begin{array}{c}0.3994 \\
8\end{array}$ & -0.235 & 0.10669 \\
\hline & Bole & 0.0339 & 0.83295 & $\begin{array}{c}- \\
0.087 \\
3\end{array}$ & 0.55888 & $\begin{array}{c}- \\
0.0771\end{array}$ & $\begin{array}{c}0.6070 \\
9\end{array}$ & $\begin{array}{c}- \\
0.0771\end{array}$ & 0.60709 \\
\hline & Wa & 0.0778 & 0.60643 & $\begin{array}{c}- \\
0.203\end{array}$ & 0.16698 & 0.202 & $\begin{array}{c}0.1675 \\
2\end{array}$ & -0.374 & $\begin{array}{c}0.01004 \\
*\end{array}$ \\
\hline & Yendi & 0.166 & 0.26092 & $\begin{array}{c}- \\
0.497\end{array}$ & $\begin{array}{c}0.000588 \\
*\end{array}$ & 0.162 & $\begin{array}{c}0.2715 \\
6\end{array}$ & -0.356 & $\begin{array}{c}0.01409 \\
*\end{array}$ \\
\hline & Navrongo & $\begin{array}{c}- \\
0.0203\end{array}$ & 0.90675 & $\begin{array}{c}- \\
0.154\end{array}$ & 0.29266 & $\begin{array}{c}- \\
0.0978\end{array}$ & $\begin{array}{c}0.5122 \\
7\end{array}$ & $\begin{array}{c}0.0033 \\
7\end{array}$ & 1 \\
\hline
\end{tabular}

*shows the trend is significant

Table S2.2: Change in variability from periods P1: 1961-1985 to P2: 1986-2010 based on F-test

\begin{tabular}{|c|c|c|c|c|c|}
\hline \multirow[t]{2}{*}{$\begin{array}{l}\text { Agro- } \\
\text { ecological } \\
\text { Zones }\end{array}$} & \multirow[t]{2}{*}{ Stations } & \multicolumn{2}{|c|}{$\begin{array}{l}\text { Variability Significance from } \\
\text { P1 to P2 (Isochrone) }\end{array}$} & \multicolumn{2}{|c|}{$\begin{array}{l}\text { Variability Significance } \\
\text { from P1 to P2 (Agronomic) }\end{array}$} \\
\hline & & $\mathrm{F}$ & p-value & $\mathrm{F}$ & p-value \\
\hline \multirow[t]{3}{*}{ COAST } & Accra & 0.77136 & 0.2649 & 1.1502 & 0.3672 \\
\hline & Ada & 0.51591 & $0.05589^{*}$ & 0.43536 & $0.02339 * *$ \\
\hline & Salpond & 0.62965 & 0.1321 & 0.58178 & $0.0959 *$ \\
\hline \multirow[t]{4}{*}{ SOUTH } & Kumassi & 1.5194 & 0.3457 & 1.5243 & 0.1543 \\
\hline & Ho & 0.806 & 0.3007 & 1.454 & 0.1828 \\
\hline & Akuse & 1.178 & 0.1561 & 1.7159 & $0.0966^{*}$ \\
\hline & Axim & 0.53351 & $0.06541 *$ & 0.7154 & 0.209 \\
\hline \multirow[t]{2}{*}{ TRANSITION } & Kerekrachi & 0.37327 & $0.009552 * *$ & 0.35384 & $0.00684 * *$ \\
\hline & Wenchi & 0.58106 & $0.0954 *$ & 0.69973 & 0.194 \\
\hline \multirow[t]{2}{*}{ NORTH } & Tamale & 1.4028 & 0.2065 & 1.1815 & 0.3431 \\
\hline & Bole & 1.8924 & $0.06257 *$ & 1.3846 & 0.2156 \\
\hline
\end{tabular}




\begin{tabular}{lllll}
\hline Wa & 0.58439 & $0.09773 *$ & 0.68514 & 0.1804 \\
Yendi & 0.46427 & $0.03302 * *$ & 0.54302 & $0.07091 *$ \\
Navrongo & 0.89553 & 0.3946 & 1.7053 & $0.09917 *$
\end{tabular}

$(*)$ and $(* *)$ indicate significant increasing variability at $\mathrm{p}<0.10$ and $\mathrm{p}<0.05$ respectively, $\mathrm{F}<1$ and $\mathrm{F}>1$ indicate increasing and decreasing variability respectively.

Table S2.3: Testing homogeneity of variance between P1: 1961-1985 and P2: 1986-2010 using Fligner-Killeen non-parametric test

\begin{tabular}{|c|c|c|c|}
\hline $\begin{array}{l}\text { Agro- } \\
\text { ecological } \\
\text { Zones }\end{array}$ & Stations & $\begin{array}{l}\text { Variability Significance } \\
\text { from P1 to P2 (Isochrone) }\end{array}$ & $\begin{array}{l}\text { Variability Significance } \\
\text { from P1 to P2 } \\
\text { (Agronomic) }\end{array}$ \\
\hline & & p-value & p-value \\
\hline \multirow[t]{3}{*}{ COAST } & Accra & 0.1027 & 0.7116 \\
\hline & Ada & 0.1225 & $0.009211 * *$ \\
\hline & Saltpond & $0.02658 * *$ & 0.2808 \\
\hline \multirow[t]{4}{*}{ SOUTH } & Kumassi & 0.9754 & 0.3714 \\
\hline & Ho & 0.7366 & 0.7466 \\
\hline & Akuse & 0.8962 & 0.4002 \\
\hline & Axim & 0.1634 & 0.1425 \\
\hline \multirow[t]{2}{*}{ TRANSITION } & Kerekrachi & $0.01233 * *$ & $0.009435^{* *}$ \\
\hline & Wenchi & 0.4087 & 0.4281 \\
\hline \multirow[t]{5}{*}{ NORTH } & Tamale & 0.8378 & 0.7934 \\
\hline & Bole & 0.7288 & 0.9445 \\
\hline & Wa & $0.07719 *$ & 0.3305 \\
\hline & Yendi & 0.1758 & $0.02999 * *$ \\
\hline & Navrongo & 0.5251 & $0.09016 *$ \\
\hline
\end{tabular}

$(*)$ and $(* *)$ indicate significant increasing variability at $\mathrm{p}<0.10$ and $\mathrm{p}<0.05$ respectively

S2.6. Resampling of interannual variability for the ensemble members 


\section{Supplemental materials}
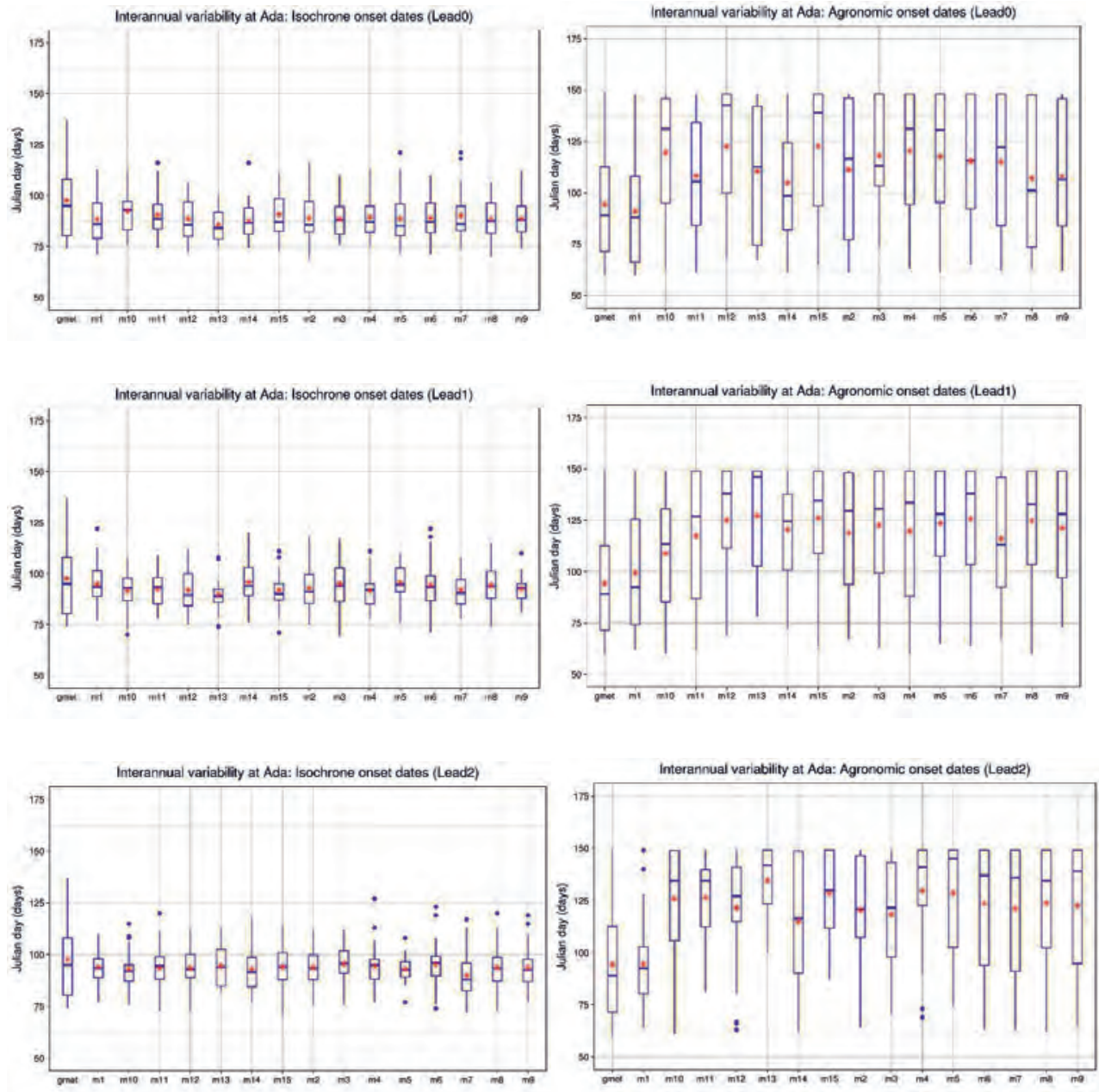

Figure 2.5: Interannual variability of onset dates at Ada for each of the 15 ensemble members across the hindcast years (1981-2010). The isochrones and agronomic methods are presented for leadtime 0,1 , and 2 . 

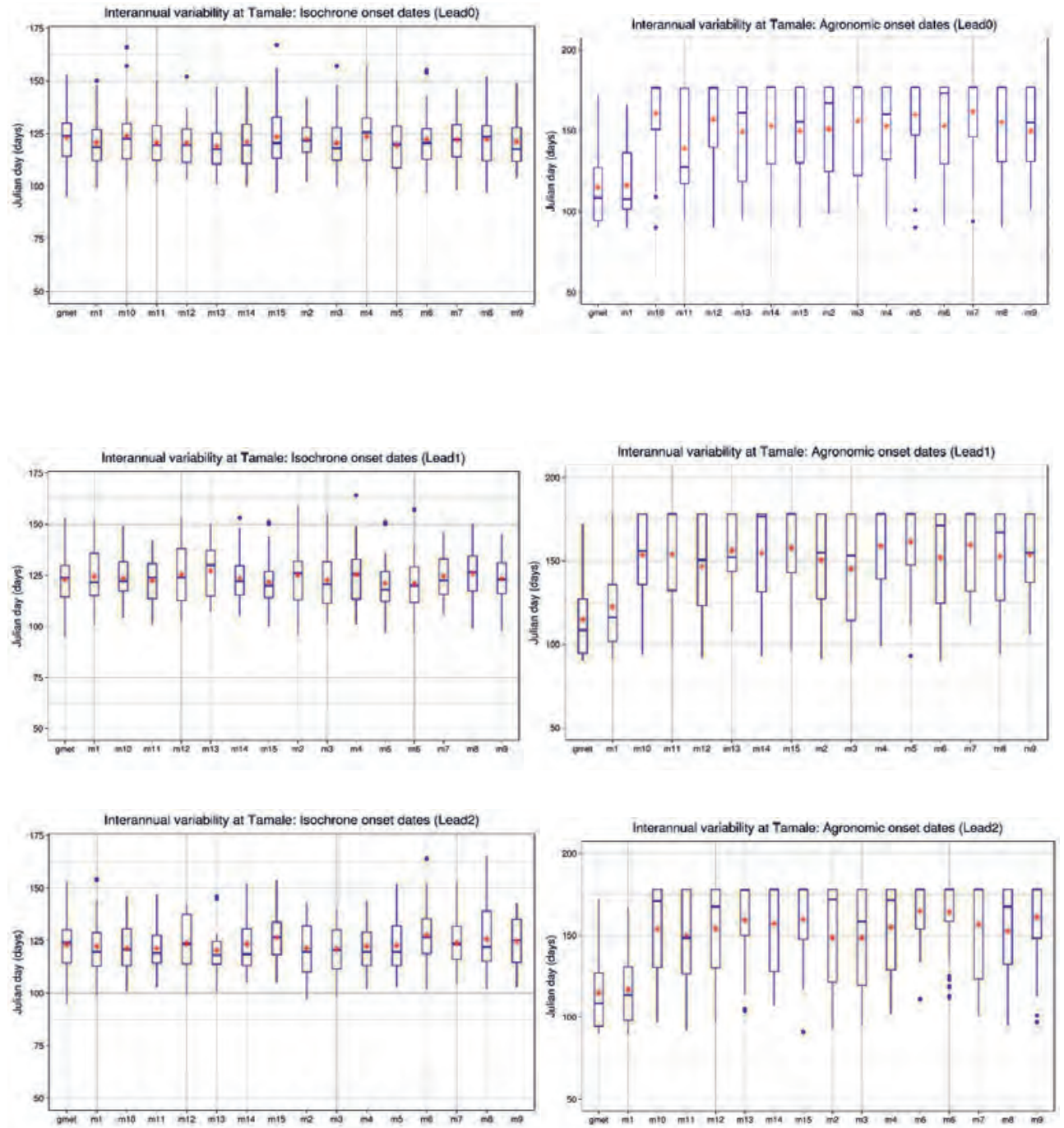

Figure S2.6 : Interannual variability of onset dates at Tamale for each of the 15 ensemble members across the hindcast years (1981-2010). The isochrones and agronomic methods are presented for leadtime 0,1 , and 2 .

\section{S2.7. Significance test for the skill scores for Ada and Tamale}


Supplemental materials

Table S2.4: P-values for the skill score significance at 95\% confidence level (after verification of normality)

\begin{tabular}{clllllll}
\hline \multicolumn{1}{l}{ STATIONS } & ADA & \multicolumn{5}{l}{ TAMALE } \\
\hline Method & Categories Lead0 & Lead1 & Lead2 & Lead0 & Lead1 & Lead2 \\
\hline Early & $0.03441^{*}$ & 0.8827 & 0.5123 & $0.03786^{*}$ & 0.2744 & 0.679 \\
isochrones Normal & 0.2073 & 0.5174 & 0.4375 & 0.3839 & 0.3255 & 0.5787 \\
& Late & $0.0001616^{*}$ & 0.07033 & 0.1075 & $0.02842^{*}$ & $0.03145^{*}$ & 0.2259 \\
\hline Early & 0.2172 & 0.2573 & 0.1484 & 0.2744 & 0.3445 & 0.7073 \\
agronomic Normal & 0.8504 & 0.5 & 0.1484 & 0.3255 & 0.3633 & 0.5338 \\
& Late & $0.04391 *$ & 0.268 & 0.07337 & $0.03145^{*}$ & 0.2775 & 0.5531 \\
\hline
\end{tabular}

*Indicates significant skill scores

\section{Supplemental Material Chapter 3}

S3.1. Comparing local observations with large-scale data at Ada and Tamale sample stations 
(a)
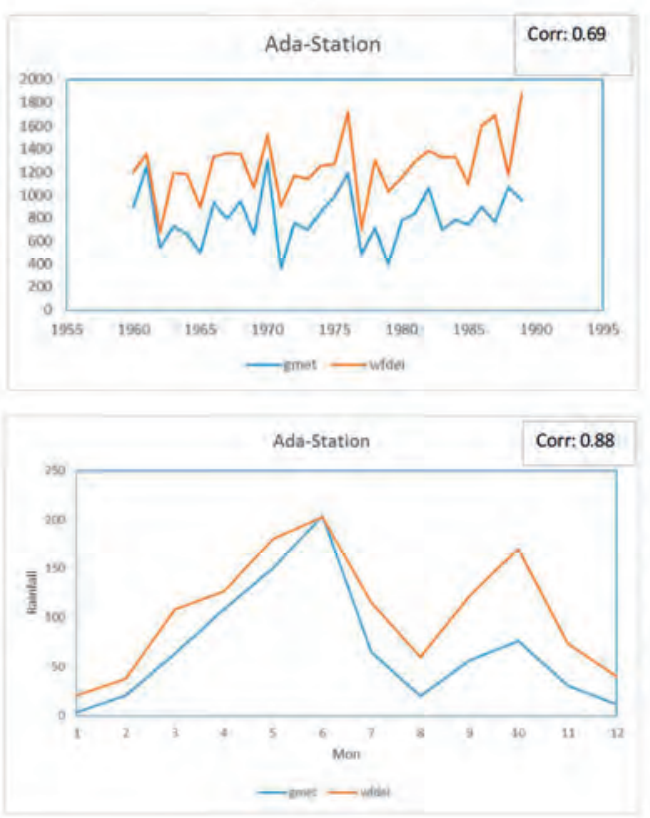

(b)
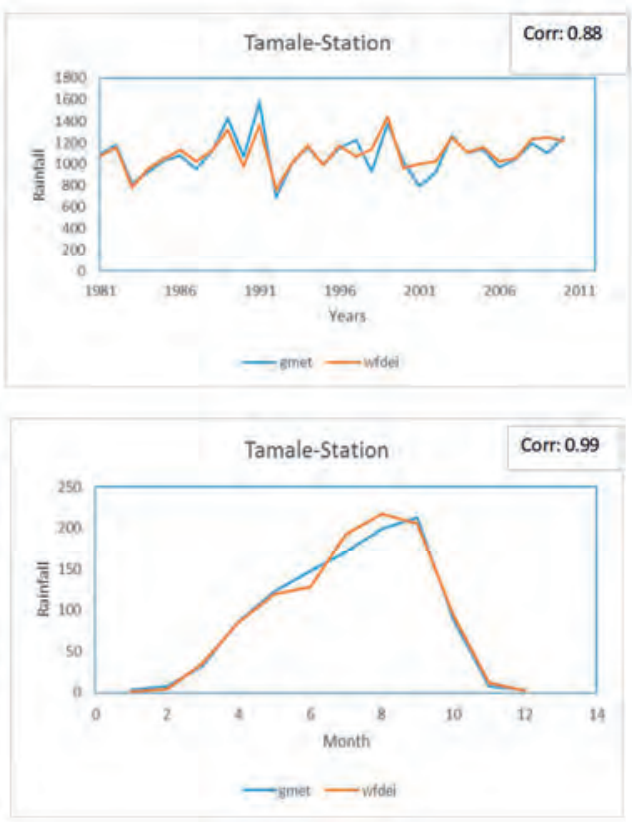

Figure S3.1: Comparing inter-annual rainfall and annual cycle of rainfall between GMet and WFDEI at Ada (Gbangou et al. 2019)

\section{S3.2. Frequency Adaptation Verification for the bias-correction}

In order to check the need for frequency adaptation correction we compared the frequency in dry days in the model and observations. We defined precipitation $<1 \mathrm{~mm}$ as dry day for both models and observations (see Polade et al., 2014) ${ }^{5}$ and found that the number of dry days in the models for the seasons considered (MAM/AMJ) was not larger than in observations (see Table S3.1). We therefore concluded that the correction for the frequency adaptation was not needed. This is, especially, because these seasons represent the beginning of the rainy season in Ghana and therefore have a lot of observed dry days.

Table S3.1: Checking the need for Frequency adaptation correction

\footnotetext{
${ }^{5}$ Polade, S.D., Pierce, D.W., Cayan, D.R., Gershunov, A. and Dettinger, M.D., 2014. The key role of dry days in changing regional climate and precipitation regimes. Scientific reports, 4, p.4364.
} 


\begin{tabular}{ccc}
\hline Stations & $\begin{array}{c}\text { Number of dry days in System } 4 \\
\text { days in GMet Observations }\end{array}$ & $\begin{array}{c}\text { Numers } \\
\text { simulations } \\
\text { (Largest number among the }\end{array}$ \\
Ada & 2548 & 1133 \\
Accra & 2772 & 1193 \\
Saltpond & 2664 & 1288 \\
Axim & 2011 & 743 \\
Akuse & 2694 & 918 \\
Ho & 2483 & 1184 \\
Kumassi & 2042 & 1056 \\
Wenchi & 2125 & 995 \\
Ketekrachi & 2596 & 1005 \\
Bole & 2055 & 1308 \\
Tamale & 2558 & 1550 \\
Yendi & 2086 & 1519 \\
Navrongo & 2129 & 1815 \\
Wa & 2239 & 1390 \\
\hline
\end{tabular}

\section{S3.2. Bias-correction Flowchart}

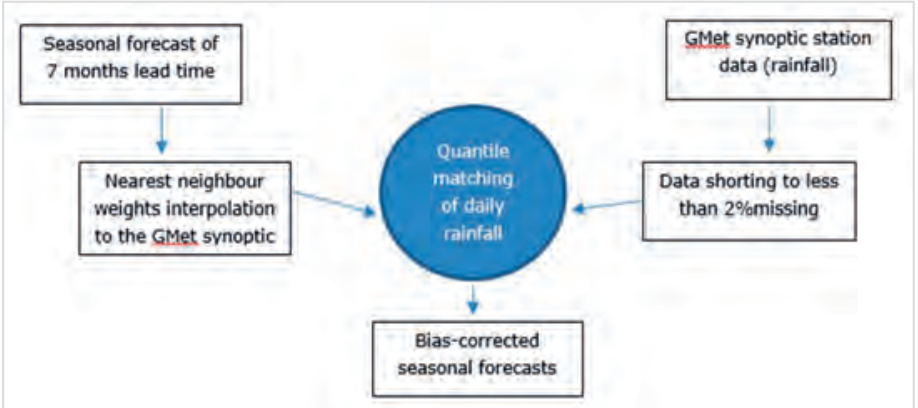


Figure S3.2: Flowchart for bias-correction of seasonal forecasts with GMet observations (Gbangou et al. 2019)

\section{S3.3. Generalized skill score (Ens2AFC) for DSF and Seasonal rainfall}
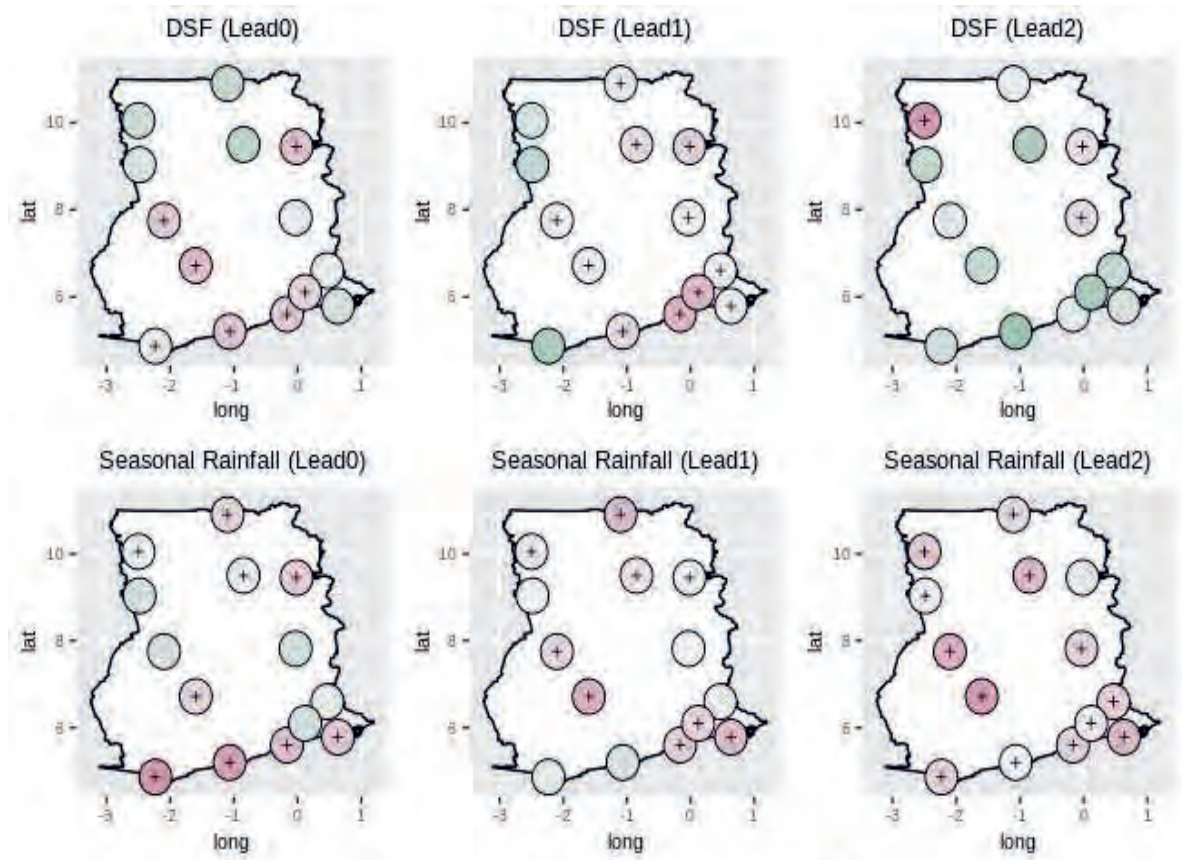

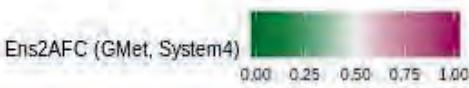

Figure S3.4 : Map plot for the generalized discriminant score (Ens2AFC) between GMet and System 4 forecasts for the dry spell frequency (DSF) and seasonal rainfall. Lead0, 1 and 2 represent initialisation in February (March), January (February), and December (January) lagged-months considered for MAM (AMJ) seasons, respectively. (+) indicates Ens2AFC $>0.5$ (i.e. forecast better than random guessing). The overall Ens2AFC scores ranges from 0.37 to 0.66 .

\section{S3.4. Summary of the binomial distribution test for Ens2AFC}

Table S3.2: Binomial significance test results for the generalized skill score of the agromet indices. $(*)$ and $(* *)$ indicate significant leadtime at $90 \%$ and $95 \%$ confidence level respectively. 
Supplemental materials

\begin{tabular}{|c|c|c|c|c|}
\hline $\begin{array}{l}\text { Agrometeorolog } \\
\text { ical Indices }\end{array}$ & Leadtime & $\begin{array}{l}\begin{array}{l}\text { Number } \\
\text { stations } \\
\text { Ens2AFC }>0.5\end{array} \\
\text { with }\end{array}$ & $\begin{array}{l}\text { Total number } \\
\text { of stations }\end{array}$ & $\mathrm{p}$-value \\
\hline \multirow[t]{3}{*}{ MDSL } & Lead 0 & 12 & 14 & $0.000916 * *$ \\
\hline & Lead 1 & 8 & 14 & 0.211975 \\
\hline & Lead 2 & 7 & 14 & 0.395264 \\
\hline \multirow[t]{3}{*}{ DSF } & Lead 0 & 7 & 14 & 0.395264 \\
\hline & Lead 1 & 7 & 14 & 0.395264 \\
\hline & Lead 2 & 3 & 14 & 0.971313 \\
\hline \multirow[t]{3}{*}{$\begin{array}{l}\text { Seasonal } \\
\text { Rainfall }\end{array}$} & Lead 0 & 9 & 14 & $0.089783 *$ \\
\hline & Lead 1 & 9 & 14 & $0.089783 *$ \\
\hline & Lead 2 & 12 & 14 & $0.000916 * *$ \\
\hline
\end{tabular}

\section{S3.5. ROCSS for DSF and Seasonal rainfall}



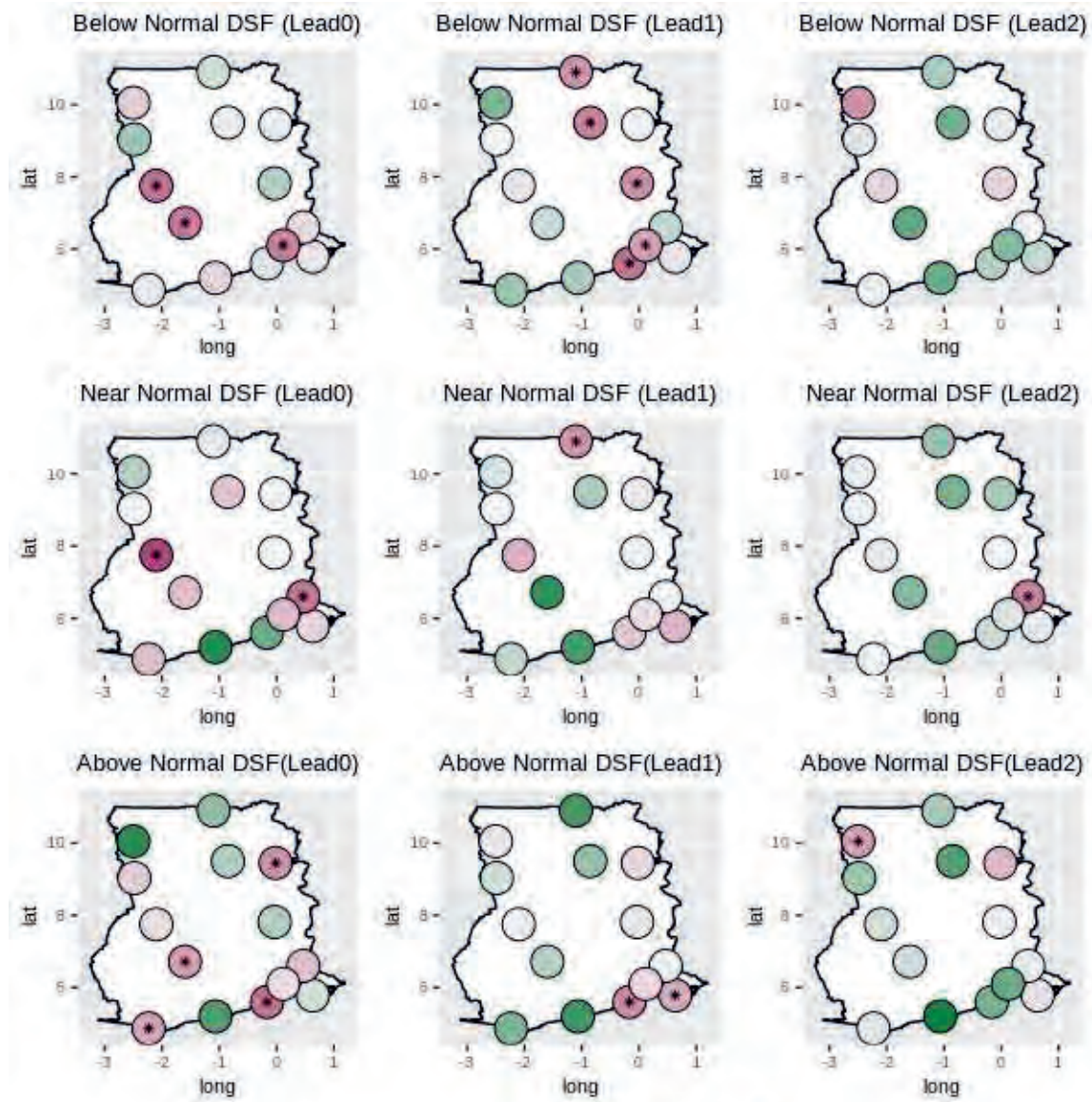

ROCSS (GMet, System4)

Figure S3.5: ROCSS between GMet and the dynamical model System 4 forecasts for the maximum dry spell frequency (DSF) and for the below normal, near normal, and above normal categories. Lead0, 1 and 2 represent initialisation in February (March), January (February), and December (January) lagged-months considered for MAM (AMJ) seasons, respectively. (*) indicates the correlation significance at $\mathrm{p}<0.10$. The overall positive ROCSS ranges from 0 to 0.58 . 

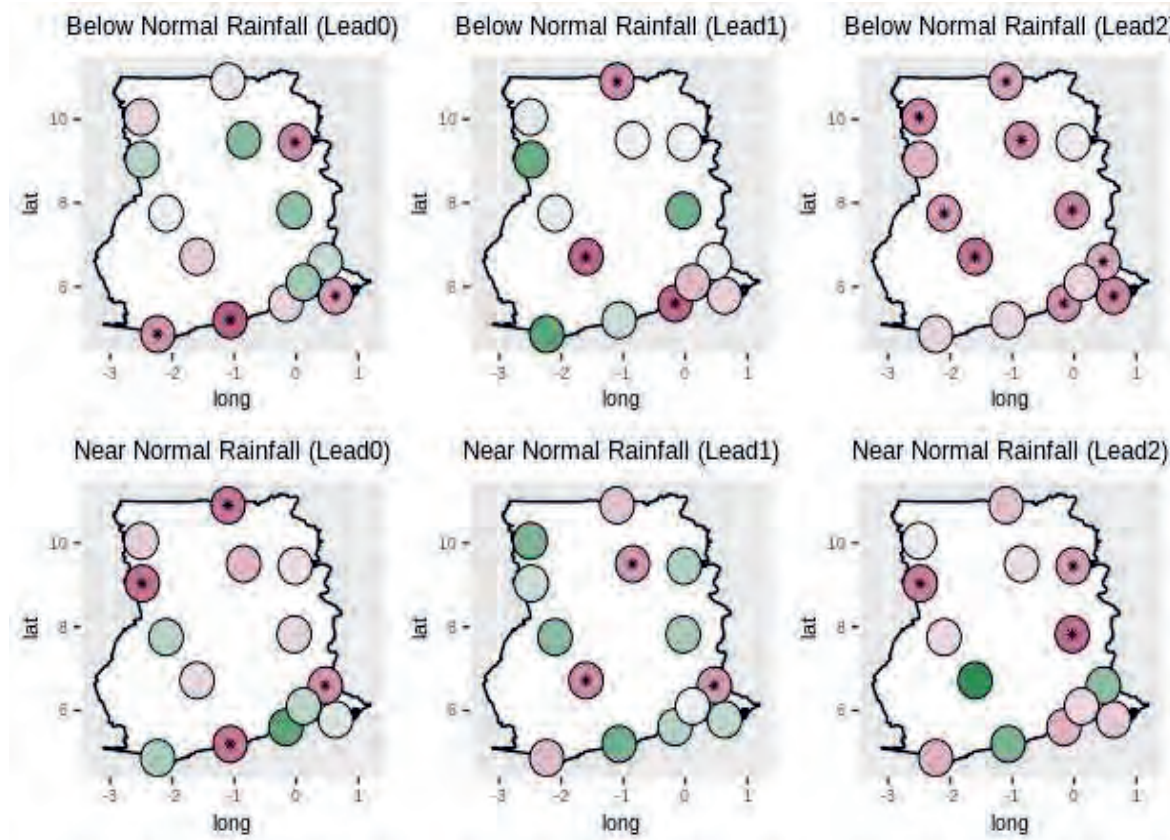

Above Normal Rainfall(Lead0)
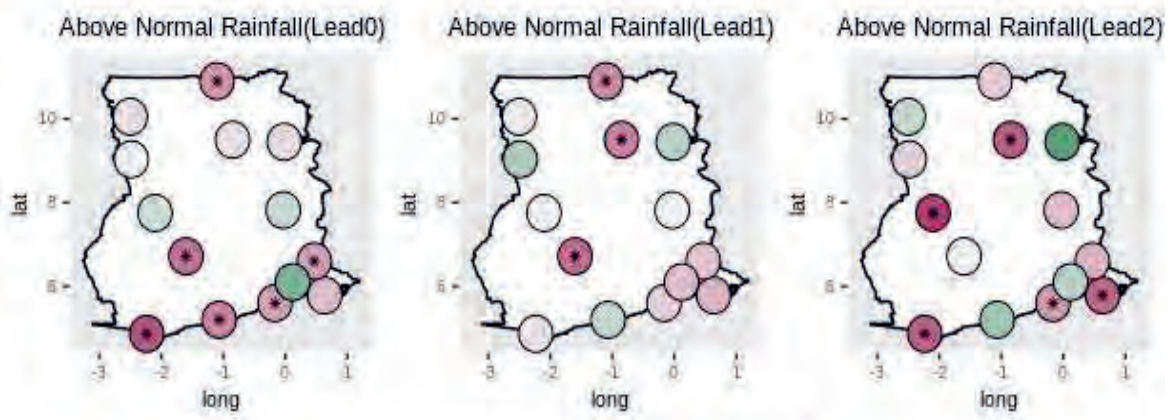

ROCSS (GMet, System4)

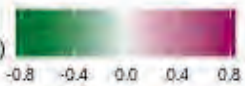

Figure S3.6: ROCSS between GMet and the dynamical model System 4 forecasts for the maximum dry spell frequency (DSF) and for the below normal, near normal, and above normal categories. Lead0, 1 and 2 represent initialisation in February (March), January (February), and December (January) lagged-months considered for MAM (AMJ) seasons respectively. $\left(^{*}\right)$ indicates the correlation significance at $\mathrm{p}<0.10$. The overall positive ROCSS ranges from 0 to 0.58 .

\section{S3.6. Reliability diagram results for two sample locations}



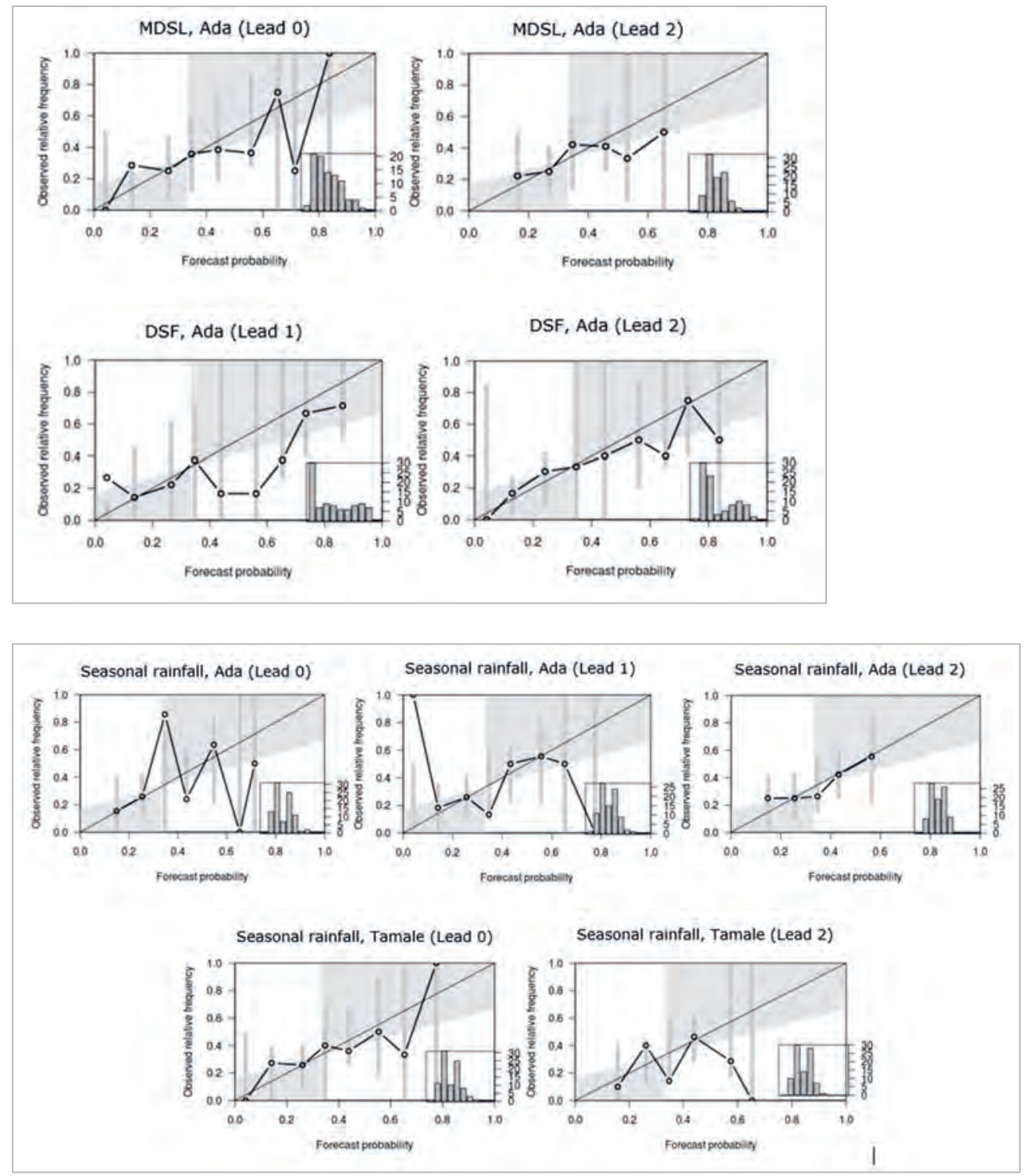

Figure S3.7: Reliability diagrams with consistency bars for the maximum dry spell length (MDSL), Dry spell frequency (DSF) and Seasonal rainfall at Ada and Tamale for Leadtime 0, 1 and 2. 


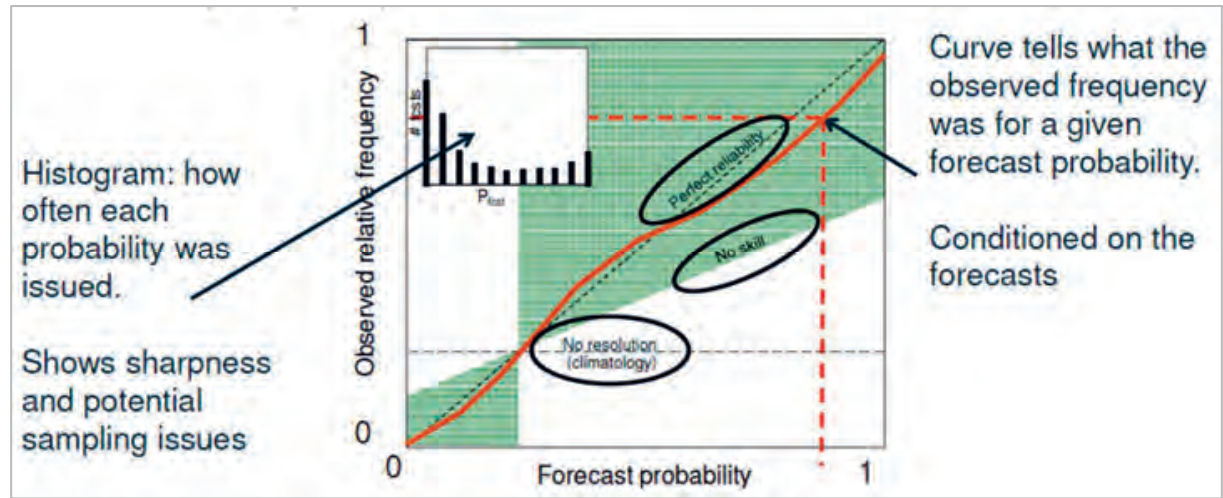

Figure S3.8: Interpretation of the reliability diagram

S3.7. Correlation between the GMet and the statistical model driven by Nino3.4 SST for SON (OND) lagged-months 

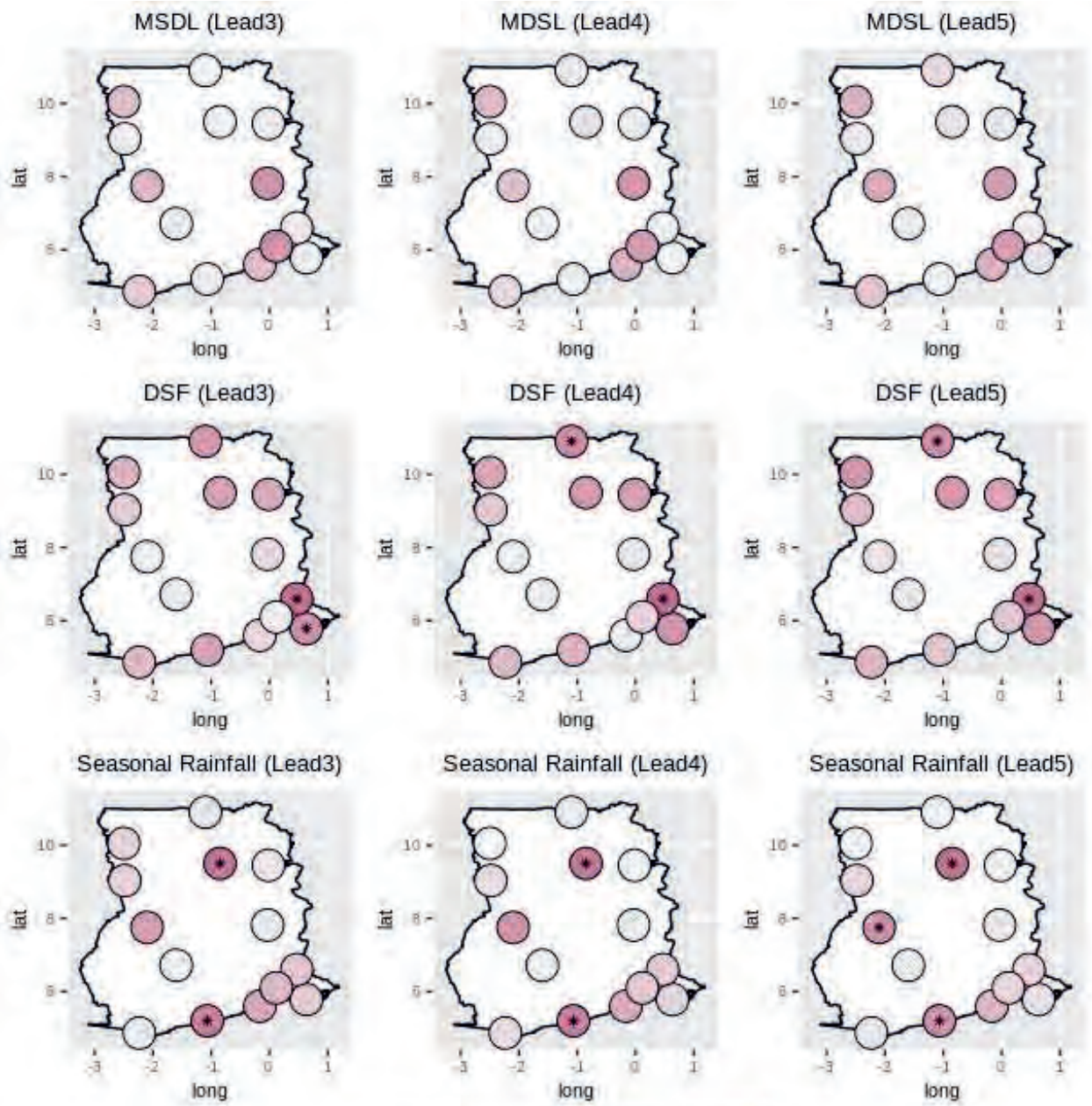

Corr (GMet, SM_Nino3.4)

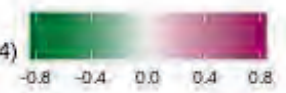

Figure S3.9: Correlation between GMet and the statistical model forecasts driven Nino3.4 SSTs for the maximum dry spell length (MDSL), dry spell frequency (DSF) and seasonal rainfall. Lead3, 4 and 5 represent the relation between SSTs for November (December), October (November), and September(October) and agrometeorological indices considered for MAM (AMJ) seasons respectively. $(*)$ indicates significance at $\mathrm{p}<0.10$. 
Supplemental materials

S3.8. Correlation between the GMet and the statistical model driven by TSA-SST for leadmonths and for MAM(AMJ) seasons
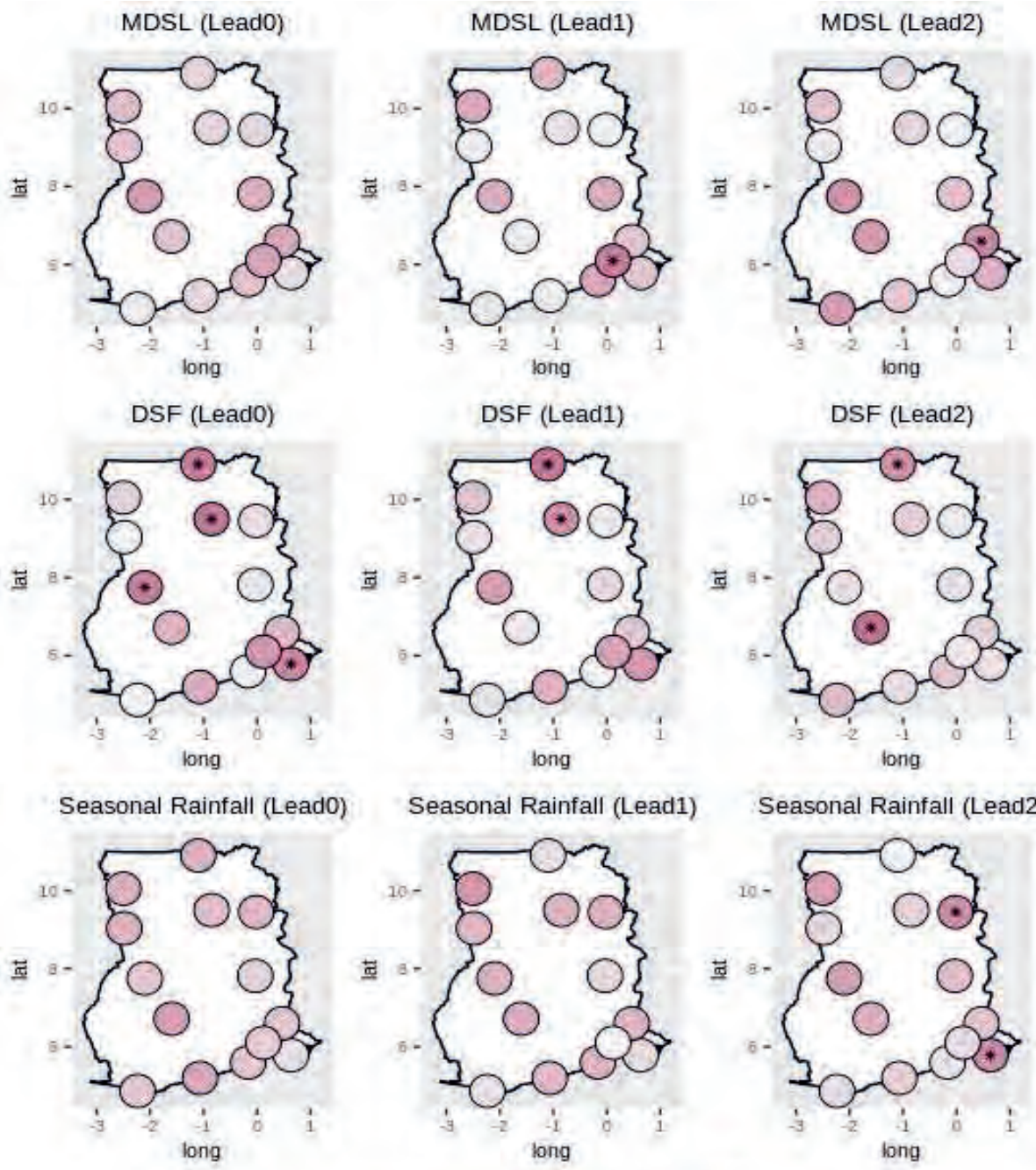

Corr (GMet, SM_TSA)

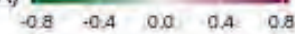

Figure S3.10: Correlation between GMet and the statistical model forecasts driven TSA-SST (SM_TSA) for the maximum dry spell length (MDSL), dry spell frequency (DSF) and seasonal 
rainfall. Lead0, 1 and 2 represent the relation between SSTs for February (March), January(February), and December(January) and agrometeorological indices considered for MAM (AMJ) seasons respectively. $\left(^{*}\right)$ indicates significance at $\mathrm{p}<0.10$. The overall correlations significant coefficients range from 0.30 to 0.43 .

S3.9. Comparison between the dynamical model and statistical model driven by SAT-SST 

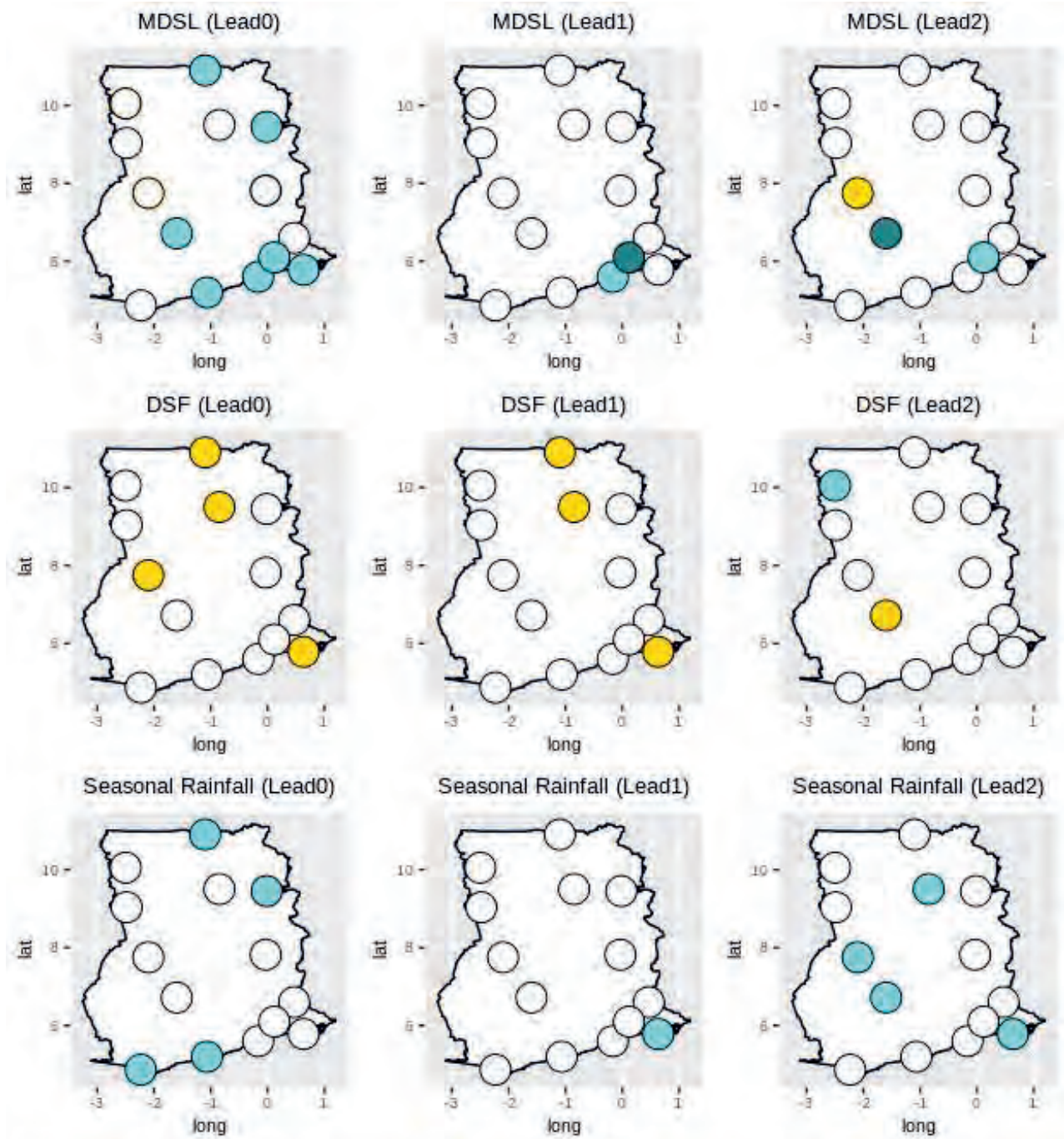

\footnotetext{
Com,DMand SMman sig. $\bigcirc$ com, DManlysig.

Com.smaniysig

Both oart. sig. whi DM > SM O Bath carr. sig. wht DM <.5M
}

Figure S3.11: Comparison of the predictive skill between the dynamical model System 4 (i.e. DM) and statistical model driven by SAT (i.e. SM) in terms difference in correlation relationship with GMet observed agro-meteorological indices. Lead 0, 1 and 2 represent the relation between SSTs for February (March), January(February), and December(January) and agrometeorological indices 
considered for MAM (AMJ) seasons, respectively. "Corr." and "sig." mean respectively correlation and significant.

\section{Supplemental Material Chapter 4}

S4.1. Example of rain gauge used with local farmers to measure rainfall from 5th April to 17th July in order to verify/evaluate the skills of local forecasting knowledge indicators collected
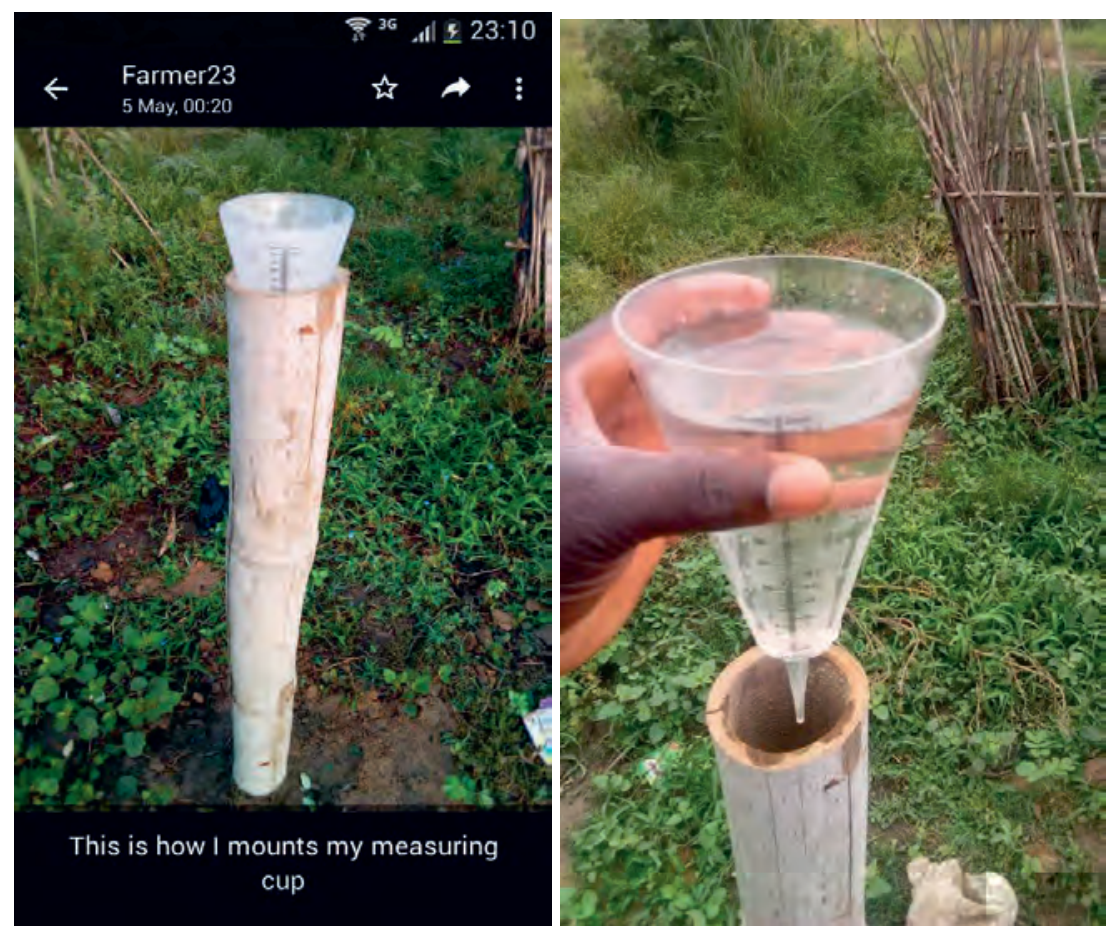

Figure S4.1: Example of rain gauged used by a farmer to measure rainfall occurrence during the data collection period. Daily rainfall is recorded at 9 AM. Rainfall occurrence is defined as rainfall record more than $1 \mathrm{~mm}$ and is based on the average rainfall collected from all stations/communities.

\section{S4.2. Notes on the intuitive integration between local and scientific forecasting knowledge}

Practical example on the judgmental/intuitive integration: Field observations with expert GMet meteorological officers shows that satellite imagery such the Multi-Sensor Precipitation Estimate 
Supplemental materials

Real-Time imagery (MPE, EUMETSAT) can help predict the speed and direction of a storm coming from remote places (e.g. Nigeria and Benin) and moving towards Ada (see Supplementary 4.2, Figure S4.2). This information is usually not perceived by farmers from their local area (i.e. Ada). This prevents local farmers from making longer term forecast based on clouds observations. In the meantime, local forecasting knowledge observation on the presence of dew by farmers, from their position, can help inform meteorologists that coastal area is likely to be subjected to atmospheric stability (i.e. high pressure) that can result in a scattering of the incoming storm. Thus, meteorologists may be aware of the uncertainty related to the incoming considering LFK provided by farmers. 


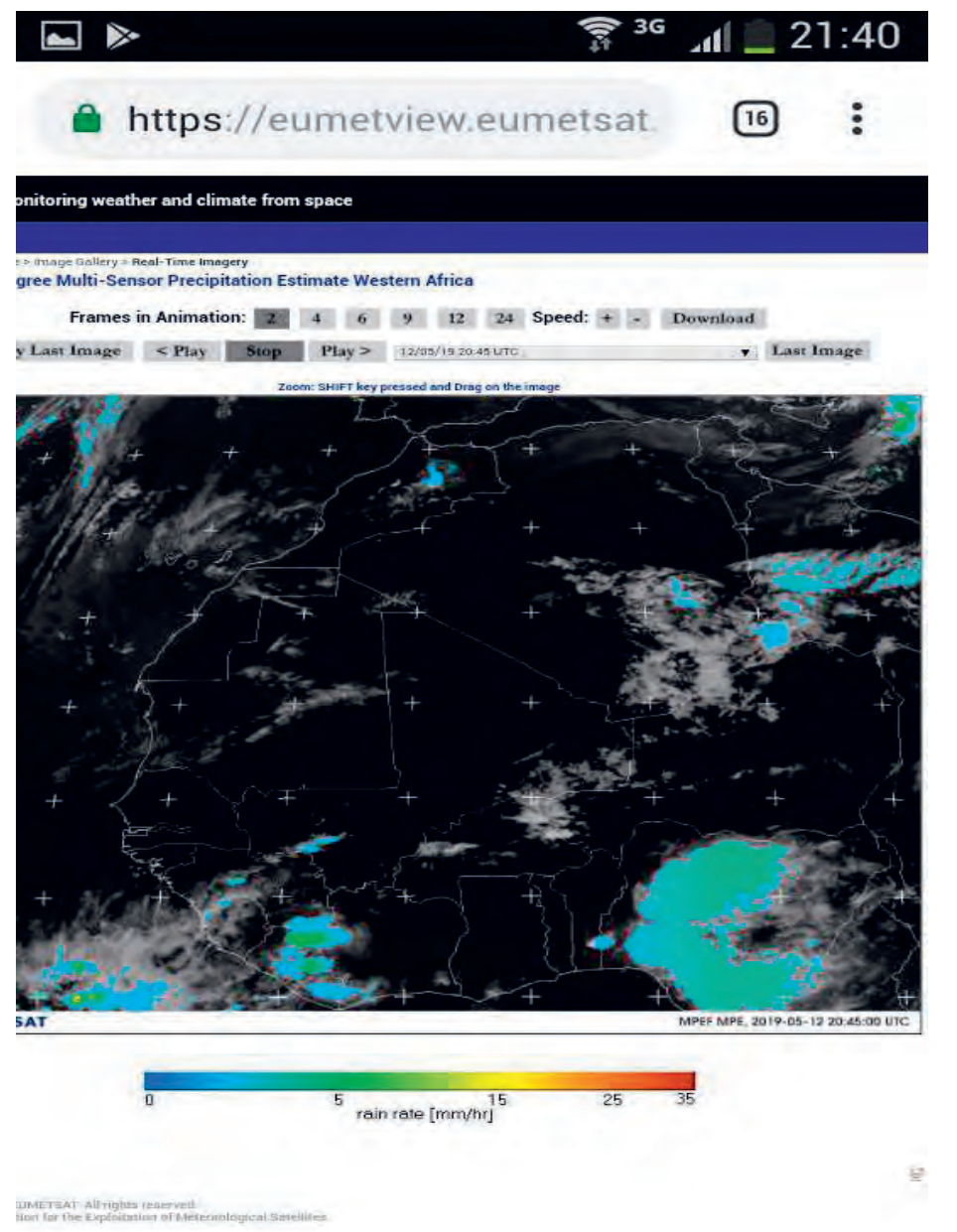

Figure S4.2: Multi-sensor estimation of a storm from EUMETSAT moving towards Ada East District that was not observed by local farmers on $12^{\text {th }}$ May 2019.

\section{Supplemental Material Chapter 5}

S5.1. Summary of local forecast indicators for daily rainfall forecast in the WeatherApp (Gbangou et al. (2020b)) 
Supplemental materials

Table S5.1: List of the local rainfall forecasting knowledge indicators for the weather timescale in Ada East district used in the WeatherApp (adapted from Gbangou et al. 2020b)

\begin{tabular}{ll}
\hline Indicators name & Indicator' signal used for daily rainfall prediction \\
Wind & $\begin{array}{l}\text { When strong winds blow from the sea (usually from West to East } \\
\text { direction) } \\
\text { When the wind is blowing from the sea carrying dust (West-East } \\
\text { direction) with high intensity of the sun }\end{array}$ \\
\hline $\begin{array}{l}\text { Halo (around } \\
\text { Sun) }\end{array}$ & $\begin{array}{l}\text { If at sunset there is a red circle around the sun } \\
\text { Sun }\end{array}$ \\
$\begin{array}{ll}\text { If high intensity of sunshine is observed } \\
\text { If high intensity of sunshine and dust-wind blowing (from West to East) } \\
\text { is observed }\end{array}$ \\
\hline $\begin{array}{ll}\text { Bird (Torle, Ploceus } \\
\text { cucullatus) }\end{array}$ & When frogs start croaking a lot \\
\hline Frog & When pigs catch the grass and turning around it \\
\hline Pig & $\begin{array}{l}\text { When the moon shape is curved such that the shadow is on the left side } \\
\text { Moon (distribution) } \\
\text { When the moon shape is curved such that the shadow is on the right side }\end{array}$ \\
\hline Worm (Abotele) & Spread all over the grass after a previous rain \\
\hline Scorpion & When big black scorpions appear frequently on the farm \\
\hline Clouds & A thick cloud appears at the eastern side of the sea \\
\hline Ants & Carry their food or eggs to their holes \\
\hline Dew & If from mid-night to the following morning there is a lot of dews falling \\
\hline
\end{tabular}

S5.2. Farming decisions that were made using the forecasts and data

Table S5.2. Farming decisions that the co-produced experiment information has helped to support. It gives the percentage of decisions that were more of interest by the 28 participants ( 22 Farmers and 6 extension agents).

\begin{tabular}{llllllll}
\hline & $\begin{array}{l}\text { Prepare } \\
\text { land }\end{array}$ & $\begin{array}{l}\text { Amount } \\
\text { of water to } \\
\text { allocate }\end{array}$ & $\begin{array}{l}\text { Seeding/ } \\
\text { transplan } \\
\text { t }\end{array}$ & Fertilizing & $\begin{array}{l}\text { Pesticide } \\
\text { applicati } \\
\text { on }\end{array}$ & $\begin{array}{l}\text { Labor/we } \\
\text { eding }\end{array}$ & $\begin{array}{l}\text { Othe } \\
\text { rs }\end{array}$ \\
\hline $\begin{array}{l}\text { Rainfall } \\
\text { monitoring data }\end{array}$ & $64 \%$ & $29 \%$ & $68 \%$ & $64 \%$ & $50 \%$ & $61 \%$ & $50 \%$ \\
$\begin{array}{l}\text { Daily forecasts } \\
\text { from farmers }\end{array}$ & $50 \%$ & $25 \%$ & $57 \%$ & $50 \%$ & $46 \%$ & $46 \%$ & $50 \%$ \\
$\begin{array}{l}\text { Daily forecasts } \\
\text { from scientific }\end{array}$ & $57 \%$ & $29 \%$ & $61 \%$ & $57 \%$ & $46 \%$ & $46 \%$ & $50 \%$ \\
\hline
\end{tabular}


models

(meteoblue)

Table S5.3. Significance of the results on the engagement, usability, usefulness, understanding and decisions improvement when considering a binomial distribution for the medium and high categories of responses. (for farmers)

\begin{tabular}{|c|c|c|c|c|c|c|c|c|c|}
\hline $\begin{array}{l}\text { Eval } \\
\text { uatio } \\
\mathrm{n} \\
\text { metri } \\
\mathrm{cs}\end{array}$ & $\begin{array}{l}\text { Digital } \\
\text { items or } \\
\text { tools }\end{array}$ & $\begin{array}{l}\text { Category } \\
\text { Level }\end{array}$ & $\begin{array}{l}\text { Functi } \\
\text { onality }\end{array}$ & $\begin{array}{l}\text { Numb } \\
\text { er of } \\
\text { succe } \\
\text { ss }\end{array}$ & $\begin{array}{l}\text { Total } \\
\text { numb } \\
\text { er of } \\
\text { farme } \\
\text { rs }\end{array}$ & $\begin{array}{l}\text { Prob } \\
\text { abilit } \\
\mathrm{y}\end{array}$ & $\begin{array}{l}\text { Succ } \\
\text { ess } \\
\text { Probi } \\
\text { lity }\end{array}$ & $\begin{array}{l}\mathrm{p}- \\
\text { value }\end{array}$ & $\begin{array}{l}\text { Sign } \\
0.05 \\
(*) ; \\
0.01 \\
(* *) ; \\
0.001 \\
(* * *)\end{array}$ \\
\hline \multirow{2}{*}{$\begin{array}{l}\text { Enga } \\
\text { geme } \\
\text { nt }\end{array}$} & & $\begin{array}{l}\text { Medium and } \\
\text { High }\end{array}$ & & 15 & 22 & 0.5 & $\begin{array}{l}0.97 \\
3761 \\
\end{array}$ & $\begin{array}{l}0.0262 \\
39\end{array}$ & $*$ \\
\hline & & Low & & 7 & 22 & 0.5 & $\begin{array}{l}0.06 \\
69 \\
\end{array}$ & 0.9331 & \\
\hline \multirow[t]{6}{*}{$\begin{array}{l}\text { Usab } \\
\text { ility }\end{array}$} & \multirow{2}{*}{$\begin{array}{l}\text { WeatherA } \\
\text { pp (After } \\
\text { experime } \\
\text { nt) }\end{array}$} & $\begin{array}{l}\text { Somehow and } \\
\text { Very easy }\end{array}$ & \multirow[t]{2}{*}{$\begin{array}{l}\text { Manup } \\
\text { ilation }\end{array}$} & 16 & 22 & 0.5 & $\begin{array}{l}0.99 \\
155\end{array}$ & $\begin{array}{l}0.0084 \\
5\end{array}$ & $* *$ \\
\hline & & $\begin{array}{l}\text { Not easy and } \\
\text { NA }\end{array}$ & & 6 & 22 & 0.5 & $\begin{array}{l}0.02 \\
6239 \\
\end{array}$ & $\begin{array}{l}0.9737 \\
61 \\
\end{array}$ & \\
\hline & \multirow{2}{*}{$\begin{array}{l}\text { WhatsAp } \\
\mathrm{p} \quad \text { (After } \\
\text { experime } \\
\text { nt) }\end{array}$} & $\begin{array}{l}\text { Somehow and } \\
\text { Very easy }\end{array}$ & \multirow[t]{2}{*}{ Graphs } & 16 & 22 & 0.5 & $\begin{array}{l}0.99 \\
155 \\
\end{array}$ & $\begin{array}{l}0.0084 \\
5\end{array}$ & $* *$ \\
\hline & & $\begin{array}{l}\text { Not easy and } \\
\text { NA }\end{array}$ & & 6 & 22 & 0.5 & $\begin{array}{l}0.02 \\
6239 \\
\end{array}$ & $\begin{array}{l}0.9737 \\
61 \\
\end{array}$ & \\
\hline & \multirow{2}{*}{$\begin{array}{l}\text { Rain } \\
\text { gauges } \\
\text { (After } \\
\text { experime } \\
\text { nt) } \\
\end{array}$} & $\begin{array}{l}\text { Somehow and } \\
\text { Very easy }\end{array}$ & \multirow[t]{2}{*}{$\begin{array}{l}\text { Reporti } \\
\text { ng }\end{array}$} & 15 & 22 & 0.5 & $\begin{array}{l}0.97 \\
3761 \\
\end{array}$ & $\begin{array}{l}0.0262 \\
39 \\
\end{array}$ & $*$ \\
\hline & & $\begin{array}{l}\text { Not easy and } \\
\text { NA }\end{array}$ & & 7 & 22 & 0.5 & $\begin{array}{l}0.06 \\
69\end{array}$ & 0.9331 & \\
\hline \multirow{5}{*}{$\begin{array}{l}\text { Usef } \\
\text { ulnes } \\
\text { s/Rel } \\
\text { even } \\
\text { ce }\end{array}$} & \multirow[t]{5}{*}{ Tools } & $\begin{array}{l}\text { Somehow and } \\
\text { Very } \\
\text { Relevant }\end{array}$ & \multirow[t]{2}{*}{$\begin{array}{l}\text { Interne } \\
\mathrm{t}\end{array}$} & 14 & 22 & 0.5 & $\begin{array}{l}0.93 \\
31\end{array}$ & 0.0669 & + \\
\hline & & $\begin{array}{l}\text { Not Relevant } \\
\text { and NA }\end{array}$ & & 8 & 22 & 0.5 & $\begin{array}{l}0.14 \\
3139 \\
\end{array}$ & $\begin{array}{l}0.8568 \\
61 \\
\end{array}$ & \\
\hline & & $\begin{array}{l}\text { Somehow and } \\
\text { Very } \\
\text { Relevant }\end{array}$ & \multirow[t]{2}{*}{$\begin{array}{l}\text { Rain } \\
\text { gauge }\end{array}$} & 18 & 22 & 0.5 & $\begin{array}{l}0.99 \\
9572\end{array}$ & $\begin{array}{l}0.0004 \\
28\end{array}$ & $* * *$ \\
\hline & & $\begin{array}{l}\text { Not Relevant } \\
\text { and NA }\end{array}$ & & 5 & 22 & 0.5 & $\begin{array}{l}0.00 \\
845 \\
\end{array}$ & $\begin{array}{l}0.9915 \\
5 \\
\end{array}$ & \\
\hline & & $\begin{array}{l}\text { Somehow and } \\
\text { Very } \\
\text { Relevant }\end{array}$ & $\begin{array}{l}\text { Smartp } \\
\text { hone }\end{array}$ & 17 & 22 & 0.5 & $\begin{array}{l}0.99 \\
7828\end{array}$ & $\begin{array}{l}0.0021 \\
72\end{array}$ & $* *$ \\
\hline
\end{tabular}




\begin{tabular}{|c|c|c|c|c|c|c|c|c|c|}
\hline & & $\begin{array}{l}\text { Not Relevant } \\
\text { and NA }\end{array}$ & & 6 & 22 & 0.5 & $\begin{array}{l}0.02 \\
6239 \\
\end{array}$ & $\begin{array}{l}0.9737 \\
61\end{array}$ & \\
\hline & & $\begin{array}{l}\text { Somehow and } \\
\text { Very } \\
\text { Relevant }\end{array}$ & $\begin{array}{l}\text { Weath } \\
\text { erApp }\end{array}$ & 18 & 22 & 0.5 & $\begin{array}{l}0.99 \\
9572\end{array}$ & $\begin{array}{l}0.0004 \\
28\end{array}$ & $* * *$ \\
\hline & & $\begin{array}{l}\text { Not Relevant } \\
\text { and NA }\end{array}$ & & 5 & 22 & 0.5 & $\begin{array}{l}0.00 \\
845\end{array}$ & $\begin{array}{l}0.9915 \\
5\end{array}$ & \\
\hline & & $\begin{array}{l}\text { Somehow and } \\
\text { Very } \\
\text { Relevant }\end{array}$ & $\begin{array}{l}\text { Whats } \\
\text { App }\end{array}$ & 16 & 22 & 0.5 & $\begin{array}{l}0.99 \\
155\end{array}$ & $\begin{array}{l}0.0084 \\
5\end{array}$ & ** \\
\hline & & $\begin{array}{l}\text { Not Relevant } \\
\text { and NA }\end{array}$ & & 7 & 22 & 0.5 & $\begin{array}{l}0.06 \\
69\end{array}$ & 0.9331 & \\
\hline & \begin{tabular}{l}
\multicolumn{2}{l}{ Informati } \\
on and \\
data co-
\end{tabular} & $\begin{array}{l}\text { Somehow and } \\
\text { Very } \\
\text { Relevant }\end{array}$ & $\begin{array}{l}\text { local } \\
\text { forecas } \\
\mathrm{t}\end{array}$ & 18 & 22 & 0.5 & $\begin{array}{l}0.99 \\
9572\end{array}$ & $\begin{array}{l}0.0004 \\
28\end{array}$ & $* * *$ \\
\hline & produced & $\begin{array}{l}\text { Not Relevant } \\
\text { and NA }\end{array}$ & & 5 & 22 & 0.5 & $\begin{array}{l}0.00 \\
845\end{array}$ & $\begin{array}{l}0.9915 \\
5\end{array}$ & \\
\hline & & $\begin{array}{l}\text { Somehow and } \\
\text { Very } \\
\text { Relevant }\end{array}$ & $\begin{array}{l}\text { rainfall } \\
\text { data }\end{array}$ & 18 & 22 & 0.5 & $\begin{array}{l}0.99 \\
9572\end{array}$ & $\begin{array}{l}0.0004 \\
28\end{array}$ & $* * *$ \\
\hline & & $\begin{array}{l}\text { Not Relevant } \\
\text { and NA }\end{array}$ & & 5 & 22 & 0.5 & $\begin{array}{l}0.00 \\
845\end{array}$ & $\begin{array}{l}0.9915 \\
5\end{array}$ & \\
\hline & & $\begin{array}{l}\text { Somehow and } \\
\text { Very easy }\end{array}$ & $\begin{array}{l}\text { Scienti } \\
\text { fic }\end{array}$ & 18 & 22 & 0.5 & $\begin{array}{l}0.99 \\
9572 \\
\end{array}$ & $\begin{array}{l}0.0004 \\
28\end{array}$ & $* * *$ \\
\hline & & $\begin{array}{l}\text { Not relevant } \\
\text { and NA }\end{array}$ & $\begin{array}{l}\text { forecas } \\
\mathrm{t}\end{array}$ & 5 & 22 & 0.5 & $\begin{array}{l}0.00 \\
845\end{array}$ & $\begin{array}{l}0.9915 \\
5\end{array}$ & \\
\hline $\begin{array}{l}\text { Unde } \\
\text { rstan } \\
\text { ding }\end{array}$ & $\begin{array}{l}\text { Forecast } \\
\text { uncertaint } \\
\text { y }\end{array}$ & $\begin{array}{l}\text { Somehow and } \\
\text { highly } \\
\text { improved }\end{array}$ & & 18 & 22 & 0.5 & $\begin{array}{l}0.99 \\
9572\end{array}$ & $\begin{array}{l}0.0004 \\
28\end{array}$ & $* * *$ \\
\hline & & $\begin{array}{l}\text { Not improve } \\
\text { and NA }\end{array}$ & & 5 & 22 & 0.5 & $\begin{array}{l}0.00 \\
845\end{array}$ & $\begin{array}{l}0.9915 \\
5\end{array}$ & \\
\hline & $\begin{array}{l}\text { Rainfall } \\
\text { distributio } \\
\mathrm{n}\end{array}$ & $\begin{array}{l}\text { Somehow and } \\
\text { highly } \\
\text { improved }\end{array}$ & & 18 & 22 & 0.5 & $\begin{array}{l}0.99 \\
9572\end{array}$ & $\begin{array}{l}0.0004 \\
28\end{array}$ & $* * *$ \\
\hline & & $\begin{array}{l}\text { Not improve } \\
\text { and NA }\end{array}$ & & 5 & 22 & 0.5 & $\begin{array}{l}0.00 \\
845\end{array}$ & $\begin{array}{l}0.9915 \\
5\end{array}$ & \\
\hline & Decisions & $\begin{array}{l}\text { Somehow and } \\
\text { highly } \\
\text { improved }\end{array}$ & & 18 & 22 & 0.5 & $\begin{array}{l}0.99 \\
9572\end{array}$ & $\begin{array}{l}0.0004 \\
28\end{array}$ & $* * *$ \\
\hline & & $\begin{array}{l}\text { Not improve } \\
\text { and NA }\end{array}$ & & 5 & 22 & 0.5 & $\begin{array}{l}0.00 \\
845\end{array}$ & $\begin{array}{l}0.9915 \\
5\end{array}$ & \\
\hline
\end{tabular}


Table S5.4. Significance of the results on the usefulness, understanding and decisions improvement when considering a binomial distribution for the medium and high categories of responses (for extension agents).

\begin{tabular}{|c|c|c|c|c|c|c|c|c|c|}
\hline $\begin{array}{l}\text { Eval } \\
\text { uatio } \\
\mathrm{n} \\
\text { metri } \\
\mathrm{cs}\end{array}$ & $\begin{array}{l}\text { Digital } \\
\text { items or } \\
\text { tools }\end{array}$ & $\begin{array}{l}\text { Category } \\
\text { Level }\end{array}$ & $\begin{array}{l}\text { Functi } \\
\text { onality }\end{array}$ & $\begin{array}{l}\text { Numb } \\
\text { er of } \\
\text { succe } \\
\text { ss }\end{array}$ & $\begin{array}{l}\text { Total } \\
\text { numb } \\
\text { er of } \\
\text { farme } \\
\text { rs }\end{array}$ & $\begin{array}{l}\text { Prob } \\
\text { abilit } \\
y\end{array}$ & $\begin{array}{l}\text { Succ } \\
\text { ess } \\
\text { Probi } \\
\text { lity }\end{array}$ & $\begin{array}{l}\mathrm{p}- \\
\text { value }\end{array}$ & $\begin{array}{l}\text { Sign } \\
0.05 \\
(*) ; \\
0.01 \\
(* *) ; \\
0.001 \\
(* * *)\end{array}$ \\
\hline \multirow{13}{*}{$\begin{array}{l}\text { Usef } \\
\text { ulnes } \\
\text { s/Rel } \\
\text { evan } \\
\text { ce }\end{array}$} & \multirow[t]{10}{*}{ Tools } & $\begin{array}{l}\text { Somehow and } \\
\text { Very } \\
\text { Relevant }\end{array}$ & \multirow[t]{2}{*}{$\begin{array}{l}\text { Interne } \\
\mathrm{t}\end{array}$} & 3 & 6 & 0.5 & $\begin{array}{l}0.65 \\
625\end{array}$ & $\begin{array}{l}0.3437 \\
5\end{array}$ & \\
\hline & & $\begin{array}{l}\text { Not Relevant } \\
\text { and NA }\end{array}$ & & 3 & 6 & 0.5 & $\begin{array}{l}0.65 \\
625 \\
\end{array}$ & $\begin{array}{l}0.3437 \\
5\end{array}$ & \\
\hline & & $\begin{array}{l}\text { Somehow and } \\
\text { Very } \\
\text { Relevant }\end{array}$ & \multirow[t]{2}{*}{$\begin{array}{l}\text { Rain } \\
\text { gauge }\end{array}$} & 4 & 6 & 0.5 & $\begin{array}{l}0.89 \\
0625\end{array}$ & $\begin{array}{l}0.1093 \\
75\end{array}$ & + \\
\hline & & $\begin{array}{l}\text { Not Relevant } \\
\text { and NA }\end{array}$ & & 2 & 6 & 0.5 & $\begin{array}{l}0.34 \\
375\end{array}$ & $\begin{array}{l}0.6562 \\
5\end{array}$ & \\
\hline & & $\begin{array}{l}\text { Somehow and } \\
\text { Very } \\
\text { Relevant }\end{array}$ & \multirow[t]{2}{*}{$\begin{array}{l}\text { Smartp } \\
\text { hone }\end{array}$} & 6 & 6 & 0.5 & 1 & 0 & $* * *$ \\
\hline & & $\begin{array}{l}\text { Not Relevant } \\
\text { and NA }\end{array}$ & & 0 & 6 & 0.5 & $\begin{array}{l}0.01 \\
5625\end{array}$ & $\begin{array}{l}0.9843 \\
75\end{array}$ & \\
\hline & & $\begin{array}{l}\text { Somehow and } \\
\text { Very } \\
\text { Relevant }\end{array}$ & \multirow[t]{2}{*}{$\begin{array}{l}\text { Weath } \\
\text { erApp }\end{array}$} & 6 & 6 & 0.5 & 1 & 0 & $* * *$ \\
\hline & & $\begin{array}{l}\text { Not Relevant } \\
\text { and NA }\end{array}$ & & 0 & 6 & 0.5 & $\begin{array}{l}0.01 \\
5625\end{array}$ & $\begin{array}{l}0.9843 \\
75\end{array}$ & \\
\hline & & $\begin{array}{l}\text { Somehow and } \\
\text { Very } \\
\text { Relevant }\end{array}$ & \multirow[t]{2}{*}{$\begin{array}{l}\text { Whats } \\
\text { App }\end{array}$} & 6 & 6 & 0.5 & 1 & 0 & $* * *$ \\
\hline & & $\begin{array}{l}\text { Not Relevant } \\
\text { and NA }\end{array}$ & & 0 & 6 & 0.5 & $\begin{array}{l}0.01 \\
5625\end{array}$ & $\begin{array}{l}0.9843 \\
75\end{array}$ & \\
\hline & \multirow{3}{*}{$\begin{array}{l}\text { Informati } \\
\text { on and } \\
\text { data co- } \\
\text { produced }\end{array}$} & $\begin{array}{l}\text { Somehow and } \\
\text { Very } \\
\text { Relevant }\end{array}$ & \multirow[t]{2}{*}{$\begin{array}{l}\text { local } \\
\text { forecas } \\
t\end{array}$} & 6 & 6 & 0.5 & 1 & 0 & $* * *$ \\
\hline & & $\begin{array}{l}\text { Not Relevant } \\
\text { and NA }\end{array}$ & & 0 & 6 & 0.5 & $\begin{array}{l}0.01 \\
5625 \\
\end{array}$ & $\begin{array}{l}0.9843 \\
75 \\
\end{array}$ & \\
\hline & & $\begin{array}{l}\text { Somehow and } \\
\text { Very } \\
\text { Relevant }\end{array}$ & $\begin{array}{l}\text { rainfall } \\
\text { data }\end{array}$ & 6 & 6 & 0.5 & 1 & 0 & $* * *$ \\
\hline
\end{tabular}




\begin{tabular}{|c|c|c|c|c|c|c|c|c|c|}
\hline & & $\begin{array}{l}\text { Not Relevant } \\
\text { and NA }\end{array}$ & & 0 & 6 & 0.5 & $\begin{array}{l}0.01 \\
5625\end{array}$ & $\begin{array}{l}0.9843 \\
75\end{array}$ & \\
\hline & & $\begin{array}{l}\text { Somehow and } \\
\text { Very easy }\end{array}$ & $\begin{array}{l}\text { Scienti } \\
\text { fic }\end{array}$ & 6 & 6 & 0.5 & 1 & 0 & $* * *$ \\
\hline & & $\begin{array}{l}\text { Not relevant } \\
\text { and NA }\end{array}$ & $\begin{array}{l}\text { forecas } \\
\mathrm{t}\end{array}$ & 0 & 6 & 0.5 & $\begin{array}{l}0.01 \\
5625\end{array}$ & $\begin{array}{l}0.9843 \\
75\end{array}$ & \\
\hline $\begin{array}{l}\text { Unde } \\
\text { rstan } \\
\text { ding }\end{array}$ & $\begin{array}{l}\text { Forecast } \\
\text { uncertaint } \\
\mathrm{y}\end{array}$ & $\begin{array}{l}\text { Somehow and } \\
\text { highly } \\
\text { improved }\end{array}$ & & 6 & 6 & 0.5 & 1 & 0 & $* * *$ \\
\hline & & $\begin{array}{l}\text { Not improve } \\
\text { and NA }\end{array}$ & & 0 & 6 & 0.5 & $\begin{array}{l}0.01 \\
5625\end{array}$ & $\begin{array}{l}0.9843 \\
75\end{array}$ & \\
\hline & $\begin{array}{l}\text { Rainfall } \\
\text { distributio } \\
n\end{array}$ & $\begin{array}{l}\text { Somehow and } \\
\text { highly } \\
\text { improved }\end{array}$ & & 6 & 6 & 0.5 & 1 & 0 & $* * *$ \\
\hline & & $\begin{array}{l}\text { Not improve } \\
\text { and NA }\end{array}$ & & 0 & 6 & 0.5 & $\begin{array}{l}0.01 \\
5625\end{array}$ & $\begin{array}{l}0.9843 \\
75\end{array}$ & \\
\hline & Decisions & $\begin{array}{l}\text { Somehow and } \\
\text { highly } \\
\text { improved }\end{array}$ & & 6 & 6 & 0.5 & 1 & 0 & $* * *$ \\
\hline & & $\begin{array}{l}\text { Not improve } \\
\text { and NA }\end{array}$ & & 0 & 6 & 0.5 & $\begin{array}{l}0.01 \\
5625\end{array}$ & $\begin{array}{l}0.9843 \\
75\end{array}$ & \\
\hline
\end{tabular}

S5.3. Statistics on messages received via the WhatsApp group

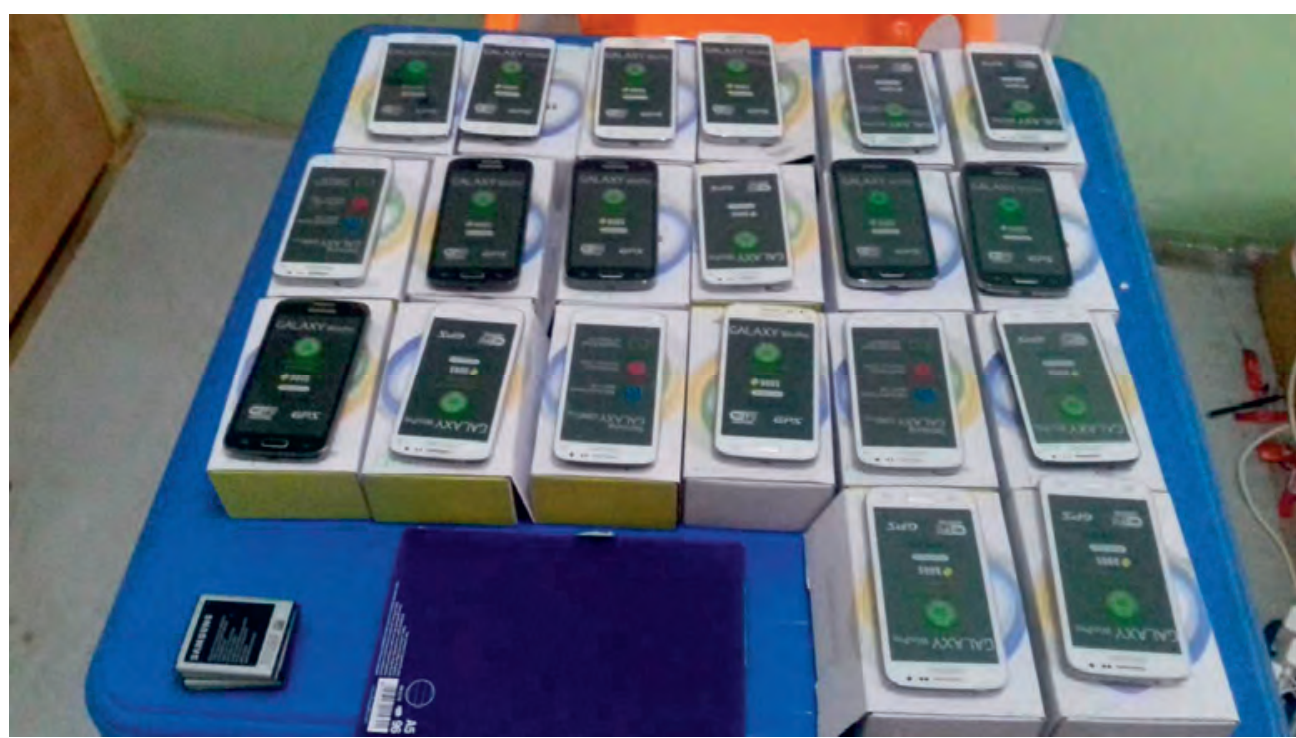


Figure 5.1. Sample photos of the smartphones used by farmers and extension agents.

Table S5.5. Count of messages, pictures and emojis exchanged via the WhatsApp group.

\begin{tabular}{|c|c|c|c|}
\hline Months & Messages & Pictures/Graphs (forecasts) & Emojis exchanges \\
\hline April & 164 & 33 & 92 \\
\hline May & 324 & 70 & 103 \\
\hline June & 154 & 61 & 62 \\
\hline July & 93 & 35 & 30 \\
\hline Total ( $5^{\text {th }}$ April- $17^{\text {th }}$ July 2019$)$ & 736 & 199 & 287 \\
\hline
\end{tabular}
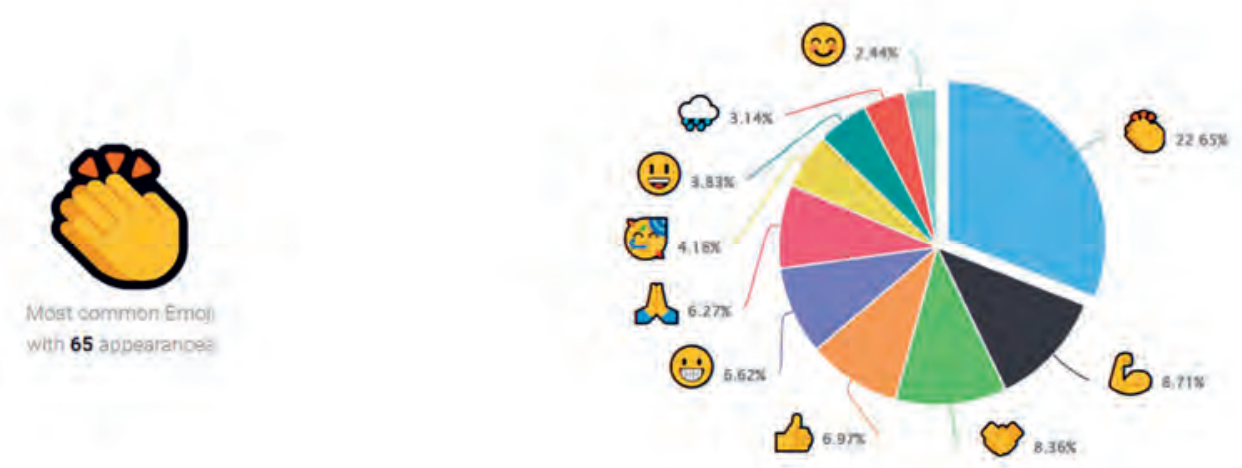

Figure S5.2. Statistics on emojis shared in the WhatsApp group.

S5.4. Technical reports on issues by socio-demographic characteristics (age, gender and literacy)

Table S5.6 Analysis of the technical issues reported by age, gender and literacy level from a total of 92 technical issues recorded during the testing phase.

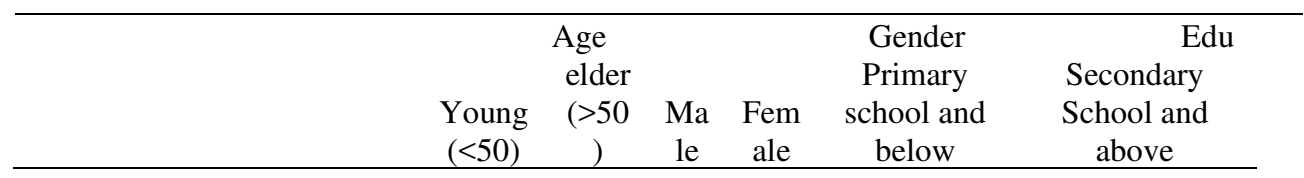




\begin{tabular}{ccccccc}
\hline Number & 14 & 8 & 18 & 4 & 5 & 17 \\
\hline $\begin{array}{c}\text { Technical issues report } \\
\text { (smartphone use, internet } \\
\text { handling) }\end{array}$ & 23 & 28 & 45 & 12 & 35 & 17 \\
\hline Ratio & 1.64 & 3.50 & $\begin{array}{c}2.5 \\
0\end{array}$ & 3.00 & 6.93 & 1.02 \\
\hline
\end{tabular}

\section{S5.5. FarmerSupport mobile APP developed based on insight from this study}

\begin{tabular}{|l|l|}
\hline What indicators \\
\hline
\end{tabular}




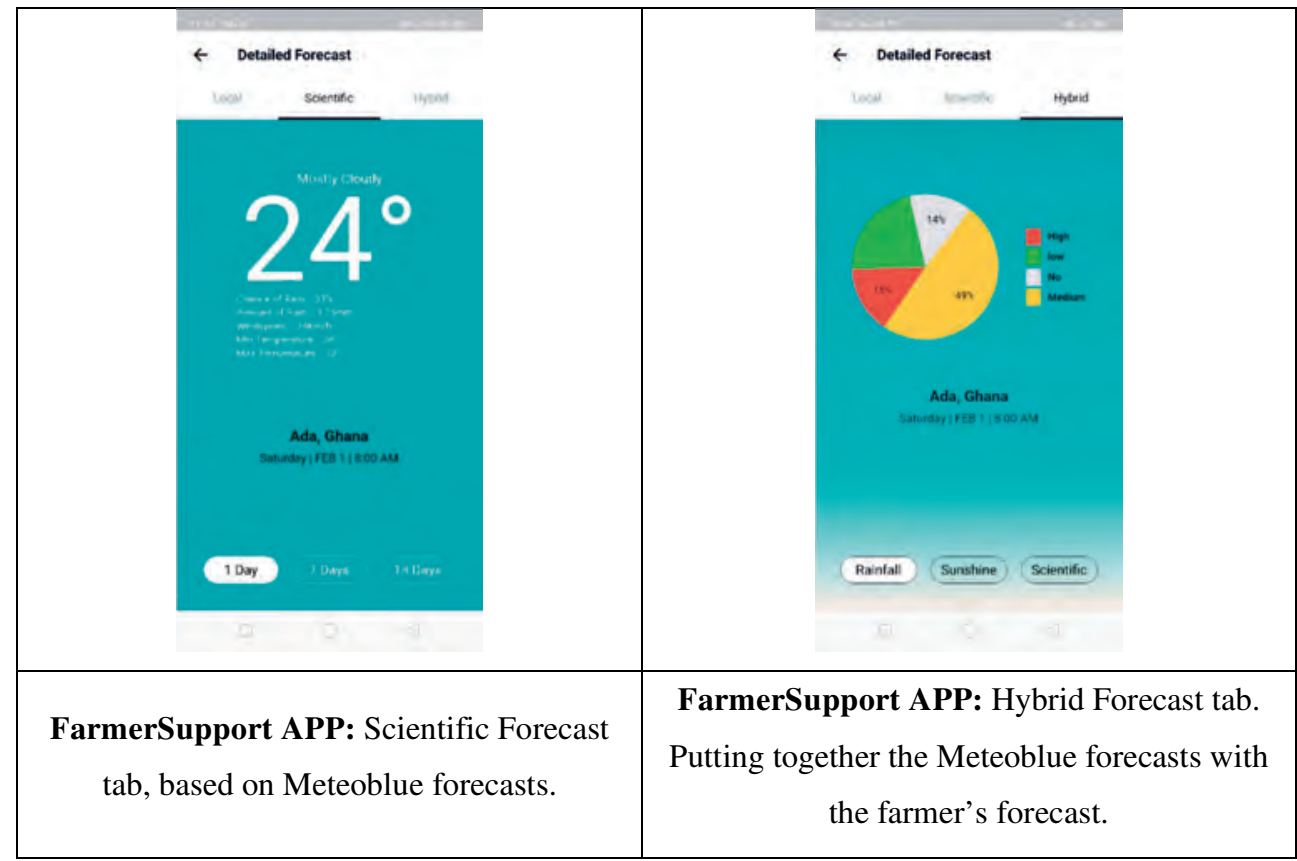

Figure 5.3. Details on the integrated APP developed under the Waterapps project (based on lessons from the present study) and which is available on google play store (https://play.google.com/store/apps/details?id=com.spacewek.farmersupport). 
Supplemental materials 


\section{Summary}

Smallholder farmers represent the backbone of Ghana's agricultural production. However, they are the most disadvantaged population group as they are mostly involved in traditional and rainfed agriculture characterized by low productivity. The high dependence on rainfall and limited access to reliable climate services (and other agricultural technologies and inputs) render smallholders more vulnerable to current and future weather and climate shocks. Providing accessible and reliable weather and climate information is crucial for smallholder farmers to increase their adaptive capacity in the face of climate variability and change. Yet, most smallholder farmers rely only on traditional or local forecasts to make short and long-term decisions for farm and water management. Effective agrometeorological forecast information service can improve farmers' decision-making about selecting crop types/varieties, planting and harvesting dates, fertilizer applications, water allocation optimization, and preparation for extreme events.

Therefore, this $\mathrm{PhD}$ thesis explored ways to improve the quality, access to and use of weather and climate information by smallholder farmers in Ghana. To this end, I formulated four research questions.

The first two research questions focus on the tailoring of scientific, model-based forecasts to meet local farmers' needs. The first question is how and with what results can a dynamical model be used to tailor and improve predictions of the onset of the rainy season (RQ1, Chapter 2)?

The second research question is how and with what results can dynamical and statistical models be used to tailor and improve predictions of dry spell occurrence and seasonal rainfall (RQ2, Chapter 3)?

The third research question focused on the integration of local and scientific forecasting systems. Thus, our third research question asks what are local forecast indicators, their accuracy and integration opportunities between local and modern forecasting systems (RQ3, Chapter 4)?

The final research question focused on principles for designing ICT-based weather and climate services tailored for smallholder farmers: What are the benefits and design principles of ICT-based climate service coproduction with and for smallholder farmers (RQ4, Chapter 5)? 


\section{Summary}

A multimethodological approach was used for data collection and analyses to address the objectives and research questions. Chapters 2 and 3 focus on tailoring scientific, model-based forecasts to meet local farmers' needs. I started this research by proposing two different definitions of local onset dates of the rainy season and assessed the performance of seasonal forecast models (ECMWF System 4) in predicting these onset dates (chapter 2). Both definitions were suitable for the raw and bias-corrected ECMWF System 4 seasonal forecasts. I then assessed trends in observed rainy season onset, variability and prediction performance of the forecast models in Ghana with a focus on the coastal delta zone where the pilot station was located. I found that onset dates vary significantly locally, particularly over the coastal savanna and northern Ghana, which pose a challenge for local farmers to foresee the start of the rainy season only based on local knowledge. ECMWF-System 4 seasonal climate forecasts exhibit significant skills that vary by location, leadtime, and categories but more present in the coastal savanna zone. I conclude that there is a potential to provide tailor-made scientific, model-based seasonal forecast information to support local farmers.

Next, in chapter 3, I analyzed the trends, variability, and predictability of seasonal rainfall, dry spell length and frequency at critical stages of crop production in Ghana using both dynamical (i.e. ECMWF-System 4) and statistical forecasts (i.e. influence of sea surface temperature (SSTs)). Results show that these agrometeorological indicators are also highly variable, especially over the coastal and northern Ghana. Again, this indicates the difficulties that local farmers face in predicting these decision-relevant agrometeorological indicators. Skillful (significant) forecasts also depend on the location, lead-time and categories but are more concentrated in the coastal savanna area. Using the dynamical and statistical forecasts (together) helps to synergize the decision-relevant agrometeorological indicators' predictability to address the occurring local climate variability.

Chapter 4 focuses on integrating local and scientific forecasting systems. I explore the potential for improving local weather and climate information by integrating local forecasting knowledge (LFK) and scientific forecasting knowledge (SFK) for farmers in Ada, Ghana. To achieve this, I documented local forecasting knowledge (LFK) using qualitative methods (interviews and focus group discussions) and collected LFK-indicators in real-time using a citizen experiment involving ICT-based digital tools (apps). I developed ways to quantify the skills and integrate LFK and SFK. 
There, I found that combining a specific set of local forecast indicators can result in higher local forecasts' performance. Notably, to increment one-day rainfall forecast, local and scientific forecasts can be used side-by-side but alternated depending on the set of local forecast indicators observed by farmers. The diversity of local forecast indicators also offers the potential to develop other integration approaches between local and modern forecasting systems to improve and enrich each system.

Chapter 5 focuses on the benefits and design principles of ICT-based climate services tailored for smallholder farmers. I analyzed outputs from the citizen science experiment involving farmers, extension agents, and scientists to design and test ICT-based climate services that include local and scientific forecasts. I found that the joined-up design of user-friendly digital tools (apps) and production of local and scientific forecasting knowledge with and for farmers facilitated smallholders' access to tools and information for decision-making and their understanding and use of these tools and information. Principles for designing such ICT-based climate services require an intensive collaboration of researchers with a dedicated and targeted group of farmers and extension agents to build a basis for weather and climate information production and dissemination in the area of interest. This collaboration includes capacity building, monitoring and technical assistance, especially during the development phase. Forecasting experience, age, gender and literacy level are also among the socio-demographic characteristics that need to be considered in the design.

Last, in Chapter 6, I reflected on the overall research and derived implications for Ghana (and elsewhere)'s climate services development. Firstly, this thesis demonstrated that uncertainties in predicting locally decision-relevant agrometeorological indicators are a real challenge for farmers, especially over the coastal savanna and northern Ghana. I showed that the use of large-scale scientific (model-based) forecasts together with local information and data can useful (significant) predictions to address local climate variability that undermine smallholders' adaptive capacity. Secondly, I provided novel methods for quantifying the local forecasting knowledge and integrating (combining) local and model-based forecasts at the Ada East district, the Waterapps pilot site. These integration technics represent an added-value for small-scale predictions as they can potentially enhance the accuracy of integrated forecasts compared to the standalone local or scientific forecasts. Finally, I demonstrated the benefits and design requirements of an ICT-based climate information service that facilitate the coproduction of local and scientific forecasting 
Summary

knowledge. Such service engages a targeted and dedicated group of farmers and extension agents to collaborate with researchers and generate forecasts and share forecast information within the targeted community.

My thesis contributes to enlightening and orienting science on ways to develop locally-effective climate services that integrate the bottom-up and top-down approaches within an environment of knowledge coproduction and sharing process. Considering the predominance and contribution of small-scale farming, national and international stakeholders are encouraged to adopt agricultural policies that facilitate the proposed process of local climate service development. This process will increase the quality, access, and use of smallholder farmers' climate services in developing countries. 


\section{Acknowledgments}

During the last four years, I had a fulfilling $\mathrm{PhD}$ journey. The journey has been a happy but also a challenging period. I gained more knowledge and confidence as a researcher. At the same time, I experienced being a father. $\mathrm{My} \mathrm{PhD}$ journey has not been an individual experience; instead, it took place in a social context and included several persons, whom I would like to thank for their support.

Foremost, I would like to express my sincere gratitude to my supervision team. First, to my promotor, Prof. dr. Fulco Ludwig. Fulco, you are a smart and great thinker! During my PhD, you encouraged and supported me with your insightful comments and patience, which helped me grow and improve my scientific skills. Next, I would like to thank my daily supervisor Dr. Erik van Slobbe. Erik, thank you for being supportive both in and outside the research environment. Thank you for always showing concerns and continuously querying to ensure that I am doing well. I appreciate your patience, quick reaction in giving feedbacks and facilitating my research in Ghana and Netherlands. Also, to my co-promotor, Prof. Gordana Kranjac-Berisavljevic, thank you for your prompt support, particularly, during fieldwork. You have made the arrangements necessary to facilitate my integration and fieldwork in Ghana.

Aside from my supervision team, I would like to thank other people who contributed in one way or the other to the success of my study. First, I would like to thank Dr. Greuell Wouter for his critical thinking and contribution to my technical papers related to seasonal forecasting. Dr. Long Hoang and Dr. Spyros Paparrizos thank you for being available, sometimes on short notices, and contributing to my research's success. To Prof. dr. Carolien Kroeze, your advice, at the start of my $\mathrm{PhD}$, on the importance of independent thinking guided me during my research. Thank you also for the encouragements during Ph.D. meetings. I also wish to thank Saskia, Ronald, Wietse, Iwan and Maartje at the Water System and Global Change group and Art from the public administration group for the diverse ways you have supported me.

Furthermore, I would like to thank my colleagues and fellow PhDs. Special thanks to Rebecca and Uthpal from the Waterapps project Emmanuel and Andy from the Evoca project. Your support and company have been inspiring for my research. Thanks to all colleagues and PhD peers at WSG: Geoffrey, Mengru, Richard, Ang, Coco, Smolenaars, Bram, Daniel, Dianneke, Maryna, Annette, Joreen, Maria, Nancy and many others. Discussing and socializing with all of you has inspired me. 


\section{Acknowledgements}

My sincerest gratitude goes to Ada East District communities' farmers for their commitment and engagement during this research project. I also thank Ghana Meteorological Agency and the Agriculture and Development Unit, Ada East, Ghana, for facilitating my fieldwork in Ghana.

It would have been very difficult to go through the $\mathrm{PhD}$ journey without the support from my family. To my late parents Boari Gbangou and Diakpampoa Naba, you are gone but your belief in me has made this journey possible. To my brothers, sister, nephews and nieces in Burkina Faso, thank you for your encouragements. Last and not the least, to my wife Glwadys Koumbo Nombre, I am grateful for your love and for being there during the past years of my $\mathrm{PhD}$ journey. You gave birth to our daughter Thalia Yendie in France while I was away for fieldwork in Ghana. You supported me by taking care of Thalia Yendie all by yourself. I can't thank you enough. Thank you Thalia Yendie for being our kid, you have been my motivation during this journey. 


\section{About the author}

Talardia Gbangou was born on $31^{\text {st }}$ December 1988 in Komadougou, Burkina Faso. After completing a high school in mathematics and physics, he was awarded a competitive scholarship in 2009 by Burkina's ministry of water resources to study engineering at the International Institute for Water

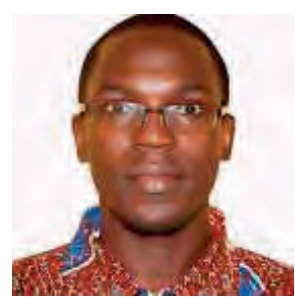
and Environmental Engineering (2iE), Burkina Faso. In August 2012, he completed his bachelor in water and environmental engineering at $2 \mathrm{iE}$ with distinction (top of the class). In September 2013, he was awarded a scholarship by the German Federal Ministry of Education and Research through the West Africa Science Service Centre on Climate Change and Adapted land use (WASCAL) to pursue a Master of Technology in Climate Change and Adapted Land Use at Federal University of Technology, Minna, Niger State, Nigeria.

Next, in September 2015, he was received fellowship by UNESCO and IAEA to undertake a Pre$\mathrm{PhD}$ Diploma training in Earth System Physics at the Abdus Salam International Centre of Theoretical Physics (ICTP), Trieste, Italy. Talardia has been involved in research projects that seek to improve water, weather and climate modeling and services for society. $\mathrm{He}$ is, particularly, passionate about developing and applying research methods, tools and theories to address environmental issues towards a sustainable future.

In October 2016, he started his PhD study under the Waterapps project at the Water System and Global Change group, Wageningen University and Research, funded by the Netherlands Organization for Scientific Research (NWO). This study focuses on developing weather and climate information, tailored for small-scale farming in developing countries (over the urbanizing delta), by combining scientific and local forecasting knowledge. During his $\mathrm{PhD}$ project, he collaborated with the Ghana Meteorological Agency and Water Resource Commission in Ghana. He contributed to developing tools and principles for coproducing ICT-based climate services. These tools and principles are being tested in other locations within Ghana. He also attended several conferences and summer school on weather and climate. In October 2020, he started working as a researcher under the Wagrinnova project at Water System and Global Change group, Wageningen University and Research. 
About the author 


\section{List of publications}

1. Gbangou, T.; Sarku, R.; Slobbe, E.V.; Ludwig, F.; Kranjac-Berisavljevic, G.; Paparrizos, S. 2020.Coproducing Weather Forecast Information with and for Smallholder Farmers in Ghana: Evaluation and Design Principles. Atmosphere, 11(9), 902. Atmosphere. https://doi.org/10.3390/atmos11090902

2. Gbangou, T., van Slobbe E., Ludwig F., Kranjac-Berisavljevic, G., and Paparrizos S., 2020.Harnessing local forecasting knowledge on weather and climate in Ghana: documentation, skills and integration with scientific forecasting knowledge. Wea. Climate Soc., 13, 23-37, https://doi.org/10.1175/WCAS-D-20-0012.1.

3. Gbangou, T., Ludwig, F., van Slobbe, E., Greuell, W., and Kranjac-Berisavljevic, G., 2020. Rainfall and dry spell occurrence in Ghana: trends and seasonal predictions with a dynamical and a statistical model. Theor Appl Climatol. https://doi.org/10.1007/s00704020-03212-5

4. Gbangou, T., Ludwig, F., van Slobbe, E., Hoang, L. and Kranjac-Berisavljevic, G., 2019. Seasonal variability and predictability of agro-meteorological indices: Tailoring onset of rainy season estimation to meet farmers' needs in Ghana. Climate Services, 14, pp.19-30. https://doi.org/10.1016/j.cliser.2019.04.002

5. Gbangou, T., Sylla, M.B., Jimoh, O.D. and Okhimamhe, A.A., 2018. Assessment of projected agro-climatic indices over Awun river basin, Nigeria for the late twenty-first century. Climatic Change, 151(3-4), pp.445-462. https://doi.org/10.1007/s10584-0182295-y

6. Paparrizos, S.; Smolenaars, W.; Gbangou, T.; Slobbe, E.; Ludwig, F. 2020. Verification of Weather and Seasonal Forecast Information Concerning the Peri-Urban Farmers' Needs in the Lower Ganges Delta in Bangladesh. Atmosphere, 11, 1041. https://doi.org/10.3390/atmos11101041

7. Sarku, R., Gbangou, T., Dewulf, A., Slobbe, E. 2020. Beyond 'experts knowledge': Locals and experts in a joint production of weatherApp and weather information for farming in the Volta Delta, Ghana. Handbook of Handbook of Climate Change Management, Springer (Accepted manuscript) 
SENSE training and education diploma 


\section{SENSE}

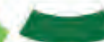

Netherlands Research School for the

Socio-Economic and Natural Sciences of the Environment

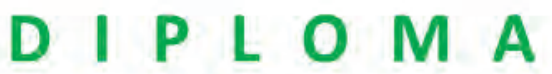

for specialised PhD training

The Netherlands research school for the Socio-Economic and Natural Sciences of the Environment (SENSE) declares that

\section{Talardia Gbangou}

born on 31 December 1988 in Komadougou, Burkina Faso

has successfully fulfilled all requirements of the educational PhD programme of SENSE.

Wageningen, 18 January 2021
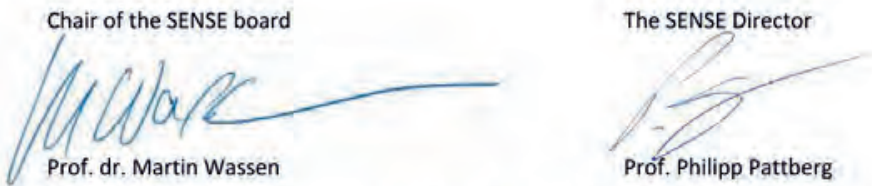

The SENSE Research School has been accredited by the Royal Netherlonds Academy of Arts and Sciences (KNAW)

K O N I N K L I J K E N E D E R L A N D S E

A K A D E M I E V A N W E T E N S C H A P P 


\section{(sises)}

The SENSE Research School declares that Talardia Gbangou has successfully fulfilled all requirements of the educational PhD programme of SENSE with a work load of $44.2 \mathrm{EC}$, including the following activities:

\section{SENSE PhD Courses}

Environmental research in context (2016)

6 Research in context activity: 'Codesigning ICT-based applications for the coproduction of weather forecast information with and for smallholder farmers in Ghana' (2018-2020)

Dther PhD and Advanced MSc Courses

- Efficient Writing Strategies Course, Wageningen Graduate Schools (2018)

- Information Literacy for PhD including EndNote Introduction, Wageningen Graduate Schools (2018)

i. Summer School on Effective HPC for Climate and Weather, The Centre of Excellence in Simulation of Weather and Climate in Europe (2020)

a Principles of Machine learning: Python edition, Microsoft (2020)

\section{Management and Didactic Skills Training}

- Co-organization of the EVOCA and WaterApps in-country Workshop in Ghana (2019)

- Participating in the Water Systems and Global Change chair group strategy day (2016, 2019, 2020)

- Supervising MSc student with thesis entitled 'Constraints for farmers to use weather forecasts for farm management decision making: A case study in the Ada East district, Ghana' (2019)

6. Teaching in the MSc course 'Climate Change' (2017 and 2020)

. Teaching in the MSc course 'Adaptation and Mitigation Strategies for Society' (20192020)

\section{Selection of Oral Presentations}

- Role of mobile applications in collecting, documenting and disseminating integrated weather and climate forecasts for farmers: The case study of Ada East district in Ghana. 6th Climate Change and Development in Africa conference (CCDA-VII), 27 October 2017, Addis Ababa, Ethiopia

a Co-production of hydro-meteorological information services for sustainable agriculture in Ghana using seasonal climate forecasts and digital tools, 2nd International EVOCA Workshop, 3-7 July 2017, Accra, Ghana

- Success of the co-production and delivery of local and scientific weather forecasts information with and for smallholder farmers in Ghana. Sharing Geoscience Online, EGU General Assembly, 4-8th May 2020

SENSE coordinator PhD education

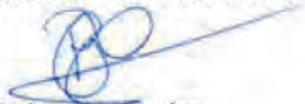

Dr. ir. Peter Vermeulen 
The research described in this thesis was financially supported by the Netherlands Organization for Scientific Research (NWO/WOTRO); grant No. W 07.69.204, under the Urbanizing Deltas of the World Program (UDW) and Waterapps project: Water information services for sustainable food production in peri-urban delta areas in Ghana and Bangladesh.

Financial support from Wageningen University for printing this $\mathrm{PhD}$ thesis is highly appreciated.

Thesis cover design : Talardia Gbangou

Photograph on the cover page : Talardia Gbangou

Printed by: proefschriftmaken (https://www.proefschriftmaken.nl/en/) 



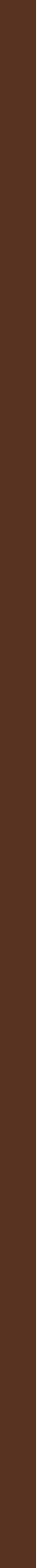

